\title{
EFECTO DEL CELO Y DEL ESTRÉS SOBRE EL RECUENTO DE CELULAS SOMATICAS EN LA LECHE DE CABRA
}

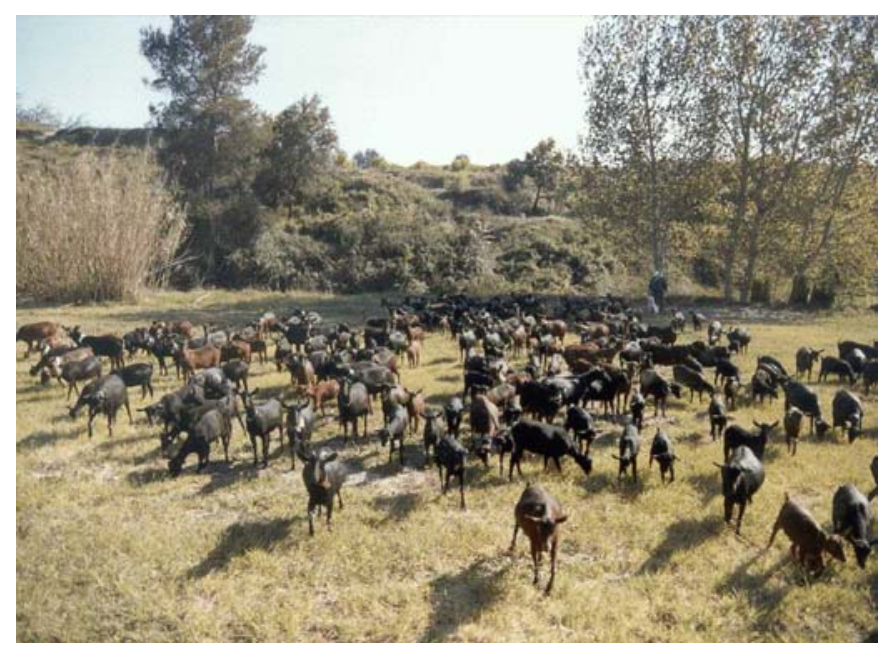

TESIS DOCTORAL

MEHDID MOHAMMED EL AMINE 



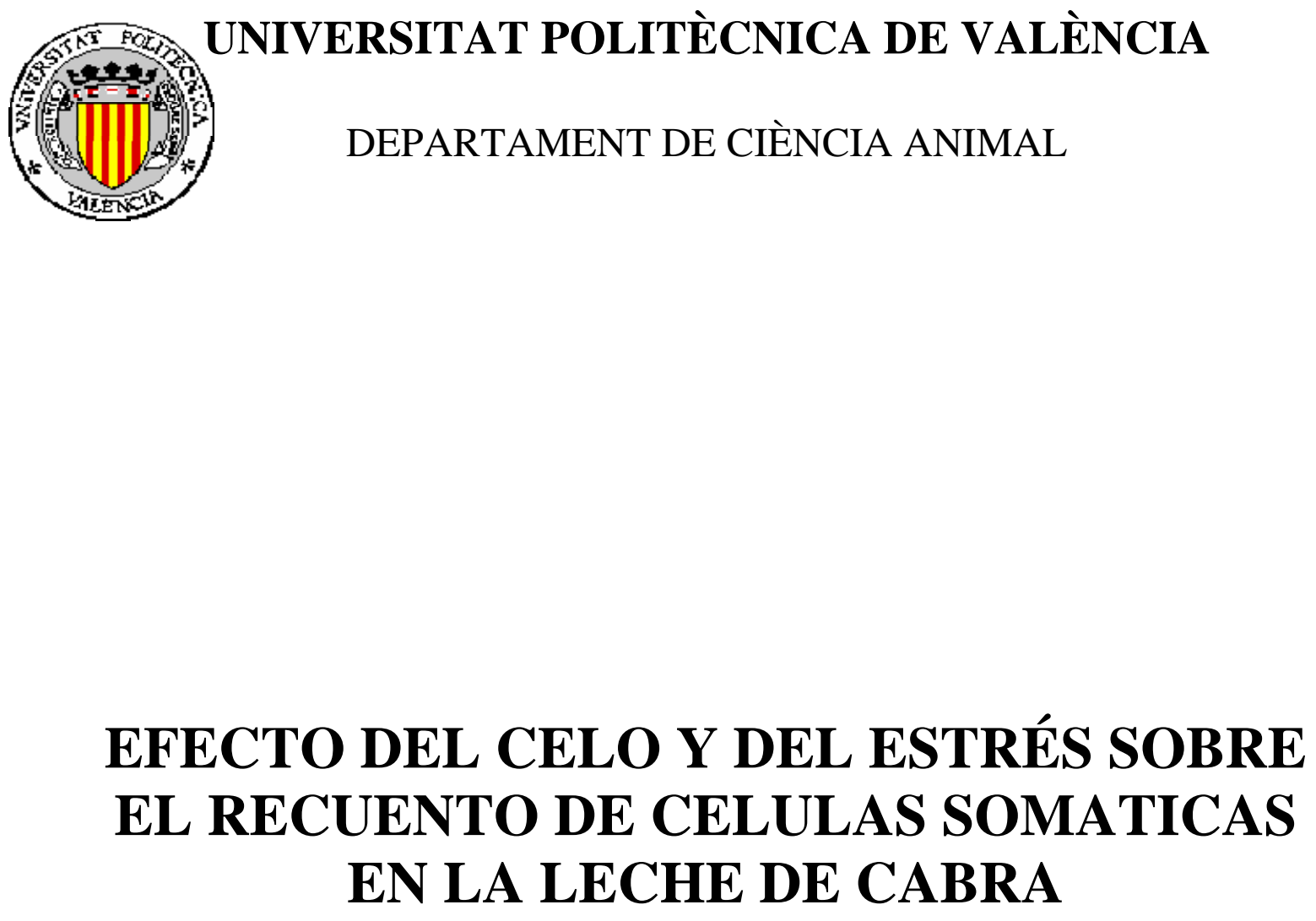

TESIS DOCTORAL PRESENTADA POR MEHDID MOHAMMED EL AMINE

Bajo la dirección de CRISTÒFOL PERIS i RIBERA

València, diciembre 2009 



\section{EFECTO DEL CELO Y DEL ESTRÉS SOBRE EL RECUENTO DE CELULAS SOMATICAS EN LA LECHE DE CABRA}

Tesis Doctoral presentada por Mehdid Mohammed El Amine, bajo la dirección del Dr. Cristòfol Peris i Ribera del Departament de Ciència Animal de la Universitat Politècnica de València, para optar al grado de Doctor.

València, diciembre de 2009

$$
\mathrm{V}^{\mathrm{o}} \mathrm{B}^{\mathrm{o}}
$$

Dr. Cristòfol Peris Ribera 



\section{$\underline{\text { AGRADECIMIENTOS }}$}

Esta Tesis Doctoral es parte de mi vida y de comienzo de otras etapas, y por eso quiero manifestar mi agradecimiento a todos las personas que, de un modo u otro, han contribuido a que pudiera llegar este momento:

A mi Director de Tesis, Cristòfol Peris Ribera, no solo por su apoyo académico para realizar esta tesis, sino también por su apoyo moral y económico durante mi estancia.

A toda la gente amable de LICOVAL con la que he trabajado, especialmente a Elena, Yolanda y los demás: Eugenio, Ana, Silvia y Paco.

A Mari Carmen Beltrán, mi compañera de despacho, por su apoyo y consejos.

A Nemesio Fernández, Martín Rodríguez, Pilar Molina y Antonio Torres.

A Gema Vidal, por ser amiga y su ayuda en los trabajos experimentales del Tercer Estudio.

A José luís, por sus sugerencias durante el desarrollo de los ensayos en la granja experimental, y también a José Vicente.

A ION, Tamara, Carlos y Vicente, por ofrecerme sus amistades y sus apoyos.

Al Profesor A. Contreras y su equipo de investigación, por su ayuda para poder llevar a cabo el recuento de leucocitos polimorfonucleares del Tercer Estudio.

A José Salvador Vicente y su equipo, por la ayuda material prestada.

A todas las personas con las que me he cruzado en el Departamento de Ciencia Animal.

Gracias a todos 

Pentru nevasta mea Nicoleta cu Dragostea

Pour ma chére famille: mère, père, ma soeur Zakia et frère Zakaria 



\section{$\underline{\text { Listado de las abreviaturas }}$}

AEC: Virus de la Artritis Encefalitis Caprina.

AMURVAL: Asociación de ganaderos de caprino de raza Murciano-Granadina de la Comunidad Valenciana.

AO: muestras de leche tomadas Antes del Ordeño (media de las dos glándulas)

AOD: muestras de leche tomadas Antes del Ordeño (glándula derecha)

AOI: muestras de leche tomadas Antes del Ordeño (glándula izquierda)

ECN: Estafilococos coagulasa-negativo.

$\mathbf{E T}_{\mathbf{R C S}}$ : Elevación transitoria del Recuento de Células Somáticas.

Céls : Células

IIM: Infección intramamaria.

LICOVAL: Laboratorio Interprofesional lácteo de la Comunidad Valenciana.

LOG: logaritmo

LT: Leche Total ordeñada.

PCH: Muestras de leche de Primeros chorros.

PMN: Leucocitos Polimorfonucleares Neutrófilos.

RCS: Recuento de Células Somáticas.

$\mathbf{R C S}_{\mathbf{L T}}$ Recuento de Células Somáticas en muestras de la Leche Total ordeñada

$\mathbf{R C S}_{\text {AO }}$ Recuento de Células Somáticas en muestras de de leche tomadas Antes del Ordeño (media de las dos glándulas)

Sanas-S: Glándulas sanas, cuya colateral también esta sana.

Sanas-I : Glándulas sanas, cuya colateral está infectada.

SC: grupo experimental de cabras sometido a sincronización de celos mediante un tratamiento hormonal (Tercer Estudio).

TAN: Muestras de leche de Tanque. 



\section{RESUMEN}




\section{TESIS DOCTORAL}

\section{EFECTO DEL CELO Y EL ESTRÉS SOBRE EL RECUENTO DE CÉLULAS SOMÁTICAS EN LA LECHE DE CABRA}

\section{RESUMEN}

Esta Tesis Doctoral se sitúa en el contexto del estudio de los factores no infecciosos que influyen sobre el recuento de células somáticas (RCS) de la leche de cabra. Se han planteado tres objetivos: 1) Caracterizar las elevaciones bruscas y transitorias del RCS (ET $\mathbf{R C S}_{\text {) }}$ en la leche de cabra de origen no infeccioso (Estudios 1 y 2); 2) Determinar si el celo provoca $\mathrm{ET}_{\mathrm{RCS}}$, y si el efecto sobre el RCS es diferente según el número de lactación y el estado sanitario de la ubre (Estudio 3); 3) Estudiar el efecto de varios tipos de estrés sobre el RCS y la presencia de $\mathrm{ET}_{\mathrm{RCS}}$ (Estudio 4). Todos los experimentos se llevaron a cabo en cabras de raza Murciano-Granadina que estaban entre el $2^{\circ}$ y $5^{\circ}$ mes de lactación y eran ordeñadas a máquina una vez al día.

El Primer Estudio fue un experimento previo con el objetivo de confirmar si era posible detectar las elevaciones del RCS que se puedan producir en la leche total ordeñada de un animal, a partir de muestras de leche tomadas por glándula antes del ordeño (primeros chorros). Se utilizaron 22 cabras $\left(7,12\right.$ y 3 cabras de $1^{\mathrm{a}}, 2^{\mathrm{a}}$ y $\geq 3^{\mathrm{a}}$ lactaciones, respectivamente) libres de infecciones intramamarias (IIM) a las que se controló semanalmente, durante 12 semanas, el RCS por glándula (primeros chorros) y ubre (control lechero). El RCS en las muestras de primeros chorros fue, de media, inferior respecto a los recuentos obtenidos en las muestras del control lechero. Sin embargo, en los animales que presentan recuentos superiores a un millón de céls $/ \mathrm{ml}$, ambos tipos de recuentos tienden a igualarse. Se concluye que, en ausencia de IIM, las elevaciones transitorias del RCS de origen no infeccioso, con valores superiores a 1 millón de cels $/ \mathrm{ml}$, pueden ser detectadas en las muestras tomadas por glándula antes del ordeño.

En el Segundo Estudio se utilizaron 32 cabras $\left(11,17\right.$ y 4 en $1^{\mathrm{a}}, 2^{\mathrm{a}}$ y $\geq 3^{\mathrm{a}}$ lactaciones, respectivamente; 20 sanas y 12 con IIM unilateral causadas por estafilococos coagulasa negativo- ECN) a las que se controló, durante 53 días consecutivos, el RCS de la leche de glándula (primeros chorros) y, semanalmente, la producción de leche ordeñada, su composición y el RCS. Se definió como $\mathbf{E T}_{\mathbf{R C S}}$, aquellas elevaciones del 
RCS que ocurrieron en las glándulas libre de IIM, con incrementos de al menos 2.5 veces respecto a los recuentos precedentes, alcanzando valores superiores a 1 millón de céls $/ \mathrm{ml}$ (0.7 millones de céls/ml en primíparas). Los resultados confirmaron la existencia de $\mathrm{ET}_{\mathrm{RCS}}$ de naturaleza no infecciosa en el ganado caprino. Aunque su duración fue variable, normalmente se situó entre 1 y 3 días. Casi el $60 \%$ de las cabras mostraron un caso de $\mathrm{ET}_{\mathrm{RCS}}$, apareciendo tanto en las cabras sanas como en las infectadas y en primíparas como en multíparas. El aumento de los recuentos durante las $\mathrm{ET}_{\mathrm{RCS}}$ no puede ser explicado por cambios en la producción de leche, ya que solamente disminuyó en un 11$16 \%$. En este experimento las $\mathrm{ET}_{\mathrm{RCS}}$ afectaron significativamente a la proteína (incremento) y la lactosa (descenso).

En el Tercer Estudio se plantearon dos experimentos (E1 y E2) con el mismo diseño. Se utilizaron 33 cabras en E1 (11 y 22 de $1^{\mathrm{a}}$ y $\geq 2^{\mathrm{a}}$ lactaciones, respectivamente; 20 sanas y 13 con IIM unilateral causadas mayoritariamente por ECN) y 35 cabras en E2 (11 y 24 de $1^{\mathrm{a}} \mathrm{y} \geq 2^{\mathrm{a}}$ lactaciones, respectivamente; 25 sanas y 10 con IIM unilateral todas provocadas por ECN) asignando aproximadamente a la mitad de las cabras un tratamiento hormonal de sincronización de celos (grupo SC) y el resto permaneció como grupo Control. Durante un periodo de 32 días consecutivos (6 pre-experimental, 11 de tratamiento hormonal y 15 días tras la retirada de las esponjas) se controló el RCS por glándula y ubre a todos los animales. A las 24,32 y $48 \mathrm{~h}$ tras la retirada de las esponjas se detectó si cada animal estaba en celo. En E2 también se controló diariamente, para cada animal, la producción y composición de la leche ordeñada; además también se llevó a cabo el recuento de leucocitos PMN (en porcentaje) en 12 cabras (6 en cada grupo), en el día de máximo recuentos y en los dos días previos y posteriores a la elevación del RCS. Tras el tratamiento hormonal, el RCS del grupo SC se elevó significativamente durante 3 días respecto al grupo control, tanto en E1 como en E2. Este incremento sucedió tanto en las cabras primíparas como en las multíparas y en las ubres sanas como en las infectadas. El celo disminuyó significativamente la producción de leche (-13\%) y aumentó significativamente la proteína y la materia seca de la leche. A lo largo de ambos experimentos se identificaron el mismo número de $\mathrm{ET}_{\mathrm{RCS}}$ en el grupo $\mathrm{SC}$ que en el grupo Control (n=29). En el grupo SC, estas elevaciones fueron más frecuentes en los primeros 3 días tras la retirada de las esponjas. Las características de las $\mathrm{ET}_{\mathrm{RCS}}$ en el grupo SC y control fueron similares. En las elevaciones provocadas por el celo los recuentos aumentaron más en las cabras multíparas que en las primíparas. 
En el Cuarto Estudio se ensayaron tres tipos de estrés, dos de ellos aparentemente moderados y habituales en las explotaciones (experimentos 1 y 2) y el tercero extremo e infrecuente (experimento 3 ). Los tres experimentos tuvieron el mismo diseño: 8 días de duración (5 días previos y 3 posteriores al inicio del estrés) y control diario en cada animal del RCS, por glándula y ubre, y de la producción y composición de la leche ordeñada, así como del cortisol en sangre. En el experimento 1 se estudió el efecto del estrés provocado por la extracción del estiércol, utilizándose 30 cabras $(6,10$ y 14 de $1^{\mathrm{a}}, 2^{\mathrm{a}} \mathrm{y} \geq 3^{\mathrm{a}}$ lactaciones, respectivamente; 18 sanas, 10 con IIM unilateral y 2 con IIM bilateral, mayoritariamente causadas por ECN). En el experimento 2 se estudió el efecto del reagrupamiento utilizando 70 cabras que fueron distribuidas en 3 lotes (control, $\mathrm{n}=12$; reagrupadas $\sin$ cambio de local, $\mathrm{n}=29$, y con cambio de local, $n=29$ ). En ambos experimentos el estrés no afectó significativamente al RCS, ni al cortisol en sangre, con independencia del número de lactación o estado sanitario de la ubre. La producción de leche solamente disminuyó significativamente en las cabras primíparas que fueron trasladadas al parque de multíparas en el experimento 2 (descenso del 8-10\%). En ambos experimentos el estrés apenas afectó a la composición de la leche, aunque se observó una tendencia a disminuir la grasa y materia seca. En el experimento 3 se estudió el efecto de un fuerte estrés (contacto con un perro durante unos 30 minutos) utilizando 38 cabras (13, 5 y 20 de $1^{\mathrm{a}}, 2^{\mathrm{a}}$ y $\geq 3^{\mathrm{a}}$ lactaciones, respectivamente; 24 sanas y 14 con mamitis subclínicas mayoritariamente causadas por ECN) que fueron separadas en dos grupos (Estrés y Control). El estrés incrementó significativamente el cortisol, pero su efecto sobre las otras variables fue distinto según el número de lactación de los animales. En cabras de 1+2 partos el estrés no afectó significativamente al RCS, a la producción ni a la composición de la leche. Por el contrario en las cabras de 3 o más partos, el estrés provocó un aumento significativo del RCS (alrededor del 260\%), una disminución de la producción de leche (-7 a $-12 \%)$, un aumento de la grasa y un descenso de la lactosa. A consecuencia de este estrés el $90 \%$ de las cabras multíparas presentaron una $\mathrm{ET}_{\mathrm{RCS}}$.

Se concluye que la $\mathrm{ET}_{\mathrm{RCS}}$, de origen no infeccioso, es un fenómeno fisiológico, característico y relativamente frecuente en el ganado caprino. Probablemente el celo es el principal factor que causa estas elevaciones en condiciones de campo, ya que el estrés, en los niveles o situaciones que ocurren habitualmente en las explotaciones, no parece que afecten en gran medida al RCS. 


\section{TESI DOCTORAL}

\section{EFECTE DEL ZEL I DE L'ESTRÈS SOBRE EL RECOMPTE DE CÈL·LULES SOMÀTIQUES EN LA LLET DE CABRA}

\section{RESUM}

Aquesta Tesi Doctoral se situa en el context de l'estudi dels factors no infecciosos que influeixen sobre el recompte de cèl-lules somàtiques (RCS) de la llet de cabra. S'han plantejat tres objectius: 1) Caracteritzar les elevacions brusques i transitòries del RCS (ETRCS) a la llet de cabra d'origen no infecciós (Estudis 1 i 2); 2) Determinar si el zel provoca ETRCS, i si l'efecte sobre el RCS és diferent segons el nombre de lactació i l'estat sanitari del braguer (Estudi 3); 3) Estudiar l'efecte de diversos tipus d'estrès sobre el RCS i la presència de ETRCS (Estudi 4). Tots els experiments es van dur a terme en cabres de raça Murciano-Granadina que estaven entre el 2n i 5è mes de lactació i eren munyides a màquina un cop al dia.

El Primer Estudi va ser un experiment previ amb l'objectiu de confirmar si era possible detectar les elevacions del RCS que es puguen produir en la llet total munyida d'un animal, a partir de mostres de llet preses per glàndula abans de munyir (primers raigs). Es van utilitzar 22 cabres (7, 12 i 3 cabres de $1^{\mathrm{a}}, 2^{\mathrm{a}} \mathrm{i} \geq 3^{\mathrm{a}}$ lactació, respectivament) lliures d'infeccions intramamaries (IIM) a les quals es va controlar setmanalment, durant 12 setmanes, el RCS per glàndula (primers raigs) i braguer (control lleter). EL RCS en les mostres de primers raigs va ser, de mitjana, inferior respecte els recomptes obtinguts en les mostres del control lleter. No obstant això, en els animals que presenten recomptes superiors a un milió de cels/ml, ambdós tipus de recomptes tendeixen a igualar-se. Es conclou que, en absència de IIM, les elevacions transitòries del RCS d'origen no infecciós, amb valors superiors a 1 milió de cels $/ \mathrm{ml}$, poden ser detectades en les mostres preses per glàndula abans del munyiment.

En el Segon Estudi es van utilitzar 32 cabres (11, 17 i 4 en 1 a, $2^{\mathrm{a}}$ i $\geq 3^{\mathrm{a}}$ lactació, respectivament, 20 sanes i 12 amb IIM unilateral causades per estafilococs coagulasa negatiu-ECN) a les quals es va controlar, durant 53 dies consecutius, el RCS de la llet de glàndula (primers raigs) i, setmanalment, la producció de llet munyida, la seva composició i el RCS. Es va definir com ETRCS, les elevacions del RCS que van ocórrer en les glàndules lliure de IIM, amb increments almenys de 2.5 vegades respecte als 
recomptes precedents, arribant a valors superiors a 1 milió de cels $/ \mathrm{ml}$ ( 0.7 milions de cels/ml en primípares ). Els resultats van confirmar l'existència d'ETRCS de naturalesa no infecciosa en el bestiar cabrum. Encara que la seva durada va ser variable, normalment es va situar entre 1 i 3 dies. Gairebé el 60\% de les cabres van mostrar un cas de ETRCS, apareixent tant en les cabres sanes com en les infectades i en primípares com en multípares. L'augment dels recomptes durant les ETRCS no pot ser explicat per canvis en la producció de llet, ja que només va disminuir en un 11-16\%. En aquest experiment les ETRCS van afectar significativament a la proteïna (increment) i la lactosa (descens).

En el Tercer Estudi es van plantejar dos experiments (E1 i E2) amb el mateix disseny. Es van utilitzar 33 cabres a E1 (11 i 22 de $1^{\mathrm{a}} \mathrm{i} \geq 2^{\mathrm{a}}$ lactació, respectivament, 20 sanes i 13 amb IIM unilateral causades majoritàriament per ECN) i 35 cabres a E2 (11 i 24 de $1^{\mathrm{a}} \mathrm{i} \geq 2^{\mathrm{a}}$ lactació, respectivament, 25 sanes i $10 \mathrm{amb}$ IIM unilateral totes provocades per ECN) assignant aproximadament a la meitat de les cabres un tractament hormonal de sincronització de zels (grup SC) i la resta va romandre com a grup control. Durant un període de 32 dies consecutius (6 pre-experimental, 11 de tractament hormonal i 15 dies després de la retirada de les esponges) es va controlar el RCS per glàndula i braguer a tots els animals. A les 24, 32 i 48 h després de la retirada de les esponges es va detectar si cada animal estava en zel. En E2 també es va controlar diàriament, per a cada animal, la producció i composició de la llet munyida, a més també es va dur a terme el recompte de leucòcits Polimorfonuclears Neutròfils (PMN, en percentatge) en 12 cabres (6 a cada grup), en el dia de màxim recomptes i en els dos dies previs i posteriors a l'elevació del RCS. Després del tractament hormonal, el RCS del grup SC es va elevar significativament durant 3 dies respecte al grup control, tant en E1 com a E2. Aquest increment va succeir tant a les cabres primípares com en les multípares i en els braguers sans com en els infectats. El zel va disminuir significativament la producció de llet ($13 \%$ ) i va augmentar significativament la proteïna i la matèria seca de la llet. Al llarg de tots dos experiments es van identificar el mateix nombre de ETRCS en el grup SC que en el grup control $(\mathrm{n}=29)$. En el grup $\mathrm{SC}$, aquestes elevacions van ser més freqüents en els primers 3 dies després de la retirada de les esponges. Les característiques de les ETRCS en el grup SC i control van ser similars. En les elevacions provocades pel zel els recomptes van augmentar més en les cabres multípares que en les primípares 
En el Quart Estudi es van assajar tres tipus d'estrès, dos d'ells aparentment moderats $\mathrm{i}$ habituals en les explotacions (experiments 1 i 2) i el tercer extrem i infreqüent (experiment 3). Els tres experiments van tenir el mateix disseny: 8 dies de durada (5 dies previs i 3 posteriors a l'inici de l'estrès) i control diari a cada animal del RCS, per glàndula i mamella, i de la producció i composició de la llet munyida, així com del cortisol en sang. En l'experiment 1 es va estudiar l'efecte de l'estrès provocat per l'extracció del fem, utilitzant-30 cabres $\left(6,10\right.$ i 14 de $1^{\mathrm{a}}, 2^{\mathrm{a}} \mathrm{i} \geq 3^{\mathrm{a}}$ lactació, respectivament, 18 sans, 10 amb IIM unilateral i 2 amb IIM bilateral, majoritàriament causades per ECN). En l'experiment 2 es va estudiar l'efecte del reagrupament utilitzant 70 cabres que van ser distribuïdes en 3 lots (control, $n=12$; reagrupades sense canvi de local, $n=29$, i amb canvi de local, n=29). En ambdós experiments l'estrès no va afectar significativament al RCS, ni al cortisol en sang, amb independència del nombre de lactació o estat sanitari del braguer. La producció de llet només va disminuir significativament en les cabres primípares que van ser traslladades al parc de multípares en l'experiment 2 (descens del 8-10\%). En ambdós experiments l'estrès a penes va afectar la composició de la llet, encara que es va observar una tendència a disminuir el greix i matèria seca. En $\underline{\text { l'experiment } 3}$ es va estudiar l'efecte d'un fort estrès (contacte amb un gos durant uns 30 minuts) utilitzant 38 cabres (13, 5 i 20 de 1a, 2a i $\geq 3$ a lactació, respectivament; 24 sanes i $14 \mathrm{amb}$ mastitis subclíniques majoritàriament causades per ECN) que van ser separades en dos grups (Estrès i Control). L'estrès va incrementar significativament el cortisol, però el seu efecte sobre les altres variables va ser diferent segons el nombre de lactació dels animals. En cabres de $1+2$ parts l'estrès no va afectar significativament al RCS, a la producció ni a la composició de la llet. En canvi en les cabres de 3 o més parts, l'estrès va provocar un augment significatiu del RCS (al voltant del 260\%), una disminució de la producció de llet (-7 a $-12 \%)$, un augment del greix i un descens de la lactosa. A conseqüència d'aquest estrès el $90 \%$ de les cabres multípares van presentar una ETRCS.

Es conclou que les ETRCS, d'origen no infecciós, és un fenomen fisiològic, característic i relativament freqüent en el bestiar cabrum. Probablement el zel és el principal factor que causa aquestes elevacions en condicions de camp, ja que l'estrès, en els nivells o situacions que ocorren habitualment en les explotacions, no sembla que afecten en gran mesura al RCS. 


\title{
PhD THESIS
}

\section{EFFECT OF ESTRUS AND STRESS ON SOMATIC CELL COUNT IN GOAT MILK}

\begin{abstract}
This doctoral thesis is in the context of studying non-infectious factors that influence the somatic cell count (SCC) of goat milk. three objectives were planned: 1) Characterize the sudden and transient elevations of SCC (TE $\mathbf{S C C})$ of non-infectious goat milk (Studies 1 and 2),2) Determine if the estrus causes $\mathrm{TE}_{\mathrm{SCC}}$, and whether the effect on the SCC is different depending of the number of lactation and health status of the udder (Study 3), 3) to study the effect of various types of stress on the SCC and the presence of $\mathrm{TE}_{\mathrm{SCC}}$ (Study 4). All experiments were conducted in Murciano-Granadina breed goats, which were between the 2nd and 5th month of lactation and they were machine milked once daily.
\end{abstract}

The first study was a previous experiment in order to confirm whether it was possible to detect elevations of SCC that can be produced in total milk, of an animal, from milk samples taken before milking per gland (first jet). Twenty-two free of intramammary infections (IMI) goats were used (7, 12 and 3 goats 1st, 2nd and third lactations $\geq 3$, respectively). They were monitored weekly for 12 weeks, the SCC per gland (foremilk) and udder (milk recording). The SCC in foremilk samples was on average lower to the counts obtained in the udder samples. However, in animals with counts exceeding one million cells $/ \mathrm{ml}$, both types of counts tend to equalize. We conclude that in the absence of IMI, transient elevations of SCC of non infectious origin, with values greater than 1 million cells/ml, can be detected in the samples taken by gland before milking.

In the second study we used 32 goats $(11,17$ and 4 in 1st, 2 nd and third lactations $\geq 3$, respectively, 20 healthy and 12 with unilateral IMI caused by coagulase-negative staphylococci -CNS) in which has been monitored for 53 consecutive days, the SCC by gland (foremilk), and weekly, milk production, and its composition and SCC. TE $\mathrm{SCC}$ was defined as those elevations that occurred in the IMI-free glands, with increases at least 
2.5 times that of previous counts, reaching over 1 million cells $/ \mathrm{ml}(0.7$ million cells $/ \mathrm{ml}$ in primiparous goats). The results confirmed the existence of non-infectious $\mathrm{TE}_{\mathrm{SCC}}$ in goats. Although its duration was variable, usually it ranged between 1 and 3 days. Nearly $60 \%$ of goats showed a case of $\mathrm{TE}_{\mathrm{SCC}}$, appearing in both, healthy goats as in infected ones, as well as in primiparous and in multiparous goats. The increase of counts during $\mathrm{TE}_{\mathrm{SCC}}$ can not be explained by changes in milk production, because only decreased in $11-16 \%$. In this experiment the $\mathrm{TE}_{\mathrm{SCC}}$ affected significantly the protein (increase) and lactose (decrease).

In the third study two experiments (E1 and E2) were carried out with the same design. Thirty-three goats were used in E1 (11 and 22 of 1 st and $\geq 2$ lactations, respectively; 20 healthy and 13 with unilateral IMI caused mainly by CNS), and 35 goats in E2 (11 and 24 of 1 st and $\geq 2$ lactations, respectively; 25 healthy and 10 with unilateral IMI all caused by CNS) assigning approximately half of goats to a estrus hormonal treatment synchronization (group SC) and the rest remained as Control group. During a period of 32 consecutive days (6 pre-experimental, 11 hormonal therapy and 15 days after the removal of sponges) SCC by gland and udder were controlled for all animals. At 24, 32 and $48 \mathrm{~h}$ after removal of the sponges, estrus was detected if each animal. In E2 was also monitored daily for each animal, production and composition of total milk; in addition PMN leukocyte count (percentage) was also carried out in 12 goats (6 in each group), on the day of maximum counts and two days preceding and two days following the increase of SCC. After hormone treatment, the SCC of the SC group was elevated significantly during 3 days respect to the control group, both in E1 and in E2. This increase occurred both in primiparous and multiparous goats, in healthy udders and in those infected. Estrus decreased milk production significantly (-13\%) and increased protein and dry matter of milk significantly. Throughout both experiments we identified the same number of $\mathrm{TE}_{\mathrm{SCC}}$ in the SC group than in the control group $(\mathrm{n}=29)$. In the SC group, these elevations were more frequent in the first 3 days after removal of the sponges. The characteristics of $\mathrm{TE}_{\mathrm{SCC}}$ in $\mathrm{SC}$ and control group were similar. SCC elevations caused by estrus were higher in multiparous than in primiparous goats.

In the fourth study we planned three types of stress, two of them apparently moderate and commonly used in farms (Experiments 1 and 2) and the third strong and infrequent (experiment 3 ). The three experiments had the same design: 8-days (5 days 
before and 3 after the onset of stress) and daily control in each animal of the SCC, by gland and udder, the production and composition of total milk and the cortisol in blood. In experiment 1 we studied the effect of stress caused by the removal of manure, using 30 goats $(6,10$ and 14 of 1 st, 2 nd and $\geq 3$ lactations, respectively; 18 healthy, 10 with unilateral IMI and 2 bilateral IMI, mainly caused by CNS). In experiment 2 we studied the effect of regrouping using 70 goats that were distributed in 3 lots (control, $n=12$; grouped without change of location, $\mathrm{n}=29$, and local change, $\mathrm{n}=29$ ). In both experiments the stress did not significantly affect the SCC and blood cortisol, regardless of the number of lactation and health status of the udder. In experiment 2, milk production decreased significantly $(8-10 \%)$ only in primiparous goats that were taken to the multiparous pen. In both experiments the stress just affected the composition of milk, although there was a tendency to decrease fat and dry matter. In experiment 3 we studied the effect of a strong stress (contact with a dog for about 30 minutes) using 38 goats (13, 5 and 20 of 1 st, 2 nd and $\geq 3$ lactations, respectively; 24 healthy and 14 with subclinical mastitis mainly caused by CNS) who were separated into two groups (Stress and Control). Stress significantly increased blood cortisol, but its effect on other variables differed according to the number of lactation. In $1+2$ lactations goats stress did not significantly affect the SCC, the production or the composition of milk. On the contrary in 3 or more lactations goats stress caused a significant increase in the SCC (around $260 \%$ ), decreased milk production ( -7 to $-12 \%)$, increased fat and decreased lactose. As a consequence of this stress $90 \%$ of multiparous goats showed a $\mathrm{TE}_{\mathrm{SCC}}$.

We conclude that $\mathrm{TE}_{\mathrm{SCC}}$, from non-infectious origin, is a physiological phenomenon, characteristic and relatively common in goats. Estrus is probably the main factor causing these elevations in farm conditions. It seems that stress levels or situations that commonly occur on farms, apparently did not affect the SCC 
ÍNDICE 


\section{ÍNDICE DE MATERIAS}

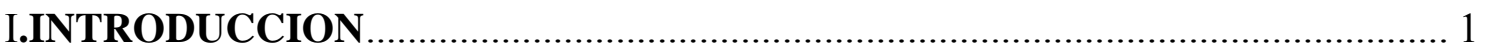

1.LA PRODUCCIÓN DE LECHE DE CABRA EN EL MUNDO EN LA UNIÓN EUROPEA Y EN ESPAÑA...................................................

2.DEFINICIÓN Y CARACTERÍSTICAS DE LAS CÉLULAS SOMÁTICAS EN LA LECHE DE CABRA ……………………………….............................

3.FACTORES QUE INFLUYEN SOBRE EL RCS ……………………………..... 11

3.1.FACTORES DE ORIGEN INFLAMATORIO.......................................... 12

3.1.1.Factores de origen infeccioso ........................................................... 12

3.1.1.1. Mamitis de etiología bacteriana.............................................. 13

3.1.1.2.El virus de la artritis encefalitis caprina ................................ 14

3.1.2.Factores de origen inflamatorio pero no infeccioso ............................. 16

3.2.FACTORES DE VARIACIÓN DE ORIGEN NO INFLAMATORIO ........ 16

3.2.1.Factores intrínsecos del animal......................................................... 17

3.2.1.1.Las fracciones del ordeño ................................................... 17

3.2.1.2.Tiempo entre ordeños ........................................................... 19

3.2.1.3. Numero de ordeños al día..................................................... 20

3.2.1.4. Variaciones diarias ............................................................. 21

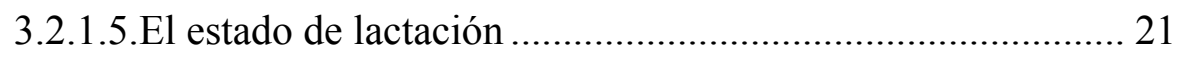

3.2.1.6.Número de lactación............................................................. 25

3.2.1.7.Tipo de parto y sistema de lactancia....................................... 26

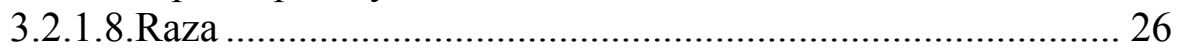

3.2.1.9. Nivel productivo .................................................................. 27

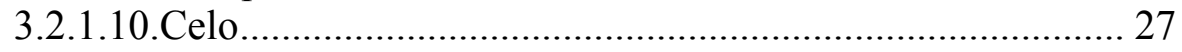

3.2.2.Factores extrínsecos del animal....................................................... 28

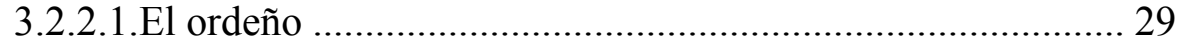

3.2.2.2.La alimentación ................................................................... 30

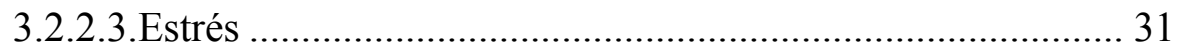

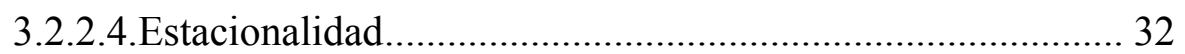

3.2.2.5. Tratamiento hormonal ...................................................... 34

3.3.OTROS FACTORES DE VARIACIÓN .................................................... 34

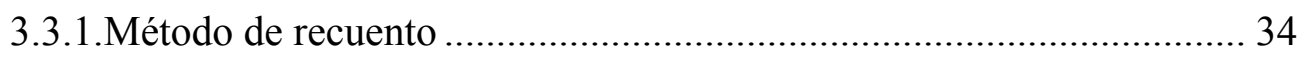

3.3.2.Conservación y almacenamiento de las muestras................................36

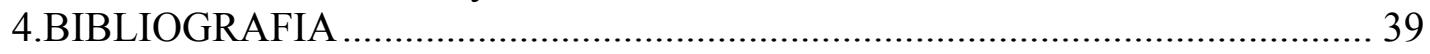

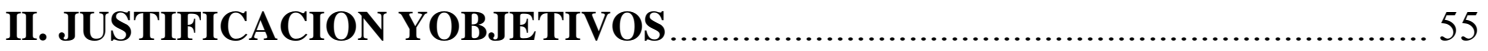

III.MATERIAL Y METODOS GENERALES ………………………………....... 61

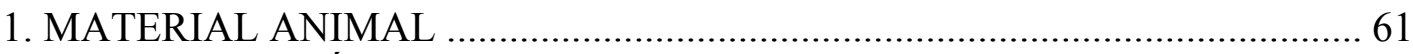

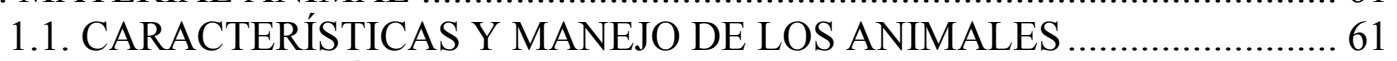

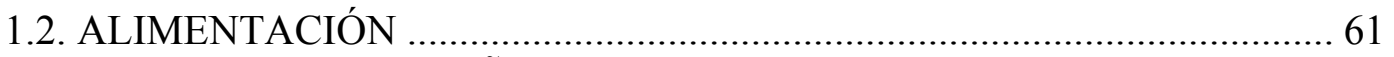

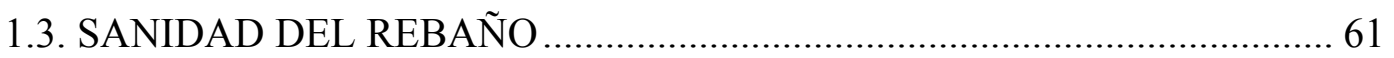

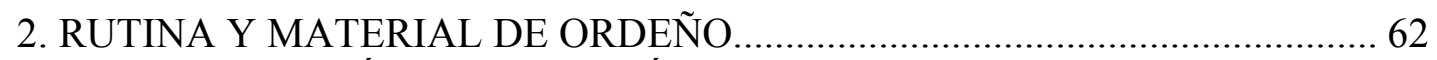

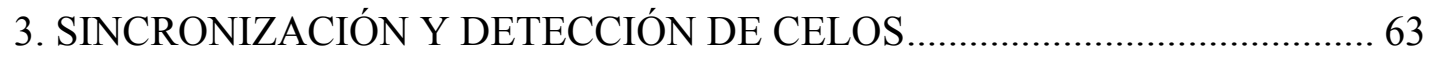

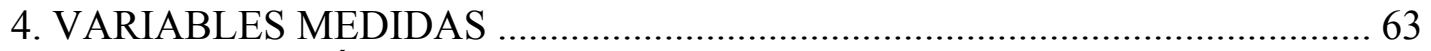

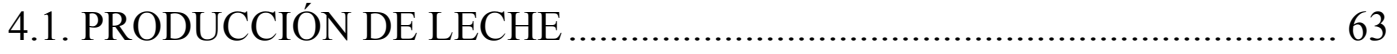




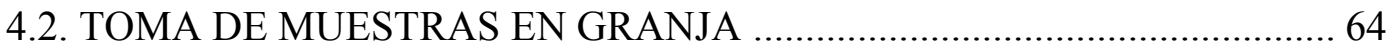

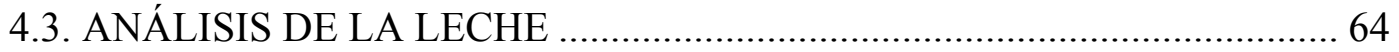

4.4. RECUENTO DE LEUCOCITOS POLIMORFONULECARES NEUTROFILOS

4.5. CORTISOL

IV.PRIMER ESTUDIO: EFECTO DEL TIPO DE MUESTRA (PRIMEROS

CHORROS VS CONTROL LECHERO) SOBRE EL RCS EN LA LECHE DE

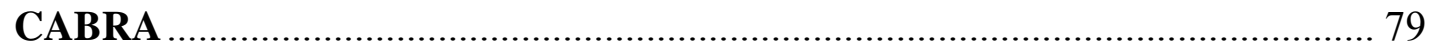

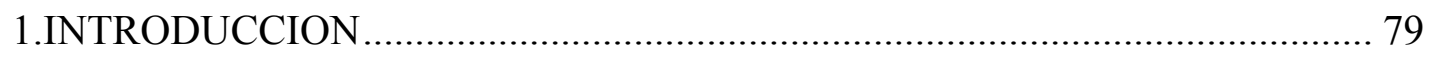

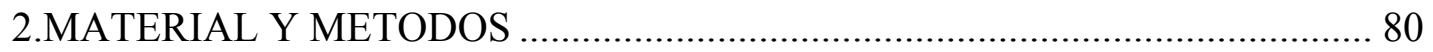

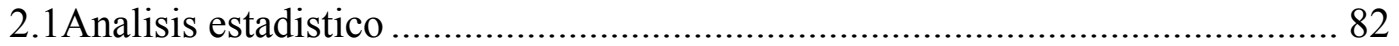

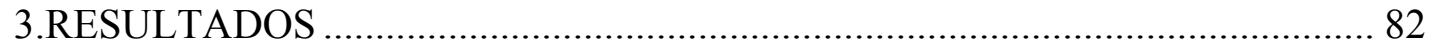

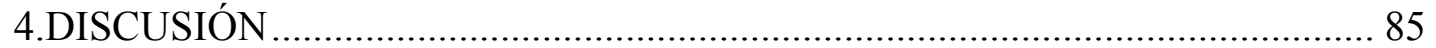

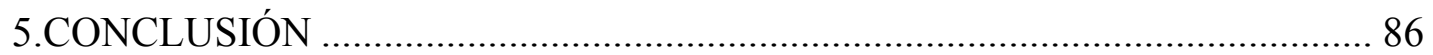

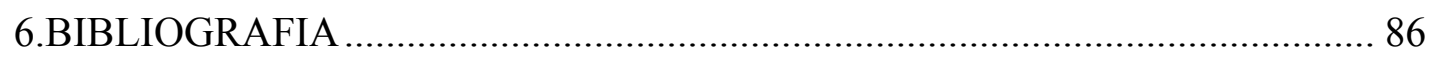

V. SEGUNDO ESTUDIO: VARIACIÓN DIARIA Y ELEVACIONES DEL RECUENTO DE CÉLULAS SOMÁTICAS DE ORIGEN NO INFECCIOSO

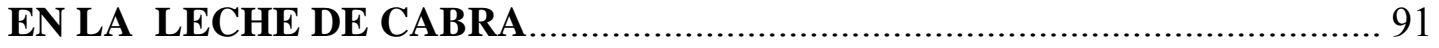

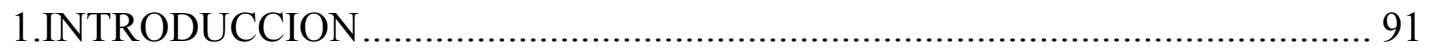

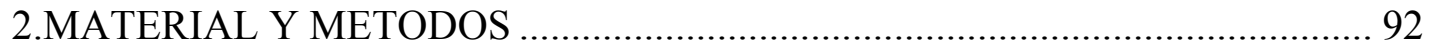

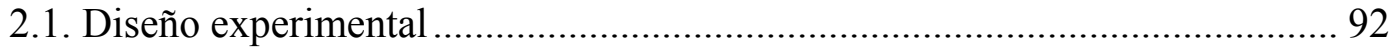

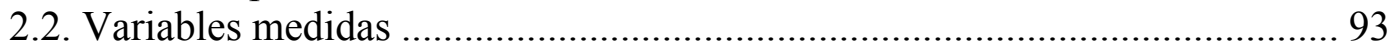

2.3. Definición de una elevación transitoria del RCS ......................................... 93

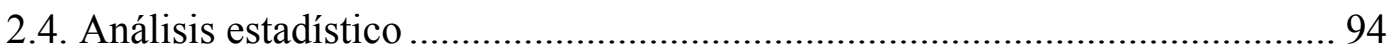

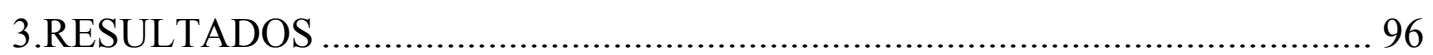

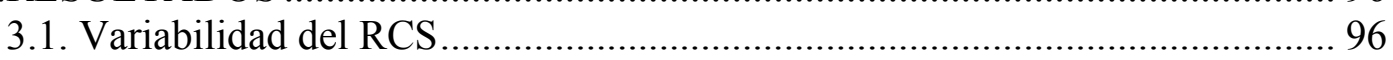

3.1.2Variabilidad individual del RCS .................................................. 100

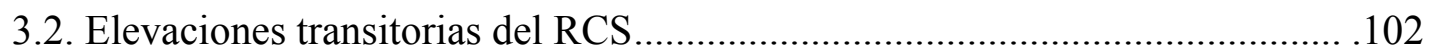

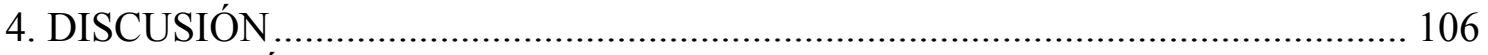

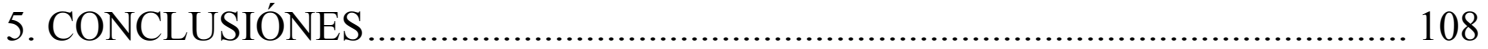

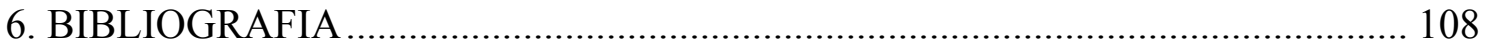

VI. TERCER ESTUDIO: EFECTO DEL CELO SOBRE EL RECUENTO DE CÉLULAS SOMÁTICAS EN LA LECHE DE CABRA ............................... 113

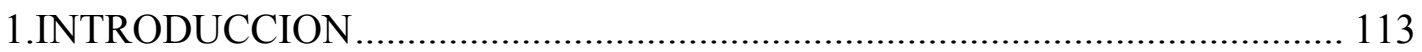

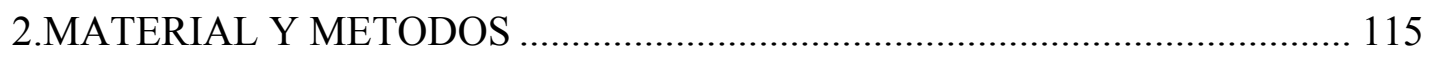

2.1.Diseño experimental ... ............................................. 115

2.2.Variables medidas... ................................................116

2.3.Definición de una elevación transitoria del RCS ... .......................117

2.4.Análisis estadístico ............................................... 118

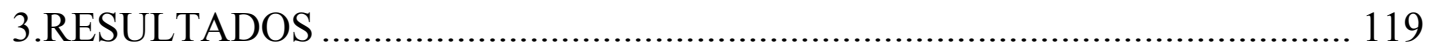

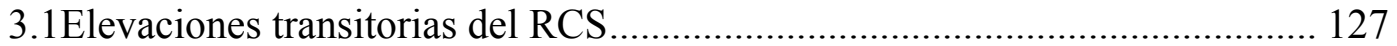

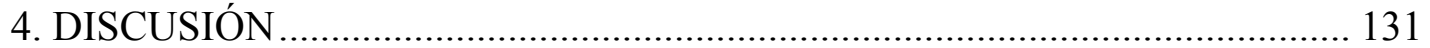

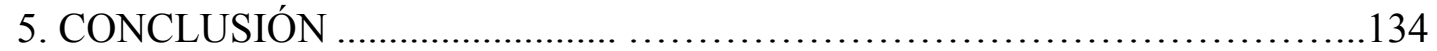

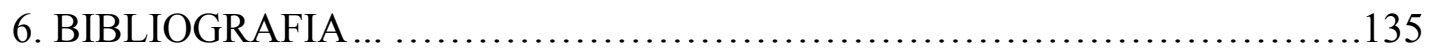

VII. CUARTO ESTUDIO: EFECTO DE VARIOS TIPOS DE ESTRÉS SOBRE EL RECUENTO DE CÉLULAS SOMÁTICAS EN LA LECHE DE CABRA ... 140 


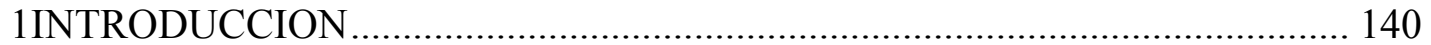

2.MATERIAL Y METODOS ................................................... 142

2.1.Diseño experimental ................................................... 142

2.2. Variables medidas........................................................ 146

2.3.Definición de una elevación transitoria del RCS ..............................147

2.4.Análisis estadístico ......................................................... 147

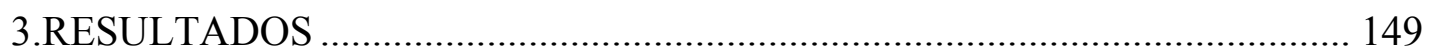

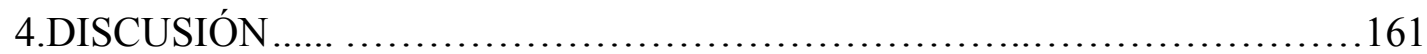

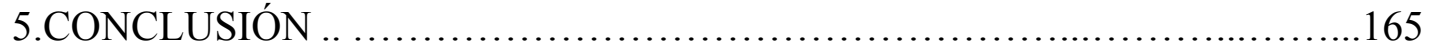

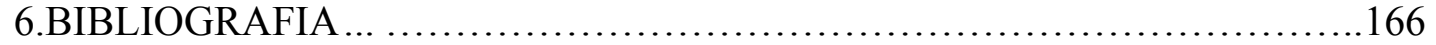




\section{INDICE DE TABLAS.}

\section{INTRODUCCION}

TABLA 1.Comparación del RCS y la distribución de los tipos de células de leche de diferentes especies

TABLA 2.Distribución porcentual de los tipos de células somáticas en la leche de cabra

TABLA 3.Principales factores de variación del RCS en leche de cabra

TABLA 4.Influencia del estado de lactación sobre el RCS en función del estado infeccioso de la ubre en ganado caprino.

IV. PRIMER ESTUDIO: EFECTO DEL TIPO DE MUESTRA (PRIMEROS CHORROS VS CONTROL LECHERO) SOBRE EL RCS EN LA LECHE DE CABRA.

TABLA 1. Comparación del RCS en muestras tomadas por glándula antes del ordeño (AOD y AOI) y de la leche total ordeñada (LT) en 19 cabras libres de IIM que fueron controladas semanalmente durante 12 semanas. 82

TABLA 2. Coeficientes de correlación del RCS analizado en diferentes tipos de muestras de leche (por glándula antes del ordeño y por ubre de la leche total ordeñada) en 19 cabras libres de IIM que fueron controladas semanalmente durante 12 semanas

TABLA 3. Relación entre el RCS de las muestras de la leche total ordeñada (RCSLT) y de las muestras tomadas antes del ordeño (RCSAO), según el nivel de RCSLT, en 19 cabras que permanecieron sanas durante el experimento

TABLA 4. Relación entre el RCS de las muestras de la leche total ordeñada $\left(\mathrm{RCS}_{\mathrm{LT}}\right)$ y de las muestras tomadas antes del ordeño $\left(\mathrm{RCS}_{\mathrm{AO}}\right)$ en 19 cabras que permanecieron sanas a lo largo el experimento, según su número de lactación

\section{SEGUNDO ESTUDIO: VARIACIÓN DIARIA Y ELEVACIONES DEL RECUENTO DE CÉLULAS SOMÁTICAS DE ORIGEN NO INFECCIOSO EN LA LECHE DE CABRA}

TABLA 1 Resultados del análisis estadístico por glándulas y por ubres del RCS y la producción (PL) y composición de la leche en 32 cabras que fueron 
controladas diariamente (glándula) o semanalmente (ubres) durante un periodo de 53 días

TABLA 2. RCS según el estado sanitario de las glándulas o ubres en 32 cabras que fueron controladas diariamente (glándulas) o semanalmente (ubres) durante un periodo de 53 días.

TABLA 3 Producción y composición de la leche según el estado sanitario de las ubres en 32 cabras que fueron controladas semanalmente durante un periodo de 53 días

TABLA 4. Distribución de frecuencias de las glándulas sanas e infectadas de acuerdo a los valores calculados, para cada glándula, de la media aritmética (MA) y desviación estándar (DS) del RCS y del log10RCS de todos los controles diarios

TABLA 5. Distribución de las 32 cabras utilizadas según el estado sanitario de la ubre y el número de elevaciones transitorias del RCS ( $\left.\mathrm{ET}_{\mathrm{RCS}}\right)$ que presentó cada animal a lo largo del experimento

TABLA 6. Distribución de las $\mathrm{ET}_{\mathrm{RCS}}$ según el estado sanitario de la ubre, el número de lactación y los días que duró cada elevación

TABLA 7. Medias estimadas por mínimos cuadrados $\left( \pm\right.$ ES) del $\log _{10} \mathrm{RCS}$ y la producción y composición de la leche en tres controles semanales (controles 0,1 y 2) de 8 cabras libres de IIM que manifestaron una $\mathrm{ET}_{\mathrm{RCS}}$ (control 0) y en 8 cabras Testigo que no sufrieron ninguna ETRCS.

\section{TERCER ESTUDIO: EFECTO DEL CELO SOBRE EL RECUENTO DE CÉLULAS SOMÁTICAS EN LA LECHE DE CABRA.}

TABLA 1.Resultados del análisis estadístico utilizado para estudiar la influencia de diversos factores sobre las variables de RCS, determinado por glándula y ubre, y la producción y composición de la leche ordeñada registrada por ubre

TABLA 2. Comparación del $\operatorname{logRCS}$, en la leche de ubre, entre el grupo de cabras que recibió un tratamiento de sincronización de celos (SC) y otro grupo de animales que no recibió ningún tratamiento (control), en los experimentos realizados en el año 1 y 2

TABLA 3. Comparación del $\log \mathrm{RCS}$, en la leche de ubre, entre el grupo de cabras que recibió un tratamiento de sincronización de celos (SC) y otro grupo de animales que no recibió ningún tratamiento (control), según el número de lactación de las cabras

TABLA 4. Comparación del $\log \mathrm{RCS}$, en la leche de ubre, entre el grupo de cabras que recibió un tratamiento de sincronización de celos (SC) y otro grupo 
de animales que no recibió ningún tratamiento (control), según el estado sanitario de la ubre

TABLA 5. Evolución de la producción y composición de la leche de ubre en el grupo SC (sincronización de celos; $n=34$ ) y en el grupo Control ( $n=34)$. RE: retirada de esponjas.

TABLA 6. Distribución de las ETRCS identificadas en el grupo de cabras SC (sincronización de celos) y Control, según el estado sanitario de la ubre, el número de lactación y los día que duró cada ETRCS

TABLA7. Numero de cabras que manifestaron al menos una ETRCS a lo largo del experimento en el grupo SC (sincronización de celos) y Control ..... 129

TABLA 8. RCS (en log), porcentaje de leucocitos polimorfonucleares (PMN) y recuento de PMN (en log) en la leche de glándula, durante 5 días en un grupo de cabras (6 cabras, 12 glándulas) que manifestaron celo y una Elevación Transitoria del RCS (Grupo ET) y en otro grupo de cabras Control (6 cabras, 12 glándulas).

\section{CUARTO ESTUDIO: EFECTO DE VARIOS TIPOS DE ESTRÉS SOBRE EL RECUENTO DE CÉLULAS SOMÁTICAS EN LA LECHE DE CABRA}

TABLA 1. Evolución diaria del log del RCS (céls/ml) durante el experimento 1, según el número de lactación, estado sanitario de la ubre y grupo de RCS de las cabras.

TABLA 2. Evolución diaria de la producción y composición de la leche y del cortisol en plasma en las cabras utilizadas en el experimento 1

TABLA 3. Resultados del análisis estadístico del Experimento 2

TABLA 4. Evolución diaria del RCS en los tres grupos de cabras del experimento 2, separadas según número de lactación

TABLA 5. Evolución diaria del Cortisol en suero sanguíneo en los tres grupos de cabras del experimento 2, separadas según el número de lactación

TABLA 6. Evolución diaria de la producción de leche en los tres grupos de cabras del experimento 2 (A, B y C), separadas según el número de lactación... 154

TABLA 7. Evolución diaria de la composición de la leche en los tres grupos de cabras del experimento 2, separadas según en el número de lactación..... 156

TABLA 8. Resultados del análisis estadístico del Experimento3.

TABLA 9. Evolución diaria del RCS en los dos grupos de cabras del experimento 
TABLA 10. Evolución diaria del Cortisol en suero sanguíneo en los dos grupos de cabras del experimento 3, separadas según el número de lactación

TABLA 11 Evolución diaria de la producción de leche en los dos grupos de cabras del experimento 3(Control y Estrés), separadas según el número de

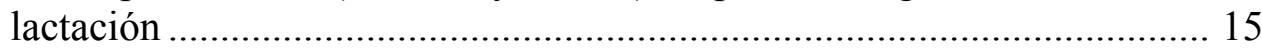

TABLA 12 Evolución diaria de la composición de la leche (grasa, proteína, lactosa y materia seca) en los dos grupos de cabras del experimento 3 (Control y Estrés), separadas según el número de lactación 


\section{INDICE DE FIGURAS.}

\section{INTRODUCCION}

FIGURA 1. Censo de caprino (en millones de cabezas) y producción de leche de cabra

FIGURA 2. Censo de ganado caprino ( $\times 10^{4}$ cabezas) y producción de leche de cabra $\left(\times 10^{3} \mathrm{Tm}\right)$ en los principales países de la Unión Europea en el año

FIGURA 3. RCS según el estado serológico frente al virus de la AEC y el estado sanitario de la glándula mamaria

FIGURA 4.RCS en de muestras de leche tomadas antes del ordeño (primeros chorros), hacia la mitad del ordeño y después del ordeño (repaso manual) en 11 cabras alpinas

FIGURA 5. Dos ejemplos de fluctuaciones diarias del RCS en la leche ordeñada de una cabra

FIGURA 6. Evolución de la producción de leche y del RCS en ganado caprino a lo largo de la lactación

FIGURA 7. Evolución del RCS a lo largo de la lactación según el número de lactación de las cabras

FIGURA 8. Evolución mensual de la media aritmética del RCS y del porcentaje de muestras con recuentos inferiores a 1.500 x $10^{3} \mathrm{UFC} / \mathrm{ml}$ $(\%$ RCS. $<1.500)$ en muestras de leche de cabra procedentes de las CC.AA. Valenciana y de Murciana

III. MATERIAL Y METODOS GENERALES

FIGURA 1. Máquina de ordeño utilizada en los distintos experimentos

FIGURA 2. Equipos utilizados para el análisis del RCS (Fossomatic 5000) y la composición de la leche (MilkoScan FT 120).

FIGURA 3.Material y procedimiento en la toma de muestras para el análisis bacteriológico

FIGURA 4. Siembra en placas de agar- sangre

FIGURA 5. Conservación de gérmenes aislados 68

FIGURA 6. Citospina ( Shadon Cytospin) 71

FIGURA 7. Extracción de sangre para las muestras del cortisol 71 


\section{IV.PRIMER ESTUDIO: EFECTO DEL TIPO DE MUESTRA (PRIMEROS CHORROS VS CONTROL LECHERO) SOBRE EL RCS EN LA LECHE DE CABRA.}

FIGURA 1. Evolución de las medias aritméticas (a) y geométricas (b) del RCS en muestras de leche tomadas antes del ordeño $\left(\mathrm{RCS}_{\mathrm{AO}}\right)$ y de la leche total ordeñada $\left(\mathrm{RCS}_{\mathrm{LT}}\right)$ a lo largo de todo el estudio en 19 cabras libres de IIM

FIGURA 2. Comparación del RCS, en $\log 10$, de las muestras de la leche total ordeñada $\left(\log \mathrm{RCS}_{\mathrm{LT}}\right)$ y de las muestras tomadas antes del ordeño $\left(\log \mathrm{RCS}_{\mathrm{AO}}\right)$ y de la relación $\mathrm{RCS}_{\mathrm{LT}} / \mathrm{RCS}_{\mathrm{AO}}$ en 216 controles de 19 cabras que permanecieron sanas a lo largo del experimento.

\section{V.SEGUNDO ESTUDIO: VARIACIÓN DIARIA Y ELEVACIONES DELRECUENTO DE CÉLULAS SOMÁTICAS DE ORIGEN NO INFECCIOSO EN LA LECHE DE CABRA}

FIGURA 1. Evolución diaria de la media aritmética (a), desviación estándar (b) y media geométrica (c) del RCS en glándulas sanas (Sanas-S, cuando la colateral también es sana, $\mathrm{n}=20$; Sanas-I, cuando la colateral está infectada, $n=12)$ y glándulas infectadas $(n=12)$ de ganado caprino

FIGURA 2. Evolución semanal de la media aritmética (a) y media geométrica (b) del RCS en ubres sanas e infectadas en leche de cabra.

FIGURA 3. Evolución de la media aritmética del RCS de las muestras de primeros chorros $(\mathrm{PCH})$ y de la leche de Tanque procedente de 20 cabras que permanecieron libres de IIM. El RCS de la leche de Tanque fue estimado partir de la producción y el RCS de la leche ordeñada de cada animal (control lechero

FIGURA 4.Evolución a lo largo del estudio del número de cabras que presentaban en un mismo día una $\mathrm{ET}_{\mathrm{RCS}}$, separadas según el estado sanitario de la ubre (a-sanas; b-infectadas)

FIGURA 5. Evolución diaria del RCS por glándula en las $\mathrm{ET}_{\mathrm{RCS}}$, considerando el periodo comprendido entre 6 días antes y 6 días después de finalizar la elevación, y de forma separada según el estado sanitario de la ubre y la duración en días de la $\mathrm{ET}_{\mathrm{RCS}}$. En ubres sanas: PD y PI, glándula derecha e izquierda, respectivamente. En ubres infectadas: P.SANO y P.INF, glándula sana e infectada, respectivamente

\section{IV.TERCER ESTUDIO: EFECTO DEL CELO SOBRE EL RECUENTO DE CÉLULAS SOMÁTICAS EN LA LECHE DE CABRA.}

FIGURA 1. Evolución diaria de las medias aritméticas del RCS en la leche de ubre en dos grupos de cabras ( $\mathrm{SC}$ - tratamiento hormonal de sincronización 
de celos- y Control), en cada uno de los años que realizó el experimento.

FIGURA 2. Evolución diaria de las medias aritméticas del RCS en la leche de ubre en dos grupos de cabras ( $\mathrm{SC}$ - tratamiento hormonal de sincronización de celos- y Control), según el número de lactación de las cabras.

FIGURA 3 Evolución diaria de las medias aritméticas del RCS en la leche de ubre en dos grupos de cabras ( $\mathrm{SC}$ - tratamiento hormonal de sincronización de celos- y Control), según el estado sanitario de la ubre

FIGURA 4.Evolución diaria de las medias aritméticas del RCS en la leche de glándula en dos grupos de cabras ( $\mathrm{SC}$ - tratamiento hormonal de sincronización de celos- y Control), según el estado sanitario de la ubre y el número de lactación

FIGURA 5. Evolución diaria del número de cabras que presentaban en un mismo día una Elevación Transitoria del RCS ( $\mathrm{ET}_{\mathrm{RCS}}$ ) en el grupo de cabras SC (tratamiento hormonal de sincronización de celos) y Control....

FIGURA 6. Incremento máximo del RCS durante las $\mathrm{ET}_{\mathrm{RCS}}$, según el RCS (en log) que tenían los animales en los tres días previos al estrés (RCSprevio). Incremento de RCS expresado como: a) diferencia (RCSmaxRCSprevio) y b) relación (RCSmax/RCSprevio)

\section{CUARTO ESTUDIO: EFECTO DE VARIOS TIPOS DE ESTRÉS SOBRE EL RECUENTO DE CÉLULAS SOMÁTICAS EN LA LECHE DE CABRA}

FIGURA 1. Extracción del estiércol y traslado de los animales (experimento 1)....... 143

FIGURA 2. Luchas entre las cabras después del reagrupamiento (experimento 2).... 144

FIGURA 3.Traslado de los animales al exterior de la explotación y estrés ocasionado por el contacto con un perro (experimento 3 ).

FIGURA4. Evolución diaria de la media geométrica del RCS en las cabras multíparas. A) Según el estado sanitario de la ubre (sanas $n=26$; infectadas $n=24)$. B) Según el RCS previo al estrés (Bajo, $<1$ millón céls/ml, $\mathrm{n}=31$; Alto, $>1$ millóncéls/ml, $\mathrm{n}=19$ )

FIGURA 5. Evolución diaria de la media geométrica del RCS en las cabras de $\geq 3$ partos según el estado sanitario de la ubre ( $\operatorname{sanas} n=6$, infectadas $n=4$; Experimento 3).

FIGURA 6.Incremento de células somáticas en las cabras de 3 o más partos sometidas a un estrés extremo $(\mathrm{n}=10)$, según el RCS (en $\log )$ que tenían estos animales en los dos días previos al estrés (RCS0). Incremento de RCS expresado como: A) diferencia (RCS1- RCS0) o $\mathrm{B})$ relación $(\mathrm{RCS} 1 / \mathrm{RCS} 0)$ 



\section{INTRODUCCIÓN}




\section{INTRODUCCIÓN}

\section{LA PRODUCCIÓN DE LECHE DE CABRA EN EL MUNDO, EN LA UNIÓN EUROPEA Y EN ESPAÑA}

Desde tiempos históricos la cabra ha cubierto un importante papel en la supervivencia de los pueblos que viven en condiciones extremas. La versatilidad de este animal para adaptarse a distintos medios y condiciones de explotación, así como su destacada capacidad para suministrar alimentos proteicos de excelente calidad (carne y leche), le confieren especial interés dentro de los animales útiles al hombre (Haenlein, 2007). Por este motivo, no es de extrañar que el ganado caprino se localice mayoritariamente en aquellos países o regiones con condiciones ambientales rigurosas y/o con altos índices de pobreza. Por otra parte, las características específicas de la leche de cabra y productos derivados, unido a los hábitos de los consumidores de ciertas zonas geográficas, han hecho que este sector haya adquirido una relevancia específica en ciertos países desarrollados (Boyazoglu y Morand-Fehr, 2001)

En el año 2007 existían en el mundo 850 millones de cabezas de ganado caprino (FAO, 2008) y se produjeron casi 14,8 millones de Tm de leche de cabra (Figura 1), lo cual representa el 2,2\% de la producción total de leche en el mundo. La mayor parte del censo
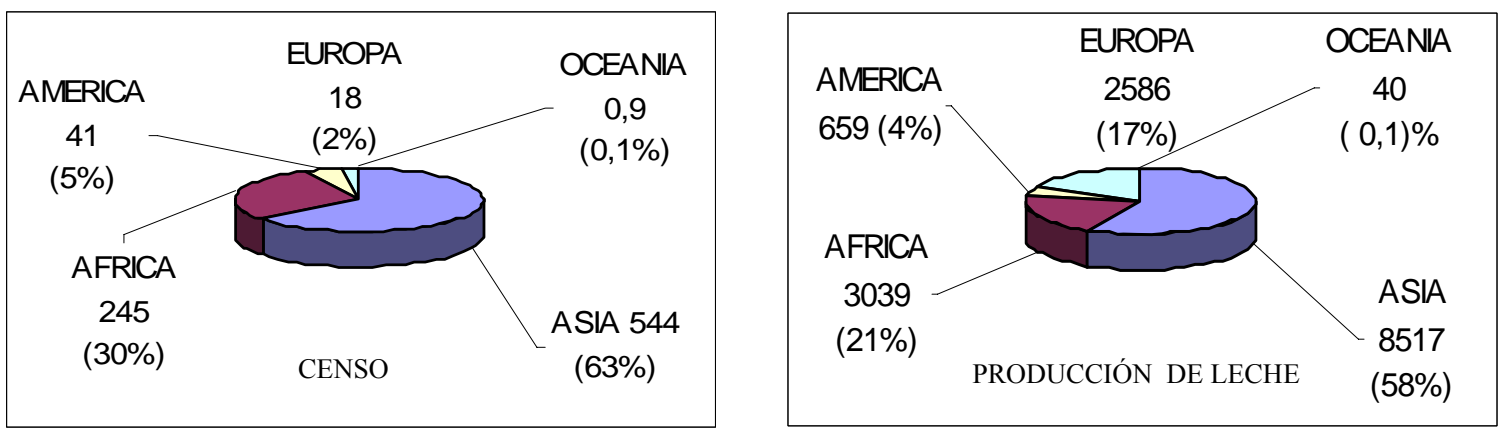

FIGURA 1. Censo de ganado caprino (millones de cabezas) y producción de leche de cabra (miles de Tm) en el mundo en el año 2007 (FAO, 2008). 
se concentra en países subdesarrollados o en vías de desarrollo de Asia (China: 197 millones de cabezas; India: 125 millones; Pakistán: 53,8 millones; Bangladesh: 52,5 millones) y de África (Sudán: 42 millones; Nigeria: 28,5 millones; Somalia: 12,7 millones; Kenia: 10,5 millones; Mali: 13 millones; Etiopía: 18 millones).

Así mismo, la producción de leche de cabra también se encuentra localizada mayoritariamente en Asia (58\% de la producción mundial, principalmente en la India, con 3,8 millones de Tm, Bangladesh, con 2 millones de Tm y Pakistán con 0.7 millones Tm) y en África (21\% de la producción mundial, principalmente en Sudán, con 1,45 millones de Tm y Mali, con 0,26 millones de Tm). Además, también podemos destacar la elevada producción que existe en Europa (17\% de la producción mundial; Figura 1), a pesar del escaso censo de ganado caprino que existe en este continente (tan solo el $2 \%$ del censo mundial).

En el Magreb la población caprina se encuentra mayoritariamente en Mauritania (5,6 millones de cabezas), Marruecos (5,3 millones) y Argelia (3,7 millones), mientras que la producción de leche prácticamente se concentra en Argelia (190.000 Tm) y Mauritania (110.000 Tm), ya que en el resto de países la producción es muy baja (Marruecos: 34.000 Tm; Libia: 15.000 Tm; Túnez: 12.000 Tm).

En la Unión Europea existen tan solo 13,9 millones de cabras (1,6 \% del censo mundial), pero se producen anualmente 1,9 millones de $\mathrm{Tm}$ de leche $(13,2 \%$ de la producción mundial de leche de cabra). Tanto el censo como la producción de leche de cabra se concentran en los países mediterráneos (Figura 2): Grecia (40\% del censo y $26 \%$ de producción de leche), España (21\% y 25\%), Francia ( $9 \%$ y 31\%) e Italia ( $7 \%$ y 6\%).

De acuerdo a Daza (2004) el sector caprino en la Unión Europea reúne las siguientes características:

- La mayor parte del censo, entre el $80 \%$ y el $90 \%$, se localiza en zonas desfavorecidas y de montaña, que no pueden ser aprovechadas para otras actividades, como la agricultura o la ganadería de otras especies. 


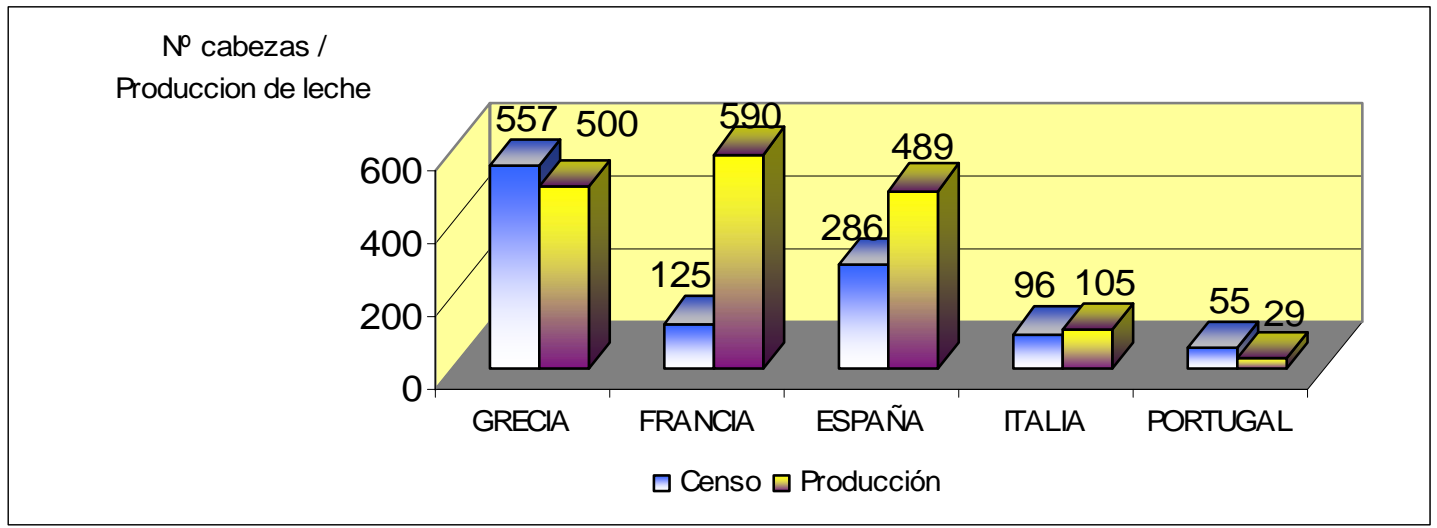

FIGURA 2. Censo de ganado caprino ( $\times 10^{4}$ cabezas) y producción de leche de cabra $\left(\times 10^{3}\right.$ Tm) en los principales países de la Unión Europea en el año 2007 (FAO, 2008)

- Tradicionalmente, los sistemas de producción en los países productores más importantes han sido extensivos o semiextensivos, exceptuando el caso de Francia, país en el que predominan los sistemas intensivos con razas de alto grado de especialización lechera.

- La producción de leche se destina básicamente a la industria quesera, bien sea para la producción de quesos puros de cabra o de tipo mezcla, siendo muy bajo el consumo en líquido.

- La normativa europea no establece limitaciones a la producción de leche de cabra, hecho que si sucede en la producción de leche de ganado vacuno.

En España existen 2,5 millones de cabras, el 70\% de de las cuales se destinan a ordeño, y se producen unas 489.000 Tm de leche anuales (MARM, 2009). La principal área productora está situada en las zonas sur y centro del país, destacando las siguientes comunidades autónomas: Andalucía (42\% del censo caprino y 51\% de la producción de leche), Canarias (10\% y 17\%), Castilla la Mancha (12\% y 13\%), Extremadura ( $9 \%$ y 6\%), Castilla y León (6\% y 3\%) y Murcia (4\% y 3\%). En la Comunidad Valenciana existen unas 100.000 cabras y se producen unas 10.000 Tm de leche anuales (2\% de España).

De acuerdo a Esteban (2009), las principales razas caprinas autóctonas españolas son: Murciano-Granadina (517.000 animales), Malagueña (300.000), Florida (100.000), 
Majorera (200.000), Palmera (14.000) y Tinerfeña (28.000). Son razas de buena aptitud láctea y están muy bien adaptadas a zonas semiáridas, con baja pluviometría y altas temperaturas (Martínez, 2000).

En España la leche de cabra se destina mayoritariamente a la elaboración de quesos, existiendo una gran variedad de ellos. Así, Ramírez et al. (2009) identifica un total de 28 quesos puros de leche de cabra y 21 quesos de mezcla con leche de oveja y/o vaca. De entre ellos podemos destacar aquellos que poseen una Denominación de Origen Protegida: Majorero, Palmero, Murcia, Murcia al vino, Ibores y, en los quesos de mezcla, Cabrales, Gamonedo, Picón y Quesucos de Liebana. En la Comunidad Valenciana adquieren importancia los quesos frescos de Alicante, Casoleta, Nucia y Servilleta. De este modo es posible ofrecer al mercado un producto de calidad y diferenciado que presenta una demanda creciente por parte de los consumidores, especialmente a medida que estos aumentan su poder adquisitivo.

En la actualidad, las industrias queseras españolas ya están pagando la leche de cabra a los ganaderos en función de su calidad química (grasa+proteína), y, en ocasiones, también aplican primas o penalizaciones en función de la calidad higiénico-sanitaria (bacteriología, inhibidores, recuento de células somáticas) y la presencia de agua añadida. En otros países europeos el pago de la leche por calidad también incluye otros parámetros como la lipólisis, el contenido en IgG (Francia) o una evaluación sensorial (Noruega; Pirisi et al., 2007)

\section{DEFINICIÓN Y CARACTERÍSTICAS DE LAS CÉLULAS SOMÁTICAS EN LA LECHE DE CABRA}

La leche de todos los mamíferos contiene distintos tipos de células que provienen del propio organismo animal, y que no tienen capacidad para multiplicarse en la leche, a diferencia de las células de los microorganismos. En la década de los 60 el profesor M.J. Paape acuñó por primera vez el concepto de células somáticas (Contreras, 2000) para referirse a este tipo de células ("somático"= relativo al cuerpo), término que se suele utilizar hoy en día bajo la denominación de recuento de células somáticas (RCS). Las 
células somáticas presentes en la leche pueden clasificarse, según su origen, en dos grandes grupos: a) células de origen sanguíneo y b) células epiteliales.

Las células de origen sanguíneo son en su totalidad leucocitos: macrófagos, polimorfonucleares (principalmente neutrófilos) y linfocitos (Sordillo y Streicher, 2002). En general, se considera que la presencia en la leche de estos tipos celulares es de origen, fundamentalmente, inflamatorio e inmunitario, a diferencia de las partículas citoplasmáticas y células epiteliales (Bergonier et al., 1996). Todas estas células se encuentran presentes en las glándulas mamarias sanas, si bien ante un proceso inflamatorio, cualquiera que sea la causa, se produce un incremento del trasvase de leucocitos a la leche, especialmente de PMN, por quimiotactismo y diapédesis (Sordillo y Streicher, 2002). De este modo, la presencia de leucocitos en la leche y, por tanto, el RCS, puede considerarse un indicador del estado inflamatorio de la glándula mamaria (Bergonier et al., 1996), aunque para su interpretación habrá que tener en cuenta los factores no infecciosos que también pueden influir sobre estas células (Paape et al., 2001).

Las células epiteliales de la leche provienen de la descamación del epitelio alveolar y de los conductos de la glándula mamaria. El significado de la presencia de este tipo de células en la leche es principalmente fisiológico, por regeneración normal de los epitelios. Estudios recientes han demostrado que una gran mayoría de las células epiteliales presentes en la leche son viables y presentan características de células alveolares totalmente diferenciadas, de modo que, tras su cultivo in vitro, han sido utilizadas como modelo en estudios relacionados con la lactogénesis, cáncer, inmunología e infecciones virales (Boutinand y Jammes, 2002).

Además de la presencia de células somáticas, en la leche también podemos encontrar material extracelular membranoso, restos nucleares y fragmentos celulares (Gonzalo et al., 1998a) que se corresponden a grandes fragmentos de citoplasma originados a partir de la porción distal de las células secretoras alveolares mamarias. Estas formaciones se suelen denominar como partículas citoplasmáticas y son muy abundantes cuando la secreción de la leche es apocrina y muy escasos, o prácticamente ausentes, cuando la secreción es merocrina. 
En ausencia de infección, la leche de cabra presenta, respecto a la de oveja y vaca, tres características peculiares relacionadas con los elementos celulares que contiene: elevado porcentaje de polimorfonucleares neutrófilos (PMN), elevado contenido de partículas citoplasmáticas y un mayor recuento de células somáticas (Tablas 1 y 2).

La primera especificidad en la secreción láctea caprina es que los polimorfonucleares neutrófilos (PMN) suponen el principal componente celular tanto en glándulas sanas como en infectadas (Dulin et al., 1983; Rota et al., 1993a; Sierra et al., 1999) representando aproximadamente el $70 \%$ de las células somáticas (Tabla 2). En cambio en el ganado vacuno tan solo constituyen el 26\% en glándulas no infectadas y entre el 29-40\% en glándulas infectadas (Miller et al., 1991), y en la oveja alrededor del 30\% cuando el RCS es bajo (menos de 100.000 células $/ \mathrm{ml}$ ) y más del 70\% cuando el RCS sobrepasa el millón de células somáticas (Gonzalo 1985). Un aspecto interesante a remarcar es que los factores quimiotácticos que atraen a los PMN a la leche en las glándulas sanas son distintos de los factores quimiotácticos que existen en las glándulas afectadas de mamitis (Manlongat et al., 1998).

TABLA 1. Comparación del RCS y la distribución de los tipos de células en la leche de diferentes especies (Boutinand y Jammes , 2002 ; Paape et al., 2001).

\begin{tabular}{|l|c|c|c|c|c|c|}
\hline \multirow{2}{*}{ Especie } & \multicolumn{7}{|c|}{ Tipos de células } \\
\cline { 2 - 8 } & $\begin{array}{c}\text { RCS } \\
10^{6} \text { células/mL }\end{array}$ & $\begin{array}{c}\text { Part. Citopl. } \\
10 \% / \mathrm{ml}\end{array}$ & $\begin{array}{c}\text { Cels. Epitel. } \\
\%\end{array}$ & $\begin{array}{c}\text { PMN } \\
\%\end{array}$ & $\begin{array}{c}\text { Linfocitos } \\
\%\end{array}$ & $\begin{array}{c}\text { Macrófagos } \\
\%\end{array}$ \\
\hline Humano & 0.009 & 90 & $50-90$ & 6 & $5-9$ & 8 \\
\hline Bovino & 0.075 & No observado & Muy bajo & $5-20$ & $20-30$ & 61 \\
\hline Ovino & 0.110 & 15 & Muy bajo & 22 & $10-25$ & 70 \\
\hline Caprino & 1.1 & 128 & $10-20$ & $45-75$ & $3-10$ & $10-35$ \\
\hline Porcino & 1 & - & $60-90$ & $5-10$ & $15-25$ & $5-10$ \\
\hline
\end{tabular}

Los linfocitos representan entre el 5-20\% de las células somáticas en la leche de cabra (Tabla 2). En cambio en la vaca suponen alrededor del 24\% (Miller et al., 1991) y en la oveja del $20 \%$ cuando la concentración celular es baja (menos de 100.000 cels $/ \mathrm{ml}$ ) y desciende por debajo del $12 \%$ cuando sobrepasa la cifra de 1.000 .000 de cels $/ \mathrm{ml}$ 
TABLA 2. Distribución porcentual de los tipos de células somáticas en la leche de cabra (Martínez, 2000)

\begin{tabular}{|c|c|c|c|c|c|c|}
\hline Autor & Tipo muestra & PMN & Linfocitos & Epitelial & Macrófagos & $\mathrm{PC}^{1}$ \\
\hline Okada, 1960 & Ubre & 69,3 & 21,3 & 9,4 & - & - \\
\hline Dulin et al., 1982 & Glándula infectada & $71-86$ & $5-11$ & - & $8-18$ & $6-30$ \\
\hline Dulin et al., 1982 & Glándula no infectada & $45-74$ & $9-20$ & - & $15-35$ & $35-74$ \\
\hline Rota et al., 1993b & Ubre & 63 & 7,2 & $13^{2}$ & 16,1 & - \\
\hline Droke et al., 1993 & Tanque & 87,3 & 2,8 & - & 9,9 & - \\
\hline Sierra et al., 1999 & Glándula infectada & 75,3 & 16,8 & 1,2 & 4,8 & 31,5 \\
\hline Sierra et al., 1999 & Glándula no infectada & 74 & 14,9 & 5,7 & 4,4 & 35,2 \\
\hline Jaubert et al., 1996 & Tanque $^{3}$ & 70,3 & 17,4 & 10,5 & 1,8 & - \\
\hline Jaubert et al., 1996 & Tanque $^{4}$ & 80,3 & 11,4 & 6,8 & 1,5 & - \\
\hline Gajdusek et al., 1996 & Ubre & $40-70$ & $5-20$ & $10-15$ & $10-20$ & - \\
\hline
\end{tabular}

1: con respecto al total de células. 2: Otros tipos celulares. 3: Bajo RCS (710.000células/ml). 4: Alto RCS (2.332.000células/ml)

(Gonzalo, 1985). Porcentualmente, el número de macrófagos en la leche de cabra (alrededor del 15\%) también es inferior al encontrado en la leche de oveja y vaca (Tablas 1 y 2). De hecho, en las vacas y ovejas libres de IIM, los macrófagos son el principal tipo celular de la leche, llegando a representar entre el 40 y el $80 \%$ de todas las células somáticas (Paape et al., 2001).

Por último, la presencia de células epiteliales en la secreción láctea caprina es muy reducida representando aproximadamente entre el 6-10\% del total de células (Tabla 2). Tras la infección intramamaria la presencia de células epiteliales disminuye porcentualmente a favor de un aumento de las células inflamatorias (Contreras et al., 1998). Por tanto su proporción es menor a medida que se incrementa el RCS. En la vaca las células epiteliales representan alrededor del 19\% en la leche de glándulas no infectadas y desciende hasta el 6-14\% en glándulas infectadas (Miller et al., 1991), mientras que en la oveja suponen aproximadamente el 10\% cuando el RCS es bajo y menos del 5\% cuando es elevado (Gonzalo 1985). En los últimos años se han utilizado nuevas técnicas para identificar a las células epiteliales de la leche (anticuerpos monoclonales y citometría de flujo), pero los recuentos con esta metodología han sido superiores a los citados anteriormente, tanto en la leche de cabra ( $26 \%$ de células epiteliales; Boutinand y Jammes, 
2002) como en la leche de vaca procedente de glándulas libres de infección intramamaria (40\%; Leitner et al., 2000).

Una segunda especificidad de la leche de cabra es que presenta un elevado número de partículas citoplasmáticas (Tablas 1 y 2), lo cual es debido a que la secreción láctea de la cabra es de tipo apocrino (Dulin et al., 1982; Dulin et al., 1983; Paape y Capuco, 1997). Este tipo de secreción se caracteriza porque, al final de la fase secretora, la parte apical de la célula epitelial se separa de su base, liberándose en la luz del alveolo bajo forma de una partícula citoplásmica (Perin y Baudry, 1993). Por el contrario, la secreción de la leche en la vaca es de tipo merocrino ya que se produce el paso de los componentes de la leche de la membrana apical de la célula hacia el lumen alveolar sin perdida del citoplasma (Neveu et al., 2002). Aunque en la oveja la secreción de la leche también tiene un importante componente apocrino, la concentración de particulas citoplasmáticas es normalmente muy baja, del orden de la décima parte de la que existe en la leche de cabra (Paape et al., 2001).

Estas partículas tienen morfología esférica, de un tamaño similar al de los leucocitos (entre 5 y 30 micrómetros) y en su mayoría carecen de núcleo (menos del 1\% poseen núcleo; Dulin et al., 1983; Paape y Capuco, 1997). Es importante destacar que el recuento de partículas citoplasmáticas no está afectada significativamente por la infección intramamaria ni por el número y el estado de lactación (Contreras et al., 1998) tomando valores entre 50.000 y 250.000 partículas/ml (Dulin et al., 1983). En consecuencia el porcentaje de partículas citoplasmáticas, respecto a la concentración total de elementos celulares, presenta grandes variaciones (entre el 3\% y el 94\%; Dulin et al., 1983), observándose una tendencia a disminuir conforme aumenta el RCS (Dulin et al., 1983; Sierra et al., 1999).

Finalmente, un tercer aspecto característico de la leche de cabra es que su concentración celular es más elevada que en la leche de vaca y oveja (Dulin et al., 1983; Droke et al., 1993; Contreras et al., 1997a, Paape et al., 2007; entre otros). Así, en ausencia de mamitis, el RCS en la leche de cabra pueden variar entre 270.000 y 2 millones de cels $/ \mathrm{ml}$, mientras que en la leche de vaca y oveja se situaría entre 10.000 y $200.000 \mathrm{cels} / \mathrm{ml}$ (Paape et al., 2001). Además, los estudios histopatológicos realizados en ubres de ganado caprino con altos RCS, pero sin IIM, no han encontrado ningún tipo de trastorno en la 
glándula, lo cual sugiere que los altos RCS son de naturaleza fisiológica y no patológica (Zeng y Escobar, 1995).

\section{FACTORES QUE INFLUYEN SOBRE EL RCS}

El RCS en la leche de cabra es muy variable debido a la diversidad e importancia de los distintos factores que le afectan (Poutrel y Lerondelle, 1983; Rota et al., 1993b; Sánchez et al., 2000, entre otros). Dada la diversidad de factores que afectan al RCS, para una mejor compresión de los mismos vamos a agruparlos y clasificarlos según sean de origen inflamatorio o no inflamatorio (Tabla 3).

TABLA 3. Principales factores que influyen en el RCS de la leche de cabra (Martínez, 2000).

\begin{tabular}{|c|c|c|}
\hline \multirow[t]{2}{*}{ INFLAMATORIOS } & INFECCIOSOS & $\begin{array}{l}\text { Bacterias } \\
\text { Virus de la AEC }\end{array}$ \\
\hline & NO INFECCIOSOS & Traumatismos... \\
\hline \multirow[t]{2}{*}{ NO INFLAMATORIOS } & INTRINSECOS & $\begin{array}{l}\text { La fracción del ordeño } \\
\text { Tiempo entre ordeños } \\
\text { Número de ordeños/día } \\
\text { Variaciones diarias } \\
\text { Estado de lactación } \\
\text { Número de lactación } \\
\text { Tipo de parto } \\
\text { Raza } \\
\text { Nivel productivo } \\
\text { Celo }\end{array}$ \\
\hline & EXTRINSECOS & $\begin{array}{l}\text { El ordeño } \\
\text { La alimentación } \\
\text { Estrés } \\
\text { Estacionalidad }\end{array}$ \\
\hline OTROS FACTORES & $\begin{array}{l}\text { MÉTODO DE RECUENTO } \\
\text { CONSERVACIÓN Y ALMACENA }\end{array}$ & LAS MUESTRAS \\
\hline
\end{tabular}


Dentro de los factores de tipo inflamatorio destacan los de origen infeccioso, entre los que se encuentra la infección intramamaria de origen bacteriano y la infección por el virus de la AEC. Además, en determinadas circunstancias los factores de origen no infeccioso (factores físicos y químicos) pueden cobrar cierta importancia.

Los factores de origen no inflamatorio se pueden agrupar en factores fisiológicos o intrínsecos a los animales (edad de los animales, estado de lactación, tipo de parto, etc.), y en factores de manejo o extrínsecos a los animales (ordeño, alimentación, vacunaciones, etc).

Finalmente, también existen otros factores que pueden influir en el RCS relacionados con la metodología utilizada para realizar el recuento (conservación y almacenamiento de las muestras, método analítico).

\subsection{FACTORES DE ORIGEN INFLAMATORIO}

Cualquier proceso inflamatorio, de origen infeccioso o no, da lugar a un aumento del RCS. Los factores de naturaleza inflamatoria que modifican el RCS pueden clasificarse en factores infecciosos y no infecciosos, dependiendo de si están implicados microorganismos o no.

\subsubsection{Factores de origen infeccioso}

Varias revisiones bibliográficas (Contreras et al., 2003; Bergonier et al., 2003; Contreras et al., 2007) señalan que la incidencia anual de mamitis clínica en ganado caprino es muy baja $(<5 \%)$ y esta causada principalmente por $S$. aureus, estafilocoos coagulasa negativo (ECN), Estreptococos y Enterobacterias. Por otra parte, la prevalencia de mamitis subclínica suele situarse entre el 5 y el 30\% y los gérmenes responsables suelen ser ECN (alrededor del 70\% de las infecciones), S. aureus (8\%), Gram-negativo (8\%) y Estreptococos (6\%). 


\subsubsection{Mamitis de etiología bacteriana}

La infección intramamaria de origen bacteriano es la causa principal del aumento del RCS en la leche de cabra (Poutrel y Lerondelle, 1983; Poutrel et al., 1997; Luengo et al., 2004; Raynal-Ljutovac et al., 2007), de oveja (Gonzalez-Rodriguez et al., 1995; Gonzalo et al., 2002) y de vaca (Harmon, 1994). En efecto, la inflamación de la glándula mamaria da lugar a un mayor flujo de leucocitos a la leche y, en consecuencia, se produce un aumento de células somáticas. Por ello el RCS puede utilizarse como método para el diagnóstico indirecto de las infecciones intramamarias.

Aunque la infección intramamaria incrementa el RCS, la intensidad de la reacción inflamatoria va a depender del microorganismo involucrado (Lerondelle y Poutrel, 1984; Corrales et al., 1996; Sánchez et al., 1996; Ziluaga et al., 1998), considerándose dicho parámetro un buen indicador de la virulencia del mismo (Contreras et al., 1994).

Los microorganismos que elevan en mayor medida el RCS son aquellos que, clásicamente, han sido clasificados como patógenos mayores (S. aureus, Streptococcus spp., Pseudomonas spp., enterobacterias), pues dan lugar a valores de RCS que oscilan, en líneas generales, entre 2.000.000-4.000.000 células/ml de media geométrica (Martínez, 2000), es decir, un incremento de unas 10 veces respecto a los recuentos de las glándulas sanas (Raynal-Ljutovac et al., 2007). Los micoplasmas también incrementan de forma importante el RCS cuando se producen episodios clínicos de agalaxia contagiosa (media geomética de los recuentos en la leche de tanque superiores a 2.9 millones; Corrales et al., 2004). En cambio, los micoplasmas aislados de mamitis subclínicas ocasionan una elevación del RCS moderada, ya que el valor obtenido de glándulas infectadas por estos patógenos es aproximadamente el doble al hallado de glándulas no infectadas (Sánchez et al., 1999; Martínez et al., 1999). De este modo, en las explotaciones sin síntomas clínicos de micoplasmas, el RCS en la leche de tanque no llega a diferir según se aísle o no este germen (Corrales et al., 2004)

En general la infección intramamaria por estafilococos coagulasa-negativo (ECN) incrementa significativamente el RCS en el ganado caprino (Lerondelle et al., 1992; Sánchez et al., 1996; Corrales et al., 1996), aunque existen grandes diferencias en los RCS dependiendo de la especie aislada (Martínez, 2000; Raynal-Ljutovac et al., 2007). 
Habitualmente los menores valores de RCS se obtienen a partir de glándulas infectadas por S. caprae, S. xylosus y S. hominis (media geométrica entre 600.000 y 800.000 céls $/ \mathrm{ml}$ ), y los valores más elevados cuando se aísla $S$. epidermidis y S. simulans (media geométrica de 1.000.000 céls/ml aproximadamente; Martínez, 2000). Asimismo, Deinhofer (1993) encuentra que los gérmenes ECN resistentes a la novobiocina provocan menores recuentos que aquellos que son sensibles a este antibiótico. No obstante, la relación de los ECN novobiocina sensibles/resistentes con el RCS parece ser menos obvio en ganado caprino que en ganado ovino (Raynal-Ljutovac et al., 2007).

Finalmente, podemos mencionar a las corinebacterias ya que, por una parte, no modifican significativamente el RCS (Corrales et al., 1996) y, por otra parte, no suelen producir infecciones persistentes (Contreras et al., 1994). Por tanto, la importancia de estos agentes como patógenos para la glándula mamaria caprina hay que considerarla secundaria.

La relación entre los valores medios de los RCS de las glándulas infectadas y no infectadas es menor al final de la lactación que al inicio (Aleandri et al., 1996; Corrales et al., 1996) debido al incremento fisiológico que se produce en el RCS durante la lactación, lo que dificulta el diagnóstico indirecto de las mamitis subclínicas al final de la lactación mediante métodos basados en la concentración celular.

\subsubsection{El virus de la artritis encefalitis caprina}

El virus de la artritis encefalitis caprina (AEC) presenta un tropismo muy marcado hacia la glándula mamaria, pero el efecto que tiene sobre el RCS podría depender de la presencia o no de la infección intramamaria (Sánchez et al., 1998a) y de la edad de las cabras (Lerondelle et al., 1992; Nord y Adnoy, 1997).

En ausencia de infección intramamaria, los animales AEC seropositivos presentan un RCS significativamente más elevado que los animales seronegativos (Ryan et al., 1993; Sánchez et al., 1997; Sánchez et al., 1998b; Martínez, 2000; Figura 3), si bien este efecto sería más importante en las cabras multíparas que en las primíparas, de modo que en estas últimas las diferencias no llegan a ser significativas (Lerondelle et al., 1992). El aumento 
del RCS ocasionado por el virus de la AEC es moderado, siendo del mismo orden al ocasionada por ECN (Ryan et al., 1993) o incluso inferior (Lerondelle et al., 1992; Sánchez et al., 1997). Por el contrario, en las glándulas infectadas por bacterias, el virus del AEC tiende a disminuir el RCS (Sánchez et al., 1998a; Martínez, 2000; Figura 3).

A pesar de lo señalado, debemos destacar que un trabajo reciente (Luengo et al., 2004) no ha confirmado que exista una interacción significativa entre el virus de la AEC y el estado infeccioso de la glándula mamaria sobre el RCS .

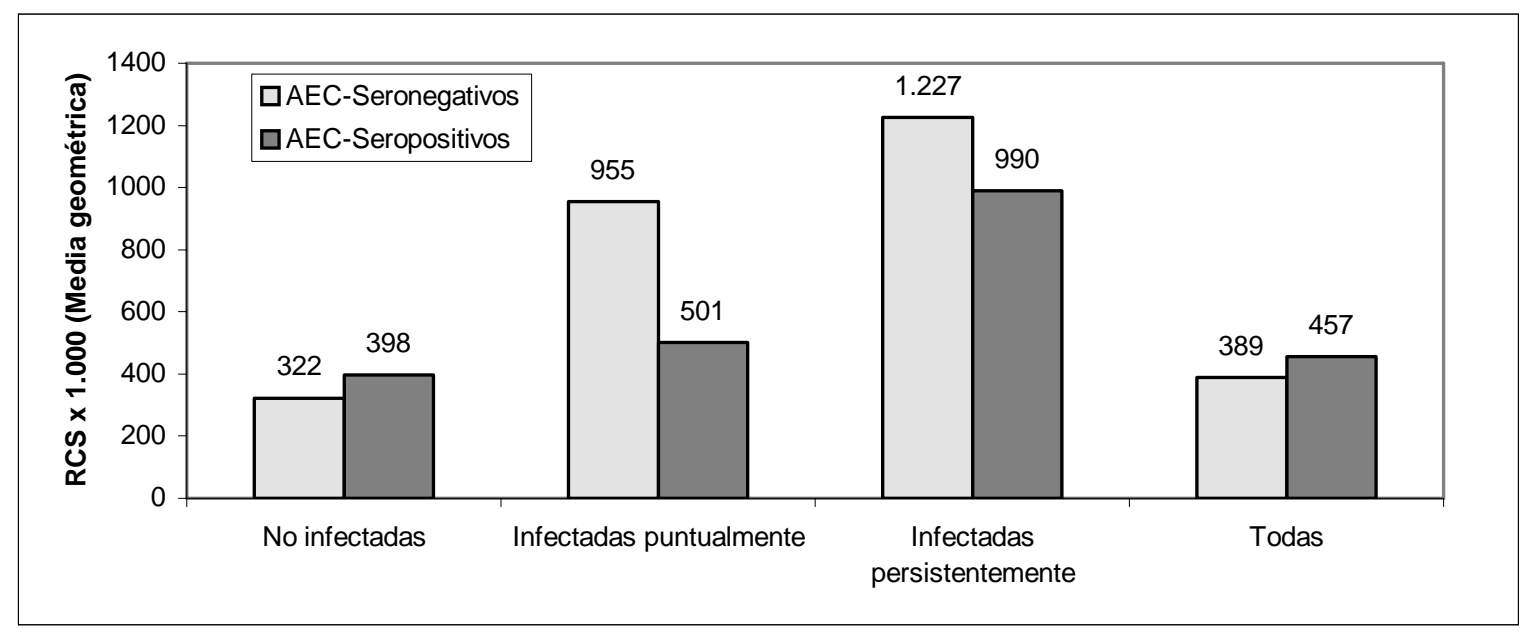

FIGURA 3. RCS según el estado serológico frente al virus de la AEC y el estado sanitario de la glándula mamaria (Martínez, 2000).

De acuerdo a Sánchez (1998) la falta de efecto aditivo sobre el RCS de la infección bacteriana (incremento de los PMN) y la infección por el virus de la AEC (incremento de los macrófagos), puede atribuirse a una disminución de la funcionalidad de los macrófagos, provocada por la infección vírica, limitando la respuesta celular ocasionada por la infección bacteriana (efecto inmunosupresor debido a la alteración de la función de los macrofagos; Bergonier et al., 2003). Esto podría deberse a una alteración de los mediadores de la inflamación como factores quimiotácticos para los neutrófilos (Sánchez et al., 1998a). 


\subsubsection{Factores de origen inflamatorio pero no infeccioso}

Los factores de origen físico que afecten a la glándula mamaria, como son los traumatismos de diferente naturaleza, ya sean puntuales (durante el pastoreo o en el corral) o repetidos (durante el ordeño o en la lactancia natural), podrían dar lugar a incrementos en el RCS en ausencia de infección intramamaria (Perrin y Baudry, 1993). Asimismo algunos productos químicos como son los principios activos y los excipientes de preparaciones terapéuticas intramamarias pueden elevar el RCS (Long et al., 1984). Igualmente, algunos metabolitos, como la urea, podrían tener un efecto irritativo sobre el tejido mamario (Issartial, 1990).

El ejercicio intenso provoca un aumento de los leucocitos en sangre en humanos (aumento de neutrófilos y descenso de linfocitos; Suzuki et al., 1999; Suzuki et al., 2000), y del RCS de la leche en el ganado vacuno (Coulon et al., 1998). Aunque los mecanismos precisos de estos hechos no están claros, los autores citados sugieren que podrían estar asociados a un aumento de las hormonas del estrés (cortisol) y/o al hecho de que el ejercicio provoque microlesiones e inflamación en la musculatura.

\subsection{FACTORES DE ORIGEN NO INFLAMATORIO}

La correcta interpretación de los datos del RCS de glándula, de ubre (control lechero) o de la leche de tanque precisa del conocimiento de los factores no infecciosos que influyen sobre dicho parámetro, con el fin de evitar una errónea clasificación del estado sanitario de glándulas, animales o de rebaños basada en el RCS (Gonzalo et al., 1998b). De hecho algunos autores (Wilson et al., 1995) han encontrado que la variación del RCS en rebaños comerciales de ganado caprino puede ser en un $90 \%$ debida a factores no infecciosos. La cuantificación de dichos factores es relevante en dos grandes áreas: la detección de animales/glándulas afectados/as de mamitis y la utilización del RCS de la leche de tanque como criterio para el pago por calidad.

Por ejemplo, en EEUU los ganaderos tienen dificultades para mantener el RCS en la leche de tanque por debajo de límite legal establecido en ese país (1 millón de células/ml) debido a la influencia de los factores no infecciosos (Haenlein y Hackley, 
1996; Paape et al., 2001). Por tanto, estos factores deberían ser tenidos en cuenta cuando en un futuro se establezca el limite legal en la Unión Europea (Luengo et al., 2004; Paape et al., 2007; Raynal-Ljutovac et al., 2007).

Cuando se estudian los diferentes factores no inflamatorios que pueden influir sobre el RCS debería conocerse el estado sanitario de la glándula mamaria y el estado serológico de los animales frente al virus de la AEC, con el fin de neutralizar el efecto que ambos tienen sobre el RCS. Sin embargo en algunas ocasiones estos datos no son conocidos.

\subsubsection{Factores intrínsecos del animal}

De manera sintética podemos señalar que las variaciones fisiológicas del RCS están ligados a la doble ciclicidad de la producción lechera: ciclicidad de la lactación y ciclicidad del vaciado de la mama (Bergonier et al., 1996). Los principales factores, ordenados de mayor a menor importancia cuantitativa, serían: estado de lactación, número de lactación, fluctuaciones diarias y la fracción del ordeño (Bergonier et al., 2003). No obstante, desde un punto de vista descriptivo, a continuación se presentan los diferentes factores de variación, por orden de intervalo de tiempo creciente: desde la variación entre las fracciones de un mismo ordeño hasta las diferentes lactaciones de una cabra.

\subsubsection{Las fracciones del ordeño}

Podemos distinguir varias fracciones de leche obtenidas durante un ordeño mecánico completo. En primer lugar se extrae la leche máquina que se corresponde a la leche cisternal y una parte de la leche alveolar. Posteriormente, antes de la retirada de las pezoneras, puede practicarse el apurado a máquina, que consiste en un masaje vigoroso de la ubre acompañado frecuentemente de una tracción con las pezoneras. Esto permite la extracción de una cantidad adicional de leche que la máquina no puede evacuar por si sola. Después de la retirada de las pezoneras, aún permanece leche en la ubre. Una parte podría ser extraída mediante repaso manual, si bien actualmente no es practicado en el ganado caprino; el resto, que corresponde a la leche residual, tan solo podrá ser extraída tras la aplicación de oxitocina. 
En algunas ocasiones el RCS se determina por glándula en la fracción de primeros chorros, generalmente utilizando las mismas muestras que se recogen para el análisis bacteriológico. No obstante, suele ser más frecuente disponer del RCS en las muestras del control lechero (leche ordeñada de un animal), las cuales incluyen las fracciones de leche máquina y la leche de apurado a máquina.

Varios trabajos han encontrado que la leche de primeros chorros presenta una RCS similar, aunque siempre ligeramente inferior, respecto a la fracción del control lechero (Figura 4). Por ejemplo, Contreras et al. (1997b) encuentran un RCS medio de 687.000 y 763.000 cels $/ \mathrm{ml}$., en las fracciones de primeros chorros y control lechero, respectivamente. Así mismo, Martínez (2000), analizando unas 600 muestras procedentes de casi 100 cabras, halla una media aritmética del RCS en primeros chorros y control lechero de, 998.000 y 1.139 .000 cels $/ \mathrm{ml}$, respectivamente, mientras que las correspondientes medias geométricas fueron 355.000 y 494.000 cels $/ \mathrm{ml}$.

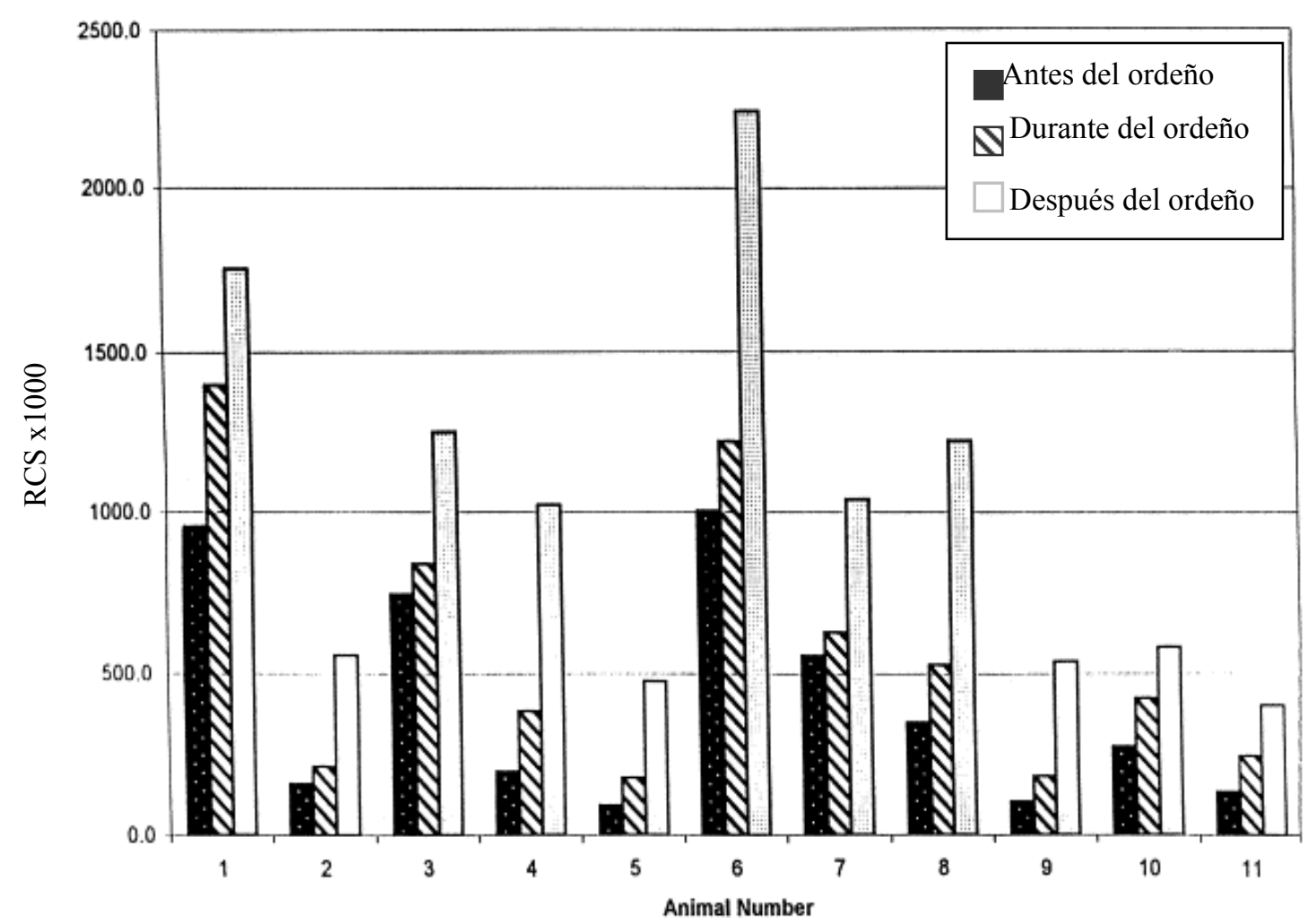

FIGURA 4. RCS en muestras de leche tomadas antes del ordeño (primeros chorros), hacia la mitad del ordeño y después del ordeño (repaso manual) en 11 cabras alpinas (Haenlein, 2002). 
La fracción de leche obtenida después del ordeño (repaso manual) presenta siempre recuentos bastante más elevados que las dos fracciones anteriores (Figura 4). La relación entre el RCS del repaso manual y el de primeros chorros parece ser más elevada a medida que se incrementa el nivel productivo de las especies: así es de 1,7 veces en ganado ovino (Peris et al., 1991; Gonzalo et al., 1993), de 2,9 en ganado caprino (Contreras et al., 1997b) y entre 3-10 veces en ganado vacuno (Berning et al., 1987; Vangroenweghe et al., 2002). Por ello, la muestra de leche de apurado no debería utilizarse para determinar la concentración celular de la leche ni para el diagnóstico indirecto de mamitis basado en dicho parámetro.

Por otra parte, en ganado vacuno se ha visto que, en glándulas libres de infección intramamaria, la distribución de los leucocitos en la leche varía según la fracción del ordeño (Sarikaya et al., 2005): los macrófagos predominan en la leche cisternal (50\% de los leucocitos), mientras que los PMN se concentran en la leche alveolar y residual (60$65 \%$ de los leucocitos); por el contrario, los linfocitos prácticamente no varían con la fracción de ordeño.

\subsubsection{Tiempo entre ordeños}

Los trabajos realizados en ganado caprino han encontrado que el RCS de la leche obtenida en el ordeño de la tarde es entre un $17-78 \%$ superior al RCS de muestras recogidas durante el ordeño de la mañana (Randy e tal., 1988; Sinapis y Vlachos, 1998; Cedden et al., 2008)). Algunos autores lo explican por un efecto dilución, ya que la cantidad de leche ordeñada por la mañana es entre un 35-69\% superior a la ordeñada por la tarde (Randy et al., 1988; Aleandri et al., 1996; Contreras et al., 1997b).

Bergonier et al. (1996) opinan que este hecho podría ser debido al efecto de las modificaciones de presión intraalveolar sobre la diapédesis leucocitaria hacia la luz de los acini. Es decir, dado que en el ordeño de la mañana existe en la ubre una mayor cantidad de leche y, por tanto, de presión intramamaria, se producirá un menor trasvase de leucocitos de la sangre a la leche, por lo que disminuirá la concentración de RCS en la propia leche. La relación entre la presión intramamaria y la migración de leucocitos a la 
leche ha sido demostrada en ganado vacuno, al observar que, inmediatamente tras el ordeño, la concentración de polimorfonucleares en la sangre de la vena subcutanea abdominal disminuye, mientras que en la leche aumenta (Paape et al., 2002).

Otro aspecto que también puede explicar este fenómeno, es la existencia de un "efecto arrastre" desde el ordeño de la mañana (mayor intervalo horario) hacia la tarde (menor intervalo horario), lo cual afectaría tanto al RCS como a la grasa, es decir a los dos componentes de la leche de mayor tamaño (3-10 $\mu \mathrm{m})$. Efectivamente, antes de un ordeño la distribución de la grasa y RCS no es uniforme en la ubre, sino que existe una mayor concentración en la zona alveolar, respecto a la zona cisternal, dado que ambos componentes se encuentran retenidos en los alvéolos y finos conductos por fuerzas de capilaridad. Además, la cantidad de leche que queda retenida en la ubre en la zona alveolar tras el ordeño (leche residual, con una alta concentración de células somáticas y grasa) es proporcional a la cantidad de leche que había en la ubre antes del ordeño. Es decir, tras el ordeño de la mañana queda más leche residual que tras el ordeño de la tarde. Por tanto, tras el ordeño de la mañana una gran cantidad de leche residual, con alta concentración de células somáticas, desciende hasta la cisterna; en las siguientes horas esta leche va diluyéndose (Gonzalo et al., 1994) a medida que va descendiendo a la cisterna la leche nuevamente sintetizada. En resumen, en la leche obtenida en el ordeño de la tarde (menor intervalo horario) habrá una mayor concentración de células somáticas, respecto al ordeño de la mañana, por dos motivos: a) porque inicialmente en la ubre existía (tras el ordeño de la mañana) una mayor cantidad de leche residual, con alta concentración de células somáticas; b) porque transcurren menos horas desde el ordeño anterior (de la mañana), de forma que se sintetiza menos leche y por tanto, se diluye, menos la leche residual que había permanecido en la ubre.

\subsubsection{Número de ordeños al día}

Al reducir o aumentar el número de ordeños al día la producción diaria de leche disminuye o se incrementa, respectivamente. En la raza Murciano-Granadina, el incremento de producción de leche al pasar de un ordeño al día (1X) a dos ordeños al día (2X) está en un 15-18\% (Salama et al., 2003a). En la raza Alpina, al pasar de 2X a 1X la producción de leche se reduce en un 15-17\% (Marnet et al., 2005; Lefrileux et al., 2008). 
En principio, cabría esperar que, por un efecto de dilución, el RCS variara en sentido contrario a la producción de leche. Sin embargo, los resultados de la bibliografía no son coincidentes. Por ejemplo, en la raza Murciano-Granadina Salama et al. (2003a) no encuentran diferencias en el RCS de la leche de tanque al comparar los ordeños $1 \mathrm{X}$ y $2 \mathrm{X}$. Por el contrario, Komara et al. (2009), en dos experimentos realizados con cabras Alpina, encuentra que solamente en uno de ellos, y considerando exclusivamente a las cabras multíparas, se produce un aumento de los recuentos al pasar de 2X a $1 \mathrm{X}(179.800 \mathrm{y}$ 400.300 céls $/ \mathrm{ml}$, respectivamente). En otros trabajos realizados en ganado vacuno (Rémond et al., 2004) y ovino (Nudda et al., 2002) coinciden en encontrar un incremento de los recuentos en $1 \mathrm{X}$ respecto a $2 \mathrm{X}$.

\subsubsection{Variaciones diarias}

En el ganado caprino varios autores han señalado una importante variabilidad del RCS tanto diaria (Randy et al., 1988; Zeng et al., 1997) como semanal (Pettersen, 1981) y mensual (Martínez, 2000). Así, el RCS en cabras de primer parto puede pasar de un día a otro de valores de menos de 200.000 cels $/ \mathrm{ml}$ a 1.000 .000 cels $/ \mathrm{ml}$ (e incluso más de 2.000.000 cels $/ \mathrm{ml}$ ) para al día siguiente volver a la normalidad (Zeng et al., 1997). Además estas elevaciones bruscas se pueden producir en varias ocasiones durante la lactación (Figura 5). En los trabajos de Randy et al (1988) y Zeng et al. (1997) no se aportan datos sobre el análisis bacteriológico ni sobre el virus de la AEC, lo cual no permite descartar que este hecho pueda tener, en última instancia, una causa infecciosa. Pero el experimento realizado por Martínez (2000) si que confirma la existencia de bruscas fluctuaciones mensuales del RCS, en ambas glándulas del mismo animal, en ausencia de IIM.

\subsubsection{El estado de lactación}

Se trata de la variabilidad fisiológica ligada al ciclo lactación-secado, observándose recuentos elevados durante la fase calostral (Cattaneo et al., 2006), un descenso durante los primeros 20 días de lactación (Rota et al., 1993b) y, a continuación, un aumento continuado a medida que avanza la lactación (Figura 6), con una elevación más marcada 

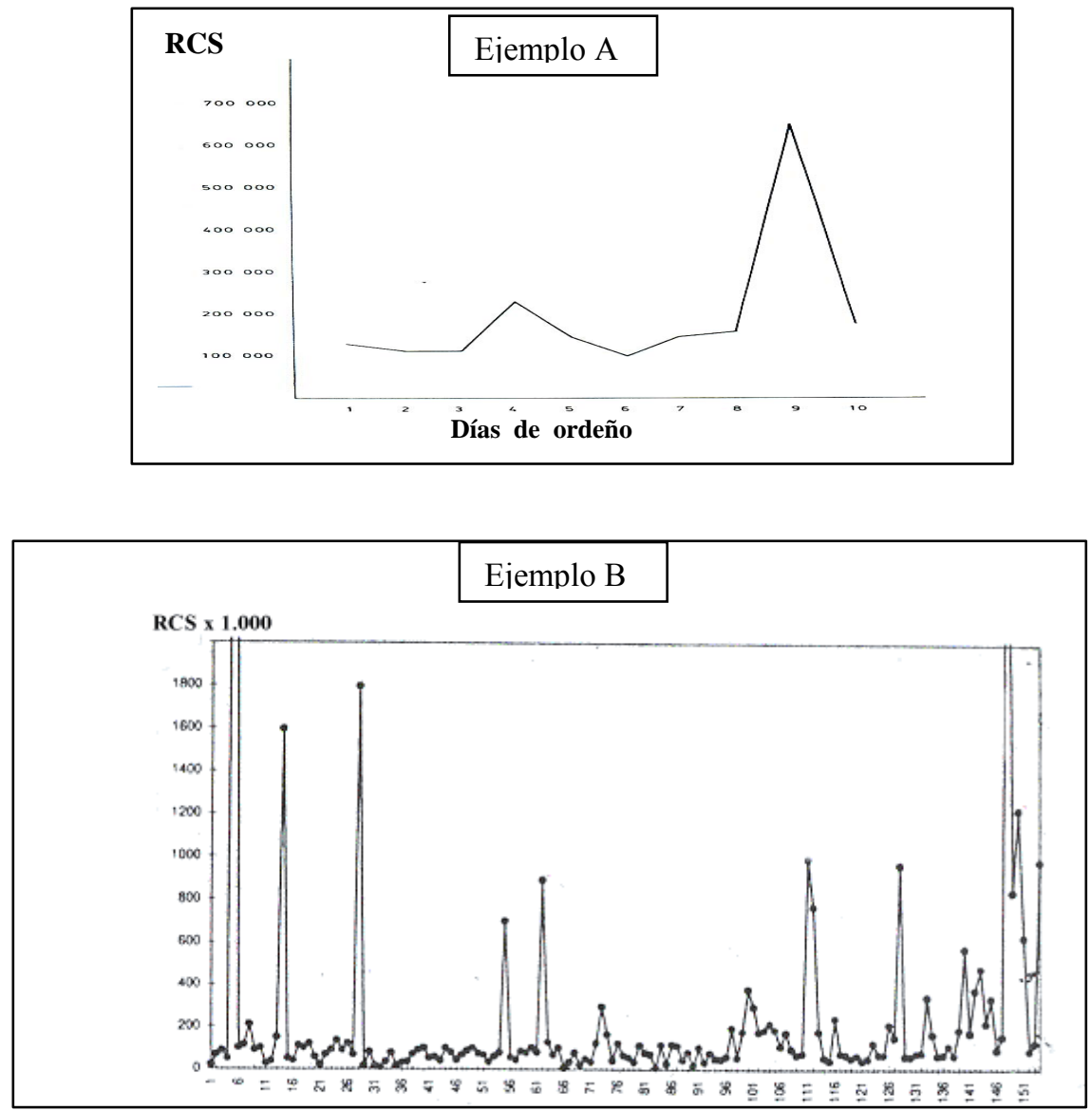

FIGURA 5. Dos ejemplos de fluctuaciones diarias del RCS en la leche ordeñada de una cabra (Ejemplo A: Randy et al., 1988; Ejemplo B: Zeng et al., 1997).

durante los días previos al secado. Hay varios trabajos que describen lactaciones enteras proporcionando resultados de bacteriología (Dulin et al., 1983, Kalogridou-Vassiliadou et al., 1992; Sánchez, 1998). Dichos estudios muestran como la curva de la concentración celular es la imagen inversa a la curva de producción lechera (Figura 6). Los valores medios obtenidos por dichos autores a partir de glándulas libres de infección intramamaria son: 200.000 a 500.000 cels $/ \mathrm{ml}$ al inicio de lactación y luego aumenta progresivamente hasta 1.000.000-3.100.000 cels/ml al final de la misma, e incluso más durante los últimos días. De este modo, la concentración celular de la leche de cabra es tan elevada al final de la lactación que es imposible distinguir entre glándulas no infectadas y sanas mediante el RCS (Corrales et al., 1996; Moroni et al., 2005). En base a ello algunos autores (De Cremoux et al., 1996) indican que el estado de lactación se puede considerar como el 
principal factor de variación del RCS de naturaleza no infecciosa a nivel de leche individual. Otra consecuencia de este hecho es que, en rebaños que se manejan en un único lote, el RCS en la leche de tanque aumenta tanto al final de la lactación que podría llegar a ocasionar penalizaciones en el pago de la leche por calidad.

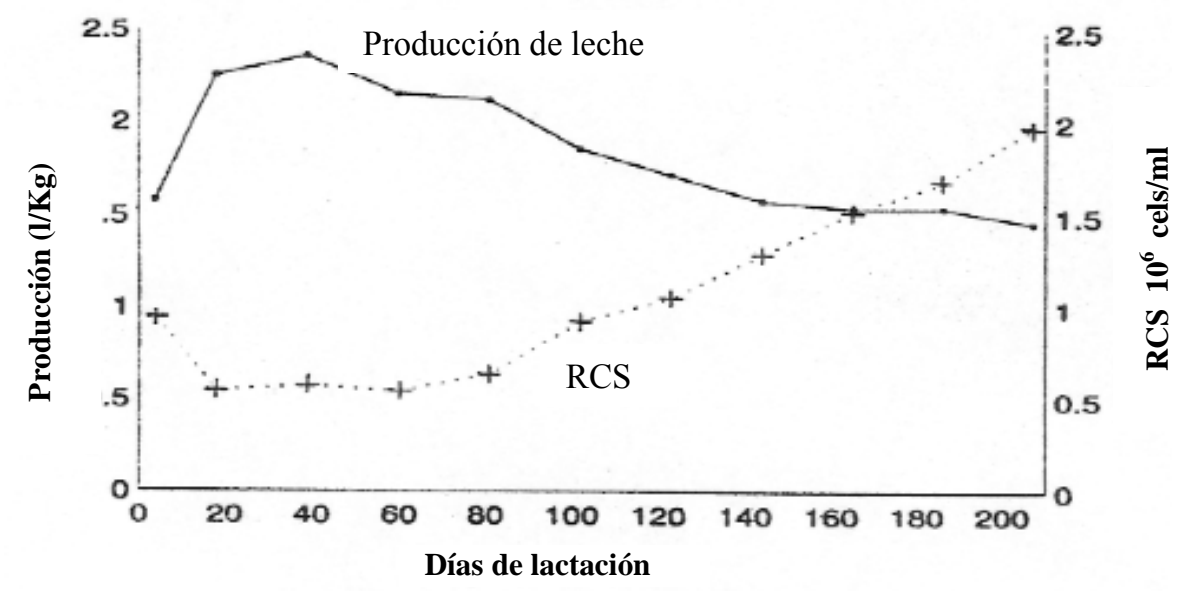

FIGURA 6. Evolución de la producción de leche y del RCS en ganado caprino a lo largo de la lactación (Rota et al., 1993b).

El aumento del RCS conforme avanza la lactación depende del estado infeccioso de la ubre, ya que se observa de forma más clara en glándulas no infectadas que en infectadas (Ferrer et al., 1996a y 1996b). En este sentido, De Cremoux et al. (1996) encuentran que el estado de lactación únicamente es significativo cuando las cabras presentan ambas glándulas sanas o alguna/s infectada/s por ECN, y no es significativo cuando los animales están infectados por patógenos mayores. Esta elevación hace que, al final de la lactación, las cabras sanas presenten similares recuentos que las infectadas por ECN al inicio de la misma, pero siempre inferiores a los observados en cabras infectadas por patógenos mayores (Tabla 4).

Varios autores han explicado el incremento del RCS a lo largo de la lactación a través de un efecto dilución (Paape et al., 2007) ya que el avance de la lactación lleva implícito una disminución de la producción y existe una correlación significativa y negativa entre el RCS y la producción láctea (Rota et al., 1993a; Zeng y Escobar; 1995), 
TABLA 4. Influencia del estado de lactación sobre el RCS en función del estado infeccioso de la ubre en ganado caprino (De Crémoux et al., 1996).

\begin{tabular}{|c|c|c|c|c|c|c|c|c|}
\hline \multirow{3}{*}{$\begin{array}{l}\text { Estado Lactación } \\
\text { (Días) }\end{array}$} & \multicolumn{2}{|c|}{ Sanas } & \multicolumn{2}{|c|}{ Infectadas por ECN } & \multicolumn{4}{|c|}{ Infectadas por PM } \\
\hline & Lac $1+2$ & Lac $\geq 3$ & Lac $1+2$ & Lac $\geq 3$ & \multicolumn{2}{|c|}{ Lac $1+2$} & \multicolumn{2}{|c|}{ Lac $\geq 3$} \\
\hline & n M.G. & $\mathrm{n} \quad$ M.G. & n M.G. & $\mathrm{n}^{\circ}$ M.G. & & M.G. & $\mathrm{n}$ & M.G. \\
\hline $0-100$ & $307 \quad 244$ & $273 \quad 421$ & $354 \quad 680$ & 503798 & 16 & 2097 & 42 & 2428 \\
\hline $101-200$ & $349 \quad 370$ & $284 \quad 628$ & 454887 & 6181132 & 25 & 2881 & 47 & 2649 \\
\hline$>201$ & $388 \quad 590$ & 2561175 & 5311289 & 5781742 & 30 & 2990 & 39 & 3268 \\
\hline
\end{tabular}

Lac: Número de lactación, ECN: estafilococos coagulasa negativo, PM: patógenos mayores, n: número de efectivos, M.G.: media geométrica.

siendo ésta más elevada al final de la lactación que al principio (Baudry et al., 1993). No obstante, es posible que el brusco aumento del RCS que se produce al final de la lactación no sea debido solamente al descenso de la producción, ya que algunos autores han encontrado que en esos momentos existe una mayor actividad de el/los factor/es quimiotácticos de PMN y, por tanto, un aumento de la transferencia de estas células de la sangre a la leche, lo cual podría desempeñar una función reguladora fisiológica en la involución de la glándula mamaria (Manlongat et al., 1998).

En el ganado caprino a medida que avanza la lactación aumenta el porcentaje de PMN en la leche, mientras que el porcentaje de macrófagos disminuye (Dulin et al., 1983; Rota et al., 1993a ). La evolución de los linfocitos no está clara, dado que los trabajos anteriores muestran una tendencia contraria. Además, en esta especie no se dispone de información sobre el recuento diferencial en la fase de calostro o en el entorno del secado. En ganado vacuno, se ha comprobado que existen importantes cambios en la población de leucocitos en las dos fases citadas: los PMN son el tipo celular mayoritario durante la fase calostral, mientras que durante el resto de la lactación y, especialmente durante el secado, los macrófagos son mayoritarios (Lee et al., 1980). 


\subsubsection{Número de lactación}

El número de lactación es un importante factor de variación del RCS, de manera que las cabras de mayor edad presentan valores significativamente superiores (De Cremoux et al., 1996; Ferrer et al., 1996b; Baudry et al., 1996; Kosev et al. 1996; Sinapis et al., 1999; Paape et al., 2007; Figura 7), lo cual podría ser debido a un aumento paralelo de las infecciones subclínicas y/o a la mayor sensibilidad de la glándula mamaria a los traumatismos ocasionados por el ordeño (De Cremoux et al., 1996). No obstante, en ausencia de infección intramamaria, todos los autores también encuentran que el RCS aumenta al pasar de la $1^{\mathrm{a}}$ a la $3^{\mathrm{a}}$ lactación; por el contrario está en discusión si en las cabras de $2^{\text {a }}$ lactación el RCS aumenta significativamente (Sánchez, 1998) o no (Dulin et al., 1983; De Cremoux et al., 1996; Martínez, 2000; Leitner et al., 2007) respecto a las cabras de $1^{\mathrm{a}}$ lactación.

Sánchez (1998) también observa en animales AEC-seronegativos y en ausencia de infección intramamaria que el RCS aumenta de la primera (140.000 células/ml, media geométrica) a la quinta lactación (667.000 cels/ml). Paradójicamente los animales de siete lactaciones presentan valores inferiores (311.000 células $/ \mathrm{ml}$ ), lo cual es explicado por la elevada producción de los mismos.

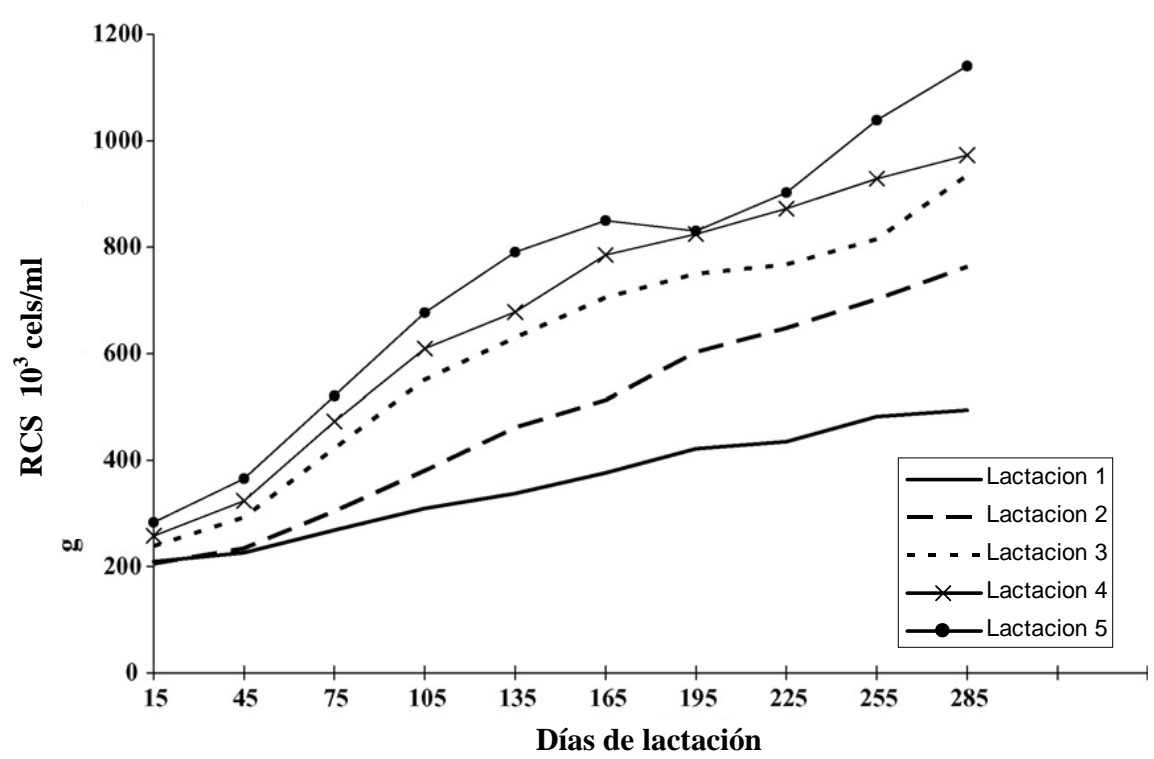

FIGURA 7. Evolución del RCS a lo largo de la lactación según el número de lactación de las cabras (Paape et al., 2007).Datos procedentes del control lechero de 26.600 cabras. 
En realidad la influencia del número de lactación sobre el RCS está en función del estado sanitario de la ubre del animal, así como del agente implicado en caso de que exista infección intramamaria. Así, De Cremoux et al. (1996) encuentran que la edad no tiene una influencia significativa sobre el RCS en cabras infectadas por patógenos mayores, mientras que en el caso de cabras infectadas por ECN el efecto de la edad es tan solo significativo a partir de los 100 días de lactación (Tabla 4). Por otra parte, Luengo et al. (2004) encuentran que, considerando solamente a las glándulas con IIM, el RCS no es más elevado en los animales de mayor edad.

\subsubsection{Tipo de parto y sistema de lactancia}

La mayoría de trabajos encuentran que el tipo de parto influye sobre el RCS de la leche. Así, en caprino (Sinapis et al., 1999) y en ovino (Gonzalo et al., 1994; Lagriffoul et al., 1996) se obtienen recuentos más elevados en los animales con parto y cría múltiple que en aquellos con parto y cría simple, a pesar de que los primeros producen más leche que los segundos. Este resultado podría ser atribuido a que empeora el estado sanitario de la ubre en aquellas madres que dan de mamar a dos crías frente a las que únicamente amamantan a una. Sin embargo, esta explicación parece insuficiente, dado que Luengo et al. (2004) también encuentran que, criando los cabritos en lactancia artificial, las cabras de parto múltiple también tienen recuentos más elevados que los de parto simple. A pesar de lo señalado anteriormente, debemos precisar que algunos estudios no encuentran que el tipo de parto influya sobre el RCS (Fuertes et al., 1998 y Sanchez et al., 2000, en ovino y caprino, respectivamente).

Respecto al sistema de lactancia, Delgado-Pertínez et al. (2009) no encuentran que el sistema de media leche (cría de cabritos y ordeño) incremente el RCS respecto al sistema de lactancia artificial (ordeño exclusivo desde el parto).

\subsubsection{8. $\underline{\text { Raza }}$}

El efecto que tiene la raza sobre el RCS ha sido estudiado en varios trabajos obteniéndose resultados contradictorios. A partir de glándulas libres de infección 
intramamaria Kosev et al. (1996) no encuentran diferencias significativas entre los RCS obtenidos en dos razas autóctonas búlgaras. En cambio Calderini et al. (1996) hallan en la raza Saanen recuentos inferiores $(575.000$ células $/ \mathrm{ml})$ con respecto a la raza Alpina (716.000 células/ml), considerando solamente en este estudio a los animales libres de IIM, mantenidos en las mismas condiciones, y constatando una similar producción láctea en ambas razas.

Otros autores también han estudiado este aspecto aunque sin realizar el correspondiente análisis bacteriológico. Aleandri et al. (1996) y Paape et al (2007) también observan que las cabras Saanen dan lugar a RCS más bajos que las Alpinas. En cambio Baudry et al. (1996) encuentran para dichas razas valores similares a partir de la leche del control lechero. Igualmente, Schmidlin et al. (1996) observan en Suiza valores de RCS del control lechero similares en diferentes razas. Finalmente, Zeng y Escobar (1996) tampoco encuentran diferencias significativas del RCS entre las razas Alpina y Nubian.

Con los resultados presentados por dichos autores no se puede concluir que exista una influencia de la raza sobre el RCS. De este modo, en los estudios donde se constatan diferencias entre razas, estas se podrían atribuir a la diferente situación sanitaria, nivel de producción y particularidades de manejo entre las mismas (Sánchez et al., 1998).

\subsubsection{Nivel productivo}

En ganado vacuno, varios autores han encontrado que, en ausencia de infección intramamaria, y considerando el conjunto de una lactación, la media del RCS es independiente de la producción media diaria; es decir el RCS no depende de la producción lechera (Badinand, 1994). Por el contrario la información disponible en ganado caprino (Wilson et al., 1995, Sánchez et al., 2000; Martínez, 2000) indica que, en ausencia de infección, los animales menos productivos dan lugar a recuentos más elevados.

\subsubsection{0. $\underline{\text { Celo }}$}

Algunos autores han encontrado que cuando las cabras se encuentran en celo, ya sea natural (Moroni et al., 2007) o inducido (aplicación de esponjas vaginales impregnadas de progestágenos e inyección de $\mathrm{PMSG}+$ prostaglandinas) tanto en la estación de estro 
(Aleandri et al., 1996) como en la de anoestro (McDougall y Voermans, 2002), se produce un importante incremento del RCS en la leche. Este aumento no se explica por el ligero descenso de la producción de leche, lo cual indicaría que es el propio celo el responsable directo del aumento celular, probablemente por mecanismos fisiológicos aún desconocidos (McDougall y Voermans, 2002).

Debemos precisar que los tres trabajos citados anteriormente se llevaron a cabo con animales que se encontraban a final de la lactación (hacia el $8^{\circ}$ mes) por lo que permanece la duda de si el efecto del celo es similar en otros estadios de la lactación. Además existe controversia en cuanto a si el efecto del celo sobre el RCS depende o no del estado infeccioso de la glándula. Así, Bergonier et al. (2003) indican que el estro podría provocar un mayor aumento del RCS en las glándulas con IIM que en las glándulas sanas. Por el contrario, McDougall y Voermans (2002) no encuentran que el efecto del celo sobre el RCS sea diferente en las glándulas sanas y en las infectadas.

Finalmente, debemos remarcar que los trabajos disponibles en ganado vacuno sobre el efecto del estro, natural o inducido, sobre el RCS no aportan resultados concluyentes (McDougall y Voermans, 2002).

\subsubsection{Factores extrínsecos a los animales}

El manejo del rebaño es uno de los factores más destacados que influyen sobre el RCS (Sánchez et al., 1998a), de manera que diferentes autores (Nesbakken, 1976; Manser, 1986) detectan grandes diferencias entre la media de los RCS de las glándulas sanas de diferentes rebaños. Sin embargo, es posible que las diferencias en cuanto a la edad de los animales, periodo productivo, etc. hayan influido en esos resultados, y por tanto ello nos impide, en ocasiones, hacer comparaciones entre rebaños. En otros trabajos, en los que se han realizado análisis estadísticos contemplando los factores infecciosos y no infecciosos, también encuentran que el efecto rebaño influye de forma marcada sobre el RCS (Luengo et al., 2004; Leitner et al., 2007) 
En general se observa que algunas actuaciones sobre los animales en lactación (estrés, vacunación, salida al pasto, introducción del macho etc.. ) pueden ocasionar incrementos puntuales del RCS, mientras que los factores que provocan aumentos persistentes del RCS lo hacen, probablemente, a través de su efecto sobre la prevalencia de infecciones intramamarias.

\subsubsection{El ordeño}

El ordeño es uno de los factores de manejo que más influye en la epidemiología de la infección intramamaria y, por consiguiente, sobre el RCS. Los diferentes aspectos relacionados con el ordeño (diseño, mantenimiento y uso de la máquina de ordeño) pueden incrementar la incidencia de mamitis a través de dos efectos: a) por ser fuente y vehículo de transmisión de gérmenes, y b) por su acción traumática sobre el extremo del pezón, lo que facilitaría la colonización de la glándula mamaria por las bacterias. Varias revisiones bibliográficas sobre este tema pueden ser consultadas en Peris et al. (2002a, 2003, 2004a y 2004b) y Díaz et al. (2004).

El efecto que tiene el tipo de ordeño (manual o mecánico) sobre el RCS en ganado caprino ha sido estudiado por varios autores, aunque los resultados no siempre son coincidentes. Randy et al. (1991) obtienen recuentos inferiores en los animales ordeñados a máquina, mientras que Kosev et al. (1996) y Delgado-Pertíñez et al. (2003), este último en leche de tanque, hallan menores recuentos en el ordeño efectuado a mano. Por su parte, Zeng y Escobar (1996) observaron recuentos similares en ambos tipos de ordeño. Posiblemente las diferencias halladas en estos estudios sean debidas a diferentes prevalencias de la infección intramamaria, distintos periodos productivos, edad de los animales, etc.

Varios trabajos ( $\mathrm{Lu}$ et al., 1991; Sinapis et al., 1999) han encontrado que los diferentes parámetros de la máquina de ordeño tienen un efecto significativo sobre el RCS. Así, Lu et al. (1991) observan que la utilización de un nivel de vacío bajo (38 kPa) ocasiona RCS menores (392.000 cels/ml) que cuando el nivel de vacío es más elevado $(563.000$ cels $/ \mathrm{ml}$ a $45 \mathrm{kPa}$, y 704.000 cels $/ \mathrm{ml}$ a $52 \mathrm{kPa})$. Con respecto a la relación de 
pulsación, los citados autores detectan los menores recuentos a 60:40 (704.000 cels $/ \mathrm{ml})$ y los mayores a 70:30 (854.000 cels $/ \mathrm{ml})$ y a 50:50 (1.259.000 cels $/ \mathrm{ml})$. En cuanto a la velocidad de pulsación los menores recuentos se obtienen a 120 p/min $(602.000 \mathrm{cels} / \mathrm{ml})$, ligeramente mayores a $90 \mathrm{p} / \mathrm{min}(705.000 \mathrm{cels} / \mathrm{ml})$ y muy superiores a $60 \mathrm{p} / \mathrm{min}(1.687 .000$ cels/ml). No obstante, las diferencias observadas entre distintos valores de los parámetros de la máquina de ordeño podrían deberse más a un efecto favorecedor de la instauración de una infección intramamaria que a un efecto directo sobre el RCS, ya que en dichos trabajos no se aportan resultados de análisis bacteriológicos. Billón et al. (1999) también encuentran que la aparición de un defecto puntual de la pulsación (un déficit de la fase de masaje) aumenta el RCS en ganado caprino, incluso en ausencia de infecciones intramamarias

En cabras de raza Murciano-Granadina, Díaz (2009; comunicación personal) no encuentra que dos combinaciones de parámetros (vacío, velocidad y relación de pulsación de 40/90/60 vs 36/120/60) influyan sobre el RCS. Manzur (2007) no consigue demostrar que el RCS varíe con el tipo de conducción de leche (línea media vs línea baja), pero si observa que la utilización de pezoneras con válvulas automáticas, en las que no se corta manualmente el vacío antes de la retirada de las pezoneras, aumenta el riesgo de mamitis y eleva el RCS al inicio de la lactación.

\subsubsection{La alimentación}

Los diferentes trabajos realizados no permiten relacionar claramente determinadas materias primas, o diferentes niveles de energía o de nitrógeno de la ración, con el RCS. Sin embargo, se acepta que la falta o deficiencia de ciertos elementos presentes en la dieta puede favorecer la instauración de una infección intramamaria. Por ejemplo, la vitamina $\mathrm{A}$ y el $\beta$-caroteno por una parte, y la vitamina $E$ y el selenio por otra, tienen un papel importante en la conservación de la integridad, estructural y funcional, de los PMN, y la estimulación de las defensas celulares de la mama (Bergonier et al., 1996). Sanchez et al. (2007) encuentran que la administración de selenio, en explotaciones extensivas situadas en areas deficitarias en este elemento, disminuye la incidencia de mamitis clínica y el RCS de la leche. Asimismo la suplementación de la dieta de las cabras con metionato de zinc parece incrementar la resistencia a la mamitis y, además, aumentar la resistencia del animal 
frente al estrés dado que éste último provoca una menor elevación del RCS (Salama et al., 2000).

Una ración no equilibrada en nitrógeno, energía o minerales puede ser el origen del aumento del RCS en la leche de tanque. Generalmente, cuando la alimentación causa trastornos metabólicos (acidosis, alcalosis, etc.) provoca elevaciones del RCS (Lerondelle et al., 1992; Fedele et al., 1996). Probablemente este incremento sea debido, al menos en parte, a una menor producción láctea en los animales que sufren dichos trastornos, lo cual se traduce en una mayor concentración celular.

Fedele et al. (1996) han estudiado el efecto de diferentes tipos de raciones sobre el RCS. Estos autores observan que cuando las cabras son alimentadas únicamente en pastoreo (sin suplementación) los valores medios de RCS son ligeramente más bajos que cuando se les suplementa con un concentrado energético (cebada), mientras que los mayores recuentos se obtienen cuando se suplementa con un concentrado proteico. Esto podría deberse a un efecto irritativo de la urea eliminada por la glándula mamaria (Issartial, 1990), como consecuencia de un exceso de proteína en la ración.

\subsubsection{Estrés}

Diversas actuaciones en el rebaño, que presumiblemente crean algún tipo de estrés en los animales, provocan elevaciones del RCS, probablemente puntuales, en la leche de tanque.

Por ejemplo, en la época de cubrición de las cabras, época en que se introducen los machos en el rebaño, suele producirse un aumento del RCS en la leche de tanque (Calderini et al., 1996; Aleandri et al., 1996; Wilson et al., 1995; Borges et al., 2004). Sin embargo, permanece la duda de si este aumento es debido exclusivamente al efecto del celo (ver apartado 3.2.1.9.) o si, además, la introducción del macho genera en las cabras suficiente estrés como para elevar el RCS.

Por otro lado, diversas prácticas de manejo como las extracciones de sangre y la intradermorreacción tuberculínica pueden elevar los recuentos a nivel de leche de tanque 
de forma pasajera (Corrales et al., 1997). Asimismo también se ha detectado un incremento del RCS tras la vacunación frente a la enterotoxemia (Lerondelle et al., 1992).

Algunos autores indican que ciertos cambios bruscos en el manejo del ordeño también pueden elevar puntualmente el RCS. Salama et al. (2003b) encuentran que un ordeño ocasional a mano, en animales que están habituados al ordeño a máquina, genera suficiente estrés como para duplicar el RCS en el ordeño siguiente. Karzis et al. (2004) observan que un ordeño irregular, a consecuencia de fallos en el suministro de electricidad a la máquina de ordeño, también provoca una elevación del RCS en el ordeño siguiente.

Finalmente, el ejercicio físico intenso o el transporte de los animales también podrían elevar el RCS. Por ejemplo, en ganado vacuno se ha comprobado que cuando se somete a los animales a largas marchas se eleva el RCS, siendo este incremento más marcado en los animales afectados de mamitis (Coulon et al., 1998). Respecto al transporte, el único trabajo disponible realizado en ganado caprino (McDougall et al., 2002) encuentra que el estrés provocado por el transporte de los animales en camión durante 45 minutos no afecta, a corto plazo (una hora después del transporte), al RCS de la leche.

\subsubsection{Estacionalidad}

Los resultados analíticos obtenidos en los laboratorios interprofesionales, en muestras de leche de tanque, indican que el RCS en la leche de cabra sufre una fuerte estacionalidad. En general existe coincidencia en que los valores mínimos se alcanzan a principios de la primavera, entre los meses de marzo y abril, mientras que existen discrepancias en cuanto a la época en que se obtienen los valores máximos. En la Comunidad Valenciana, en la Comunidad Murciana, y, probablemente, también en Andalucía, los valores máximos aparecen entre julio y septiembre (Torres et al., 1999; Peris et al., 2002b; Delgado-Pertíñez et al., 2003; Figura 8), mientras que en Castilla-León (LILCYL, 2000) y en varias regiones de Francia (De Cremoux, 1999) los máximos recuentos se sitúan en el otoño.

El principal factor que puede explicar esta evolución estacional es la distribución de los partos en cada zona geográfica. Así, en las Comunidades de Valencia y Murcia suele 
ser más frecuente los partos de otoño, de forma que durante los meses de otoño e invierno las cabras están en su primera mitad de lactación y, por tanto, los recuentos son bajos (ver apartado 3.2.1.5.), mientras que en verano los animales se encuentran al final de la lactación (en muchas ocasiones se deja de ordeñar en agosto) y, por consiguiente, los recuentos son los más altos del año. En otras zonas más frías, suele ser más frecuente planificar los partos hacia final de invierno o principios de primavera, de modo que las cabras se encuentran al final de la lactación durante el otoño y, por tanto, es la época de valores máximos de RCS.

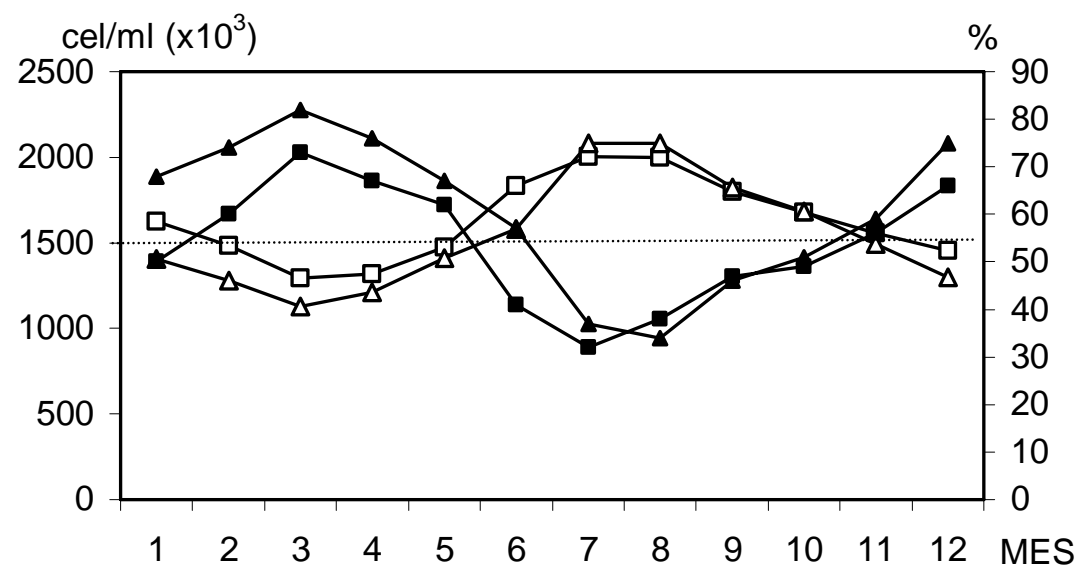

$\rightarrow \square$ RCS C. Valenciana.

$\neg-\mathrm{RCS}$ C. Murcia

$\rightarrow$ - $\mathrm{RCS}<1.500 \mathrm{C}$. Valen.

$\multimap \% R C S<1.500$ C. Murcia

FIGURA 8. Evolución mensual de la media aritmética del RCS y del porcentaje de muestras con recuentos inferiores a $1.500 \times 10^{3} \mathrm{UFC} / \mathrm{ml} \quad(\% \mathrm{RCS} .<1.500)$ en muestras de leche de cabra procedentes de las CC.AA. Valenciana y Murciana ( Peris et al., 2002)

El binomio fotoperiodo-temperatura influye sobre la producción de leche e indirectamente, de forma inversa, sobre el RCS. Así, en la primavera (fotoperíodo creciente, temperaturas suaves, en ocasiones mejor alimentación) tiende a aumentar la producción de leche de los animales y, por tanto, el RCS disminuye. Por el contrario en los meses de otoño la situación sería la inversa. Por otra parte, en el verano cabe esperar que los recuentos tiendan a aumentar en la medida que las altas temperaturas disminuyan la producción de leche. Finalmente, los recuentos también tenderán a aumentar en el/los mes/es que se concentren las cubriciones, tal y como ya se comentó en los apartados 3.2.1.10 y 3.2.2.3. 


\subsubsection{Tratamientos hormonales}

Moroni et al. (2007) encuentran que el RCS evoluciona a lo largo del ciclo estral de la cabra, de modo que los recuentos son mínimos en la fase luteal (cuando están aplicadas las esponjas con progestágenos en la sincronización de celos), y aumentan los recuentos durante el celo. Por otra parte, Jiménez et al. (2009) observan que los implantes de melatonina disminuyen los recuentos en el ganado caprino.

\subsection{OTROS FACTORES DE VARIACIÓN}

\subsubsection{Método de recuento}

Tal y como ya se ha comentado, la leche de cabra presenta la peculiaridad de contener un elevado número de partículas citoplasmáticas. Por tanto, para realizar el RCS sin tener en cuenta estas partículas se deberían utilizar exclusivamente métodos específicos de ADN (Dulin et al., 1982; Dulin et al., 1983; Sierra et al., 1998).

El recuento a microscopio es el método de referencia para llevar a cabo el RCS (ISO/IDF, 2008). Las tinciones específicas de ADN que se han utilizado con mayor frecuencia han sido la de rojo metilo-verde pironina (tinción de referencia en EE.UU.), May-Grünwald-Giensa y tricrómico de Gallego (Contreras et al., 1998; Gonzalo et al., 1998a; Berry y Broughan, 2007). Sin embargo la tinción con azul de metileno, a pesar de estar reconocida por la IDF como tinción de referencia para la leche de vaca (tinción de Newman-Lampert modificada; ISO/IDF, 2008), no debería utilizarse en la leche de cabra dado que no es específica de ADN y, por tanto, no permite diferenciar entre leucocitos y partículas citoplasmáticas, lo que implicará que los recuentos sean superiores a los reales (Quervel y Trossat, 2005; citado por Raynal-Ljutovac et al., 2007). De hecho, la nueva normativa sobre recuento de células somáticas (ISO/IDF, 2008) ya recomienda la tinción rojo metilo-verde pironina para realizar el RCS en la leche de cabra. 
En cuanto a los métodos automatizados utilizados en laboratorio, podemos señalar dos tipos: el contador de partículas (Coulter Counter; EEUU) y el método fluoro-optoelectrónico (Fossomatic; Foss, Dinamarca; Somacount, Bentley, EEUU; Somascope, Delta, EEUU). El primero de ellos también contabiliza las partículas citoplasmáticas, obteniéndose recuentos aproximadamente el doble a los hallados mediante un contador tipo Fossomatic (Dulin et al., 1982; Poutrel y Lerondelle, 1983a; Lerondelle, 1984; Ferrer et al., 1996b), de modo que su uso también está desaconsejado en la leche de cabra.

El método fluoro-opto-electrónico es un método específico de ADN basado en el recuento de elementos nucleados después de la tinción especifica del ADN del núcleo celular con un colorante fluorescente (bromuro de etidio). De acuerdo a Gonzalo (1996), este método presenta adecuados valores de precisión y repetibilidad en comparación con el método microscópico de referencia, con un coeficiente de correlación de 0,96. Asimismo, Droke et al. (1993) también confirman la validez de este método, dado que no observan diferencias significativas respecto al recuento directo mediante la tinción rojo metilo-verde pironina. Algunos autores han encontrado que si el equipo se calibra con leche de vaca, los recuentos tienden a ser más elevados respecto a los obtenidos mediante el recuento a microscopio (Zeng et al., 1999; Arcuri et al., 2004). Sin embargo, un trabajo reciente (Quervel y Trossat, 2005) confirma que los resultados no difieren estadísticamente al calibrar el equipo con leche de vaca o leche de cabra.

Por otra parte, también podemos destacar que en los últimos años se están comercializando equipos portátiles para poder realizar los recuentos a pie de granja. Así podemos mencionar el PortaSCC (PortaScience, EEUU), basado en una reacción enzimática, y dos equipos que realizan el recuento electrónico de las células marcadas con un colorante fluorescente (bromuro de etidio o ioduro de propidio): el C-Reader system (Digital Bio Tech., Corea) y el Direct Cell Counter (De Laval, Suecia). Este último equipo ha sido evaluado en la leche de vaca ( Malinowski et al., 2008), cabra (Berry y Broughan, 2007) y oveja (Gonzalo et al., 2006; 2008), mostrando buenos resultados de precisión y repetibilidad, aunque es necesario realizar adaptaciones en la preparación de la muestra cuando se utiliza con leche de alto contenido en grasa y proteína (Gonzalo et al., 2008) . 


\subsubsection{Conservación, almacenamiento y temperatura de análisis de las muestras}

El RCS se lleva a cabo de forma rutinaria en los laboratorios mediante el método fluoro-opto-electrónico con equipos que realizan el recuento por citometría en disco o, mayoritariamente en la actualidad, por citometría de flujo. Varios trabajos (Gonzalo et al., 1993, Gonzalo et al., 1998a; Sánchez et al., 2005; entre otros) han mostrado la importancia de estandarizar la metodología de conservación de las muestras y de su análisis, ya que existen ciertos factores que pueden influir en la precisión de los resultados: la conservación de la muestra (temperatura y tiempo), el tipo de conservante y la temperatura de análisis. Estos factores han sido estudiados ampliamente en la leche de vaca (Miller et al., 1986; Bertrand, 1996; Barkema et al., 1997), oveja (Gonzalo et al., 1993; Gonzalo et al., 1998a; Martínez et al., 2003; Gonzalo et al., 2003; Gonzalo et al., 2004) y, más recientemente, en la leche de cabra (Zeng et al., 1999; Sánchez et al., 2005; Sierra et al., 2006).

En primer lugar debemos señalar que se obtienen menores recuentos cuando las muestras se analizan demasiado pronto tras el ordeño. Por ejemplo, en la leche de vaca se aconseja no analizar el RCS antes de doce horas post-ordeño, si no se emplea conservante, y antes de 6 horas si se emplea conservante (IDF, 1995). En leche de cabra, Sierra et al. (2006) observan un ligero descenso en el RCS cuando las muestras se analizan tan solo $3 \mathrm{~h}$ tras la recogida, con independencia de si se utiliza o no conservante (bronopol) y la temperatura de análisis de la leche $\left(40^{\circ} \mathrm{C}\right.$ ó $\left.60^{\circ} \mathrm{C}\right)$. En leche de oveja, Gonzalo et al. (2003) también encuentran menores recuentos si las muestras se analizan en las primeras 12 horas tras la recogida y no disponen de conservante o éste es el azidiol.

Respecto a la conservación de la muestras, estas no se deben mantener a temperatura ambiente. En este caso si las muestras no contienen conservante se producirá un crecimiento bacteriano y la formación de "pelotas de gérmenes" que darán lugar a recuentos excesivamente elevados (Gonzalo et al., 1998; Gonzalo et al., 2003). Por el contrario si las muestras contienen un conservante, éste impedirá el crecimiento de los gérmenes, pero a temperatura ambiente se produce un rápido deterioro de las integridad de las células somáticas $\mathrm{y}$, por tanto, descienden los recuentos a medida que van transcurriendo los días (Kennedy et al., 1982 y Gonzalo et al., 2003, en leche de vaca y oveja, respectivamente). 
En un trabajo reciente realizado con leche de cabra, Sanchez et al (2005) encuentran que la conservación de las muestras en refrigeración $\left(4^{\circ} \mathrm{C}\right)$, sin ningún conservante, permite recuentos estables hasta 10 días. No obstante, otros autores desaconsejan realizar los recuentos en muestras refrigeradas sin conservante, por que éstos tienden a disminuir o a empeorar la correlación con el método de referencia (Arcuri et al., 2004; Gonzalo et al., 1998a, en leche de oveja). Entre los conservantes utilizados en muestras refrigeradas, el bronopol es el que, en general, ha permitido obtener mejores resultados, ya que los recuentos disminuyen en poca medida $(<5 \%$ en leche de cabra y $<2.8 \%$ en leche de oveja; Sánchez et al., 2005; Gonzalo et al., 2003) durante los primeros 10 días de refrigeración. Así mismo, es muy probable que el dicromato potásico también permita obtener resultados similares a los que se logran con el bronopol, tal y como se ha demostrado en la leche de oveja (Gonzalo et al., 1998a) y vaca (Bertrand, 1996). Finalmente varios trabajos coinciden en que la utilización de azidiol, en leche refrigerada, provoca un descenso de los recuentos tanto en leche de cabra (del 15\%, Sánchez et al., 2005) como en leche de oveja (Gonzalo et al., 1998a).

En general la congelación de las muestras tiende a disminuir los recuentos, probablemente por la degeneración nuclear que se produce y, por tanto, por que disminuye la capacidad del núcleo para tomar el colorante fluorescente. Por ejemplo, en la leche de vaca no se recomienda congelar las muestras de leche ya que los recuentos pueden disminuir entre un 10 y un $20 \%$, dependiendo de la edad de las muestras y el proceso de descongelación (ISO/FIL, 2008). No obstante, esta práctica si que podría ser utilizada cuando los recuentos se llevan a cabo para identificar a los animales afectados de mamitis (Barckema et al., 1997). En leche de oveja, Martínez et al. (2003) encuentran que tras la congelación de muestras con azidiol disminuyen los recuentos, pero esto no ocurre en muestras sin conservante o con bronopol o con dicromato potásico. En leche de cabra, Sánchez et al. (2005) también encuentran que el bronopol permite una mayor estabilización de los recuentos tras la congelación (respecto al azidiol o la no utilización de conservante) aunque éstos disminuyeron en un 4-7\%. De acuerdo a estos últimos autores, es posible que el bronopol ayude a que el colorante fluorescente penetre en mayor medida en las células, lo que daría unas señales fluorescentes más fuertes en los equipos que analizan mediante el método fluoro-opto-electrónico. 
Varios trabajos han estudiado el efecto de la temperatura de análisis (40 vs $60^{\circ} \mathrm{C}$ ) con resultados no siempre coincidentes. Los primeros estudios realizados en leche de vaca encontraron que los recuentos eran más elevados a $60^{\circ} \mathrm{C}$ que a $40^{\circ} \mathrm{C}$, en muestras que se analizaban el mismo día de la recogida y no disponían de conservante (Miller et al., 1986). La hipótesis era que el tratamiento térmico deterioraba las células, lo que facilitaba la penetración del colorante hasta el núcleo. Este hecho también fue encontrado por Gonzalo et al. (2003) en la leche de oveja. Sin embargo, trabajos posteriores en leche de vaca (Hachana et al., 2008), oveja (Gonzalo et al., 2004) y cabra (Sierra et al., 2006) no han confirmado que, en muestras sin conservante analizadas en las primeras horas tras el ordeño, los recuentos varíen según la temperatura de análisis $\left(40^{\circ} \mathrm{C}\right.$ vs $\left.60^{\circ} \mathrm{C}\right)$. Por otra parte, en muestras de leche de oveja conservadas mediante congelación, Martínez et al. (2003) encontró que el análisis a $60^{\circ} \mathrm{C}$ provocaba un descenso en los recuentos, en relación al análisis a $40^{\circ} \mathrm{C}$. Sin embargo, un experimento similar realizado en leche de cabra (Sierra et al., 2006) no encontró que los recuentos difirieran en ambos tipos de temperatura de análisis.

En resumen, en base a los trabajos citados, Gonzalo (2005) y Raynal-Ljutovac et al (2007) indican que, en la leche de oveja y cabra, los mejores resultados de precisión y repetibilidad del RCS se obtienen utilizando muestras de leche conservadas con bronopol, almacenadas a temperatura de refrigeración y analizadas a $40^{\circ} \mathrm{C}$ dentro de los 5 días tras su recogida. Además, la mayoría de los trabajos también encuentran que, en muestras sin conservante mantenidas en refrigeración, los recuentos a $24-48 \mathrm{~h}$ tras la recogida apenas difieren respecto a las condiciones señaladas anteriormente (Martínez et al., 2003; Gonzalo et al., 2003; Sánchez et al., 2005 


\section{BIBLIOGRAFIA}

ALEADRI, M.; FAGIOLO, A.; CALDERINI, P.; COLAFRANCESCO, R.;GIANGOLINI, G.; ROSATI, R.; DE MICHELIS, F. (1996). Studies conduced on somatic cells counts of goats milk. En: Somatic Cells and milk of Small Ruminant. (Ed:Rubino,R.).Wageningen Pers.(EAAP,77): 65-70.

ARCURI, E.F.; LIMA DA SILVA, P.D.; BRITO, J.R.F.; SILVA, M.R.; SOUZA,G.N. (2004).Use of Somacount 300, calibrated with cow milk standard, for somatic cell count in goat mik . Ciência Rural.34: 1497-1500.

BADINAND, F. (1994). Maîtrise du taux cellulaire du lait. Recueil de medecine veterinaire. 170 (6/7):419-427.

BAUDRY, G.; JAUBERT, G.; PERRIN,G. (1993).Typologie des élevages des chévres en fonction de numération cellulaire du lait de troupeau. Revue de Medecine Veterinaire. 4: 335-341.

BAUDRY, C.; DE CREMOUX, R.; PERRIN, G. (1996). Composition et concentration cellulaire du lait de chevre au cours de la lactation. En: Somatic Cells and Milk of Small Ruminants. (Ed: Rubino, R.). Wageningen Pers. (EAAP, 77): 259-262.

BAUDRY, C.; DE CREMOUX, R.; CHARTIER, C.; PERRIN, G. (1997). Incidence de la concentración cellulaire du lait de chèvre sur sa production et sa composition. Veterinary Research. 28:277-286.

BARKEMA, H. W.; VAN DER SCHANS, J.; SCHUKKEN, Y. H.; DE GEE, A.L.W.; LAM, T.J.G.M.; BENEDICTUS, G. (1997). Effect of Freezing on Somatic Cell Count of Quarter Milk Samples as Determined by a Fossomatic Electronic Cell Counter . Journal of Dairy Science. 80 : 422-426.

BERGONIER, D.; LAGRIFOUL , G.; BERTHELOT, X.; BARILLET, F.(1996). Facteurs de variation non infectieux des comptages de cellules somatiques chez les ovins et les caprins laitiers.En : Somatic Cells and milk of Small Ruminant, (Ed:Rubino,R.),Wageningen Pers.(EAAP,77) : 112-135.

BERGONIER，D.;DECRÉMOUX,R.;RUPP,R.;LAGRIFFOUL,G.;BERTHELOT ,X. (2003). Mastitis of dairy small ruminants. Vet. Res.34: 689-716 .INRA, EDP Sciences.

BERNING, L.M.; PAAPE, M.J.; MILLER, R.H.; LEDANE, R.A. (1987). Variation in $\mathrm{N}$-acetyl- $\beta$-d-glucosaminidase activity and somatic cell counts among various milk fractions. Journal of Dairy Science. 70:1054-1060.

BERTRAND, J. A. (1996). Influence of shipping container, preservative, and breed on analysis of milk components of shipped samples. Journal of Dairy Science. 79:145-148. 
BERRY, E.; BROUGHAN, J. (2007) Use of the DeLaval cell counter (DCC) on goats' milk. Journal of Dairy Research. 74: 345-348.

BILLON, P. (1999). Influence du type de faisceau trayeur sur la santé de mamelles des chèvres laitières. Institut de l'élevage.Compte rendu nº 9983119.

BORGES PIZARRO, C.H.; CORDEIRO, P.R.C.; BRESSLAU, S. (2004). Seasonal variation of goat milk composition and somatic cell count in Southeastern Brazil. International symposium the future of the sheep and goat dairy sectors. Zaragoza.Spain.

BOUTINAUD, M.; JAMMES, H. (2002) Potential uses of milk epithelial cells. Reprod. Nutr. Dev. 42:133-147 INRA, EDP Sciences.

BOYAZOGLU, J.; MORAND-FEHR, P. (2001).Mediterranean dairy sheep and goat products and their quality: A critical review Small Ruminant Research. 40 1:111.

CABALLERO DE LA CALLE , J.R., BUXADÉ , C. (1996). El subsector caprino en España. En Buxadé C. (Ed) producción caprina. Zootecnia: bases de producción.

CALDERINI, P.; COLAFRANCESCO, R.; FAGIOLO, A.; REITANO ,M.E.; DE MICHELIS, F.(1996). Somatic cells count in milk from mastitis-free goats intensively reared and controlled until the sixth lactation .(1996). En: Somatic Cells and milk of Small Ruminant. (Ed:Rubino,R.).Wageningen Pers.(EAAP,77):177-181.

CATTANEO, D.; DELL’ORTO, V.; VARISCO, G.; AGAZZI, A.; SAVOINI, G. (2006).Enrichment in $\mathrm{n}-3$ fatty acids of goat's colostrum and milk by maternal fish oil supplementation. Small Ruminant research .64: 22-29..

CEDDEN, F.; KAYA,S. O.; DASKIRAN, I. (2008). Somatic cell, udder and milk yield in goat. Revue Médecine Véterinaire. 159 /4:237-242.

CONTRERAS, A.; CORRALES, J.C.; SÁNCHEZ, A. (1994). Dinámica de la infección intramamaria subclínica en el ganado caprino. XIX Jornadas Científicas de la Sociedad Española de Ovinotecnia y Caprinotecnia. Burgos. 297-302.

CONTRERAS, A.; SIERRA, D.; CORRALES, J.C.; SANCHEZ, A.; MARCO, J. (1996). Physiological threshold of somatic cell count and California Mastitis Test for diagnosis of caprine subclinical mastitis. Small Ruminant Research . 21: 259264.

CONTRERAS, A.; PAAPE, M.J.; DI CARLO, A.L.; MILLER, R.H.; RAINARD, P. (1997a). Evaluation of selected antibiotic residue screening tests for milk from individual goats. Journal of Dairy Science. 80: 1113-1118.

CONTRERAS, A.; PAAPE, M.; MILLER, R. H. (1997b). Variación de patógenos y células somáticas en diferentes fracciones de leche y su aplicación para el 
diagnóstico de la infección intramamaria caprina. XXII Jornadas Científicas de la Sociedad Española de Ovinotecnia y Caprinotecnia. Puerto de la Cruz-Tenerife.

CONTRERAS, A.; SIERRA, D.; CORRALES, J.C.; SÁNCHEZ, A.; GONZALO, C. (1998). Diagnóstico indirecto de las mamitis caprinas. En: Mamitis caprina II.Ovis. 53:25-36.

CONTRERAS, A.; SÁNCHEZ, A. (2000). Recuento de células somáticas en pequeños rumiantes II. Caprino. Ovis 67: 74 páginas.II. Ovis. 53:25-36.

CONTRERAS, A.; LUENGO, C.; SANCHEZ, A.; CORRALES, J.C. (2003). The role of intramammary pathogens in dairy goats Livestock Production Science $79: 2-3,273-283$

CONTRERAS, A.; SIERRA, D.; SANCHEZ, A.;CORRALES,J.C.;MARCO,J.C.; PAAPE, M.J.; GONZALO, C. (2007). Mastitis in small ruminant .Small Ruminant Research 68 1-2:145-153.

CORRALES, J.C.; SÁNCHEZ, A.; SIERRA, D.; MARCO, J.C.; CONTRERAS, A. (1996). Relationship between somatic cell counts and intramammary pathogens in goats. En: Somatic Cells and Milk of Small Ruminants. (Ed: Rubino, R.). Wageningen Pers. (EAAP, 77): 89-92.

CORRALES, J.C.; CONTRERAS, A.; SÁNCHEZ, A.; MARCO, J.; RABAL, F. (1997). Adaptación de las condiciones de la aplicación de la directiva comunitaria 92/46 para el recuento de células somáticas, a nivel de tanque, en leche de ganado caprino. XXI Jornadas Científicas de la Sociedad Española de Ovinotecnia y Caprinotecnia. Logroño. 221-227

CORRALES, J.C.; SÁNCHEZ, A.; LUENGO,C.; POVEDA,J.B; CONTRERAS, A. (2004).Effect of clinical contagious agalactia on the bulk tank milk somatic cell count in Murciano-Granadiana goat herds. Journal of Dairy Science. 87 :31653171 .

COULON, J. B ; PRADEL, P; COCHARD, T; POUTREL, B. (1998). Effect of extreme walking conditions for dairy cows on milk yield, chemical composition, and somatic cell. Journal of Dairy Science. 81: 994-1003

CUCCURU, A. P. ; MORONI B, A. ZECCONI B, S. CASU, A. CARIA D, A. CONTINI, (1997) Milk differential cell counts in relation to total counts in Sardinian ewes. Small Ruminant Research. 25: 169-173.

DAZA, A.; (2004). La importancia del ganado caprino, en: Ganado Caprino: Producción ,Alimentación y Sanidad . Ed .Agricola Española.Madrid . 17-28.

DEINHOFER, M. (1993).Staphylococcus spp. as mastitis-related pathogen in ewes and goats. Symposium .on Machine Milking Small Ruminants. S. Kukovics Publ.,Budapest, Hungary.136-143 
DE CRÉMOUX, R.; PILLET, R.; DUCELLIEZ, M.; HEUCHEL,V. POUTREL,B. (1996). Influence du nombre et du stade de lactation sur les numerations cellulaire du lait chevre. En: Somatic Cells and milk of Small Ruminant. (Ed:Rubino,R.).Wageningen Pers.(EAAP,77) : 161-165.

DE CRÉMOUX, R.; MÉNARD,J-L.; BAUDRY, CH.;BERNY, F. (1999). Incidence des inflammations de la mamelle sur la production et la composition de lait chez la chèvre. En: Milking and milk production of dairy sheep and goats. (Ed: Barillet, F. and Zervas, N. P.). Wageningen Pers. (EAAP, 95): 157-163.

DE CRÉMOUX, R. (2000). Facteurs de variation Maîtrise de la teneur en cellule des laits de troupeaux: supports de formation.www.inst- elevage.asso.fr

DEINHOFER, M. (1993). Staphylococcus spp. as mastitis-related pathogens in ewes and goats. $5^{\text {th }}$ International Symposium on Machine Milking of Small Ruminants. Budapest (Hungary). 136-143.

DELGADO-PERTÍÑEZ, M.; ALCALDE, M.J.; GUZMÁN-GUERRERO, J.L.; CASTEL, J.M.; MENA, Y.; CARAVACA, F.P. (2003). Effect of hygienesanitary Management on goat milk quality in semi-extensive systems in Spain. Small Ruminant Research. 47 .51-61.

DELGADO-PERTÍÑEZ,M.;GUZMÁN-GUERRERO, J.L; MENA, Y.; CASTEL, J.M.; GONZÁLEZ-REDONDO, P.; CARAVACA, F.P. (2009). Influence of kid rearing systems on milk yield, kid growth and cost of Florida dairy goats. Small Ruminant Research 81 :105-111.

DÍAZ, J. R.; ROMERO, G.; PERIS, C.; FERNANDEZ, N. (2004). Efecto de diferentes condiciones del ordeño mecánico en el estado del pezón .Bovis 118 : 49-60.

DROKE, E.A.; PAAPE, M.J.; DI CARLO, A.L. (1993). Prevalence of high somatic cell counts in bulk tank goat milk. Journal of Dairy Science. 76:1035-1039.

DULIN, A.; PAAPE, M.; WERGIN, W. (1982). Differentiation and enumeration of somatic cells in goat milk. Journal of Food Protection. 45:435-439.

DULIN, A.; PAAPE, M.; SCHULTZE, W.; WEINLAND, B. (1983). Effect of parity, stage of lactation, and intramammary infection on concentration of somatic cells and cytoplasmic particles in goat milk. Journal of Dairy Science. 66:2426-2433

ESTEBAN, C. (2009). Razas ganaderas españolas caprinas. Edita Cayo Esteban Muñoz y Feagas. 410p.

FAOSTAT, (2008). http://www.fao.org/index_es.htm

FEDELE, V.; CLAPS, S.; RUBINO, R.. (1996). Effect of feding systems on somatic cells count in goats. En: Somatic Cells and Milk of Small Ruminants. (Ed: Rubino, R.). Wageningen Pers. (EAAP, 77):167-172. 
FERNÁNDEZ , J.A.; (1990). Le lait des petits ruminants en Espagne. Options Méditerranéennes -Série A, 12:81-87.

FERRER, O.; REAL, F.; ACOSTA, B.; MOLINA, M.J. (1996a). Cellular values in milk of Canary goat (Agrupacion Caprina Canaria) with subclínical mastitis. En: Somatic Cells and Milk of Small Ruminants. (Ed: Rubino, R.). Wageningen Pers. (EAAP, 77): 77-80.

FERRER, O.; REAL, F.; ACOSTA, B.; MOLINA, M.J. (1996b). Physiological cellular values in Canary (Agrupacion Caprina Canaria) goat milk. En: Somatic Cells and Milk of Small Ruminants. (Ed: Rubino, R.). Wageningen Pers. (EAAP, 77): 81-84.

FUERTES, J.A.; GONZALO, C.; CARREDO, J.A.; SAN PRIMITIVO, F. (1998). Parameters of test day milk yield and milk components for dairy ewes. Journal of Dairy Science. 81(5): 1300-1307

GONZALEZ, L.; MARCO, J.; SAEZ DE OCARIZ,C.L.; GELABERT, J.L . (1985). Artritis Encefalitis Caprina: I.-Estudio clínico y lesional. Medicina. Veterinaria. 2 (2):95-104.

GONZALEZ-RODRIGUEZ, M.C.; GONZALO, C.; SAN PRIMITIVO, F.; CÁRMENES, P. (1995).Relationship between somatic cell count and intramammary infection of the half udder in dairy ewes. Journal of Dairy Science. 78:2753-2759.

GONZALO, C.; GAUDIOSO, V. R. (1985). Evolution des types cellulaires du lait de brebis (race Churra) en fonction des dénombrements cellulaires totaux pendant la traite mécanique et manuelle. Annales Zootechnie. 34(3):257-264.

GONZALO, C.; BARO, J.A.; CARRIEDO, J.A.; SAN PRIMITIVO, F. (1993). Use of the Fossomatic method to determine somatic cell counts in sheep milk. Journal of Dairy Science. 76:115-119.

GONZALO, C.; CARRIEDO, J.A.; BARO, J.A.; SAN PRIMITIVO, F. (1994). Factors influencing variation of test day milk-yield, somatic cell count, fat and protein in dairy sheep. Journal of Dairy Science. 77:1537-1542.

GONZALO, C. (1996). Microbiological and hygienic quality of ewe and goat milk: somatic cells and pathogens. IDF Special Issue $N^{\circ}$ 9603/1996-Production and utilization of ewe and goat milk: 59-71.

GONZALO, C.; MARTÍNEZ, J.R.; SAN PRIMITIVO, F. (1998a). Significación y métodos de valoración del recuento celular en la leche de oveja. En: El recuento de células somáticas en la leche de oveja. Ovis. 56:13-25.

GONZALO, C.; FUERTES, J.A.; CARRIEDO, J.A; SAN PRIMITIVO, F. (1998b). Factores no infecciosos de variación del recuento celular de la leche de oveja. En: El recuento de células somáticas en la leche de oveja. Ovis. 56:35-40. 
GONZALO, C.; ARIZNABARRETA, A.; CARRIEDO, J. A.; SAN PRIMITIVO, F. (2002). Mammary pathogens and their relationship to somatic cell count and milk yield losses in dairy ewes. Journal of Dairy Science. 85:1460-1467.

GONZALO, C., MARTÍNEZ, J. R.; CARRIEDO, J. A.; SAN PRIMITIVO, F. (2003). Fossomatic cell-counting on ewe milk: comparison with direct microscopy and study of variation factors. Journal of Dairy Science. 86:138-145.

GONZALO, C., BOIXO, J. C.; CARRIEDO, J. A.; SAN PRIMITIVO, F. (2004). Evaluation of rapid somatic cell counters under different analytical conditions in ovine milk. Journal of Dairy Science. 87 .3623-3628.

GONZALO, C. (2005). Somatic cell of sheep and goat milks: analytical, sanitary, productive and technological aspects. Special Issue of the International Dairy Federation 0501/part 3 (future of sheep and goats dairy sector) :128-133.

GONZALO, C., LINAGE, B.; CARRIEDO, J. A.; DE LA FUENTE, F.; SAN PRIMITIVO, F. (2006). Evaluation of the overall accuracy of the DeLaval Cell Counter for somatic cell counts in ovine milk. Journal of Dairy Science. 89:46134619.

GONZALO, C., LINAGE, B.; CARRIEDO, J. A.; DE LA FUENTE, F. (2008). Evaluation of the overall accuracy of the DeLaval Cell Counter for somatic cell counts in ovine milk: effect of soak time in diluted and undiluted milk samples. Journal of Dairy Science. 91:3114-3118.

HACHANA, Y.; KRAIEM, K.; HANI, K.; HADDADB. ; PAAPE,M. J. ;(2008). Effects of time storage and analytical temperature on Fossomatic cell counts in cows milk. Milchwissenschaft .63 3:.267-269.

HAENLEIN, G.F.W.; HINCKLEY, L.S. (1996). Somatic cell count situation in USA. En: Somatic Cells and Milk of Small Ruminants. (Ed: Rubino, R.). Wageningen Pers. (EAAP, 77): 349-355.

HAENLEIN, G.F.W. (2002). Relationship of somatic cell counts in goat milk to mastitis and productivity. Small Ruminant Research 45. 163- 178.

HAENLEIN, G.F.W. (2007). About the evolution of goat and sheep milk production. Small Ruminant Research 68 1-2: 3-6

HARMON, R. J. (1994). Physiology of mastitis and factors affecting somatic cell. Journal of Dairy Science. 77: 2103-2112.

IDF, (1995). Enumeration of somatic cells. IDF Standard No. 148, Brussels,Belgium.

ISSARTIAL, J. (1990). La numération cellulaire individuelle de lait de chèvre: rôle du virus de l'arthrite encéphalite caprine (CAEV). Thèse de Doctorat Vétérinaire, Lyon. (CITADO POR PERRIN Y BAUDRY, 1993). 
ISO/IDF (2008) Milk -Enumeration of somatic cells. Part 1:Microscopic method (reference method). ISO 13366-1 .IDF 148-1 (ISO and IDF).

JIMENEZ, A.; ANDRES, S.; SANCHEZ, J. (2009). Effect of melatonin implants on somatic cell counts in dairy goats. Small Ruminant Research. 84: 116-120.

KALOGRIDOU-VASSILIADOU, K.; MANOLKIDIS, K.; TSIDOIDA, A. (1992). Somatic cell counts in relation to infection status of the goat udder. Journal of Dairy Research. 59: 21-28.

KARZIS, J.; DONKIN, E.F.; PETZER, I.M. (2004). Antibiotic residue whithdrawal periods in milk of saanen dairy goats and udder tissue irritation : preliminary results. South African Journal of Animal Science. 34: 262-265. (supp1)

KENNEDY, B. W., SETHAR, M. S.;TONG, A. K. W.; MOXLEY, J. E.; DOWNEY. B. R. (1982). Environmental factors influencing test-day somatic cell counts in Holsteins. Journal of Dairy Science .65:275-280.

KOMARA M.; BOUTINAUD, M.; BEN CHEDLY, H.; GUINARD-FLAMENT J.; MARNET, P.-G. (2009). Once-daily milking effects in high-yielding Alpine dairy goats . Journal of Dairy Science $.92: 5447-5455$.

KOSEV, K.; TZOLOV, S.; DENEV, S.; MICHAILOVA, G.; KOLEVA, M. (1996). Influence of lactation and type of milking on the somatic cell count in goat's milk. En: Somatic Cells and Milk of Small Ruminants. (Ed: Rubino, R.). Wageningen Pers. (EAAP, 77):227-229.

LAGRIFFOUL, G.; BERGONIER, D.; BERTHELOT,; X. JACQUIN, M.; GUILLOUET, P.; BARILLET, F (1996). Facteurs de variation génétiques et non génétiques des comptages de cellules somatiques du lait de brebis en relation avec les caractères laitiers et les mesures portant sur lae lait du tank. En: Somatic Cells and Milk of Small Ruminants. (Ed: Rubino, R.). Wageningen Pers. (EAAP, 75): 149-155.

LEE, C.S.; WOODING, F.B; KEMP, P.; (1980). Identification, properties, and differential counts of cell populations using electron microscopy of dry cows secretions, colostrum and milk from normal cows. Journal of Dairy Research. 47 $1: 39-50$.

LEITNER, G.; SHOSHANI, E.; KRIFUCKS, O.; CHAFFER M. (2000). Milk leucocyte population patterns in bovine udder infection of different aetiology. Journal of Veterinary Medicine, Series B 47: 581-589.

LEITNER, G.; MERIN, U.; LAVI, Y.; EGBER, A.; SILANIKOVE, N.; (2007).Aetiology of intramammary infection and its effect on milk composition in goat flocks Journal of Dairy Research. 74: 221-225.

LEFRILEUX, Y.; POMMARET, A. ; RAYNAUD, S. (2008). Impacts de la monotraite dans une exploitation caprine fromagère à haut niveau de production. 
15ème Rencontres autour des Recherches sur les Ruminants, Paris, France. Institut de l'Élevage-INRA, Paris, France. 167-170 .

LERONDELLE,C.; POUTREL, B. (1984). Characteristics of non-clinical mammary infections of goats. Annales de Recherches Véterinaires. 15 (1): 105-112.

LERONDELLE, C.; RICHARD, Y.; ISSARTIAL, J. (1992). Factors affecting somatic cell counts in goat milk.. Small Ruminant Research. 8: 129-139.

LONG, P.E.; HEAVNER, J.E.; ZIV, G.; GELETA, J.N.; NEPOTE, K. (1984). Depletion of antibiotics from the mammary gland of goats. Journal of Dairy Science. 67:707-712.

LU, C.D.; POTCHOIBA, M.J.; LOETZ, E.R. (1991). Influence of vacuum level,pulsation ratio and rate on milking performance and udder health of dairy goat. Small Ruminant Research. 5: 1-8.

LUENGO, C.;SANCHEZ,A.;CORRALES,J.C.; FERNANDEZ, E.; CONTRERAS, A. (2004). Influence of intramammary infection and non-infection factors on somatic cell counts in dairy goats. Journal of Dairy Research. 71: 169-174.

LILCYL, (2000). Memoria anual del Laboratorio Interprofesional Lácteo de Castilla y León. Ejercicio1999.

MALINOWSKI, E., SMULSKI, S., GEHRKE, M.; KEOSSOWSKA, A.; ARCZYÑSKA, A.; KACZMAROWSKI, M. (2008). Effect of storage conditions and preservation with Bronopol on somatic cell count with the DeLaval cell counter in cow milk. Medycyna Wet 64 :11 1299-1303.

\section{MANLONGAT, N.; YANG, T .J.; HINCKLEY, L. S.; BENDEL, R .B.; KRIDER,}

H.M.(1988). Physiologic Chemoattractant Induced Migration of Polymorphonuclear Leukocytes in Milk .Clinical and Diagnostic Laboratory Immunology. Vol. 5: 375-381.

MANSER, P. (1986). Prevalence causes and laboratory diagnosis in subclínical mastitis in goats. Veterinary Record. 118 (20):552-554.

MANZUR, A (2007).Estudios de ordeño mecánico en ganado caprino. Tesis doctoral.138p.

MARM, (2009). Ministerio de Medio Ambiente y Medio Rural y Marino.

MARNET, P.-G.; GOMIS, B.; GUINARD-FLAMENT, J.; BOUTINAUD, M.; LOLLIVIER V.; (2005). Effets d'une seule traite par jour (Monotraite) sur les performances zootechniques et les caractéristiques physico-chimiques du lait chez les chèvres Alpine à haut potentiel.12ème Rencontres autour des Recherches sur les Ruminants, Paris, France. Institut de l'Élevage-INRA, Paris, France. 225-228

MARTÍNEZ, B.; PERIS, C.; VEGA, S. (1999). Relación entre el recuento de células somáticas y los patógenos intramamarios aislados en el ganado caprino lechero 
de la Comunidad Valenciana. XXIV Jornadas Científicas de la Sociedad Española de Ovinotecnia y Caprinotecnia. Soria. 325-329.

MARTÍNEZ, B. (2000). El recuento de células somáticas en la leche de cabra: factores de variación y efecto sobre la producción y composición de la leche. Tesis doctoral. Universidad Politécnica De Valencia .307p.

MARTÍNEZ, J.R.; GONZALO, C.; CARRIEDO, J. A.; SAN PRIMITIVO, $\mathbf{F}(\mathbf{2 0 0 3 )}$. Effect of freezing on fossomatic cell counting in ewe milk. Journal of Dairy Science. 86 : 2583-2587.

MCDOUGALL, S.; VOERMANS, M. (2002). Influence of Estrus on Somatic Cell Count in Dairy Goats .J. Dairy Science. 85:378-383.

MCDOUGALL, S; ANNISS, F.M; CULLUM, A.A. (2002). Effect of transport stress on somatic cell counts in dairy goats. Proceedings of the New Zealand society of animal health .62: 16-18.

MILLER, R.H.; PAAPE, M.J; ACTON, J.C. (1986). Comparison of milk somatic cell counts by Coulter and Fossomatic Counters. Journal of Dairy Science. 69: 1942-1946.

MILLER, R.H.; PAAPE, M.J; FLUTON, L.A. (1991).Variation in milk somatic cells of heifers at first calving. Journal of Dairy Science. 74: 3782-3790.

MORONI, P.; PISONI, G.; RUFFO, G.; BOETTCHER, P.J. (2005). Risk factors for intramammary infections and relationship with somatic-cell counts in Italian dairy goats. Preventive Veterinary Medicine. 69 :3-4:163-173.

MORONI, P. ; PISONI, G.; VAN LIER, E.; ACUÑA,S.; DAMIAN, J.P; MEIKER; A. (2007) . Influence of estrus of dairy goat on somatic cell milk trait,and sex steroid receptors in the mammary gland. Journal of Animal Science. $90: 790-797$.

NEUVEU, C.; RIAUBLANC. A.; MIRANDA, G.; CHICH. JF.; MARTIN, P. (2002). Is the apocrine milk secretion process observed in the goat species rooted in perturbation of intracellular transport mechanism induced by defective alleles at the alpha(s1)-Cn locus? Reprod. Nutr. Dev. $42: 142-172$.

NESBAKKEN, T. (1976). Celletallet i geitemelk (The cell count in milk of goats). Nordisk Veterinary Medicine. 28:550-556.

NORD, K.; ADNOY, T. (1997). Effects of infection by caprine arthritis-encephalitis virus on milk production of goats. Journal of Dairy Science. 80:2391-2397.

NORK, K. (1997). CAEV infection does not affect prevalence of bacterial mastitis in goats. Acta Veteterinaria Scandinavian. 38(2):197-199. 
NUDDA, A.; BENCINI, R.; MIJATOVIC, S.; PULLINA, G.; (2002). The yield and composition of milk in Sarda, Awassi, and Merino sheep milked unilaterally at different frequencies. J. Dairy Science. 85:2879-2884.

PAAPE, M. J.; Capuco, A.V. (1997) Cellular defence mechanisms in the udder and lactation of goats. Journal of Animal Science. 75:556-565.

PAAPE, M.J.; POUTREL, B.; CONTRERAS, A.; MARCO, J.C.; CAPUCO, A.V.(2001). Milk somatic cells and lactation in small ruminants .Journal of Dairy Science . 84 (E.suppl) E: 237-E244.

PAAPE, M.J.; BANNERMAN, D.D.; ZHAO, X.; LEE, J.W. (2002).The bovine neutrophil: Structure and function in blood and milk. Vet. Res. 34:597-627 INRA, EDP Sciences.

PAAPE, M.J.; WIGGANS, G.R.; BANNERMAN, D.D.; THOMAS ， D.L.; SANDERS A.H.; CONTRERAS A.; MORONI P.; MILLER R.H. (2007). Monitoring goat and sheep milk somatic cell counts. Small Ruminant Research 68 1-2:114-125.

PARK, Y.W. (1991) Interrelationships between somatic cell counts, electrical conductivity, bacteria counts, percents fat, and protein. Small Ruminant Research. 5:367-375.

PERIS, C., MOLINA, P.; FERNANDEZ, N.; RODRIGUEZ, M.; TORRES, A. (1991).Variation in somatic cell count, California mastitis test and electric conductivity among various fractions of ewe's milk. Journal of dairy Science. 74: 1553-1560.

PERIS, C.; DÍAZ, J. R.; FERNANDEZ, N.; RODRÍGUEZ, M.; MOLINA, P.; TORRES, A. (2002a). Influencia del ordeño mecánico sobre la mamitis .I. Mecanismos involucrados .Pequeños Rumiantes. (Seoc) Volumen2 no 3 /8-14.

PERIS, C.; SEGURA, C.; PALOMARES J. L. RODRÍGUEZ, M.; DÍAZ, J. R.; FERNÁNDEZ N. (2002b). La calidad de la leche de cabra producida en las comunidades autónomas de Valencia y Murcia. IV Jornadas Científicas Internacionales de Ovinotecnia y Caprinotecnia, (SEOC) Valencia. 360-366.

PERIS, C.; DÍAZ, J. R.; RODRÍGUEZ, M.; BELTRAN, M.C; FERNANDEZ, N. (2003). Influencia del ordeño mecánico sobre la mamitis .II .Características de la maquina del ordeño. Pequeños Rumiantes. (Seoc) 4 :18-25.

PERIS, C.; MANZUR, A.; MEHDID, M. A.; DÍAZ, J.R.; FERNÁNDEZ, N., (2004a) Ordeño mecánico y mamitis en pequeños rumiantes. Tierras de Castilla y León, 108:28-34

PERIS C., DÍAZ J. R., MANZUR, A., MEHDID M. A., FERNÁNDEZ N., (2004b) Estado del pezón y riesgo de mamitis. Bovis $118: 61-67$. 
PERIS, S.; SUCH, X.; CAJA, G. (1998). Características de los sistemás de ordeño en ganado caprino y su relación con el estado sanitario de la ubre. En: Mamitis Caprina II. Ovis. 54: 11-23.

PERRIN, G.G.; BAUDRY, C. (1993). Numérations cellulaires du lait de chèvre. Le Lait. 73:489-497.

PERRIN, G.G.; MALLEREAU, M.P.; LENFANT, D.; BAUDRY, C. (1997). Relationship between California mastitis test (CMT) and somatic cells cuonts in dairy goats. Small Ruminant Research. 16:167-170.

PETTERSEN, K.E. (1981). Cell content in goat's milk. Acta Veterinariae Scandinavian. 22:226-237.

PIRISI, A.;. LAURET, A; DUBEUF ,J.P. (2007). Basic and incentive payments for goat and sheep milk in relation to quality. Small Ruminant Research. 68 1-2:167178.

POUTREL, B.; LERONDELLE, C. (1983) .Cell content of goat milk: California mastitis test, coulter counter , and fossomatic for predicting half infection. Journal of Dairy Science. 66:2575-2579.

POUTREL, B.; DE CREMOUX, R.; DUCELLIEZ ,M.; VERNEAU, D. (1997). Control of intramammary infections in goats: impact on somatic cell counts. Journal of Animal Science. 75:566-570.

RAMIREZ, M.A.(2009). Guía de los quesos españoles. Publicaciones Técnicas Alimentarias, S:A 349p.

RANDY, H.A.;WILDMAN, E. E; CALER, W. A.; TULLOCH, G. L. (1988) Effect of age and time of milking on day-to-day variation in milk yield, milk constituents and somatic cell counts .Small Ruminant Research. 1: 151-155.

RANDY, H.A.; CALER, W.A.; MINER, W.A.; MINER, W.H.; ATWOOD, A.C.; HOWARG, D.B. (1991). Effect of lactation number, year, and milking management practices on milk yield and SCC of French Alpine dairy goats. Journal of Dairy Science. 74 (Suppl. 1): 311

RAYNAL-LJUTOVAC, K. ; PIRISI, A. ; DE CREMOUX, R.; GONZALO, C. (2007). Somatic cells of goat and sheep milk: analytical, sanitary, productive and technological aspects. Small Ruminant Research 68 1-2: 126-144.

RÉMOND, B.;. POMIÈS, D.; DUPONT, D.; CHILLIARD, Y. (2004). Once-a-day milking of multiparous Holstein cows throughout the entire lactation: Milk yield and composition, and nutritional status. Anim. Res. 53:201-212

ROTA, A.M.; GONZALO, C.; RODRIGUEZ, P. L.; ROJAS, A. I.; MARTIN, L.; TOVAR, J. J. (1993a). Somatic cell types in goats milk in relation to total cell count, stage and number of lactation. Small Ruminant Research 12:89-98. 
ROTA, A.M.; GONZALO, C.; RODRIGUEZ, P. L.; ROJAS, A. I.; MARTIN, L.; TOVAR, J. J. (1993b). Effects of stage of lactation and parity on somatic cell counts in milk of Verata goats and algebraic models of their lactation curves, Small Ruminant Research. 12:211-219.

RYAN, D.P.; GREENWOOD, P.L.; NICHOLLS, P.J. (1993). Effect of caprine arthritis-encephalitis virus infection on cell count and $\mathrm{N}$-acetyl-betaglucosaminidase activity in dairy goats. Journal of Dairy Science. 60:299-306.

SAlAMA, A.; CAJA, G.; SUCH, X.; ALBANELL E.; PARÉS, R.; CASALS, R. (2000). Effect of zinc-methionine on milk production, milk somatic cell counts and udder health in dairy goats. $7^{\text {th }}$ International Conference on Goats. France. 767-769.

SALAMA, A.A; SUCH, X.; CAJA,G.; ROVAI, M.; CASALS, R.; ALBANELL, E.; MARTIN, M. P.; MARTI, A. (2003 a). Effects of Once Versus Twice Daily Milking Throughout Lactation on Milk Yield and Milk Composition in Dairy Goats. Journal of Dairy Science.86: 1673-1680.

SALAMA, A.A; CAJA, G.; ALBANELL, E.; SUCH, X.; CASALS, R.;PLAIXATS, J. (2003b). Effects of dietary supplements of zinc-methionine on milk production, udder health and zinc metabolism in dairy goats. Journal of Dairy Research .70:917.

SÁNCHEZ, A.; CONTRERAS, A.; CORRALES, J.C.; SIERRA, D.; MARCO, J.C. (1996). Influencia de los patógenos intramamarios en los recuentos de células somáticas de leche de cabra. XXI Jornadas Científicas de la Sociedad Española de Ovinotecnia y Caprinotecnia. Logroño. 213-220.

SÁNCHEZ, A.; CORRALES, J.C.; MARCO, J; CONTRERAS, A. (1997). Effect of caprine arthritis-encephalitis virus infection on milk somatic cell counts. $3^{\text {rd }}$. European Workshop on ovine and caprine retroviruses. Jaca.

SÁNCHEZ, A. (1998). Dinámica celular en leche de cabra en relación con el estado sanitario de la glándula mamaria y aplicaciones diagnosticas. Tesis Doctoral Universidad de Murcia 180pp.

SÁNCHEZ, A;CORRALES,J. C; MARCO, J; CONTRERAS, A.(1998a). Aplicación del recuento de células somáticas para el control de las mamitis caprinas. Mamitis caprinas II. Ovis 54:37-51.

SÁNCHEZ, A.; LUENGO, C.; CORRALES, J.C.; CONTRERAS, A. (1998b). Modificación del recuento celular en la leche de cabras según la serología frente al virus de la artritis-encefalitis caprina y la infección intramamaria de etiología bacteriana. XV Reunión de Técnicos Especialistas en Mamitis y Calidad de Leche. Lugo.

SÁNCHEZ, A.; CORRALES, J.C.; LUENGO, C.; CONTRERAS, A. (1999). Intramammary pathogens and somatic cell counts in dairy goats. En: Milking and 
milk production of dairy sheep and goats. (Ed: Barillet, F. and Zervas, N. P.). Wageningen Pers. (EAAP, 95): 124-129.

SÁNCHEZ, A.; LUENGO, C.; CAPPELLETTI, C.; CONTRERAS, A. (2000). Análisis de los factores que modifican el RCS en la leche de cabra. En: Mamitis y calidad de lache. (Ed. Contreres, A.; Sánchez, A. y Corrales, J.C.). Diego Marin Librero-Editor. Murcia. 425 pp.

SANCHEZ, A.; SIERRA, D.; LUENGO, C.;CORRALES, J. C.;CONTRERAS,A.; MORALES, C.T.; GONZALO, C. (2005). Influence of storage and preservation on fossomatic cell count and composition of goat milk. Journal of Dairy Science. 88 : 3095-3100.

SANCHEZ, J.; MONTES, P.; JIMENEZ, A.; ANFRES, A.; (2007). Prevention of clinical mastitis with barium selenate in dairy goats from a selenium deficient area. Journal of Dairy Science 90:2350-2354.

SARIKAYA, H.; WERNER-MISOF, C.; ATZKERN,M.; BRUCKMAIER, R.M.(2005). Distribution of leucocyte populations, and milk composition, in milk fractions of healthy quarters in dairy cows . Journal of Dairy Research 72 : 486492.

SCHMIDLIN, J.; WICK, B. (1996). Détermination du nombre de germes dans le lait de chèvre en Suisse' milk. En: Somatic Cells and Milk of Small Ruminants. (Ed: Rubino, R.). Wageningen Pers. (EAAP, 77):371-374.

SCHUKKEN, Y., A. WEERSINK, K. LESLIE, S. W. MARTIN. (1993). Dynamics and regulation of bulk milk somatic cell counts. Can. J.Vet. Res. 57,131-135.

SIERRA, D.; SÁNCHEZ, A.; CORRALES, J.C.; CONTRERAS, A. (1998). Recuentos celulares diferenciales en leche de ganado caprino. XV Reunión de Técnicos Especialistas en Mamitis y Calidad de la Leche. Lugo.

SIERRA, D.; SÁNCHEZ, A.; CORRALES, J.C.; CONTRERAS, A. (1999). Differential cell counts in goat's milk. En: Milking and milk production of dairy sheep and goats. (Ed: Barillet, F. and Zervas, N. P.). Wageningen Pers. (EAAP, 95): 178-180.

SIERRA, D.; SANCHEZ, A.; LUENGO, C.; CORRALES, J. C.;MORALES, C. T.;CONTRERAS, A.;GONZALO,C.(2006).Temperature effects on Fossomatic cell counts in goats milk. International Dairy Journal, 16: 385-387.

SINAPIS ,E; VLAXHOS , L. (1999). Influence du niveau de vide de la machine a traire et des facteurs zootechniques sur les comptages de cellules somatiques chez les chévres locales greques, Milking and milk production of dairy sheep and goats (Ed Barillet, F, and Zervas,N,P,) Wageningen pers (EAAP,95) 513-518.

SORDILLO, L.M.; STREICHER, K.L. (2002).Mammary Gland Immunity and Mastitis Susceptibility. Journal of Mammary Gland Biology and Neoplasia, 7: 135-146. 
SUZUKI, K.; TOTSUKA, M.; NAKAJI, S.; YAMADA, M.; KUDOH, S.; LIU, Q.; SUGAWARA, K.; YAMAYA, K.; SATORU, K. (1999). Endurance exercise causes interaction among stress hormones, cytokines, neutrophil dynamics, and muscle damage. Journal of Applied Physiology .87: 1360-1367.

SUZUKI, K.; YAMADA, M.; KURAKAKE, S.; OKAMURA, N.; YAMAYA, K.; LIU, Q.; SATORU, K. ; KOWATARI, K.; NAKAJI, S.; SUGAWARA, K. (2002).Circulating cytokines and hormones with immunosuppressive but neutrophil-priming potentials rise after endurance exercise in humans. European Journal of Applied Physiology. 81:281-287.

TORRES, A.; LUENGO, C.; SANCHEZ, A.; CONTRERAS, A. (1999). Weekly evaluation of bulk tank milk somatic cell counts in Murciano-Granadina goats throughout an entire lactation. Production Systems and Product Quality. Molina de Segura (Murcia).

WILSON, D.J.; STEWART, K.N.; SEARS, P.M. (1995). Effects of stage of lactation, production, parity and season on somatic cell counts in infected and uninfected dairy goats Small Ruminant Research. 16: 165-169.

ZENG, S.S.; ESCOBAR, E.N. (1995). Effect of parity and milk production on somatic cell count, standard plate count and composition of goat milk. Small Ruminant Research. 17:269-274.

ZENG, S.S.; ESCOBAR ,E.N. (1996). Effect of breed and milking method on somatic cell count, standard plate count and composition of goat milk .Small Ruminant Research, 19: 196-175.

ZENG, S.S.;ESCOBAR E.N.;POPHAM, T. (1997). Daily variations in somatic cell count, composition, and production of Alpine goat milk. Small Ruminant Research 26: 253-260.

ZENG, S.S.; ESCOBAR, E.N; HART,S.P.; HINCKLEY, L; BAULTHAUS, M.; ROBINSON, G.T.; JAHNKE, G. (1999).Comparative study of the effects of testing laboratory, counting method, storage and shipment on somatic cell counts in goat milk, Small Ruminant Research 31, 103-107.

ZILUAGA, I.; ROMEO, M.; MARCO, J.C. (1998). Prevalencia, patogenicidad y epidemilogía de los microoganismos implicados en procesos mamíticos del ganado ovino. En Mamitis ovina y calidad de la leche (I). Ovis. 59.27-49. 
II. JUSTIFICACIÓN Y OBJETIVOS 


\section{JUSTIFICACIÓN Y OBJETIVOS}

Muchos trabajos han puesto de manifiesto que, en la leche de cabra, el RCS está influido por un gran número de factores infecciosos y no infecciosos, siendo estos últimos mucho más marcados que en la leche de vaca y oveja. Sin embargo, existe una gran variabilidad en los recuentos individuales que, en muchas ocasiones, no puede ser explicada. Por ejemplo, Wilson et al. (1995) encontró que el 75\% de la variación del RCS de las cabras de un rebaño no podía ser explicada a partir de los factores infecciosos y no infecciosos habitualmente descritos. Esta variabilidad en el RCS, de origen desconocido, provoca importantes perturbaciones en dos aspectos de relevancia económica:

a) La identificación de los animales afectados por mamitis a partir del RCS.

b) La relación entre el RCS de la leche de tanque, la prevalencia de mamitis en el rebaño y la propia calidad de la leche. Debemos precisar que en muchas regiones de la Unión Europea la leche de cabra se paga a los ganaderos con primas y/o penalizaciones relacionadas con el RCS en la leche de tanque.

En un trabajo anterior, nuestro equipo comprobó que, en cabras libres de IIM, existía una gran variabilidad en el RCS de los controles mensuales realizados a lo largo de toda una lactación (Martínez et al., 2000). En concreto se identificaron elevaciones del RCS bruscas (incremento del RCS de 5 veces, con valores superiores a 1 millón de cels/ml) y puntuales (es decir, en un solo control, ya que los recuentos eran bajos tanto en los controles anteriores como posteriores) que no podían ser explicadas por motivos infecciosos (análisis bacteriológicos y de AEC siempre negativos; además estas elevaciones del RCS se producía en ambas glándulas del mismo animal), ni por fenómenos de dilución (la producción de los animales apenas variaba en los controles que presentaban elevaciones bruscas del RCS). A estas elevaciones les denominamos Elevaciones Transitorias del RCS ( $\mathrm{ET}_{\mathrm{RCS}}$ ). En total se detectaron un 6\% de $\mathrm{ET}_{\mathrm{RCS}}$ (33 elevaciones de un total de 552 controles) que afectaron al 28\% de las cabras libres de mamitis utilizadas en el estudio (28 cabras de un total de 100). Además, el número de ET $_{\text {RCS }}$ aumentó ligeramente con la edad de los animales (4, 5 y $7 \%$ de elevaciones en las cabras de $1^{\mathrm{a}}, 2^{\mathrm{a}} \mathrm{y}$ $\geq 3$ lactación) y se concentraron principalmente en el $3^{\mathrm{er}}$ y $4^{\mathrm{o}}$ mes de lactación (66\% de las elevaciones). 
En otros trabajos, en que los recuentos se llevaron a cabo con periodicidad diaria (Randy et al., 1988; Zeng et al., 1997) o semanal (Pettersen, 1981), también se observó esta importante variabilidad del RCS en la leche de cabra, si bien en todos ellos hubieron aspectos metodológicos que impiden extraer conclusiones adecuadas, ya que no se realizaron análisis bacteriológicos (Randy et al., 1988; Zeng et al., 1997) o el RCS se llevó a cabo por métodos no adecuados (Pettersen, 1981).

Se han descrito algunos factores que podrían ocasionar elevaciones transitorias en el RCS, como la aparición del celo (Aleandri et al., 1996; McDougall y Voermans, 2002; Moroni et al., 2007) o ciertas prácticas de manejo que presumiblemente generan estrés en el animal (cambios bruscos en el manejo del ordeño, vacunaciones, extracciones de sangre...; Lerondelle et al., 1992; Corrales et al., 1997; Salama et al., 2003; Karzis et al., 2004). Sin embargo, a partir de la información bibliográfica disponible no es posible identificar totalmente el factor o factores que serían responsables de provocar las elevaciones transitorias del RCS descritas anteriormente, ni conocer exactamente la evolución diaria del RCS que se produce durante estas últimas.

Por consiguiente se ha planteado el presente trabajo con tres objetivos principales:

a) Confirmar la existencia de elevaciones transitorias del RCS en la leche de cabra de origen no infeccioso, mediante el seguimiento diario del RCS en glándulas/ubres libres de infección intramamaria. Además se pretende evaluar la frecuencia de estas elevaciones y como evoluciona diariamente el RCS durante estos episodios (ESTUDIOS 1 y 2).

b) Determinar si la presencia del celo, inducido mediante tratamientos hormonales, puede ser uno de los factores responsables de estas elevaciones transitorias del RCS. También se estudiará como influye este efecto según el número de lactación y el estado sanitario de la ubre (ESTUDIO 3).

c) Estudiar como influyen diferentes tipos de estrés sobre el RCS y si pueden provocar elevaciones transitorias del RCS (ESTUDIO 4). 


\section{BIBLIOGRAFIA}

ALEADRI, M.; FAGIOLO, A.; CALDERINI, P.; COLAFRANCESCO, R.;GIANGOLINI, G.; ROSATI, R.; DE MICHELIS, F. (1996). Studies conduced on somatic cells counts of goats milk. En: Somatic Cells and milk of Small Ruminant. (Ed:Rubino,R.).Wageningen Pers.(EAAP,77): 65-70.

CORRALES, J.C.; CONTRERAS, A.; SÁNCHEZ, A.; MARCO, J.; RABAL, F. (1997). Adaptación de las condiciones de la aplicación de la directiva comunitaria 92/46 para el recuento de células somáticas, a nivel de tanque, en leche de ganado caprino. XXI Jornadas Científicas de la Sociedad Española de Ovinotecnia y Caprinotecnia. Logroño. 221-227.

KARZIS, J.; DONKIN, E.F.; PETZER, I.M. (2004). Antibiotic residue whithdrawal periods in milk of saanen dairy goats and udder tissue irritation : preliminary results. South African Journal of Animal Science. 34: 262-265. (supp1)

LERONDELLE, C.; RICHARD, Y.; ISSARTIAL, J. (1992). Factors affecting somatic cell counts in goat milk. Small Ruminant Research. 8: 129-139.

PETTERSEN, K.E. (1981). Cell content in goat's milk. Acta Veterinariae Scandinavian. 22:226-237.

MARTÍNEZ, B. (2000). El recuento de células somáticas en la leche de cabra: factores de variación y efecto sobre la producción y composición de la leche. Tesis doctoral. Universidad Politécnica De Valencia .307p.

MCDOUGALL , S; ANNISS, F.M; CULLUM, A.A. (2002). Effect of transport stress on somatic cell counts in dairy goats. Proceedings of the New Zealand society of animal health .62: 16-18.

MORONI , P. ; PISONI ,G.; VAN LIER ,E.; ACUÑA ,S. ; DAMIAN .; J.P ; MEIKER .; A. (2007) . Influence of estrus of dairy goat on somatic cell ,milk trait,and sex steroid receptors in the mammary gland . Journal of Animal Science. 90 : 790- 797.

RANDY, H.A.;WILDMAN, E. E; CALER, W. A.; TULLOCH, G. L. (1988) Effect of age and time of milking on day-to-day variation in milk yield, milk constituents and somatic cell counts .Small Ruminant Research. 1: 151-155.

SALAMA, A.A; CAJA, G.; ALBANELL, E.; SUCH, X.; CASALS, R.; PLAIXATS, J.(2003). Effects of dietary supplements of zinc-methionine on milk production, udder health and zinc metabolism in dairy goats. Journal of Dairy Research 70:917.

ZENG, S.S.; ESCOBAR E.N.; POPHAM, T. (1997). Daily variations in somatic cell count, composition, and production of Alpine goat milk. Small Ruminant Research 26: 253-260. 
WILSON, D.J.; STEWART, K.N.; SEARS, P.M. (1995). Effects of stage of lactation, production, parity and season on somatic cell counts in infected and uninfected dairy goats Small Ruminant Research. 16: 165-169. 


\section{MATERIALES Y MÉTODOS GENERALES}




\section{MATERIALES Y MÉTODOS GENERALES}

\section{MATERIAL ANIMAL}

\subsection{CARACTERÍSTICAS Y MANEJO DE LOS ANIMALES}

Todos los experimentos se realizaron en la granja experimental de pequeños rumiantes del Institut de Ciència i Tecnologia Animal de la Universitat Politècnica de València. La granja tiene una capacidad para 200 animales (100 ovejas de razas Guirra y Manchega y 100 cabras de raza Murciano-Granadina) alojados en condiciones de estabulación permanente. La cubrición de las cabras se realizaba entre los meses de septiembre y octubre mediante inseminación artificial y monta natural, de forma que los partos ocurrieron en los meses de febrero y marzo del año siguiente. Los cabritos se separaban de sus madres el mismo día del parto y se criaban en lactancia artificial, mientras que las cabras pasaban a ordeñarse a máquina, una vez al día, durante unos 6 meses.

\subsection{ALIMENTACIÓN}

Durante todos los experimentos la alimentación de las cabras fue similar, siendo formulada mediante el programa informático "PORFAL", basado en programación lineal. Los alimentos que constituían la ración fueron los siguientes: pienso concentrado comercial ( 1-1.3 Kg/día de concentrado "caprilactal": 6,8\% FB, 17,9\% PB, 3900 Kcal EB; Nanta S.A.), heno de alfalfa (1-1.3 Kg/día), pulpa de naranja (unos $2 \mathrm{Kg}$ /día) y paja de cebada. El concentrado era distribuido en los comederos del aprisco y en los comederos de la sala de ordeño. Además los animales disponían de bloques de sal y de un corrector mineral-vitamínico (Ovifort, Nanta S.A.) a voluntad.

\subsection{SANIDAD DEL REBAÑO}

El rebaño se encontraba libre de brucelosis y tuberculosis, y tenía una prevalencia del virus de la artritis encefalitis caprina (AEC) inferior al 3\%. En los diferentes controles 
realizados para detectar micoplasmas, en muestras de leche individual y de tanque, los resultados siempre fueron negativos.

Los análisis de AEC en sangre se realizan anualmente, a todas las cabras de la explotación, en la Unidad de Análisis de Sanidad Animal de la Conselleria de Agricultura, Pesca y Alimentación de la Generalitat Valenciana. La técnica utilizada ha sido descrita en Martínez et al. (2008). Se emplea un ELISA indirecto siguiendo las recomendaciones del fabricante (ELISA VISNA-MAEDI/CAEV Serum Monocúpula, Pourquier $\left.{ }^{\circledR}\right)$. La lectura se efectúa con un espectrofotómetro Multiscan RC a $450 \mathrm{~nm}$. Se consideran positivos aquellos sueros cuya densidad óptica es superior al 120\% de la densidad óptica del control positivo.

De forma rutinaria se realizaban los siguientes tratamientos:

- Desparasitación de las cabras durante el periodo seco contra parásitos internos y externos.

- Vacunación contra clostridios durante la gestación, aproximadamente en el segundo tercio de la preñez. Las cabritas de reposición se vacunaron contra clostridios a los dos meses de edad y se repitió a los 21 días.

- Un mes antes del parto se aplicaba vitamina $\mathrm{AD}_{3} \mathrm{E}$ vía intramuscular $(2 \mathrm{ml}$ por animal).

\section{RUTINA Y MATERIAL DE ORDEÑO}

En todos los experimentos el ordeño se realizaba una vez al día (8:30 h.) siguiendo la rutina de apurado a máquina y retirada de pezoneras e inmersión de los pezones en yodo. La sala de ordeño utilizada era tipo "Casse" con dos plataformas de 12 plazas cada una, 6 unidades de ordeño en línea media $(2 \times 12 \times 6)$ y comedero autoblocante con entrada secuencial y tolvas para distribución automática del pienso (Figura 1). Existían tres pulsadores electrónicos ( 1 pulsador por cada dos juegos de ordeño) regulados a una frecuencia de pulsación de 90 p/min y una relación de pulsación de 60\%. El nivel de vacío utilizado para el ordeño, medido en la unidad final, era de $40 \mathrm{Kpa}$. Se utilizaron pezoneras con válvulas automáticas, pero se cortaba el vacío manualmente desde el colector antes de su retirada. 


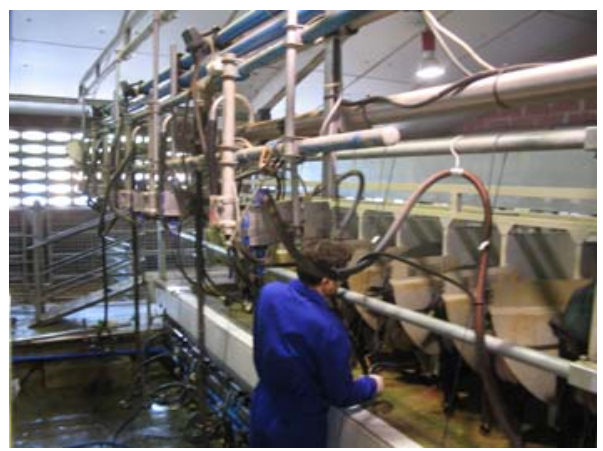

FIGURA 1. Máquina de ordeño utilizada en los distintos experimentos

\section{SINCRONIZACIÓN Y DETECCIÓN DE CELOS}

En el tercer estudio se llevó a cabo un tratamiento hormonal para provocar y sincronizar celos empleando el mismo protocolo que habitualmente utiliza AMURVAL para realizar la inseminación artificial en el ganado caprino. A las cabras se les aplicaban esponjas intravaginales impregnadas con $30 \mathrm{mg}$ de FGA (acetato de flugestona; Sincropart 30mg; Ceva Salud Animal, Barcelona) durante 11 días. Dos días (48 h) antes de la retirada de la esponja (día 9 después de la puesta) se inyectó intramuscularmente 300 UI de PMSG (Sincropart PMSG, Ceva Salud Animal) y 0,5 ml de Enzaprost (análogo sintético de la prostaglandina PGF2 $\alpha$; Ceva Salud Animal). La mayoría de las cabras deberían salir en celo a las $45 \pm 12$ horas tras la retirada de las esponjas.

La detección de celos se llevó a cabo trasladando cada cabra, individualmente, hasta un parque donde estaba un macho, considerando que la cabra estaba en celo si ésta aceptaba la monta. La detección de celos se llevó a cabo tres veces: a las 24, 36 y 48 horas de la retirada de las esponjas.

\section{VARIABLES MEDIDAS}

\subsection{PRODUCCIÓN DE LECHE}

La producción de leche se registró con medidores volumétricos de $3.500 \mathrm{ml}$ de capacidad graduados con una escala con divisiones de $50 \mathrm{ml}$ (Esneder Ref. 90001; Industrias Berango, S.L.) 


\subsection{TOMA DE MUESTRAS EN GRANJA}

Durante los experimentos se tomaban tres tipos de muestras de leche, siempre durante el momento en que se ordeñaba a los animales:

a) Muestras de primeros chorros por glándula. Antes de la puesta de pezoneras se recogían, mediante ordeño manual, unos $40 \mathrm{ml}$ de leche de cada pezón en frascos de polipropileno de $50 \mathrm{ml}$ de capacidad y con cierre hermético. Estas muestras se utilizaban exclusivamente para determinar el RCS por glándula.

b) Muestras del control lechero. A partir de la leche total ordeñada de cada animal, y tras la mezcla de la leche, se recogía una muestra de unos $40 \mathrm{ml}$ en el mismo tipo de frascos descritos anteriormente. En estas muestras se determinaba el RCS y la composición de la leche.

c) Muestras para el análisis bacteriológico por glándula. Se tomaban antes del ordeño. Para ello, primero se limpiaba el extremo del pezón con algodón empapado en alcohol etílico al $70 \%$. A continuación se eliminaban los primeros chorros y se recogían unos $3 \mathrm{ml}$ de leche en tubos estériles de cristal de $10 \mathrm{ml}$, claramente identificados y provistos de un tapón metálico estéril (Figura 3).

En el Estudio 4 se recogía diariamente, siempre a la misma hora (13:00h), una muestra de sangre de unos $3.5 \mathrm{ml}$ de cada animal. Las muestras se tomaban de la vena yugular, con jeringuillas de plástico esteriles, y se trasvasaban a tubos de vidrio estériles de $4.5 \mathrm{ml}$ que contenían anticoagulante $(54 \mu 1$ de $15 \%$ de solución EDTA).

Todas las muestras de leche y sangre permanecían en refrigeración $\left(4^{\circ} \mathrm{C}\right)$ hasta que fueron procesadas y/o analizadas en el laboratorio.

\subsection{ANÁLISIS DE LA LECHE}

Los análisis de células somáticas y composición de la leche fueron realizados en el Laboratori Interprofessional Lleter de la Comunitat Valenciana (LICOVAL). 
El recuento de células somáticas (RCS) se determinó por el método fluoro-optoelectrónico (ISO/FIL, 2008) utilizando el equipo Fossomatic 5000 (Foss-Electric S.A.; Figura 2a). Este realiza el recuento por citometria de flujo, mediante un microscopio de fluorescencia, a través del cual realiza el recuento de los núcleos de las células somáticas que previamente han sido marcadas con un colorante fluorescente (bromuro de etidio). Diariamente se contrastaban las lecturas del equipo con patrones de leche de vaca adquiridos en el laboratorio de CECALAIT (Poligny; Francia)

Las muestras permanecieron en refrigeración, sin conservante, analizándose el RCS entre las 24 y 48 tras su recogida. Inmediatamente antes del análisis, las muestras se calentaban en baño María a $40{ }^{\circ} \mathrm{C}$ y se homogenizaba la leche antes de introducir la muestra en el equipo.

La composición de la leche (grasa, proteína, lactosa y materia seca) se determinó por espectroscopia del infrarrojo medio (Milko Scan FT120, Foss Electric S.A.; Figura 2B). De forma periódica los valores obtenidos por medio del equipo se contrastaban y corregían, si era el caso, a partir de los resultados obtenidos con los siguientes métodos manuales:

- Materia Grasa (MG): Método Gerber (FIL, 1981) expresado en \% P/P

- Proteína Bruta (PB): Método Kjeldahl (ISO, 2002) expresado en \% P/P

- Materia Seca (MS): Método directo de evaporación, desecando la muestra en estufa a una temperatura de $102 \pm 2{ }^{\circ} \mathrm{C}$ (FIL, 1987)

- Lactosa (L): Estimación por diferencia (L= MS-MG-P-0.90).

El análisis bacteriológico se llevó a cabo antes de haber transcurrido $24 \mathrm{~h}$ de la recogida de las muestras. Para ello, se sembraron $20 \mu 1$ de leche de cada glándula en placas Petri en un medio de agar-sangre (Trypticasa soja suplementado con 5\% de sangre de carnero: Lab. Bio-Mèrieux). En cada placa se sembraban, por separado, las 4 muestras correspondientes a las cuatro glándulas de dos cabras. La incubación se efectuó a $37{ }^{\circ} \mathrm{C}$ durante 5 días, realizándose las lecturas en los días 1, 2, 3 y 5 post-inoculación. 

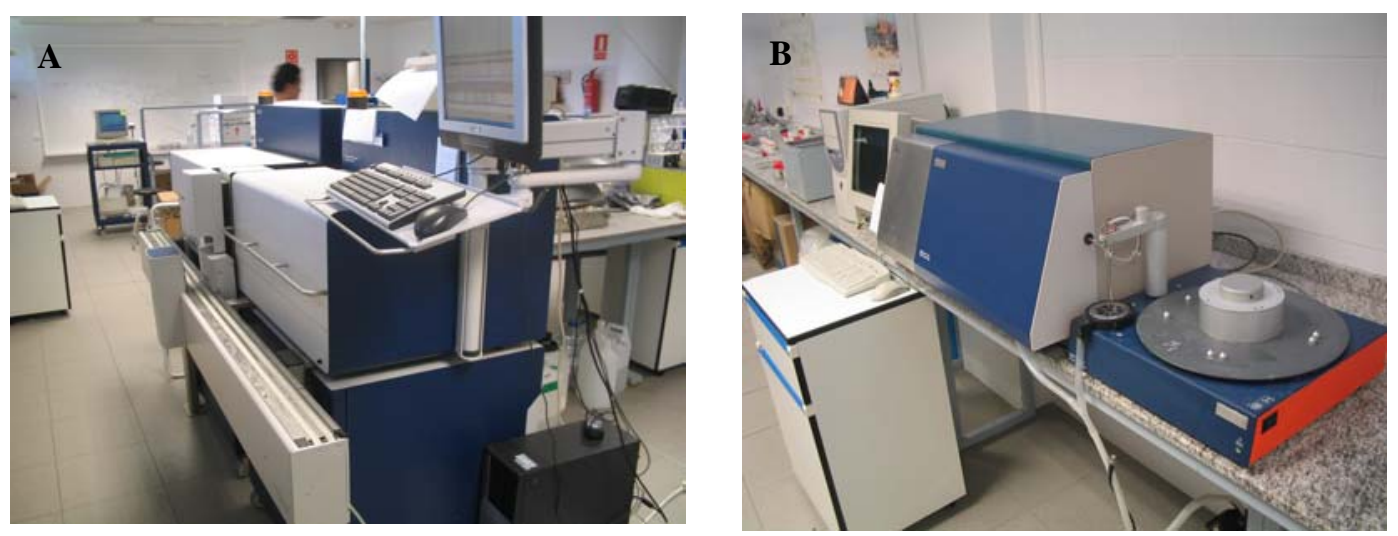

FIGURA 2. Equipos utilizados para el análisis del RCS (A-Fossomatic 5000) y la composición de la leche (B-MilkoScan FT 120)

Una muestra se consideró positiva cuando presentaba, al menos, $250 \mathrm{ufc} / \mathrm{ml}$, esto es, 5 colonias identificables en el cultivo. En el caso de $S$. aureus se consideró un aislamiento positivo a partir de 1 ufc en la muestra sembrada (Marco, 1994). Se consideró que una glándula estaba infectada cuando los resultados de dos muestreos consecutivos ofrecieron cultivos positivos.

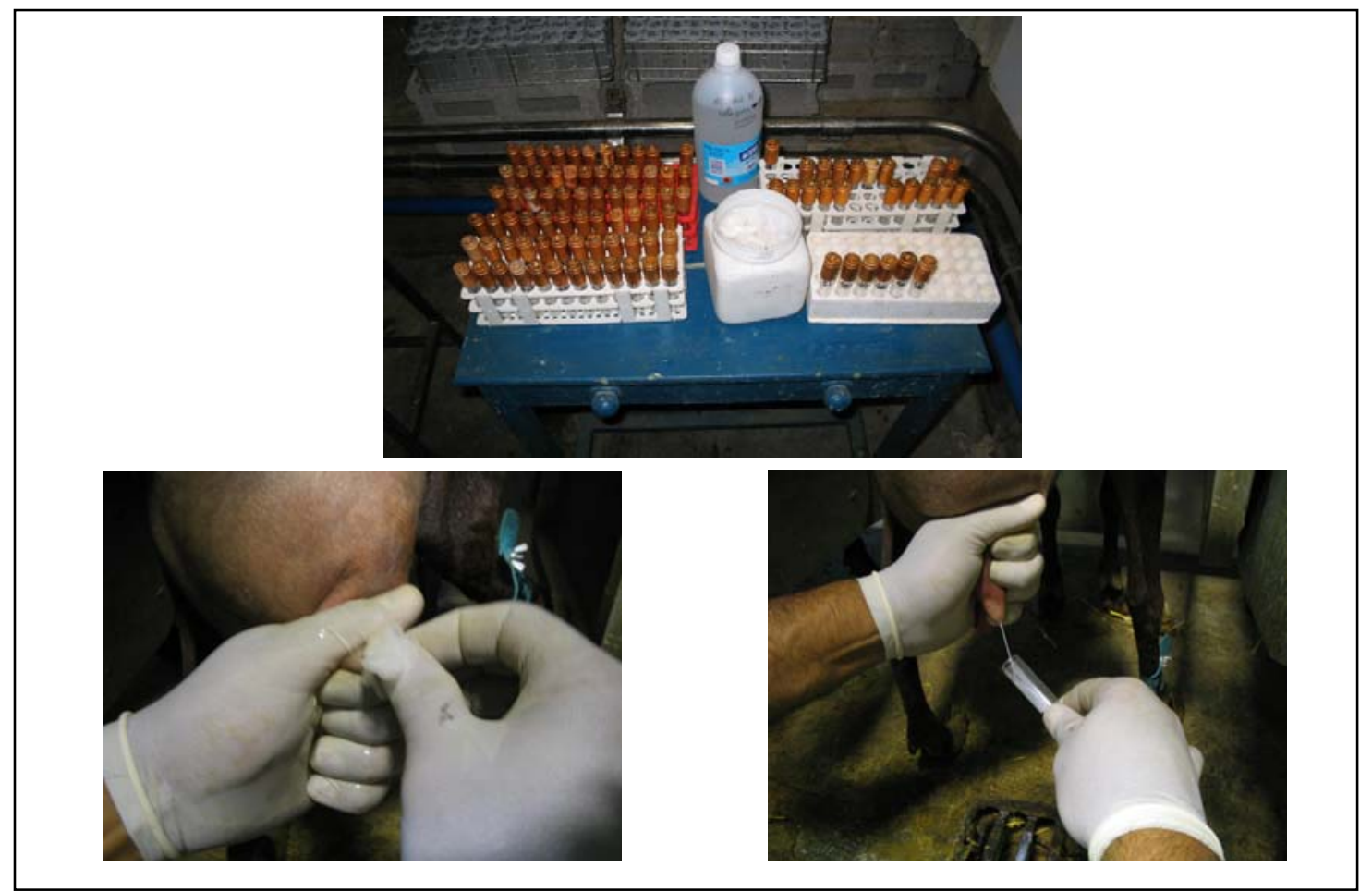

FIGURA 3. Material y procedimiento en la toma de muestras para el análisis bacteriológico 


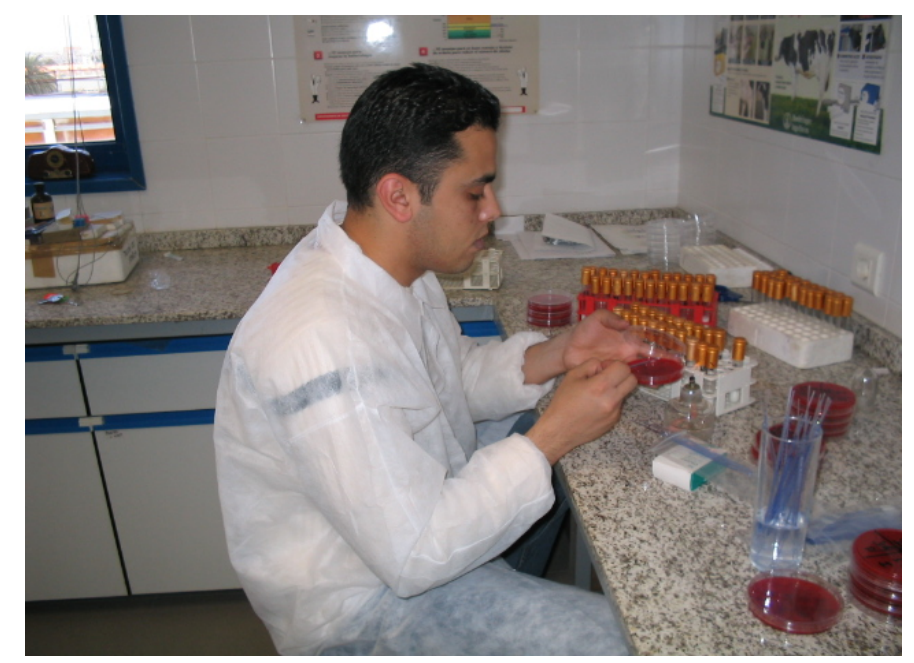

FIGURA 4 Siembra en placas de agar- sangre

Los criterios considerados en el laboratorio para la interpretación de los análisis bacteriológicos, descritos a continuación, estaban basados en las recomendaciones de Marco (1994) y del Nacional Mastitis Council (Harmon et al., 1990). Las pruebas preliminares consistieron en la anotación, durante las sucesivas lecturas, del aspecto de los cultivos, de su velocidad de crecimiento, su densidad y los rasgos fenotípicos de las colonias, especialmente los relativos a morfología, tamaño y presencia de hemólisis. En cualquiera de los casos, a las 48 horas se efectuó la tinción de Gram de todos los microorganismos aislados, junto con los ensayos preliminares de catalasa y oxidasa, en aquellas colonias de morfología compatible con microorganismos Gram+ y Gram-, respectivamente.

En el caso de los cocos Gram+ y catalasa + se realizaron rutinariamente las pruebas preliminares de coagulasa y de aglutinación rápida con partículas de latex coloreadas (Lab. Bio-Mèrieux), con el objeto de separar el $S$. aureus de los estafilococos coagulasa negativos. Los cocos Gram + y catalasa - fueron considerados como estreptococos spp. Los cocobacilos Gram+, pleomorficos, no esporulados y aerobios que no dieron lugar a colonias visibles a $24 \mathrm{~h}$ y si a $48 \mathrm{~h}$, fueron considerados como Corynebacterium spp. De cada una de las glándulas infectadas se conservaron al menos 3 de los aislamientos llevados a cabo a lo largo de los distintos controles en que permanecieron infectadas. La conservación se realizó bajo congelación $\left(-20^{\circ} \mathrm{C}\right)$ en leche desnatada estéril con un $20 \%$ de glicerol (Harmon et al., 1990; Figura 5). De este modo queda abierta la posibilidad de que, en un futuro, se pueda realizar la identificación de la especie. 

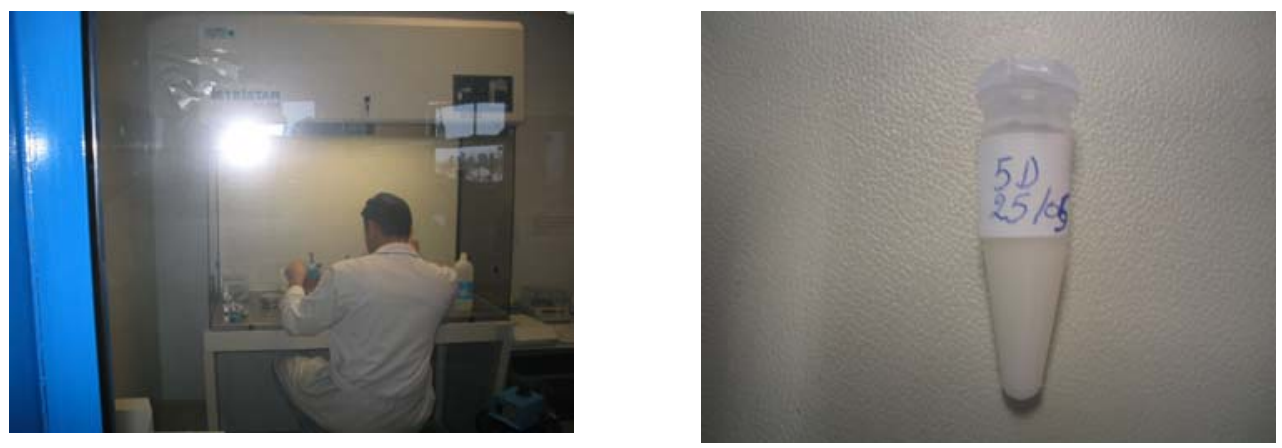

FIGURA 5. Conservación de gérmenes aislados

El análisis de micoplasmas fue realizado en el Laboratorio NEIKER (Derio, Vizcaya). Anualmente se tomaban varias muestras de leche de tanque y de leche individual de aquellas cabras que, siendo sistemáticamente negativas a los análisis bacteriológicos, presentaban elevados recuentos (más de 1 millón de células/ml). Las muestras fueron mantenidas en congelación $\left(-40^{\circ} \mathrm{C}\right)$ hasta el momento en que fueron remitidas, mediante transporte urgente refrigerado, al citado laboratorio.

La metodología empleada consiste en el aislamiento de microorganismos del genero Mycoplasma spp (anteriormente denominados microorganismos tipo pleuroneumonía) empleando un caldo de enriquecimiento (caldo PPLO) y un medio de cultivo selectivo sólido (agar PPLO). Se inoculan $20 \mu 1$ de leche en un caldo PPLO y otros $20 \mu 1$ se siembran en una placa de agar PPLPO por agotamiento. Las placas y los caldos se incuban a $37^{\circ} \mathrm{C}$ en atmósfera enriquecida con $\mathrm{CO}_{2}$ al $7 \%$ durante un periodo de 72 horas. Transcurrido este tiempo, con la ayuda de una lupa, se visualizan las placas de agar PPLO para detectar las posibles colonias de Mycoplasma spp, y se resiembran por agotamiento nuevas placas de agar PPLO con $20 \mu 1$ de los caldos de PPLO inoculados. Se incuban de nuevo las placas de agar PPLO (las iniciales y las inoculadas con los caldos) a $37^{\circ} \mathrm{C} \mathrm{y} \mathrm{en}$ atmósfera enriquecida con $\mathrm{CO} 2$ al 7\% hasta un máximo de siete días

\subsection{RECUENTO DE LEUCOCITOS POLIMORFONULECARES NEUTROFILOS}

El recuento se llevó a cabo en las muestras de leche de primeros chorros tomadas por glándula (apartado 4.2.). 
La preparación y procesado previo de las muestras para la tinción se llevó a cabo siguiendo el protocolo utilizado por el equipo del profesor A. Contreras, de la Universidad de Murcia (Sierra et al., 1999 ; comunicación personal). El procedimiento fue el siguiente:

- Inmediatamente tras la recogida de las muestras se añadían $6 \mathrm{ml}$ de leche a un tubo de $15 \mathrm{ml}$ de capacidad que contenía $4 \mathrm{ml}$ de formol tamponado al 10\%. Esto permitía la fijación de las células somáticas.

- Estos tubos fueron mantenidos en refrigeración $\left(4^{\circ} \mathrm{C}\right)$ hasta el procesado (4-6 horas desde la recogida de las muestras)

- Los tubos fueron centrifugados a $180 \mathrm{xG}(1300 \mathrm{rpm})$ durante 10 minutos a $5^{\circ} \mathrm{C}$.

- La grasa se retiraba con una espátula y una torunda de algodón $y, a$ continuación, se eliminaba el sobrenadante, hasta dejar aproximadamente 0.5 $\mathrm{ml}$ de éste.

- En función del RCS de la muestra (habían sido analizadas anteriormente con el Fossomatic 5000) se añadía un volumen entre 1 y $13 \mathrm{ml}$ de formol tamponado al 3\%, de acuerdo a la siguiente tabla:

\begin{tabular}{|l|l|}
\hline $\begin{array}{l}\text { RCS } \\
(\mathrm{x} 1000 \text { cels/ml })\end{array}$ & $\begin{array}{l}\text { Formol 3\% } \\
(\mathrm{ml})\end{array}$ \\
\hline$<100$ & 1 \\
\hline $100-200$ & 2 \\
\hline $200-300$ & 3 \\
\hline $300-400$ & 4 \\
\hline $400-600$ & 5 \\
\hline $600-800$ & 6 \\
\hline $800-900$ & 7 \\
\hline $900-1000$ & 8 \\
\hline $1000-1500$ & 9 \\
\hline $1500-2000$ & 10 \\
\hline $2000-5000$ & 11 \\
\hline $5000-10000$ & 12 \\
\hline$>10000$ & 13 \\
\hline
\end{tabular}

- Una vez homogeneizado el contenido del tubo, con una micropipeta se depositaban $0.1 \mathrm{ml}$ de muestra en la cámara de una citospina ( Shadon Cytospin 
3, con 12 cámaras; Figura 6) y fue centrifugada durante 10 minutos a $225 \mathrm{~g}$ (1500 rpm). Bajo la cámara se situaba un papel de filtro con un orificio y bajo el papel se ubicaba un portaobjetos. Tras la centrifugación, las células somáticas se adhieren a la superficie del portaobjetos que no está cubierta por papel de filtro (orificio), mientras que el sobrenadante es absorbido por el papel de filtro.

- Los portaobjetos se dejaban secar unas $12 \mathrm{~h}$ a temperatura ambiente (toda la noche)

La tinción de las muestras se realizó con el colorante verde metilo y-pironina de acuerdo al procedimiento descrito por Paape et al. (2001):

- Los portaobjetos se sumergían en la solución de fijador de Carnoy durante 10 min

- 2 minutos en etanol al 50\%

- 2 minutos en etanol al $30 \%$

- 2 minutos en agua destilada

- 6 minutos en la solución colorante verde metilo y-pironina (este colorante debe estar tapado, ya que es sensible a la luz)

- Lavado durante 20 minutos n-butanol y luego otro lavado de 3 minutos

- Lavar dos veces con xilol durante 10 minutos.

- Se montaba con un cubreobjetos y una gota de un medio de montaje (Clarion Mounting Medium)

- Se dejaba secar protegido de la luz.

Las preparaciones fueron observadas al microscopio (ocular 10X, objetivo de inmersión en aceite 100X) que estaba conectado, a través de una cámara de video, a una pantalla de ordenador. Para facilitar el recuento, en la pantalla existía una cuadricula que dividía cada campo en 4 cuadrantes. Se contaron las primeras 200 células encontradas al azar identificando si eran o no polimorfonucleares (núcleos segmentados) de acuerdo a Sarikaya et al. (2004) 


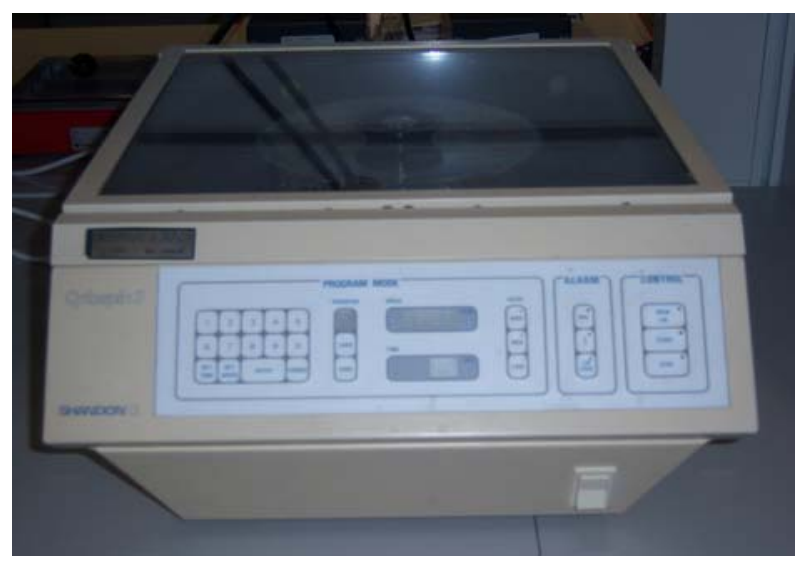

FIGURA 6. Citospina ( Shadon Cytospin)

\subsection{CORTISOL}

Las muestras de sangre fueron centrigudas a $1500 \mathrm{G}$ (3500 rpm) durante 20 minutos. A continuación el plasma fue transferido con una micropipeta a tubos eppendorf $(0,9 \mathrm{ml} /$ muestra $)$, los cuales fueron congelados a $-40^{\circ} \mathrm{C}$ hasta su análisis.

La concentración de cortisol en plasma fue analizado en el Departamento de Fisiología Animal de la Facultad de Veterinaria de la Universidad Complutense de Madrid Las muestras fueron remitidas al citado laboratorio en transporte urgente, en paquete isotermo y con placas de hielo. Se utilizó la técnica de Ensayo Immuno-Enzimático (Enzyme Inmuno Assay -EIA) de competición (Munro y Lasley, 1988), cuya descripción detallada puede consultarse en el Anejo 1 de este apartado. Los análisis fueron realizados por duplicado, expresando los resultados en ng de cortisol $/ \mathrm{ml}$

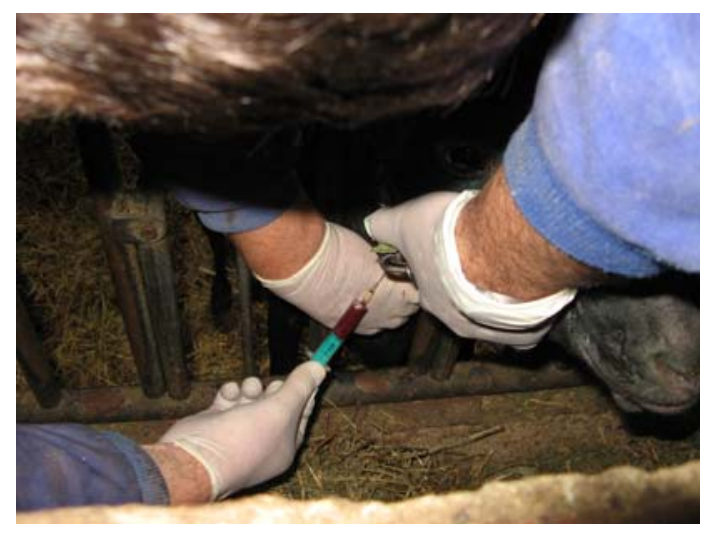

FIGURA 7. Extracción de sangre para las muestras del cortisol 


\section{BIBLIOGRAFIA}

ISO/IDF. (2008) Milk - Enumeration of somatic cells. - Part 2: Guidance on the operation of fluoro-opto-electronic counters. ISO 13366-2 .IDF 148-2

MARCO J.C. (1994). Mastitis en la oveja Latxa: epidemiologia diagnostico y control. Tesis doctoral. Universidad de Zaragoza, 398 pp.

MARTINEZ, B.; HERNANDEZ, E.; VIDAL, G.; VIVIANA, J.; PERIS, C.; GOMEZ,E. (2008). Análisis de la pérdida de información en el esquema de mejora genética de caprino Murciano-Granadina. XXXIII Jornadas Científicas Internacionales de Ovinotecnia y Caprinotecnia, (SEOC) Almería. 541-545.

MUNRO, C.J.; LASLEY, B.L.; (1988). Non-radiometric methods for immunoassay of steroid hormones. In: B.D. Albertson and F.P. Haseltine, Editors, Non-radiometric Assays: Technology and Application in Polypeptide and Steroid Hormone Detection, Alan R. Liss, Inc, cop., New York. p. 289-329.

PAAPE, M.J.; POUTREL, B.; CONTRERAS, A.; MARCO, J.C.; CAPUCO; A.V. (2001). Milk somatic cells and lactation in small ruminant's .Journal of Dairy Science 84 (E.suppl) E: 237-E244.

HARMON R.J., JASPER D.E., LANGLOIS B.E., WILSON R.A. (1990). Microbiological procedures for the diagnosis of bovine udder infection. Ed. National mastitis Council, inc., 1840 Wilson Boulevard . Arlington VA 22201: 33.

SARIKAYA, H.; PRGOMET, C.; PFAFFL, M.W.; BRUCKMAIER, R.M.; (2004)

Differentiation of leukocytes in bovine milk. Milchwissenschaft. (Journal of Nutrition Research and Food Science. 59 586-589 


\section{ANEJO 1 \\ DETERMINACIÓN DE LA CONCENTRACION DE CORTISOL POR EIA DE COMPETICIÓN EN SUERO DE CABRA.}

\section{Fundamento de la Técnica EIA de Competición}

La técnica EIA (Enzyme Inmuno Assay) de competición, es un método inmunológico de determinación hormonal que, se basa en la competición que se establece entre la hormona sin marcar (problema o estándar) y la hormona marcada con una enzima, por unirse a los sitios de unión de un anticuerpo que se ha fijado previamente a una fase sólida (microplaca de poliestireno). A continuación se mide la fracción unida al anticuerpo mediante la reacción del sustrato con la enzima, lo cuál se traduce en una reacción de oxidación con un cromógeno que lleva incorporado el sustrato, produciéndose una reacción coloreada. Posteriormente se lee la absorbancia del color desarrollado el cual será inversamente proporcional a la cantidad de hormona marcada que se ha unido al anticuerpo.

\section{MATERIALES Y REACTIVOS UTILIZADOS}

\section{Material:}

- Microplacas de poliestireno de 96 pocillos con fondo plano y con una capacidad $350 \mu 1$ por pocillo (Dynatech).

- Puntas desechables, para pipetas Eppendorf, de 10-200 $\mu 1$ y de 100-1000 $\mu 1$ (Comfortips, Eppendorf).

- Puntas de pipeta multicanal, 25-250 $\mu 1$ (Costar).

- Pipetas automáticas Eppendorf(Merck) de 10-100 $\mu 1$ y 100-1000 $\mu 1$.

- Pipeta multicanal de ocho canales, de 50-250 $\mu 1$ (Costar).

- Agitador (Vórtex) Reax 2.000 (Heindolph).

- Pipetas de cristal de doble enrase de 5 y $10 \mathrm{ml}$ (Protón).

- Selladores adhesivos de acetato para placas (ICN Biomedical Inc.).

- Tubos de ensayo de cristal de 16 x 100 mm (Corning). 
- Lector automático de placas (Bio-Tek Instruments).

\section{Reactivos:}

- Anticuerpos policlonales obtenidos y caracterizados en el Departamento de Fisiología Animal (Facultad de Veterinaria. U.C.M.): anti-cortisol.

- Conjugados hormona-peroxidasa, preparados y caracterizados en el Departamento de Fisiología Animal (Facultad de Veterinaria, U.C.M.) para cortisol.

- Hormona estándar (Steraloids Inc., N.H. USA): cortisol

- Tetrametilbenzidina Substrato K: TMB (Vitaltech).

\section{Soluciones Tampón:}

- Solución de tapizado: Carbonato-Bicarbonato: $\mathrm{pH}$ : 9,6.

- Solución Tampón EIA: pH: 7,0.

- Solución de Lavado

- Solución de Frenado: Ácido sulfúrico al 10\%

\section{CONDICIONES DEL ENSAYO}

Fase sólida: microplacas de poliestiereno de 96 pocillos y fondo plano con selladores de acetato.

\section{Condiciones de incubación:}

- Inmovilización del anticuerpo a la fase sólida: 16 horas a $4^{\circ} \mathrm{C}$.

- Reacción de competición: 2 horas a temperatura ambiente.

- Hidrólisis del sustrato: 15 minutos, en oscuridad, a temperatura ambiente.

\section{Desarrollo de la Técnica EIA de Competición}

Comprende las siguientes etapas:

\section{a) Tratamiento de las muestras:}

Para la determinación de cortisol se precisó de una extracción previa de la muestra de suero con etanol absoluto.

Se extraen $50 \mu \mathrm{l}$ de muestra en $1 \mathrm{ml}$ de etanol absoluto. Se mezclan en un vórtex durante 40 segundos y se centrífuga a 2,200 rpm durante 30 minutos. La hormona queda solubilizada en el sobrenadante, se toman $100 \mu 1$ de éste, que se introduce en otro tubo, evaporándose el solvente bajo una corriente continua de nitrógeno. 
Tapizado de los Anticuerpos a la Fase Sólida:

Diluimos el anticuerpo en tampón carbonato/bicarbonato hasta llegar a la dilución correspondiente (1/4000). A continuación se tapizan los pocillos con $100 \mu 1$ de la dilución excepto el pocillo A1 que se deja como blanco.

Se sellan las placas y se incuban a $4{ }^{\circ} \mathrm{C}$ durante 16 horas.

Seguidamente, la placa se lava tres veces con solución de lavado ( $200 \mu 1$ por pocillo) para eliminar el exceso de anticuerpo que no se ha fijado a la placa y se seca enérgicamente mediante volteo, en papel de filtro.

\section{Reacción de Competición:}

La reacción se produce entre la hormona libre, ya sea de la muestra ó estándar, y la hormona conjugada a la enzima.

Se diluye el conjugado en solución tampón EIA hasta 1/40.000. A continuación se procede a diluir las muestras /estándar o problema) en $150 \mu 1$ de la dilución de conjugado y se homogeniza cuidadosamente mediante un vórtex. Se utilizan $50 \mu 1$ de esta mezcla, junto con $50 \mu \mathrm{l}$ de tampón EIA para tapizar los pocillos de la placa de poliestireno.

La curva estándar cubre un rango de $1 \mathrm{pg} /$ pocillo a $1 \mathrm{ng} /$ pocillo. Se preparan 10 estándares que se diluyen en $150 \mu \mathrm{l}$ de la solución de conjugado. Se utilizan $50 \mu 1$ de esta mezcla junto con $50 \mu 1$ de tampón EIA para tapizar los pocillos de la placa de poliestireno. Las muestras estándar y problema se determinan por duplicado

Las placas se sellan, incubándose durante un período de dos horas a temperatura ambiente.

A continuación se vuelca el contenido de las placas y se realiza un lavado con 200 $\mu 1$ de solución de lavado por pocillo (tres veces) con el fin de eliminar el exceso de reactivos.

En todos los pocillos de la placa se añaden $100 \mu$ de TMB, se sella y se incuba 15 minutos a temperatura ambiente. 
Tras el tiempo necesario para que se desarrolle el color del cromógeno, se frena la reacción añadiendo $100 \mu 1$ de solución de frenado.

Lectura de las Placas:

Una vez frenada la reacción del sustrato, se procede a la lectura de la densidad óptica del color desarrollado. Para ello empleamos un lector automático EIA (Bio-Tek), el cual mediante filtros de 450 y $600 \mathrm{~nm}$, realiza una lectura bicromática eliminando el color producido por una posible reacción inespecífica de fondo.

Procesado de los Resultados: los resultados obtenidos se procesan mediante un software especial (ELISA AIDS, Eurogenetics). Los resultados hormonales se expresan en ng/m

\section{Parámetros de validación de la técnica EIA de cortisol en suero.}

- Límite de detección: 30 pg/ml.

- Porcentaje de recuperación (recovery): 95\%.

-CV intra-análsis: concentraciones altas de cortisol: 5,7\% concentraciones bajas de cortisol: $6,63 \%$

- CV inter-análisis: concentraciones altas de cortisol: 8,92\% concentraciones bajas de cortisol: 9,93\%

- Reacciones cruzadas del anticuerpo policlonal C1098:

- Cortisol: $100 \%$

- Prednisolona: $15,71 \%$

- Prednisona: 18,9

- Cortisona: 10,8

- Corticosterona: 6,4

- 11-Deoxycortisol: 40,31

- 21-Deoxycortisol: 5,31

- Dexametasona: $<0,1$ 
IV. PRIMER ESTUDIO

EFECTO DEL TIPO DE MUESTRA (PRIMEROS CHORROS VS CONTROL LECHERO) SOBRE EL RCS EN LA LECHE DE CABRA 


\section{PRIMER ESTUDIO}

\section{EFECTO DEL TIPO DE MUESTRA (PRIMEROS CHORROS VS CONTROL LECHERO) SOBRE EL RCS EN LA LECHE DE CABRA}

\section{INTRODUCCIÓN}

En el ganado caprino las infecciones intramamarias (IIM) suelen ser de carácter unilateral (Contreras et al., 1995), de forma que en la glándula afectada se produce una inflamación local y una elevación del RCS respecto a la glándula colateral. En las IIM bilaterales, menos frecuentes, el RCS se eleva en ambas glándulas, pero no suele ser de forma paralela, especialmente cuando los gérmenes involucrados son diferentes.

Por el contrario, los factores no infecciosos deberían tener un efecto sobre el total de la ubre, de modo que sería esperable que afecten de igual forma al RCS de ambas glándulas. De hecho, algunos autores sugieren que para identificar los factores de naturaleza no infecciosa que influyen sobre el RCS es necesario, además de realizar los análisis bacteriológicos oportunos, confirmar que el RCS aumenta de forma similar en ambas glándulas (Bergonier et al., 1996).

El registro del RCS a nivel de glándula es un proceso costoso, ya que es necesario ordeñar por separado a las dos glándulas de cada animal. Por este motivo, en ocasiones, el RCS a nivel de glándula se ha estimado a partir de muestras de los primeros chorros (20-30 ml) recogidos mediante ordeño manual inmediatamente antes de iniciar el ordeño a máquina (Contreras et al., 1996; Martínez, 2000; Leitner et al., 2001; Moroni et al., 2005). Sin embargo, trabajos previos realizados en ganado vacuno (Berning et al., 1987; Sarikaya et al., 2005), ovino (Peris et al., 1991; Gonzalo et al., 1993) y caprino (Contreras et al., 1997; Martínez, 2000; Haenlein, 2002) indican que el RCS varía con la fracción tomada en el ordeño, de forma que los recuentos tienden a aumentar a medida que se extraen las últimas fracciones de leche de la ubre. 
Una particularidad del ganado caprino es que suele presentar bruscas elevaciones transitorias del RCS, aparentemente de naturaleza no infecciosa. Esto se ha observado en varios trabajos en los que se realizaban recuentos con periodicidad diaria (Randy et al., 1988; Zeng et al., 1997), semanal (Pettersen, 1981) o mensual (Martínez, 2000). Algunos de los factores causantes de estas elevaciones transitorias del RCS son el celo (McDougall y Voermans, 2002; Moroni et al., 2007) o ciertas prácticas de manejo que podrían generar estrés en los animales (Paape et al., 2001).

El objetivo de este estudio ha sido el de comparar el RCS obtenido en las muestras de primeros chorros de glándula con las muestras del control lechero (leche total ordeñada de la ubre), para verificar si en las muestras de primeros chorros también se manifiestan las elevaciones transitorias del RCS de naturaleza no infecciosa.

\section{MATERIAL Y MÉTODOS}

Este trabajo se llevó a cabo en la granja experimental de pequeños rumiantes del Institut de Ciència i Tecnologia Animal de la Universitat Politècnica de València. Se utilizaron 22 cabras de raza Murciano Granadina (7, 12 y 3 animales de $1^{\mathrm{a}}, 2^{\mathrm{a}}$ y $\geq 3^{\mathrm{a}}$ lactación, respectivamente), inicialmente libres de IIM, que se encontraban entre el segundo y tercer mes de lactación. Todos los animales eran ordeñados una vez al día con una rutina que incluía el apurado a máquina y la inmersión de los pezones en yodo tras la retirada de las pezoneras.

Durante 12 semanas consecutivas se controló, semanalmente, el RCS por glándula y por ubre. Las muestras de leche por glándula fueron recogidas mediante ordeño manual, inmediatamente antes de la puesta de las pezoneras. Las muestras por ubre procedían de la leche total ordeñada de cada animal, y se tomaron directamente de los medidores volumétricos, tras la mezcla de la leche. Además, también se llevó a cabo semanalmente un análisis bacteriológico de cada glándula. Dado que 3 cabras ( 2 de segunda lactación y 1 de tercera o superior lactación) se infectaron a lo largo del experimento, en los resultados tan solo se tuvieron en cuenta los registros de 19 cabras. 
Las muestras de leche por glándula y ubre, todas de $30-40 \mathrm{ml}$, se recogieron en frascos de $50 \mathrm{ml}$ de polipropileno y permanecieron en refrigeración $\left(4^{\circ} \mathrm{C}\right)$ entre 24 y 48 $\mathrm{h}$ hasta que fueron analizadas en el laboratorio. El RCS se determinó mediante el método Fluoro-opto-electrónico (Fossomatic 5000; Foss-Electric S.A; ISO/IDF, 2008.) Las muestras para el análisis bacteriológico se tomaron por glándula antes del ordeño. Para ello, se limpiaba el extremo del pezón con algodón empapado con alcohol etílico al 70\%, se eliminaban los primeros chorros y se recogían unos $3 \mathrm{ml}$ de leche en tubos estériles de cristal de $10 \mathrm{ml}$, provistos de tapón. Estas muestras permanecieron en refrigeración $\left(4^{\circ} \mathrm{C}\right)$ un máximo de $24 \mathrm{~h}$ realizándose el análisis de acuerdo a la metodología descrita en Materiales y Métodos Generales.

\subsection{Análisis estadístico}

El RCS fue analizado en $\log _{10}$, con objeto de normalizar su distribución (Ali y Shook, 1980). El efecto del tipo de muestra de leche utilizada para analizar el RCS (antes del ordeño en glándula derecha -AOD- o glándula izquierda -AOI- y leche total ordeñada -LT) fue analizado estadísticamente con el siguiente modelo:

$$
Y_{i j k l}=\mu+N L_{i}+C_{a b}\left(N L_{i}\right)+M_{k}+D_{1}+M_{k} * N L_{i}+M_{k} * D_{1}+N L_{i}^{*} D_{1}+e_{i j k l}
$$

Siendo:

$\mathrm{Y}_{\mathrm{ijkl}}=\log _{10} \mathrm{RCS}$

$\mathrm{NL}_{\mathrm{i}}=$ efecto fijo del número de lactación i ( 1 y $\geq 2$ )

$\operatorname{Cab}_{j}\left(N_{i}\right)=$ efecto aleatorio de la Cabra $\mathrm{j}(\mathrm{j}=19)$, jerarquizado dentro del NLi

$\mathrm{M}_{\mathrm{k}}=$ efecto fijo del tipo de muestra (AOD, AOI y LT)

$\mathrm{Dl}=$ efecto fijo del día del control (l=1 a 12)

$\mathrm{M}_{\mathrm{k}} * \mathrm{NL}_{\mathrm{i}}=$ efecto fijo de la interacción tipo de muestra $\mathrm{x} \mathrm{n}^{\mathrm{o}}$ de lactación

$\mathrm{M}_{\mathrm{k}}{ }^{*} \mathrm{D}_{\mathrm{l}}=$ efecto fijo de la interacción tipo de muestra $\mathrm{x}$ día del control

$\mathrm{NL}_{\mathrm{i}} * \mathrm{Dl}=$ efecto fijo de la interacción número de lactación $\mathrm{x}$ día de lactación

$\mathrm{e}_{\mathrm{ijkl}}=$ efecto aleatorio del error residual

Este análisis estadístico se llevó a cabo mediante el PROC MIXED del SAS (SAS, 2008), de acuerdo a Littell et al. (1998). También se utilizó el PROC CORR del 
mismo paquete estadístico para calcular las correlaciones del RCS entre los diferentes tipos de muestras.

\section{RESULTADOS Y DISCUSIÓN}

El tipo de muestra (M) afectó significativamente al RCS $(\mathrm{P}<0.001$; Tabla 1), de modo que las muestras de la leche total ordeñada (LT) tuvieron recuentos significativamente superiores respecto a las muestras de la glándula derecha e izquierda tomadas antes del ordeño (AOD y AOI). Sin embargo las diferencias obtenidas no fueron elevadas tanto al considerar las medias aritméticas $\left(\mathrm{RCS}_{\mathrm{AOD}}=576 \times 10^{3}\right.$ y $\mathrm{RCS}_{\mathrm{AOI}}=$ $586 \times 10^{3}$ vs $\mathrm{RCS}_{\mathrm{LT}}=659 \times 10^{3}$ céls $\left./ \mathrm{ml}\right)$ como las medias geométricas $\left(219 \times 10^{3}\right.$ y $224 \times 10^{3}$ vs $331 \times 10^{3}$ céls $/ \mathrm{ml}$; Tabla 1$)$. Por otra parte, las interacciones $M^{*}$ Número de Lactación y M*Día de control no resultaron significativas. Además, los tres tipos de muestras presentaron elevados coeficientes de correlación entre si, siendo siempre superiores a 0.92 (Tabla 2).

TABLA 1 . Comparación del RCS (céls/ml) en muestras tomadas por glándula antes del ordeño (AOD y AOI) y de la leche total ordeñada (LT) en 19 cabras libres de IIM que fueron controladas semanalmente durante 12 semanas.

\begin{tabular}{|c|c|c|c|c|c|}
\hline \multirow{2}{*}{ Muestra } & \multirow{2}{*}{$\mathrm{N}^{\mathrm{o}}$} & \multirow{2}{*}{$\mathrm{N}^{\mathrm{o}}$} & \multicolumn{2}{|c|}{$\mathrm{RCS}(\mathrm{x} \mathrm{10})$} & \multirow{2}{*}{$\begin{array}{l}\text { Log RCS } \\
(\mathrm{m} \pm \mathrm{ES})\end{array}$} \\
\cline { 4 - 6 } & De cabras & de controles & $\mathrm{MA} \pm \mathrm{DS}$ & $\mathrm{MG}$ & \\
\hline AOD & 19 & 216 & $576 \pm 1199$ & 219 & $5.34 \pm 0.08^{\mathbf{a}}$ \\
\hline AOI & 19 & 216 & $586 \pm 1170$ & 224 & $5.35 \pm 0.08^{\mathbf{a}}$ \\
\hline LT & 19 & 216 & $659 \pm 1075$ & 331 & $5.52 \pm 0.08^{\mathbf{b}}$ \\
\hline Niv.Sig & - & - & - & - & $* * *$ \\
\hline
\end{tabular}

AOD y AOI : muestras de primeros chorros tomadas antes del ordeño de la glándula derecha e izquierda, respectivamente

LT: muestras de la leche total ordeñada de cada animal (control lechero).

MA: media aritmética. MG: media geométrica. DS :desviación estándar. ES : error estándar.

En la Figura 1 se representa la evolución de las medias aritméticas (Figura 1.a) y geométricas (Figura 1.b) del RCS en las muestras AO (media de las dos glándulas) y LT en los 12 controles realizados. Se observa que la evolución de ambas variables siempre fue paralela y, en general, los valores medios fueron similares. No obstante, en el caso de la media geométrica (Figura 1b), las diferencias fueron un poco mayores, pero el RCS en las muestras LT nunca llegaron a superar en un 50\% a las muestras AO. 
TABLA 2. Coeficientes de correlación del RCS analizado en diferentes tipos de muestras de leche (por glándula antes del ordeño y por ubre de la leche total ordeñada) en 19 cabras libres de IIM que fueron controladas semanalmente durante 12 semanas.

\begin{tabular}{|c|c|c|c|c|}
\hline $\begin{array}{c}\text { Tipo de } \\
\text { muestra }\end{array}$ & AOD & AOI & AO & LT \\
\hline AOD & 1 & & & \\
\hline AOI & 0.93 & 1 & & \\
\hline AO & 0.98 & 0.98 & 1 & 1 \\
\hline LT & 0.97 & 0.94 & 0.97 & de la glándula \\
AOD y AOI : RCS en muestras de primeros chorros tomadas antes del ordeño de \\
derecha e izquierda, respectivamente
\end{tabular}
AO: para cada ubre, media del RCS AOD y RCS AOI.
LT: muestras de la leche total ordeñada de cada animal (control lechero).
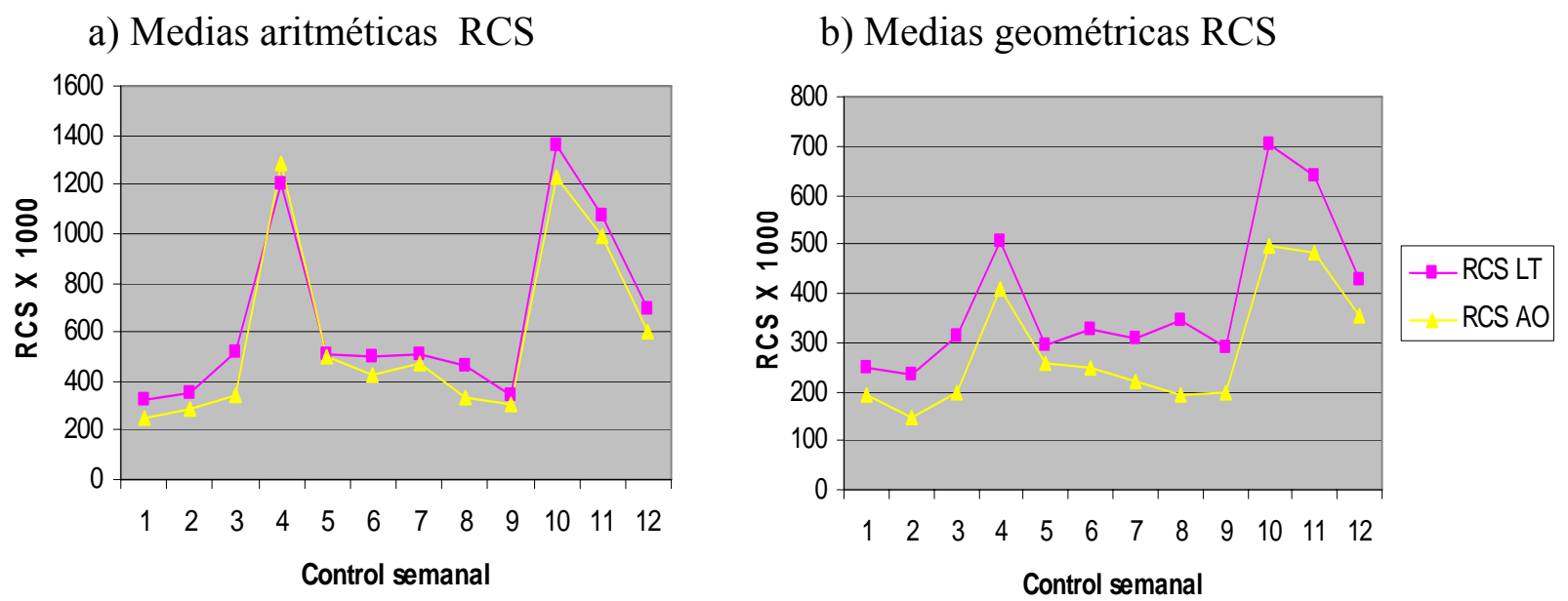

FIGURA 1. Evolución de las medias aritméticas (a) y geométricas (b) del RCS (céls $/ \mathrm{ml}$ ) en muestras de leche tomadas antes del ordeño $\left(\mathrm{RCS}_{\mathrm{AO}}\right)$ y de la leche total ordeñada $\left(\mathrm{RCS}_{\mathrm{LT}}\right)$ a lo largo de todo el estudio en 19 cabras libres de IIM.

Por otra parte, la relación $\mathrm{RCS}_{\mathrm{LT}} / \mathrm{RCS}_{\mathrm{AO}}$ obtenida para cada animal y ordeño presentó un valor medio de 1,58 (mínimo: 0,57; máximo 5,44; Tabla 3 y Figura 2), si bien esta relación tendió a disminuir a medida que aumentaban los recuentos (Tabla 3).

Por ejemplo, con valores de $\mathrm{RCS}_{\mathrm{LT}}$ inferiores a 100.000 cels $/ \mathrm{ml}$, la citada relación se situó de media en 2,33, pero con valores de $\mathrm{RCS}_{\mathrm{LT}}$ entre 1 y 5 millones de céls/ml, se situó entorno a la unidad (1,03; Tabla 3 y Figura 2b), Además, en la Tabla 4 
TABLA 3 . Relación entre el RCS (céls $/ \mathrm{ml}$ ) de las muestras de la leche total ordeñada $\left(\mathrm{RCS}_{\mathrm{LT}}\right)$ y de las muestras tomadas antes del ordeño $\left(\mathrm{RCS}_{\mathrm{AO}}\right)$, según el nivel de $\mathrm{RCS}_{\mathrm{LT}}$, en 19 cabras que permanecieron sanas durante el experimento

\begin{tabular}{|c|c|c|c|c|c|}
\hline \multirow{2}{*}{$\begin{array}{c}\text { Nivel } \\
\mathrm{RCS}_{\mathrm{LT}}\left(\mathrm{x} 10^{3}\right)\end{array}$} & \multicolumn{5}{|c|}{ Relación $\mathrm{RCS}_{\mathrm{LT}} / \mathrm{RCS}_{\mathrm{AO}}$} \\
\cline { 2 - 6 } & $\mathrm{N}^{\mathrm{o}}$ contr. & Media & $\mathrm{DS}$ & Min & Max \\
\hline $1-100$ & 44 & 2.33 & 1.03 & 1.11 & 4.99 \\
\hline $100-500$ & 115 & 1.53 & 0.79 & 0.86 & 5.44 \\
\hline $500-1000$ & 29 & 1.24 & 0.46 & 0.92 & 3.41 \\
\hline $1000-2000$ & 16 & 1.03 & 0.22 & 0.57 & 1.50 \\
\hline $2000-5000$ & 7 & 1.03 & 0.18 & 0.83 & 1.37 \\
\hline$>5000$ & 5 & 0.89 & 0.13 & 0.70 & 1.03 \\
\hline TODAS & 216 & 1.58 & 0.86 & 0.57 & 5.44 \\
\hline
\end{tabular}

RCSAO : RCS en muestras de primeros chorros tomadas antes del ordeño (media de los 2 pezones) RCSLT: RCS en muestras de la leche de todo el ordeño de un animal (control lechero) .

DS :desviación estándar Min: mínimo Max: Máximo.

También se aprecia que la relación $\mathrm{RCS}_{\mathrm{LT}} / \mathrm{RCS}_{\mathrm{AO}}$ tendió a ser inferior en las cabras multíparas $(1,46-1,49)$ que en las primíparas $(1,78)$, aunque las diferencias no fueron significativas $(\mathrm{p}>0.05)$.
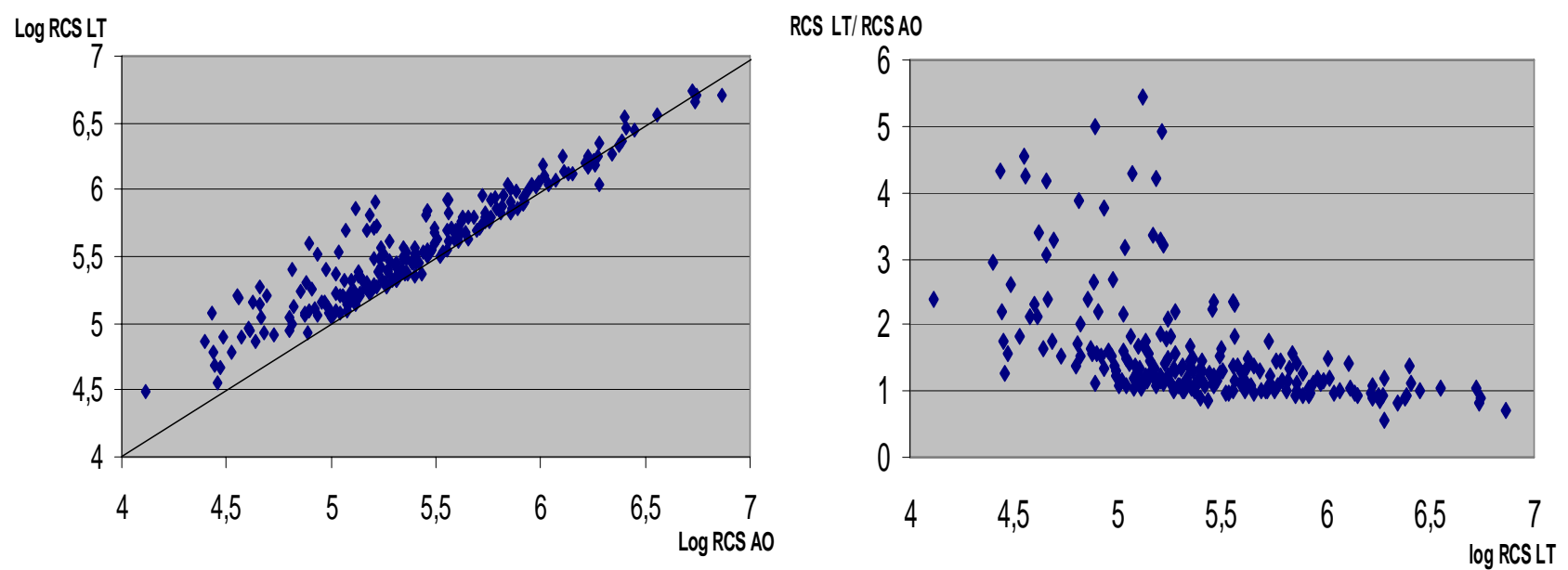

FIGURA 2. Comparación del RCS, en $\log _{10}$, de las muestras de la leche total ordeñada $\left(\log \mathrm{RCS}_{\mathrm{LT}}\right)$ y de las muestras tomadas antes del ordeño $\left(\log \mathrm{RCS}_{\mathrm{AO}}\right)$ y de la relación $\mathrm{RCS}_{\mathrm{LT}} / \mathrm{RCS}_{\mathrm{AO}}$ en 216 controles semanales de 19 cabras que permanecieron sanas a lo largo del experimento. 
TABLA 4 Relación entre el RCS (céls $/ \mathrm{ml}$ ) de las muestras de la leche total ordeñada $\left(\mathrm{RCS}_{\mathrm{LT}}\right)$ y de las muestras tomadas antes del ordeño $\left(\mathrm{RCS}_{\mathrm{AO}}\right)$ en 19 cabras que permanecieron sanas a lo largo del experimento, según su número de lactación.

\begin{tabular}{|c|c|c|c|c|c|c|}
\hline \multirow{2}{*}{$\begin{array}{c}\mathrm{N}^{\mathrm{o}} \text { de } \\
\text { lactación }\end{array}$} & \multirow{2}{*}{$\begin{array}{c}\mathrm{N}^{\mathrm{o}} \\
\text { cabras }\end{array}$} & $\mathrm{N}^{\mathrm{o}}$ de & \multicolumn{4}{|c|}{$\mathrm{RCS}_{\mathrm{LT}} / \mathrm{RCS}_{\mathrm{AO}}$} \\
\cline { 5 - 8 } & controles & Media & $\mathrm{DS}$ & $\mathrm{Min}$ & $\mathrm{Max}$ \\
\hline 1 & 7 & 74 & 1.78 & 0.97 & 0.83 & 5.44 \\
\hline 2 & 10 & 119 & 1.49 & 0.85 & 0.57 & 4.99 \\
\hline 3 & 2 & 23 & 1.46 & 0.45 & 0.70 & 2.67 \\
\hline
\end{tabular}

RCSAO : RCS en muestras de primeros chorros tomadas antes del ordeño ( media de los 2 pezones)

RCSLT: RCS en muestras de la leche de todo el ordeño de un animal (control lechero) .

DS :desviación estándar Min: mínimo Max: Máximo.

\section{DISCUSIÓN}

En este trabajo se ha comprobado que la determinación del RCS por glándula, a partir de muestras de primeros chorros tomadas antes del ordeño $\left(\mathrm{RCS}_{\mathrm{AO}}\right)$, permite estimar con bastante precisión el RCS de la leche total ordeñada $\left(\mathrm{RCS}_{\mathrm{LT}}\right)$ de una cabra. En general la media aritmética del $\mathrm{RCS}_{\mathrm{AO}}$ es similar, aunque ligeramente inferior, respecto a la media del $\mathrm{RCS}_{\mathrm{LT}}$, lo cual coincide con lo encontrado por otros autores en ganado caprino (Contreras et al., 1997; Martínez 2000; Haenlein, 2002). Así mismo, el valor medio obtenido de la relación $\mathrm{RCS}_{\mathrm{LT}} / \mathrm{RCS}_{\mathrm{AO}}(1,58)$ está cercano al valor de 1,70 hallado por Martínez (2000), en 600 muestras de 100 cabras Murciano-Granadinas. Resulta interesante que la citada relación tienda a disminuir, hasta situarse en valores próximos a 1, cuando se evalúa con animales cuyos recuentos superan el millón de céls/ml. Por tanto, es posible utilizar el RCS de las muestras de primeros chorros para identificar a los animales que presenten elevaciones bruscas y transitorias del RCS en las muestras del control lechero.

Estos resultados obtenidos permiten confirmar la metodología utilizada en el Estudio 2 de esta Tesis Doctoral de identificar la presencia de elevaciones transitorias del RCS en la leche ordeñada de un animal (con valores superiores a 1 millón céls $/ \mathrm{ml}$ ) a partir de los registros de RCS en las muestras tomadas por pezones antes del ordeño. Por 
ejemplo, de 28 casos en que el $\mathrm{RCS}_{\mathrm{LT}}$ fue superior a 1 millón de céls $/ \mathrm{ml}$, tan solo en 2 el $\mathrm{RCS}_{\mathrm{AO}}$ fue bastante inferior (en torno a 700.000 céls $/ \mathrm{ml}$ ), y en ambos casos correspondieron a dos cabras de primera lactación.

\section{CONCLUSIONES}

1- El RCS en las muestras de primeros chorros tomadas antes del ordeño $\left(\mathrm{RCS}_{\mathrm{AO}}\right)$ es, de media, inferior respecto a los recuentos obtenidos en las muestras del control lechero $\left(\mathrm{RCS}_{\mathrm{LT}}\right)$. Sin embargo, en los animales que presentan recuentos superiores a un millón de cels $/ \mathrm{ml}$, el $\mathrm{RCS}_{\mathrm{AO}}$ tiende a igualarse al $\mathrm{RCS}_{\mathrm{LT}}$.

2- En animales libres de IIM, las elevaciones transitorias del RCS de origen no infeccioso, con valores superiores a 1 millón de cels $/ \mathrm{ml}$, pueden ser detectadas en las muestras tomadas por glándula antes del ordeño.

\section{BIBLIOGRAFIA}

ALI, A.K.A.; SHOOK, G.E. (1980). An optimum transformation for somatic cell concentration in milk. Journal of Dairy Science. 63:487-490

BERNING, L.M.; PAAPE, M.J.; MILLER, R.H.; LEDANE, R.A. (1987). Variation in $\mathrm{N}$-acetyl- $\beta$-d-glucosaminidase activity and somatic cell counts among various milk fractions. Journal of Dairy Science. 70:1054-1060.

BERGONIER, D.; LAGRIFOUL , G.; BERTHELOT, X.; BARILLET, F.(1996). Facteurs de variation non infectieux des comptages de cellules somatiques chez les ovins et les caprins laitiers.En:Somatic Cells and milk of Small Ruminant, (Ed:Rubino,R.),Wageningen Pers.(EAAP,77) : 112-135.

CONTRERAS, A.; CORRALES, J.C.; SIERRA, D.; MARCO, J. (1995). Prevalence and aetiology of non-clinical intramammary infection in Murciano-Granadina goats. Small Ruminant Research. 17: 71-78. 
CONTRERAS, A.; SIERRA, D.; CORRALES, J.C.; SANCHEZ, A.; MARCO, J. (1996). Physiological threshold of somatic cell count and California Mastitis Test for diagnosis of caprine subclinical mastitis .Small Ruminant research .21: 259-264.

CONTRERAS, A.; PAAPE, M.; MILLER, R. H. (1997). Variación de patógenos y células somáticas en diferentes fracciones de leche y su aplicación para el diagnóstico de la infección intramamaria caprina. XXII Jornadas Científicas de la Sociedad Española de Ovinotecnia y Caprinotecnia. Puerto de la Cruz-Tenerife

GONZALO, C.; BARO, J.A.; CARRIEDO, J.A.; SAN PRIMITIVO, F. (1993). Use of the Fossomatic method to determine somatic cell counts in sheep milk. Journal of Dairy Science. 76:115-119.

GONZALO, C., MARTÍnEZ, J. R.; CARRIEDO, J. A.; SAN PRIMITIVO, F. (2003). Fossomatic cell-counting on ewe milk: comparison with direct microscopy and study of variation factors. Journal of Dairy Science. 86:138-145.

HAENLEIN, G.F.W. (2002). Relationship of somatic cell counts in goat milk to mastitis and productivity. Small Ruminant Research 45. 163- 178.

ISO/IDF. (2008) Milk - Enumeration of somatic cells. - Part 2: Guidance on the operation of fluoro-opto-electronic counters. ISO 13366-2 .IDF 148-2 (ISO and IDF)

LEITNER, G.; MERIN, U.; SILANIKOVE, N. (2001). Changes in Milk Composition as Affected by Subclinical Mastitis in Goats. Journal of Dairy Science 87:17191726 .

LITTELL, R.C.; HENRY, P.R.; AMMERMAN, C.B. (1998). Statitiscal analysis of repeated measures data using SAS procedures. Journal of Animal Science. 76:12161231.

MARTÍNEZ, B. (2000). El recuento de células somáticas en la leche de cabra: factores de variación y efecto sobre la producción y composición de la leche. Tesis doctoral. Universidad Politécnica De Valencia .307p.

MCDOUGAL , S.; VOERMANS , M. (2002). Influence of Estrus on Somatic Cell Count in Dairy Goats .J. Dairy Science. 85:378-383.

MORONI, P.; PISONI, G.; RUFFO, G.; BOETTCHER, P.J. (2005). Risk factors for intramammary infections and relationship with somatic-cell counts in Italian dairy goats. Preventive Veterinary Medicine. 69 :3-4:163-173.

MORONI, P.; PISONI,G.; VAN LIER, E.; ACUÑA, S.; DAMIAN, J.P; MEIKER, A. (2007).Influence of estrus of dairy goat on somatic cell ,milk trait, and sex steroid receptors in the mammary gland. Journal of Animal Science. 90 : 790- 797.

PAAPE, M.J.; POUTREL, B.; CONTRERAS, A.; MARCO, J.C.; CAPUCO; A.V. (2001). Milk somatic cells and lactation in small ruminant's .Journal of Dairy Science 84 (E.suppl) E: 237-E244. 
PETTERSEN, K.E. (1981). Cell content in goat's milk. Acta Veterinariae Scandinavian. 22:226-237.

PERIS, C., MOLINA, P.; FERNANDEZ, N.; RODRIGUEZ, M.; TORRES, A. (1991).Variation in somatic cell count, California mastitis test and electric conductivity among various fractions of ewe's milk. Journal of dairy Science. 74: $1553-1560$

RANDY, H.A.;WILDMAN, E. E; CALER, W. A.; TULLOCH, G. L. (1988) Effect of age and time of milking on day-to-day variation in milk yield, milk constituents and somatic cell counts .Small Ruminant Research. 1: 151-155.

SARIKAYA， H.; WERNER-MISOF， C.; ATZKERN,M.; BRUCKMAIER, R.M.(2005). Distribution of leucocyte populations, and milk composition,in milk fractions of healthy quarters in dairy cows . Journal of Dairy Research 72 : 486492.

SAS. (2008). User guide statistics. Version9.1. SAS Institut, Cary, NC.

ZENG, S.S.;ESCOBAR E.N.;POPHAM, T. (1997). Daily variations in somatic cell count, composition, and production of Alpine goat milk. Small Ruminant Research 26: $253-260$. 
V SEGUNDO ESTUDIO

VARIABILIDAD DIARIA Y ELEVACIONES TRANSITORIAS DEL RECUENTO DE CÉLULAS SOMÁTICAS, DE ORIGEN NO INFECCIOSO, EN LA LECHE DE CABRA 


\section{SEGUNDO ESTUDIO}

\section{VARIABILIDAD DIARIA Y ELEVACIONES TRANSITORIAS DEL RECUENTO DE CÉLULAS SOMÁTICAS, DE ORIGEN NO INFECCIOSO, EN LA LECHE DE CABRA}

\section{INTRODUCCIÓN}

El incremento del recuento de células somáticas (RCS) en la leche no solo se produce por efecto de la infección intramamaria (IIM), sino también por ciertos factores de naturaleza no infecciosa (Harmon, 1994; Haenlein, 2002; Bergonier et al., 2003). Además estos últimos factores poseen una mayor importancia en la leche de cabra que en la leche de vaca y oveja (Paape et al., 2001, 2007; Raynal-Ljutovac et al., 2007). Por tanto, para interpretar adecuadamente el RCS, como estimador indirecto del estado sanitario de la glándula mamaria o como parámetro de calidad de la leche de tanque, es necesario identificar los principales factores no infecciosos y cuantificar su relación con el RCS.

Algunos trabajos han puesto de manifiesto que, en la leche individual de cabra, el RCS presenta una importante variabilidad diaria (Randy et al., 1988; Zeng et al., 1997). No obstante, en estos trabajos no se realizaron análisis bacteriológicos, por lo que no es posible asegurar que esta variabilidad fuera causada exclusivamente por factores no infecciosos. Así mismo, en los registros mensuales del control lechero, Martínez (2000) encontró que las cabras libres de IIM y del virus del AEC pueden presentar elevaciones transitorias (un solo control) e importantes (recuentos superiores a 1 millón de céls $/ \mathrm{ml}$ ) del RCS, sin estar asociadas a una fuerte disminución de la producción lechera.

Se han identificado algunos factores no infecciosos que podrían ocasionar elevaciones transitorias del RCS, como la aparición del celo (McDougall y Voermans, 2002; Moroni et al., 2007) o ciertas prácticas de manejo que presumiblemente generan estrés en el animal (cambios bruscos en el manejo del ordeño, vacunaciones, extracciones de sangre...; Lerondell et al., 1992; Corrales et al., 1996; Salama et al., 2003; Karzis et al., 
2004). Sin embargo, no se conoce la frecuencia con que se manifiestan estas elevaciones transitorias del RCS en condiciones de campo.

El objetivo del presente trabajo ha sido el de conocer como varía diariamente el RCS en las glándulas sanas e infectadas del ganado caprino y, además, cuantificar y caracterizar las elevaciones transitorias del RCS de naturaleza no infecciosa que se puedan producir en una explotación comercial. Dado que la bibliografía sugiere que el celo y el estrés podrían elevar el RCS, el trabajo se ha planteado en ausencia de celos inducidos (ningún tratamiento hormonal ni contacto con los machos) y sin someter a ningún tipo de estrés específico a los animales, más allá del que pueda existir en el manejo habitual de una explotación.

\section{MATERIAL Y MÉTODOS}

\subsection{Diseño experimental}

Este estudio se llevó a cabo en la explotación de ganado caprino de raza MurcianoGranadina de la Universitat Politècnica de València. Todos los animales se encontraban entre el segundo y tercer mes de lactación, y se ordeñaban una vez al día, a las 8:00h, con una rutina que incluía el apurado a máquina e inmersión de los pezones en yodo tras la retirada de las pezoneras.

Se utilizaron 32 cabras (11, 17 y 4 de primera, segunda y tercera o más lactaciones; 20 sanas y 12 con IIM unilateral) a las que se controló diariamente, durante 53 días consecutivos, el RCS en la leche de cada glándula. Además, semanalmente también se realizó un análisis bacteriológico por glándula, y se controló, por ubre, la producción de leche ordeñada, su composición y el RCS. Todas las IIM estaban causadas por estafilococos coagulasa negativo.

Durante el experimento las cabras siempre estuvieron separadas de los machos y no se llevó a cabo ninguna actuación específica que pudiera generar estrés en los animales (cambios en la alimentación, reagrupamientos, vacunaciones etc...). 


\subsection{Variables medidas}

La leche total ordeñada (leche máquina más leche de apurado a máquina) de cada animal se registró mediante medidores volumétricos de 3,5 litros de capacidad, graduados con divisiones de $50 \mathrm{ml}$ (Esneder Ref. 90001; Industrias Berango S.L.).

Las muestras para los análisis de RCS y composición de la leche se tomaron en frascos de polipropileno de $50 \mathrm{ml}$ con cierre hermético. Para determinar el RCS por glándula se recogían unos $40 \mathrm{ml}$ de leche de cada pezón por separado, mediante ordeño manual antes de la puesta de pezoneras. La composición y el RCS de la leche de ubre se llevó a cabo en una muestra de la leche total ordeñada de cada animal. Todas las muestras permanecieron en refrigeración $\left(4^{\circ} \mathrm{C}\right)$ entre 24 y $48 \mathrm{~h}$ hasta que fueron analizadas en el laboratorio. El RCS se analizó mediante el método Fluoro-Opto-Electrónico (Fossomatic 5000; Foss-Electric S.A.; ISA/IDF 2008). La composición (grasa, proteína y lactosa) de la leche se determinó por espectroscopía del infrarrojo medio (MilkoScan FT120, Foss Electric S.A.).

La muestras para el análisis bacteriológico se tomaron por glándula antes del ordeño. Para ello, se limpiaba el extremo del pezón con algodón empapado con alcohol etílico al 70\%, se eliminaban los primeros chorros de leche y se recogían unos $3 \mathrm{ml}$ de leche en tubos estériles de cristal de $10 \mathrm{ml}$, provistos de tapón. Las muestras permanecieron en refrigeración $\left(4^{\circ} \mathrm{C}\right)$ un máximo de $24 \mathrm{~h}$ realizándose el análisis de acuerdo a la metodología descrita en Materiales y Métodos Generales.

\subsection{Definición de una elevación transitoria del RCS}

En principio, los factores no infecciosos podrían provocar en las cabras elevaciones transitorias del RCS de intensidad variable según el animal. Sin embargo, en esta Tesis Doctoral se han tenido en cuenta solo las elevaciones importantes, con el objeto de considerar solamente aquellas que deberían estar provocadas por el efecto directo de un factor fisiológico, y no por efectos indirectos, como las variaciones de la producción de 
leche (efecto concentración/dilución), la variabilidad normal diaria o el proceso de toma de muestras y/o análisis.

De este modo, a partir del criterio definido por Martínez (2000) y de los resultados del Estudio 1 de esta Tesis Doctoral, se ha contabilizado como Elevación Transitoria del $\mathrm{RCS}\left(\mathrm{ET}_{\mathrm{RCS}}\right)$, de origen no infeccioso, cuando se observaba que los recuentos de una cabra cumplían las siguientes características:

1- En ubres libres de IIM, el RCS de ambas glándulas sufrían un aumento importante, de al menos 2.5 veces, respecto al día anterior. En ubres infectadas (mamitis unilateral), se comprobaba que el aumento del RCS señalado anteriormente se producía en la glándula sana, y los recuentos también aumentaban en la glándula infectada

2- Durante la elevación, el RCS de cada glándula superaba los 0,7 millones de céls/ml en primíparas y 1 millón de céls/ml en multíparas.

3- Después de uno o varios días, el RCS de ambas glándulas descendía hasta alcanzar valores similares a los precedentes a la elevación.

\subsection{Análisis estadístico}

El análisis estadístico del RCS por glándula, registrado diariamente, fue realizado considerando tres tipos de glándulas : 1) Sanas-S, glándulas sanas cuya glándula colateral también estaba sana; 2) Sanas-I: sanas cuya glándula colateral estaba infectada; 3) Infectadas. Para ello se utilizó el siguiente modelo estadístico de medidas repetidas:

$\mathrm{Y}_{\mathrm{ijkl}}=\mu+\mathrm{ES}_{\mathrm{i}}+\mathrm{NL}_{\mathrm{j}}+\mathrm{Gla}_{\mathrm{k}}\left(\mathrm{ES}_{\mathrm{i}} \mathrm{NL}_{\mathrm{i}}\right)+\mathrm{Día}_{\mathrm{l}}+\mathrm{ES}_{\mathrm{i}}^{*} \mathrm{NL}_{\mathrm{j}}+\mathrm{ES}_{\mathrm{i}}^{*} \mathrm{Día}_{\mathrm{l}}+\mathrm{NL}_{\mathrm{j}}^{*} \mathrm{Día}_{\mathrm{l}}+\mathrm{e}_{\mathrm{ijkl}}$

Siendo:

$\mathrm{Y}_{\mathrm{ijkl}}=\log _{10} \mathrm{RCS}$

$\mathrm{ES}_{\mathrm{i}}=$ efecto fijo del estado sanitario de la glándula (Sanas-S, Sanas-I, Infect.) 
$\mathrm{NL}_{\mathrm{j}}=$ efecto fijo del número de lactación i ( $\left.1 \mathrm{y} \geq 2\right)$

$\operatorname{Gla}_{\mathrm{k}}\left(\mathrm{ES}_{\mathrm{i}} \mathrm{NL}_{\mathrm{j}}\right)=$ efecto aleatorio de la Glándula $\mathrm{k}$ (1 a 64), jerarquizado dentro del $\mathrm{ES}_{\mathrm{i}}$ y el NL

Día ${ }_{1}=$ efecto fijo del día (1 a 53)

$\mathrm{ES}_{\mathrm{i}} * \mathrm{NL}_{\mathrm{j}}=$ efecto fijo de la interacción $\mathrm{ES} \times \mathrm{NL}$

$\mathrm{ES}_{\mathrm{i}}^{*}{ }^{*} \mathbf{a}_{1}=$ efecto fijo de la interacción ES x Día

$\mathrm{NL}_{\mathrm{j}}{ }^{*} \mathrm{Día}_{1}=$ efecto fijo de la interacción NL x Día

$\mathrm{e}_{\mathrm{ijkl}}=$ efecto aleatorio del error residual

Las variables registradas con periodicidad semanal (producción, composición y RCS en la leche de ubre) fueron analizadas con el modelo anterior, pero introduciendo las siguientes modificaciones:
$\mathrm{ES}_{\mathrm{i}}=$ efecto fijo del estado sanitario de la ubre (Sanas e Infectadas)
$\operatorname{Gla}_{\mathrm{k}}\left(\mathrm{ES}_{\mathrm{i}} \mathrm{NL}_{\mathrm{j}}\right)=$ efecto aleatorio de la ubre k (1 a 32), jerarquizado dentro del $\mathrm{ES}_{\mathrm{i}} \mathrm{y}$ el $\mathrm{NL}_{\mathrm{j}}$

Día ${ }_{1}=$ efecto fijo del día del control semanal ( 1 a 8)

El RCS fue analizado en $\log _{10}$, con objeto de normalizar su distribución (Ali y Shook, 1980). Estos análisis estadísticos fueron realizados mediante el Proc MIXED del SAS (SAS, 2008).

Para estudiar el efecto de las $\mathrm{ET}_{\mathrm{RCS}}$ sobre la producción y composición de la leche solamente se tuvieron en cuenta los resultados de las cabras libres de IIM que presentaron una elevación que coincidió con alguno de los días en que se realizó el control lechero semanal (control 0). Esto tan solo ocurrió en $8 \mathrm{ET}_{\mathrm{RCS}}$ de 8 cabras distintas. Los resultados de producción y composición de la leche de estos animales durante tres controles semanales $(0,+1, y+2)$ fueron comparados con los de 8 cabras de referencia (para cada una de las cabras con $\mathrm{ET}_{\mathrm{RCS}}$, se eligió otra con el mismo número de lactación y similar nivel productivo) utilizando el siguiente modelo estadístico:

$\mathrm{Y}_{\mathrm{ijk}}=\mu+$ Lote $_{\mathrm{i}}+$ Cabra $_{\mathrm{j}}\left(\right.$ Lote $\left._{\mathrm{i}}\right)+$ Control $_{\mathrm{k}}+$ Lote $_{\mathrm{i}}{ }^{*}$ Control $_{\mathrm{j}}+\operatorname{COV}_{\mathrm{j}}+\mathrm{e}_{\mathrm{ijk}}$ 
Siendo:

$\mathrm{Y}_{\mathrm{ijk}}=\log _{10} \mathrm{RCS}$, producción, grasa, proteína y lactosa

Lote $_{i}=$ efecto fijo del lote $\left(\mathrm{i}=1\right.$, cabras con $\mathrm{ET}_{\mathrm{RCS}} ; \mathrm{i}=2$, cabras de referencia)

Cabra $_{\mathrm{j}}\left(\right.$ Lote $\left._{\mathrm{i}}\right)=$ efecto aleatorio de la cabra (1 a 16), jerarquizado dentro del Lote $_{\mathrm{i}}$

Control $_{\mathrm{k}}=$ efecto fijo del control semanal $(0,+1 \mathrm{y}+2)$

Lote $_{\mathrm{i}}{ }^{*}$ Control $_{\mathrm{j}}=$ efecto fijo de la interacción Lote $\mathrm{x}$ Control

$\mathrm{COVj}$ = para cada cabra, efecto de la covariable correspondiente a la media de los valores obtenidos en los dos controles previos a la elevación (-1 y -2).

$\mathrm{e}_{\mathrm{ijk}}=$ efecto aleatorio del error residual

\section{RESULTADOS}

\subsection{Variabilidad del RCS}

El factor Estado Sanitario (ES) influyó significativamente sobre el RCS ( $p<0.001$; Tabla 1), de modo que las glándulas y ubres infectadas presentaron un RCS significativamente más elevado que las glándulas y ubres sanas, respectivamente (Tabla 2).

TABLA 1 Resultados del análisis estadístico por glándulas y por ubres del RCS y la producción (PL) y composición de la leche en 32 cabras que fueron controladas diariamente (glándula) o semanalmente (ubres) durante un periodo de 53 días.

\begin{tabular}{|l|c|c|c|c|c|c|}
\hline \multirow{2}{*}{ FACTOR } & $\begin{array}{c}\text { ANÁLISIS } \\
\text { POR } \\
\text { GLÁNDULA }\end{array}$ & \multicolumn{5}{|c|}{ ANÁLISIS POR UBRE } \\
\cline { 2 - 7 } & $\log _{10}$ RCS & RCS & PL & Grasa & Proteína & Lactosa \\
\hline ES & $* * *$ & $* * *$ & NS & NS & NS & NS \\
\hline NL & NS( $(0.07)$ & NS & $* *$ & NS & NS & NS \\
\hline NL * ES & NS & NS & NS & $* *$ & NS(0.07) & NS \\
\hline Día & $* * *$ & NS & NS(0.07) & $* * *$ & $* * *$ & $* * *$ \\
\hline ES * Día & $*$ & NS & NS & NS & NS & $*$ \\
\hline NL * Día & NS & NS & NS & NS & NS & $*$ \\
\hline
\end{tabular}

ES : Estado sanitario de las glándulas (Sana-S, Sana-I, Infectadas) o ubres (Sanas, Infectadas)

$\mathrm{NL}: \mathrm{n}^{\mathrm{o}}$ de lactación

NS : Efecto no significativo

* Efecto significativo $(\mathrm{p}<0,05)$

$* * *$ Efecto significativo $(\mathrm{p}<0.001)$ 
TABLA 2. RCS (céls/ml) según el estado sanitario de las glándulas o ubres en 32 cabras que fueron controladas diariamente (glándulas) o semanalmente (ubres) durante un periodo de 53 días.

\begin{tabular}{|c|l|c|c|c|}
\hline \multirow{2}{*}{ GLÁNDULA/UBRE } & \multicolumn{1}{|c|}{$\begin{array}{c}\text { ESTADO } \\
\text { SANITARIO }\end{array}$} & $\begin{array}{c}\mathrm{N}^{\mathrm{o}} \\
\text { glán./ubres }\end{array}$ & LOG RCS \pm ES & MG $\left(\mathrm{X} 10^{3}\right)$ \\
\hline \multirow{4}{*}{ Glándula } & Sana-S & 40 & $5,23^{\mathrm{a}} \pm 0,07$ & 170 \\
\cline { 2 - 5 } & Sana-I & 12 & $5,18^{\mathrm{a}} \pm 0,10$ & 151 \\
\cline { 2 - 5 } & Infectada & 12 & $6,05^{\mathrm{b}} \pm 0,10$ & 1122 \\
\cline { 2 - 5 } & Niv. Sig. & - & $* * *$ & - \\
\hline \multirow{3}{*}{ Ubre } & Sana & 20 & $5,45^{\mathrm{a}} \pm 0,06$ & 282 \\
\cline { 2 - 5 } & Infectada & 12 & $5,89^{\mathrm{b}} \pm 0,09$ & 776 \\
\cline { 2 - 5 } & Niv.Sig. & - & $* * *$ & - \\
\hline
\end{tabular}

${ }^{1}$ Sana-S : glándula sana, cuya colateral está sana Sana-I : glándula sana, cuya colateral está infectada ES : error estándar MG: media geométrica $\quad * * *$ Efecto significativo $(p<0,001)$

$a, b$ : letras distintas en una misma columna indican diferencias significativas $(p<0,05)$

Así mismo, las glándulas Sana-S (sana cuya glándula colateral también estaba sana) y Sana-I (sana cuya glándula colateral estaba infectada) no presentaron diferencias significativas entre si (Tabla 2). Las diferencias de producción y composición de la leche entre las ubres sanas e infectadas tampoco llegaron a ser significativas (Tablas 1 y 3 )

TABLA 3. Producción y composición de la leche $(\mathrm{m} \pm \mathrm{ES})$ según el estado sanitario de las ubres en 32 cabras que fueron controladas semanalmente durante un periodo de 53 días

\begin{tabular}{|l|c|c|c|c|c|}
\hline $\begin{array}{c}\text { ESTADO } \\
\text { SANITARIO }\end{array}$ & $\mathrm{N}^{\mathrm{o}}$ ubres & $\begin{array}{c}\text { Producción } \\
(\mathrm{ml})\end{array}$ & $\begin{array}{c}\text { Grasa } \\
(\% \mathrm{p} / \mathrm{p})\end{array}$ & $\begin{array}{c}\text { Proteína } \\
(\% \mathrm{p} / \mathrm{p})\end{array}$ & $\begin{array}{c}\text { Lactosa } \\
(\% \mathrm{p} / \mathrm{p})\end{array}$ \\
\hline Sana & 20 & $1369 \pm 74$ & $4.99 \pm 0.11$ & $3.35 \pm 0.06$ & $4.42 \pm 0.04$ \\
\hline Infectada & 12 & $1420 \pm 101$ & $4.67 \pm 0.14$ & $3.40 \pm 0.09$ & $4.37 \pm 0.06$ \\
\hline Niv.Sig. & - & $\mathrm{NS}$ & $\mathrm{NS}$ & $\mathrm{NS}$ & $\mathrm{NS}$ \\
\hline
\end{tabular}

\subsubsection{Evolución de las medias diarias del RCS}

En la Figura 1a se muestra la evolución diaria de la media aritmética del RCS por glándula. Puede observarse que las glándulas infectadas presentaron una gran variabilidad, con valores medios entre 1 y 4 millones céls $/ \mathrm{ml}$ y fuertes oscilaciones diarias, en ocasiones de más de 3 millones de céls/ml de un día a otro. En las glándulas sanas las medias del RCS fueron en general más estables, situándose normalmente entre 250.000 y 500.000 céls/ml, aunque en dos momentos concretos (días 22 a 24 y días 41 a 43 ) la media del 
a) Media aritmética RCS

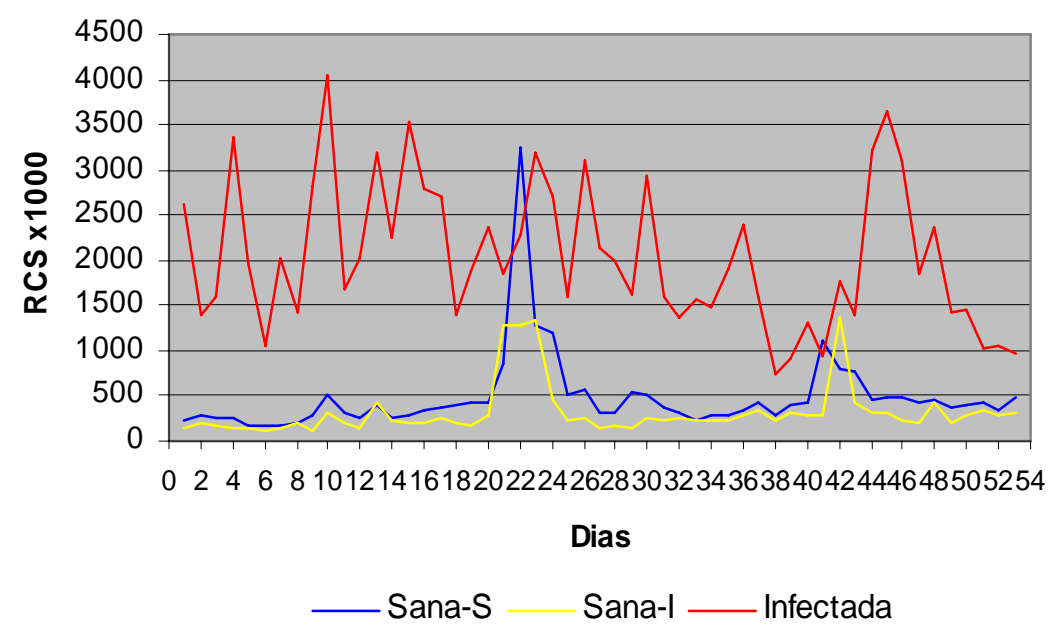

b) Desviación Estandar RCS

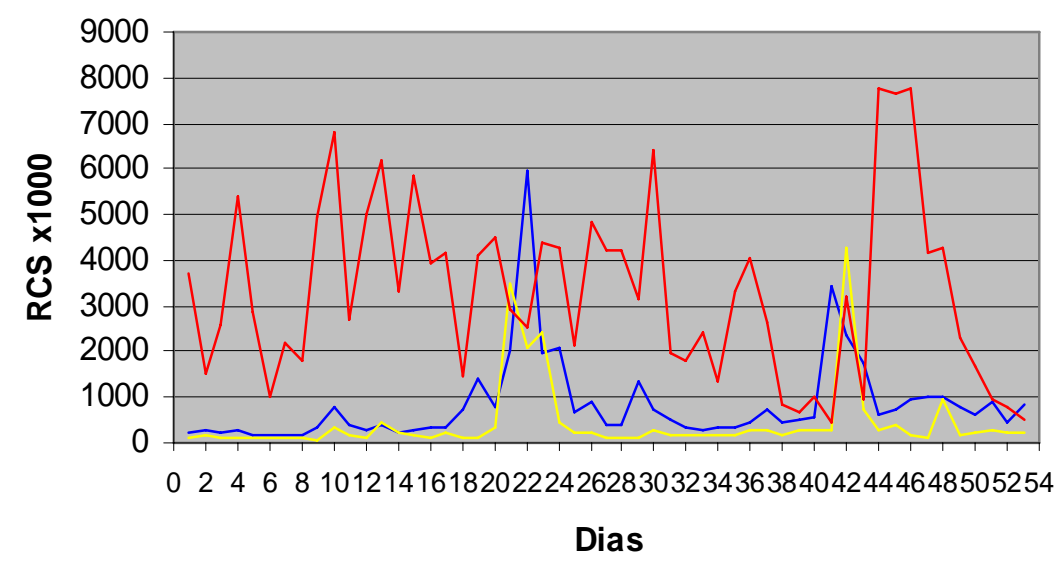

—Sana-S _ Sana-I _ Infectada

C) Media geométrica RCS

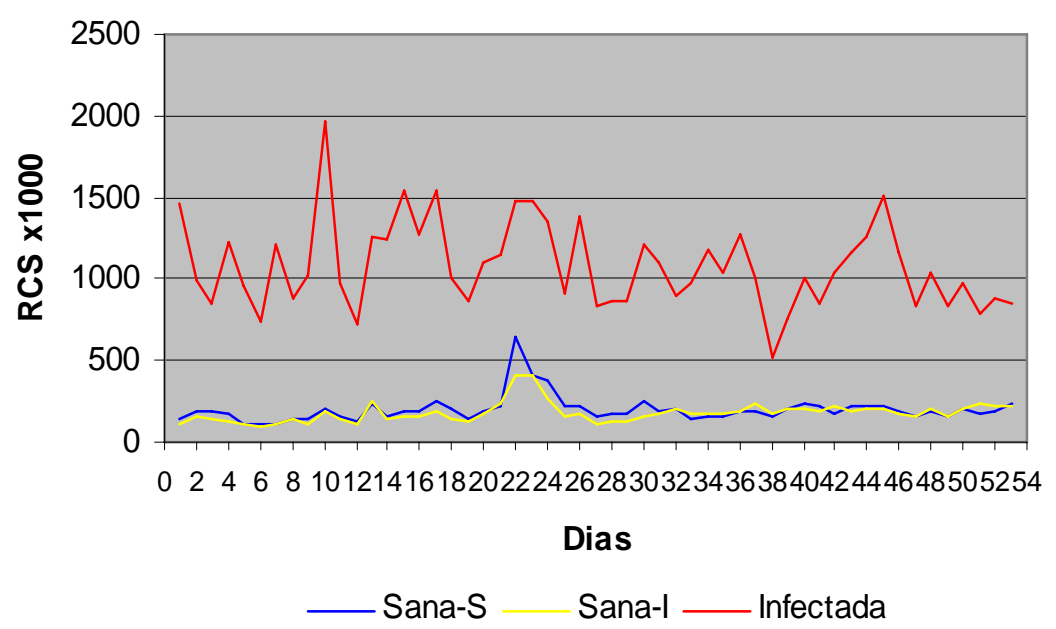

FIGURA 1. Evolución diaria de la media aritmética (a), desviación estándar (b) y media geométrica (c) del RCS (céls/ml) en glándulas sanas (Sanas-S, cuando la colateral también es sana, $\mathrm{n}=20$; Sanas-I, cuando la colateral está infectada, $\mathrm{n}=12$ ) y glándulas infectadas $(\mathrm{n}=12)$ de ganado caprino 
RCS se elevó por encima de 1 millón de céls/ml, tanto en las glándulas Sanas-S como en Sanas-I. En estos dos momentos la desviación estándar del RCS de las glándulas sanas (Figura 1b) también presentaron una fuerte elevación, igualándose a la DS del RCS de las glándulas infectadas. La evolución diaria de la media geométrica del RCS por glándula (Figura 1c) coincidió parcialmente con los resultados señalados para las medias aritméticas: mayor variabilidad en glándulas infectadas que en sanas y, además, existencia de una elevación del RCS entre los días 22 a 24; por el contrario no se manifestó la elevación de los días 21-23. Este último resultado se puede explicar porque la elevación del RCS de los días 22 a 24 fue provocado, principalmente, por elevaciones transitorias en un número importante de animales (7 sanas y 1 con mamitis, ver apartado 4 de resultados), mientras que la elevación de los días 41 a 43 fue causada casi exclusivamente por dos animales (uno sano y otro con mamitis).

En la Figura 2 se presenta la evolución semanal de las medias aritméticas y geométricas del RCS por ubres. Se aprecia nuevamente una mayor variabilidad en las ubres infectadas (media aritmética: 0,8 a 2,1 millones cels/ml; media geométrica: 0,6 a 1 millón cels/ml) que en las sanas, en las que el RCS fue bastante estable (MA normalmente entre 0,3 y 0,5 millones cels $/ \mathrm{ml}$ y MG entre 0,2 y 0,3 millones cels $/ \mathrm{ml}$ ), excepto en el día 23 en que el RCS prácticamente se duplicó, alcanzando una MA de 1,2 millones células/ml y una MG de 0,5 millones céls/ml.

a) Media aritmética (MA)

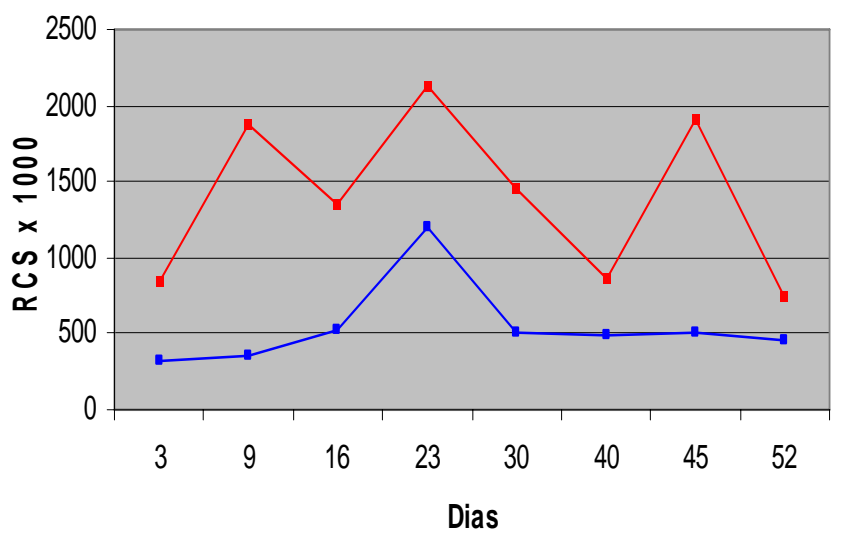

b) Media geométrica

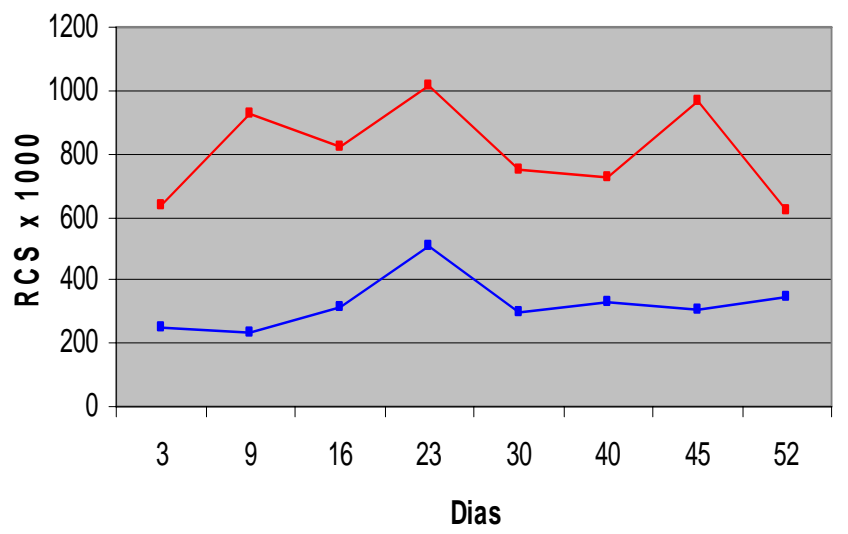

$\rightarrow$ sanas $\rightarrow-\ulcorner$ infectadas

FIGURA 2. Evolución semanal de la media aritmética (a) y media geométrica (b) del RCS (céls/ml) en ubres sanas e infectadas en leche de cabra. 
Por otra parte, en la Figura 3 se observa que, a partir de la media aritmética del RCS de la leche obtenida en los primeros chorros, se dispone de una razonable estimación del RCS de la leche de Tanque. Por ejemplo, la elevación del RCS producida en el día 23 en la leche de tanque (estimada a su vez a partir de los datos del control lechero) también se manifestó al considerar la media aritmética del RCS de primeros chorros.

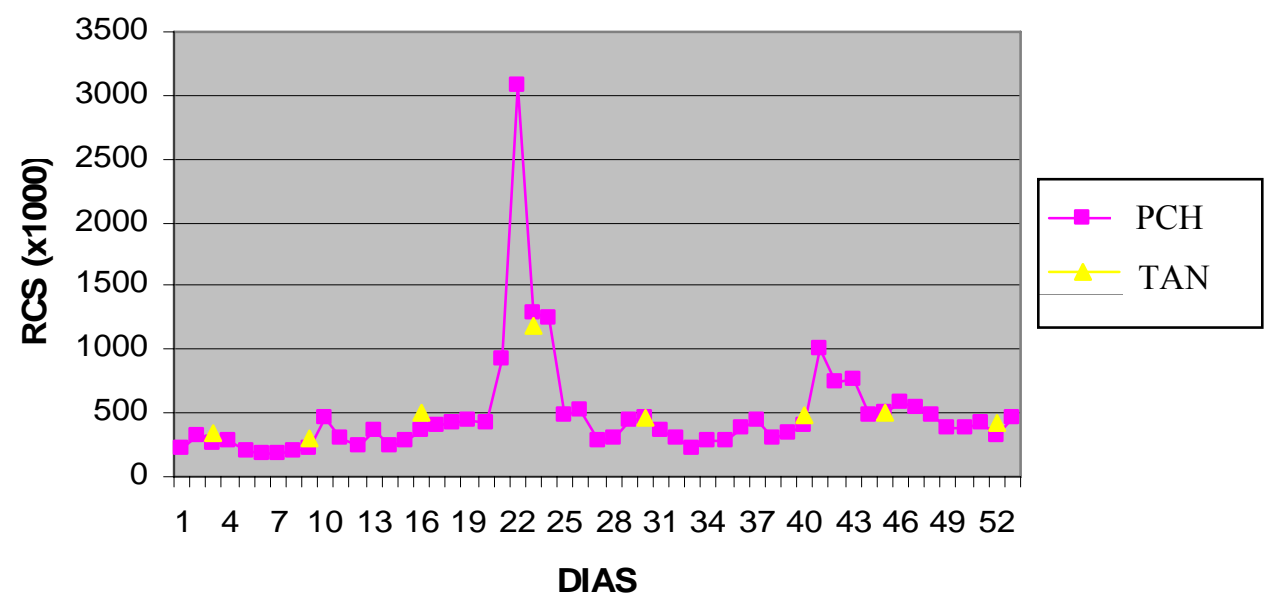

FIGURA 3. Evolución de la media aritmética del RCS (céls/ml) de las muestras de primeros chorros $(\mathrm{PCH})$ y de la leche de tanque (TAN) procedente de 20 cabras que permanecieron libres de IIM. El RCS de la leche de tanque fue estimado partir de la producción y el RCS de la leche ordeñada de cada animal (control lechero).

\subsubsection{Variabilidad en las medias por glándula del RCS}

Para cada glándula, se calculó la media aritmética (MA) y la desviación estándar (DS) del RCS, así como la media aritmética del $\operatorname{logRCS}$, de todos los controles diarios realizados en el experimento. Para cada una de las nuevas variables obtenidas $\left(\mathrm{MA}_{\mathrm{RCS}}\right.$, $\left.\mathrm{DS}_{\mathrm{RCS}}, \mathrm{MA}_{\mathrm{LogRCS}}\right)$ se llevó a cabo una distribución de frecuencias (Tabla 4).

Respecto a las glándulas sanas (Sanas-S y Sanas-I), el 75-78\% tuvieron una $\mathrm{MA}_{\mathrm{RCS}}$ inferior a 0,5 millones cels $/ \mathrm{ml}$, y el $67-73 \%$ tuvo una $\mathrm{MA}_{\mathrm{LogRCS}}$ inferior a 5.5 (MG: 0,31 millones cels $/ \mathrm{ml}$ ). Además, no hubo ninguna glándula infectada que tuviera unos recuentos que cayeran en los rangos señalados. Sin embargo, el 18\% de las glándulas Sanas-S presentaron una $\mathrm{MA}_{\mathrm{RCS}}$ muy elevada, entre 1 y 2 millones de células $/ \mathrm{ml}$, es decir en el mismo rango en el que se situaron el 34\% de las glándulas infectadas. Así mismo el 8\% de 
TABLA 4. Distribución de frecuencias de las glándulas sanas e infectadas de acuerdo a los valores calculados, para cada glándula, de la media aritmética (MA) y desviación estándar (DS) del RCS y del log10RCS de todos los controles diarios.

\begin{tabular}{|c|c|c|c|c|c|c|c|}
\hline \multirow{3}{*}{ Variable } & \multirow{3}{*}{$\begin{array}{c}\text { Tipo } \\
\text { glándula }\end{array}$} & \multicolumn{5}{|c|}{$\mathrm{N}^{0}$ de casos según $\mathrm{RCS}\left(\mathrm{x} 10^{6}\right.$ céls $\left./ \mathrm{ml}\right)$} & \multirow{3}{*}{$\begin{array}{l}\text { Media } \\
\text { (céls/ml) }\end{array}$} \\
\hline & & $<0.5$ & $0.5-1$ & $1-1.5$ & $1.5-2$ & $2-20$ & \\
\hline & & $(\%)$ & $(\%)$ & N $(\%)$ & N (\%) & $\begin{array}{ll}\mathrm{N} & (\%)\end{array}$ & \\
\hline \multirow{3}{*}{$\begin{array}{c}\text { MA RCS } \\
\left(\times 10^{3}\right)\end{array}$} & Sanas-S & $31 \quad(78)$ & (5) & $2 \quad(5)$ & $5 \quad(13)$ & $\begin{array}{ll}0 & (0)\end{array}$ & 482.000 \\
\hline & Sanas-I & $9 \quad(75)$ & (17) & $1 \quad(8)$ & $\begin{array}{ll}0 & (0)\end{array}$ & $\begin{array}{ll}0 & (0)\end{array}$ & 441.000 \\
\hline & Infecta. & (0) & $(50)$ & $2 \quad(17)$ & $2(17)$ & $2 \quad(17)$ & 1.716 .000 \\
\hline \multirow{3}{*}{$\begin{array}{c}\text { DS RCS } \\
\left(\times 10^{3}\right)\end{array}$} & Sanas-S & $24 \quad(60)$ & (23) & $2 \quad(5)$ & $1 \quad(3)$ & $4 \quad(10)$ & 728.000 \\
\hline & Sanas-I & $6 \quad(50)$ & (17) & $3(25)$ & $\begin{array}{ll}0 & (0)\end{array}$ & $(8)$ & 689.000 \\
\hline & Infecta. & $4 \quad(33)$ & $(17)$ & $\begin{array}{ll}0 & (0)\end{array}$ & $3 \quad(25)$ & $3 \quad(25)$ & 1.724 .000 \\
\hline & & \multicolumn{5}{|c|}{$\mathrm{N}^{\mathrm{o}}$ de casos según $\log _{10} \mathrm{RCS}($ céls/ml) } & \\
\hline & & $4.5-5$ & $5-5.5$ & $5.5-6$ & $6-6.5$ & $6.5-7$ & \\
\hline & & $(\%)$ & $(\%)$ & N (\%) & $\mathrm{N} \quad(\%)$ & $(\%)$ & \\
\hline \multirow{3}{*}{$\begin{array}{c}\text { MA } \\
\text { LogRCS }\end{array}$} & Sanas-S & $14 \quad(35)$ & $15 \quad(38)$ & $8 \quad(20)$ & $3 \quad(8)$ & (0) & 5.26 \\
\hline & Sanas-I & (17) & $\begin{array}{ll}6 & (50)\end{array}$ & $\begin{array}{ll}4 & (33)\end{array}$ & $\begin{array}{ll}0 & (0)\end{array}$ & (0) & 5.32 \\
\hline & Infecta. & (0) & (0) & $7 \quad(59)$ & $4 \quad(33)$ & (8) & 5.89 \\
\hline
\end{tabular}

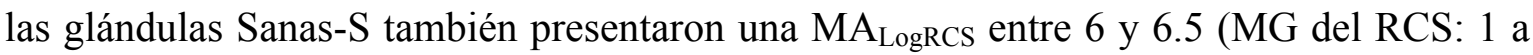
3,2 millones cels $/ \mathrm{ml}$ ), intervalo en el que se situaron el 33\% de las glándulas infectadas. En general las glándulas sanas también presentaron una menor $\mathrm{DS}_{\mathrm{RCS}}\left(50-60 \%\right.$ con $\mathrm{DS}_{\mathrm{RCS}}$ $<0.5$ millones $/ \mathrm{ml}$ ) que las infectadas (solo el $33 \%$ con $\mathrm{DS}_{\mathrm{RCS}}<0.5$ millones $/ \mathrm{ml}$ ), pero nuevamente varias glándulas (18\% de las glándulas Sanas-S) presentaron una $\mathrm{DS}_{\mathrm{RCS}}$ muy elevada, superior a 1 millón cels $/ \mathrm{ml}$.

Por tanto, se observa que entre las glándulas aparentemente sanas durante todo el experimento (sistemáticamente negativas a los análisis bacteriológicos) existe un porcentaje no despreciable (18\%) con una media y/o una DS del RCS muy elevada. Además debemos destacar que la presencia de elevados recuentos medios ( $>$ 0.9-1 millones de cels $/ \mathrm{ml}$ ) en las glándulas persistentemente sanas siempre tuvo carácter 
bilateral, es decir, siempre se manifestó simultáneamente en las dos glándulas de la misma ubre, y siempre ocurrió en cabras $(n=4)$ que estaban en su segunda o superior lactación.

\subsection{Elevaciones transitorias del RCS}

De acuerdo al criterio utilizado para identificar las $\mathrm{ET}_{\mathrm{RCS}}$, descrito en el apartado 2.3. de Material y Métodos, se contabilizaron un total de $29 \mathrm{ET}_{\mathrm{RCS}}$ a lo largo de los 53 días que duró el experimento. Globalmente, de las 32 cabras utilizadas, en 18 se manifestó al menos una $\mathrm{ET}_{\mathrm{RCS}}$ (Tabla 5). De estas últimas, 12 cabras solo tuvieron una elevación (con diferentes duraciones diarias), 4 cabras manifestaron dos elevaciones y 2 cabras tres o más elevaciones. Las $\mathrm{ET}_{\mathrm{RCS}}$ aparecieron tanto en cabras sanas (12 de 20 que permanecieron sanas durante todo el estudio) como en infectadas (6 de 12 que estuvieron permanentemente infectadas, Tabla 5). Además también se manifestó tanto en cabras de primera lactación (5 de 11) como en las de dos o más lactaciones (13 de 21).

TABLA 5 . Distribución de las 32 cabras utilizadas según el estado sanitario de la ubre y el número de elevaciones transitorias del RCS $\left(\mathrm{ET}_{\mathrm{RCS}}\right)$ que presentó cada animal a lo largo del experimento.

\begin{tabular}{|c|c|c|c|}
\hline \multirow{2}{*}{$\begin{array}{l}\mathrm{N}^{0} \mathrm{ET}_{\mathrm{RCS}} \\
\text { por cabra }\end{array}$} & \multicolumn{3}{|c|}{ ESTADO SANITARIO DE LA UBRE } \\
\hline & SANA & INFECTADA & TODAS \\
\hline Ninguna & 8 & 6 & 14 \\
\hline 1 & 8 & 4 & 12 \\
\hline 2 & 3 & 1 & 4 \\
\hline 3 & 1 & 0 & 1 \\
\hline$\geq 4$ & 0 & 1 & 1 \\
\hline $\mathrm{Al}$ menos 1 & 12 & 6 & 18 \\
\hline TOTAL & 20 & 12 & 32 \\
\hline
\end{tabular}

La duración de cada $\mathrm{ET}_{\mathrm{RCS}}$ fue variable (Tabla 6). De las 29 elevaciones identificadas, 14 (48\%) tuvieron una duración de un día, 6 (21\%) de 2 días, 4 (14\%) de 3 días y 2(7\%) de 4 días; las restantes 3 elevaciones (10\%) en realidad no fueron puntuales, dado que permanecieron entre 5 y 16 días. Podemos destacar que en las cabras de primera lactación todas las $\mathrm{ET}_{\mathrm{RCS}}$ tuvieron una duración de 1 ó 2 días. 
TABLA 6. Distribución de las $\mathrm{ET}_{\mathrm{RCS}}$ según el estado sanitario de la ubre, el número de lactación y los días que duró cada elevación

\begin{tabular}{|c|c|c|c|c|c|c|c|}
\hline \multirow[b]{2}{*}{ E.S. Ubre } & \multirow{2}{*}{$\begin{array}{c}\mathrm{N}^{\mathrm{a}} \\
\text { Lactación }\end{array}$} & \multicolumn{6}{|c|}{ DIAS QUE DURÓ CADA ET $\mathrm{RCS}_{\mathrm{R}}$} \\
\hline & & 1 & 2 & 3 & 4 & $\geq 5$ & Total \\
\hline \multirow{3}{*}{ Sana } & 1 & 4 & 1 & 0 & 0 & 0 & 5 \\
\hline & $\geq 2$ & 5 & 0 & 3 & 2 & 2 & 13 \\
\hline & Todas & 9 & 1 & 3 & 2 & 2 & 17 \\
\hline \multirow{3}{*}{ Infectada } & 1 & 0 & 1 & 0 & 0 & 0 & 1 \\
\hline & $\geq 2$ & 5 & 4 & 1 & 0 & 1 & 13 \\
\hline & Todas & 5 & 5 & 1 & 0 & 1 & 12 \\
\hline \multirow[t]{3}{*}{ Todas } & 1 & 4 & 2 & 0 & 0 & 0 & 6 \\
\hline & $\geq 2$ & 10 & 4 & 4 & 2 & 3 & 26 \\
\hline & Todas & 14 & 6 & 4 & 2 & 3 & 29 \\
\hline
\end{tabular}

En la Figura 4 se representa, para cada día, el número de cabras que presentaban una $\mathrm{ET}_{\mathrm{RCS}}$, separadas según el estado sanitario de la ubre (Figuras 5a y 5b). Se observa que, tanto en las cabras sanas como en las infectadas, las elevaciones se presentaron a lo

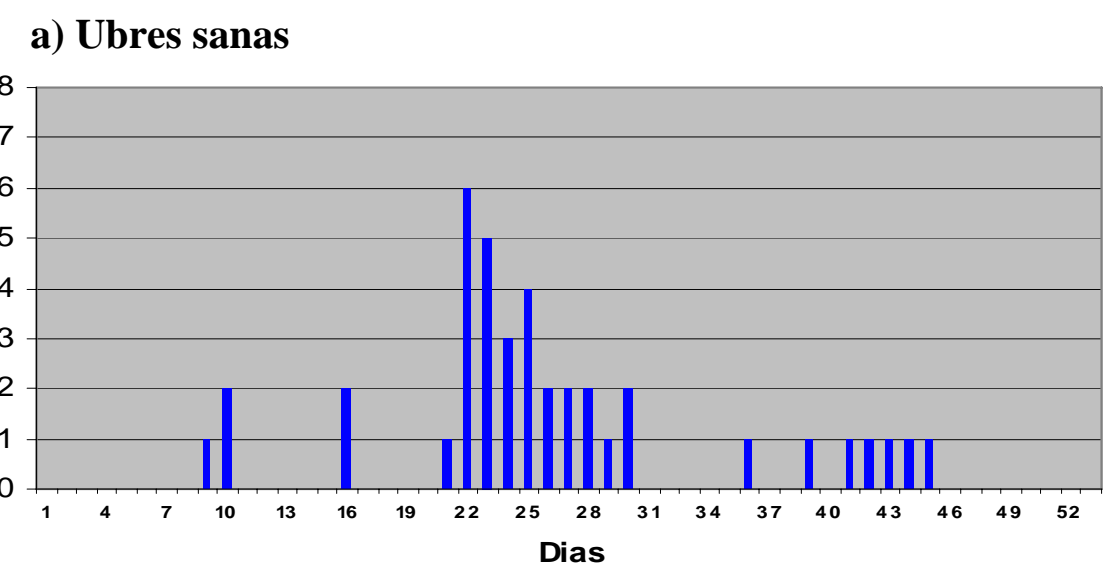

b)Ubres infectadas

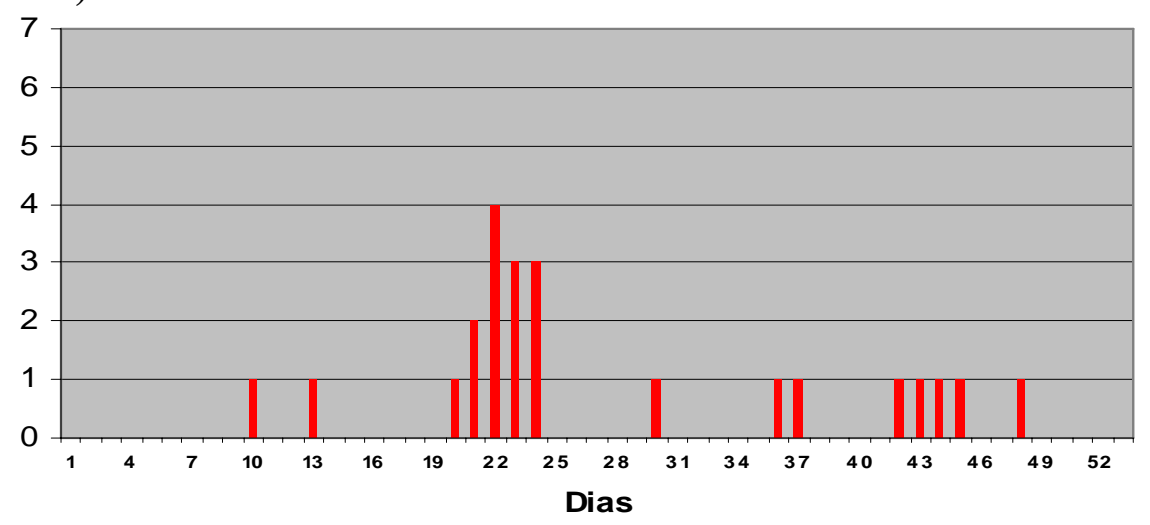

FIGURA 4. Evolución a lo largo del estudio del número de cabras que presentaban en un mismo día una $\mathrm{ET}_{\mathrm{RCS}}$, separadas según el estado sanitario de la ubre ( a-sanas; binfectadas). 
largo del todo el experimento, aunque hubo una mayor concentración entre los días 22 y 25 .

Por otra parte, en la Figura 5 se ha representado la evolución de la media del RCS en las $\mathrm{ET}_{\mathrm{RCS}}$, considerando el periodo comprendido entre 6 días antes de iniciarse la elevación y 6 días después de finalizar la elevación. En esta Figura se han separado las elevaciones según su duración (1,2 y 3 días) y el estado sanitario de la ubre. Puede apreciarse que al aumentar la duración de las $\mathrm{ET}_{\mathrm{RCS}}$, el valor máximo del RCS alcanzado

Ubres sanas. Duración 1 día (n=9)

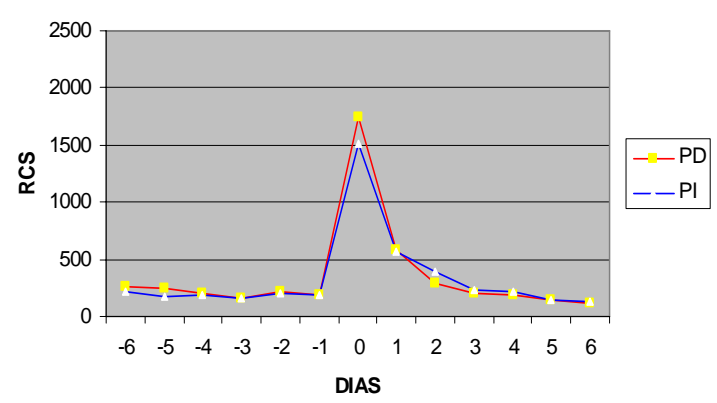

Ubres sanas. Duración 2 días (n=1)

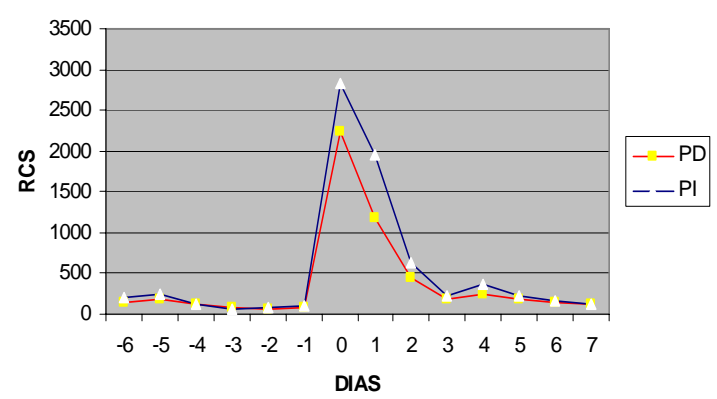

Ubres sanas. Duración 3 días $(\mathrm{n}=3)$

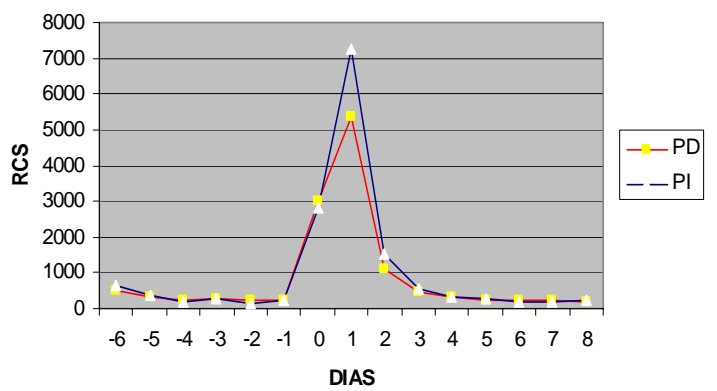

Ubres infectadas. Duración 1 día (n=5)

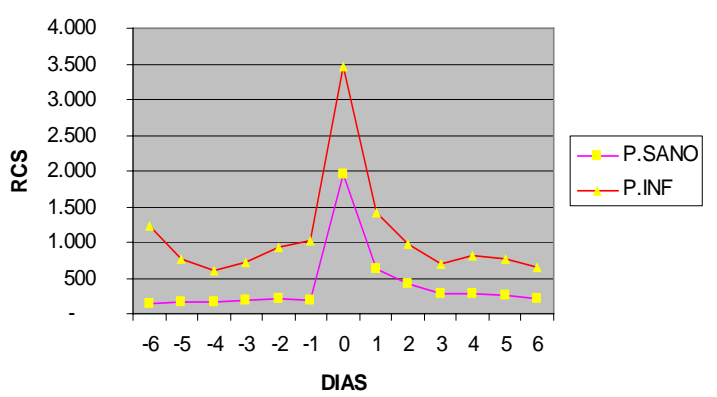

Ubres infectadas. Duración 2 días (n=5)

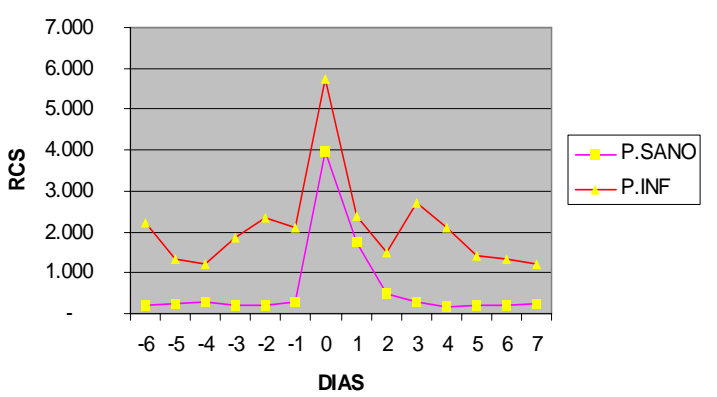

Ubres infectadas. Duración 3 días (n=1)

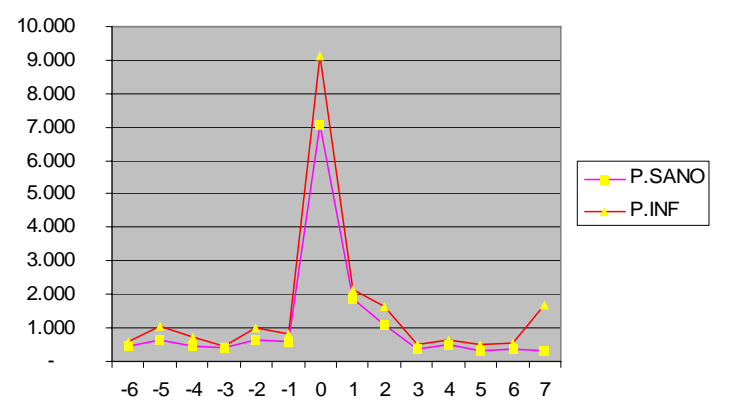

FIGURA 5. Evolución diaria del $\operatorname{RCS}\left(\times 10^{3}\right.$ céls $\left./ \mathrm{ml}\right)$ por glándula en las $\mathrm{ET}_{\mathrm{RCS}}$, considerando el periodo comprendido entre 6 días antes y 6 días después de finalizar la elevación, y de forma separada según el estado sanitario de la ubre y la duración en días de la $\mathrm{ET}_{\mathrm{RCS}}$. En ubres sanas: PD y PI, glándula derecha e izquierda, respectivamente. En ubres infectadas: P.SANO y P.INF, glándula sana e infectada, respectivamente. 
en la elevación también aumenta. Por ejemplo, en las glándulas sanas las $\mathrm{ET}_{\mathrm{RCS}}$ de 1 día tuvieron, de media, un RCS máximo entorno a $1.500 \times 10^{3}$ céls $/ \mathrm{ml}$, mientras que en las $\mathrm{ET}_{\mathrm{RCS}}$ de 3 días, la media del RCS máximo superó los $5.000 \times 10^{3}$ céls $/ \mathrm{ml}$.

El análisis realizado para estimar el efecto de las $\mathrm{ET}_{\mathrm{RCS}}$ sobre la producción y composición de la leche, en los animales libres de IIM, mostró que el factor Lote (ET vs Testigo) tan solo afectó significativamente al RCS ( $<<0.01)$ y la lactosa $(\mathrm{p}<0.01)$, mientras que la interacción Lote*Control fue significativa para el $\operatorname{RCS}(\mathrm{p}<0.001)$, la producción de leche $(\mathrm{p}<0.05)$, la proteína $(\mathrm{p}<0.05)$ y la lactosa $(\mathrm{p}<0.01)$.

En la Tabla 8 se observa que los animales que sufrieron una $\mathrm{ET}_{\mathrm{RCS}}$ (lote ET en el control semanal 0) produjeron en ese control menos leche (1279 ml) y lactosa (4.07), y más proteína (3.38), respecto a los siguientes dos controles semanales (producción :1531 y $1436 \mathrm{ml}$; lactosa: 4.33 y 4.34 \%; proteína: 3.24 y 3.28 \%); no obstante las diferencias con el lote testigo tan solo fueron significativas en el caso de la lactosa en el control semanal 0. En el caso de la grasa, ni el factor Lote, ni la interacción Lote*Control fueron significativos.

TABLA 7. Medias estimadas por mínimos cuadrados del $\log _{10} \mathrm{RCS}$ y la producción y composición de la leche en tres controles semanales (controles 0,1 y 2) de 8 cabras libres de IIM que manifestaron una $\mathrm{ET}_{\mathrm{RCS}}$ (control 0) y en 8 cabras Testigo que no sufrieron ninguna ETRCS

\begin{tabular}{|c|c|c|c|c|c|}
\hline \multirow{2}{*}{ Variable } & \multicolumn{5}{|c|}{ Control semanal } \\
\hline & Lote & 0 & 1 & 2 & ES \\
\hline \multirow{3}{*}{$\begin{array}{c}\log _{10} \mathrm{RCS} \\
\text { (céls/ml) }\end{array}$} & $\mathrm{ET}_{\mathrm{RCS}}$ & $6.48^{\mathrm{a}}$ & $5.38^{\mathrm{b}}$ & $5.43^{\mathrm{b}}$ & 0.11 \\
\hline & Testigo & $5.26^{\mathrm{a}}$ & $5.24^{\mathrm{a}}$ & $5.34^{\mathrm{a}}$ & 0.11 \\
\hline & Niv.Sig. & $* * *$ & NS & NS & - \\
\hline \multirow{3}{*}{$\begin{array}{c}\text { Producción } \\
(\% \mathrm{p} / \mathrm{p})\end{array}$} & $\mathrm{ET}_{\mathrm{RCS}}$ & $1279^{\mathrm{a}}$ & $1531^{b}$ & $1436^{b}$ & 58 \\
\hline & Testigo & $1410^{\mathrm{a}}$ & $1445^{\mathrm{a}}$ & $1404^{\mathrm{a}}$ & 58 \\
\hline & Niv.Sig. & $\mathrm{NS}$ & NS & NS & \\
\hline \multirow{3}{*}{$\begin{array}{l}\text { Grasa } \\
(\% \mathrm{p} / \mathrm{p})\end{array}$} & $\mathrm{ET}_{\mathrm{RCS}}$ & 4.98 & 4.81 & 4.76 & 0.25 \\
\hline & Testigo & 4.62 & 4.54 & 4.93 & 0.25 \\
\hline & Niv.Sig. & NS & NS & NS & - \\
\hline \multirow{3}{*}{$\begin{array}{c}\text { Proteína } \\
(\% \mathrm{p} / \mathrm{p})\end{array}$} & $\mathrm{ET}_{\mathrm{RCS}}$ & $3.38^{\mathrm{a}}$ & $3.24^{\mathrm{b}}$ & $3.28^{\mathrm{b}}$ & 0.05 \\
\hline & Testigo & $3.28^{\mathrm{a}}$ & $3.26^{\mathrm{a}}$ & $3.37^{\mathrm{a}}$ & 0.05 \\
\hline & Niv.Sig. & NS & NS & NS & - \\
\hline \multirow{3}{*}{$\begin{array}{l}\text { Lactosa } \\
(\% \mathrm{p} / \mathrm{p})\end{array}$} & $\mathrm{ET}_{\mathrm{RCS}}$ & $4.07^{\mathrm{a}}$ & $4.33^{\mathrm{b}}$ & $4.34^{\mathrm{b}}$ & 0.04 \\
\hline & Testigo & $4.33^{\mathrm{a}}$ & $4.38^{\mathrm{a}}$ & $4.40^{\mathrm{a}}$ & 0.04 \\
\hline & Niv.Sig. & $* * *$ & $\mathrm{NS}$ & NS & - \\
\hline
\end{tabular}

ES: Error Estándar

${ }^{\mathrm{a}, \mathrm{b}}$ Letras diferentes en una misma fila indica diferencia significativas $(\mathrm{p}<0,05)$ 


\section{DISCUSIÓN}

Como cabía esperar las glándulas y ubres infectadas por ECN presentaron un RCS significativamente más elevado que las glándulas y ubres sanas, respectivamente, lo cual coincide con lo señalado por otros autores (Perrin y Baudry, 1993; Paape et al., 2001; Bergonier et al., 2003; Reynal-Ljutovac et al., 2007). Resulta interesante el hecho de que las glándulas sanas colaterales a las infectadas no presentaran recuentos superiores a las glándulas de las ubres sanas, lo cual concuerda con Romero (2009). Sin embargo, este resultado discrepa de otros trabajos (Dulin et al., 1983; Moroni et al., 2005; De los Campos et al., 2006) en los que encuentran un aumento significativo de los recuentos en las glándulas sanas de las ubres con mamitis unilateral. Es posible que las diferencias en algunos factores, como el número de lactación (en nuestro caso, el 80\% de las cabras infectadas fueron de primera o segunda lactación) o la virulencia de los gérmenes involucrados (por ejemplo en Moroni et al., 2005, todas las infecciones estaban provocadas por S. aureus) pudieran explicar esta discordancia.

La evolución diaria de las medias aritméticas del RCS de las glándulas sanas ha puesto de manifiesto que, puntualmente, pueden haber elevaciones importantes en los recuentos, de modo que llegan a alcanzarse valores similares a las medias respectivas de las glándulas infectadas (más de 2 millones de céls $/ \mathrm{ml}$ ). Estas elevaciones solamente se produjeron en algunos animales (en esos días la desviación estándar se incrementó notablemente y las medias geométricas apenas mostraron estas elevaciones), lo que significa que existe variabilidad individual en la respuesta al posible factor no infeccioso responsable de estas elevaciones. Estas fluctuaciones en los recuentos también fueron encontradas por Zeng et al (1997) en leche de ubre, aunque en esta caso no se llevaron a cabo análisis bacteriológicos.

Además de las elevaciones puntuales descritas, es destacable la variabilidad individual que se observó entre animales, dado que el 18\% de las glándulas sanas (4 cabras de 20) tuvieron sistemáticamente recuentos elevados (media entre 1 y 2 millones), mientras que en el resto de glándulas la media de los recuentos fueron casi siempre inferiores a 0.5 millones de céls $/ \mathrm{ml}$ ). Estos elevados recuentos medios siempre ocurrieron en cabras multíparas, y, por tanto, es coherente con el hecho de que prácticamente todos los trabajos (Luengo et al., 2004; Moroni et al., 2005; Leitner et al., 2007) observan un mayor RCS en 
las cabras multíparas que en las primíparas. En este tipo de glándulas (recuentos sistemáticamente superiores a 1 millón céls $/ \mathrm{ml}$ y negativos a los análisis bacteriológicos) Zeng y Escobar (1995) no encontraron ningún tipo de lesión histopatológica.

Este estudio también ha confirmado que el ganado caprino presenta elevaciones bruscas del RCS en la leche, de forma que en un día los recuentos aumentan más de 2.5 veces, con valores de más de 1 millón de células, respecto a los valores precedentes. Además, estas elevaciones se caracterizan por ser transitorias, dado que normalmente solo duran entre 1 y 3 días. Teniendo en cuenta que estas elevaciones también ocurren en cabras libres de IIM (análisis bacteriológicos sistemáticamente negativos), y que siempre tenían carácter bilateral, nos permite sospechar que su origen no es infeccioso.

La presencia de estas $\mathrm{ET}_{\mathrm{RCS}}$ en el ganado caprino parece ser un fenómeno característico y relativamente frecuente. Así, estas elevaciones se observaron a lo largo del experimento (con una mayor concentración entre los días 22 y 26) y afectaron, al menos una vez, a casi un $60 \%$ de las cabras, tanto en las cabras sanas como en las infectadas y en las de primera lactación como en las de dos o más lactaciones. No obstante presentan una gran variabilidad en los valores máximos alcanzados (de 1 a 20 millones de céls $/ \mathrm{ml}$ ), la frecuencia con que aparece en una misma cabra (entre 1 y 4 veces) y en la duración de cada episodio (en 3 casos permanecieron entre 5 y 16 días).

El efecto o relación de las $\mathrm{ET}_{\mathrm{RCS}}$ con la producción (descenso alrededor del 11$16 \%$, respecto a los controles posteriores) parece confirmar que las elevaciones de los recuentos no pueden ser debidas exclusivamente a un efecto de dilución, tal y como ha sido sugerido por algunos autores (Paape et al., 2001). Sin embargo, resulta paradójico que, si bien las $\mathrm{ET}_{\mathrm{RCS}}$ tienen aparentemente un origen no infeccioso, su efecto o relación con la producción y la composición de la leche (aumento de la proteína en un 4\% y descenso de la lactosa en un 6\%) sea similar al que suele provocar las IIM causadas por bacterias de moderada patogenicidad (Raynal-Ljutovac et al., 2007) 


\section{CONCLUSIONES}

1- Este trabajo ha permitido confirmar la existencia de elevaciones bruscas y

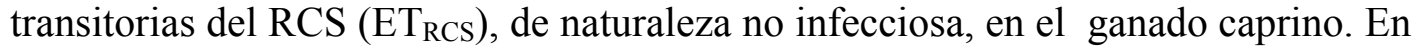
estas elevaciones los recuentos se multiplican, al menos por 2.5, de un día a otro, alcanzando valores desde 0.7 a 15 millones de céls $/ \mathrm{ml}$ en ambas glándulas. $\mathrm{Su}$ duración es variable, pero normalmente es de 1 a 3 días.

2- La presencia de $\mathrm{ET}_{\mathrm{RCS}}$ no se puede considerar como un fenómeno esporádico en el ganado caprino. En nuestro estudio afectó, al menos una vez, a casi el 60\% de las cabras, y se manifestó tanto en las cabras sanas como en las infectadas, y en las de primera lactación como en las de segunda o más lactaciones.

3- El aumento de los recuentos durante las $\mathrm{ET}_{\mathrm{RCS}}$ no puede ser explicado por cambios en la producción de leche (descenso de un 11-16\%). En las $\mathrm{ET}_{\mathrm{RCS}}$ aumenta la proteína y disminuye la lactosa.

\section{BIBLIOGRAFÍA}

ALI, A.K.A.; SHOOK, G.E. (1980). An optimum transformation for somatic cell concentration in milk. Journal of Dairy Science. 63:487-490.

BERGONIER, D.;DECRÉMOUX,R.;RUPP,R.;LAGRIFFOUL,G.;BERTHELOT ,X. (2003). Mastitis of dairy small ruminants. Vet. Res.34: 689-716 .INRA, EDP Sciences.

CORRALES, J.C.; CONTRERAS, A.; SÁNCHEZ, A.; MARCO, J.; RABAL, F. (1997). Adaptación de las condiciones de la aplicación de la directiva comunitaria 92/46 para el recuento de células somáticas, a nivel de tanque, en leche de ganado caprino. XXI Jornadas Científicas de la Sociedad Española de Ovinotecnia y Caprinotecnia. Logroño. 221-227.

DE LOS CAMPOS, G.; GIANOLA, D.; BOETTCHER, P.; MORONI, P.; (2006). A structural equation model for describing relationships between somatic cell score and milk yield in dairy goats. Journal of Animal Science. 84 :2934-2941. 
DULIN, A.; PAAPE, M.; SCHULTZE, W.; WEINLAND, B. (1983). Effect of parity, stage of lactation, and intramammary infection on concentration of somatic cells and cytoplasmic particles in goat milk. Journal of Dairy Science. 66:2426-2433

HAENLEIN, G.F.W. (2002). Relationship of somatic cell counts in goat milk to mastitis and productivity. Small Ruminant Research 45. 163- 178.

HARMON, R. J. (1994). Physiology of mastitis and factors affecting somatic cell. Journal of Dairy Science. 77: 2103-2112.

KARZIS, J.; DONKIN, E.F.; PETZER, I.M. (2004). Antibiotic residue whithdrawal periods in milk of saanen dairy goats and udder tissue irritation : preliminary results. South African Journal of Animal Science. 34: 262-265. (supp1)

LEITNER, G.; MERIN, U.; LAVI, Y.; EGBER, A.; SILANIKOVE, N.; (2007).Aetiology of intramammary infection and its effect on milk composition in goat flocks Journal of Dairy Research. 74: 221-225.

LERONDELLE, C.; RICHARD, Y.; ISSARTIAL, J. (1992). Factors affecting somatic cell counts in goat milk. Small Ruminant Research. 8: 129-139.

LUENGO, C.; SANCHEZ, A.; CORRALES, J. C.; FERNANDEZ, E.; CONTRERAS, A. (2004). Influence of intramammary infection and non-infection factors on somatic cell counts in dairy goats. Journal of Dairy Research. 71: 169-174.

MARTÍNEZ, B. (2000). El recuento de células somáticas en la leche de cabra: factores de variación y efecto sobre la producción y composición de la leche. Tesis doctoral. Universidad Politécnica De Valencia .307p.

MCDOUGALL, S; ANNISS, F.M; CULLUM, A.A. (2002). Effect of transport stress on somatic cell counts in dairy goats. Proceedings of the New Zealand society of animal health .62: 16-18.

MORONI, P.; PISONI, G.; RUFFO, G.; BOETTCHER, P.J. (2005). Risk factors for intramammary infections and relationship with somatic-cell counts in Italian dairy goats. Preventive Veterinary Medicine. 69 :3-4:163-173.

MORONI, P. ; PISONI,G.; VAN LIER,E.; ACUÑA,S.; DAMIAN, J.P; MEIKER; A. (2007) . Influence of estrus of dairy goat on somatic cell ,milk trait,and sex steroid receptors in the mammary gland. Journal of Animal Science. 90 : 790-797.

PAAPE, M.J.; POUTREL, B.; CONTRERAS, A.; MARCO, J.C.; CAPUCO; A.V.(2001). Milk somatic cells and lactation in small ruminant's .Journal of Dairy Science. 84 (E.suppl) E: 237-E244.

PERRIN, G.G.; BAUDRY, C. (1993). Numérations cellulaires du lait de chèvre. Le Lait. 73:489-497. 
RANDY, H.A.;WILDMAN, E. E; CALER, W. A.; TULLOCH, G. L. (1988) Effect of age and time of milking on day-to-day variation in milk yield, milk constituents and somatic cell counts .Small Ruminant Research. 1: 151-155.

RAYNAL-LJUTOVAC, K. ; PIRISI, A. ; DE CREMOUX, R.; GONZALO, C. (2007). Somatic cells of goat and sheep milk: analytical, sanitary, productive and technological aspects. Small Ruminant Research 68 1-2: 126-144.

ROMERO MORALEDA, G. (2009) Estudio se la conductividad eléctrica de la leche como metodo automatico de la detection de mamitis en cabras de raza MurcianoGranadina. Tesis doctoral.193p

SALAMA, A.A; CAJA, G.; ALBANELL, E.; SUCH, X.; CASALS, R.; PLAIXATS, J.(2003). Effects of dietary supplements of zinc-methionine on milk production, udder health and zinc metabolism in dairy goats. Journal of Dairy Research 70:9-17.

ZENG, S.S.; ESCOBAR, E.N. (1995). Effect of parity and milk production on somatic cell count, standard plate count and composition of goat milk. Small Ruminant Research. 17:269-274.

ZENG, S.S.;ESCOBAR E.N.;POPHAM, T. (1997). Daily variations in somatic cell count, composition, and production of Alpine goat milk. Small Ruminant Research 26: $253-260$.

SAS. (2008). User guide statistics. Version9.1. SAS Institut, Cary, NC. 
VI. TERCER ESTUDIO

EFECTO DEL CELO SOBRE EL RECUENTO DE CÉLULAS SOMÁTICAS EN LA LECHE DE CABRA 


\section{TERCER ESTUDIO}

\section{EFECTO DEL CELO SOBRE EL RECUENTO DE CÉLULAS SOMÁTICAS EN LA LECHE DE CABRA}

\section{INTRODUCCIÓN}

En el ganado vacuno, ovino y caprino lechero se suele utilizar el RCS de la leche de glándula o ubre como método indirecto para la detección de las infecciones intramamarias y, en la leche de tanque, como parámetro de calidad de la leche comercializada (Harmon, 1994; Bergonier et al., 2003; Paape et al., 2007; Pirisi et al., 2007). No obstante, muchos trabajos han puesto en manifiesto que los factores de naturaleza no infecciosa que influyen sobre el RCS son más importantes en el ganado caprino que en las otras dos especies (Paape et al., 2001; Gonzalo, 2005). Existe abundante información sobre el efecto de los principales factores no infecciosos, como el estado y numero de lactación (Dulin et al., 1983, Kalogridou-Vassiliadou et al., 1992, De Cremoux et al., 1996; Luengo et al., 2004), pero aún existen otros factores no suficientemente descritos que contribuyen a la variabilidad del RCS. Por ejemplo, Wilson (1995) encontró que el 75\% de la variabilidad del RCS individual/tanque no podía ser explicada a partir de los factores infecciosos o no infecciosos conocidos.

Varios trabajos han indicado o demostrado que, en el ganado caprino, el celo puede elevar el RCS de forma transitoria. Esto se ha observado en condiciones de campo (época de cubrición: Lerondele et al., 1992; Calderini et al., 1996; Wilson et al., 1995) y en experimentos en los que se han identificado celos espontáneos (Moroni, 2007) o se han inducido celos hormonalmente (Aleandri et al., 1996; McDougall y Voermans, 2002; Christodoulopoulos et al., 2008). Además, el aumento del RCS asociado a la presencia del celo no se explicaría por el ligero descenso de la producción de leche, lo cual sugiere que es el propio celo el responsable directo del aumento celular, probablemente por mecanismos fisiológicos aún desconocidos (McDougall y Voermans, 2002). 
En la relación que existe entre el celo y el RCS de la leche de cabra aún existen aspectos no suficientemente esclarecidos. Por un lado, no se dispone de trabajos que hayan estudiado si el efecto del celo es distinto en las cabras primíparas respecto a las multíparas. Por otra lado, existe una cierta controversia en cuanto a si el celo puede afectar al RCS de forma distinta según sea el estado sanitario de la glándula. Así, Bergonier et al. (2003) indican que el estro podría provocar un mayor aumento del RCS en las glándulas con IIM que en las glándulas sanas, mientras que McDougall y Voermans (2002) no encuentran que el efecto del celo sobre el RCS sea diferente en las ubres sanas e infectadas. Finalmente, tampoco se ha estudiado como influye el celo sobre el recuento diferencial de células somáticas. En este sentido, resultaría especialmente interesante conocer como varía el recuento de PMN, dado que es el tipo celular cuantitativamente más importante tanto en las glándulas sanas como en las infectadas (Dulin et al., 1983; Sierra et al., 1999). Por ejemplo, Moroni et al. (2007) formulan la hipótesis de que el incremento de células somáticas durante el celo seria como consecuencia de la proliferación y exfoliación de células epiteliales inducido por el aumento de los estrógenos.

Por otra parte, en otros trabajos previos (Estudio 2 de la presente Tesis Doctoral) también se ha demostrado que el ganado caprino presenta con relativa frecuencia

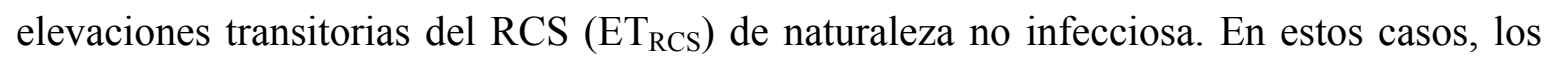
recuentos se multiplican por más de 2.5 veces, alcanzando valores entre 1 y 10 millones de cels $/ \mathrm{ml}$, y con una duración normalmente de entre 1 y 3 días. Por tanto, en base a la bibliografía citada anteriormente, es posible que el celo sea uno de los factores responsables de estas $\mathrm{ET}_{\mathrm{RCS}}$.

El objetivo de este trabajo es el de conocer en mayor medida como influye el celo sobre el RCS en ganado caprino. En concreto, se pretende determinar: a) si el efecto del celo sobre el RCS difiere con el número de lactación o el estado sanitario de la ubre; b) si el celo provoca $\mathrm{ET}_{\mathrm{RCS}}$ de características similares a las encontradas en estudios previos; c) como varía el recuento de PMN cuando se eleva el RCS por efecto del celo. 


\section{MATERIAL Y MÉTODOS}

\subsection{Diseño experimental}

El presente estudio se llevó a cabo en la granja experimental de ganado caprino de raza Murciano-Granadina de la UPV. Los controles sanitarios realizados anualmente indican que esta explotación está libre de brucelosis, tuberculosis, agalaxia contagiosa y tiene una muy baja prevalencia del virus del AEC (un $2 \%$ ).

El experimento se repitió en dos años no sucesivos, ambos en los meses de juniojulio. Todos los animales de ambos experimentos se encontraban entre el tercero y quinto mes de lactación, y eran ordeñados una vez al día (8:00h) con una rutina que incluía el apurado a máquina e inmersión de los pezones en yodo tras la retirada de las pezoneras.

En el primer año se utilizaron 33 cabras (11 de primera lactación y 22 de segunda o más lactaciones; 20 sanas y 13 con IIM unilateral) que, tras un periodo pre-experimental de 6 días, fueron distribuidas en dos grupos según número de lactación, estado sanitario de la ubre, RCS y nivel productivo. Uno de los grupos recibió un tratamiento hormonal para sincronizar celos ( $\mathrm{n}=18$; grupo $\mathrm{SC}$ ) mientras que el otro no recibió ningún tratamiento $(n=15$; grupo Control). El tratamiento hormonal fue el habitualmente utilizado en las explotaciones comerciales: 11 días con esponjas vaginales de espuma de poliuretano impregnadas con $30 \mathrm{mg}$ de acetato de flugestona (Sincropart ${ }^{\mathrm{TM}}$; Ceva Salud Animal, Barcelona) y administración de 300 UI de PMSG (Sincropart PMSG, Ceva Salud Animal) y $0.5 \mathrm{ml}$ de Enzaprost (análogo sintético de PGF2 $\alpha$, Ceva Salud Animal) 48 h antes de la retirada de las esponjas. Durante un periodo de 32 días consecutivos (6 pre-experimental, 11 de tratamiento hormonal y 15 días tras la retirada de esponjas) se controló en todos los animales el RCS por glándula y por ubre. Además, también se llevaron a cabo 6 controles del estado sanitario de cada glándula en los días -17, -13, -7, 0, 7 y 14 del experimento, siendo el día 0 el día que finalizó el tratamiento hormonal. Todas las infecciones estuvieron causadas por ECN, excepto un caso provocado por Corinebacterium spp. A todas las cabras (grupo SC y Control) se les detectó la presencia de celos a las $24 \mathrm{~h}$ tras la retirada de las esponjas y, en aquellas que no manifestaban el celo del grupo SC, se repitió a las 36 y 48 h. La detección de celos se llevó a cabo trasladando a las cabras, 
individualmente, a un parque donde estaba un macho, considerando que una cabra estaba en celo cuando aceptaba la monta.

En el segundo año se repitió el mismo diseño anterior, utilizando un total de 38 cabras (12 de primera y 26 de segunda o más lactaciones; 25 con ubres sanas y 13 con mamitis unilateral todas provocadas por ECN) de las cuales 19 fueron asignadas al grupo SC y las otras 19 al grupo Control, utilizando los mismos criterios a los descritos en el experimento 1. No obstante, en los resultados del grupo SC tan solo se consideraron 16 cabras, dado que una cabra sufrió una mamitis clínica durante el tratamiento hormonal y dos no manifestaron síntomas de celo tras la retirada de las esponjas. Además, en este experimento también se registró diariamente, para cada animal, la producción y composición (grasa, proteína, lactosa y materia seca) de la leche ordeñada. Finalmente, se realizaron tinciones en muestras de leche de todas las glándula durante 7 días consecutivos ( 2 previos a la retirada de esponjas y 5 posteriores a dicha retirada). El recuento de PMN se realizó, por glándula, en 12 cabras (6 del grupo $\mathrm{SC}$, que manifestaron celo y una $\mathrm{ET}_{\mathrm{RCS}}$ tras la retirada de las esponjas, y 6 del grupo control) durante 5 días: dos días previos al inicio de las $\operatorname{ET}_{\mathrm{RCS}}(-2$ y -1$)$, el día de máxima elevación de los recuentos (0) y en dos días posteriores a la finalización de la $\mathrm{ET}_{\mathrm{RCS}}(+1 \mathrm{y}+2)$.

\subsection{Variables medidas}

La leche total ordeñada (leche máquina más leche de apurado a máquina) de cada animal se registró mediante medidores volumétricos de 3.5 litros de capacidad, graduados con divisiones de $50 \mathrm{ml}$ (Esneder Ref. 90001; Industrias Berango S.L.).

Las muestras para los análisis de RCS y composición de la leche se tomaron en frascos de polipropileno de $50 \mathrm{ml}$ con cierre hermético. Para determinar el RCS por glándula se recogían unos $40 \mathrm{ml}$ de leche de cada pezón por separado, mediante ordeño manual antes de la puesta de pezoneras. La composición y el RCS de la leche de ubre se llevaron a cabo en una muestra de la leche total ordeñada de cada animal. Todas las muestras permanecieron en refrigeración $\left(4^{\circ} \mathrm{C}\right)$ entre 24 y $36 \mathrm{~h}$ hasta que fueron analizadas en el laboratorio. El RCS se analizó mediante el método Fluoro-optoelectrónico (Fossomatic 5000; Foss-Electric S.A; ISO/IDF, 2008). La composición de la 
leche (grasa, proteína, lactosa y materia seca) se determinó por espectroscopía del infrarrojo medio (MilkoScan FT120, Foss Electric S.A.).

El recuento de PMN se realizó en las muestras de leche tomadas por glándula, de acuerdo al procedimiento descrito en el apartado 4.4. de Materiales y Métodos Generales.

Las muestras para el análisis bacteriológico se tomaron por glándula antes del ordeño. Para ello, se limpiaba el extremo del pezón con algodón empapado con alcohol etílico al 70\%; a continuación se eliminaban los primeros chorros y se recogían unos $3 \mathrm{ml}$ de leche en tubos estériles de cristal de $10 \mathrm{ml}$, provistos de tapón. Las muestras permanecieron en refrigeración $\left(4^{\circ} \mathrm{C}\right)$ un máximo de $24 \mathrm{~h}$ realizándose el análisis de acuerdo a la metodología descrita en el apartado 4.3. de Materiales y Métodos Generales.

\subsection{Definición de una elevación transitoria del RCS}

Basándose en el criterio definido por Martínez (2000), y en los resultados del Estudio 1 de esta Tesis Doctoral, solamente se contabilizaron como "Elevaciones

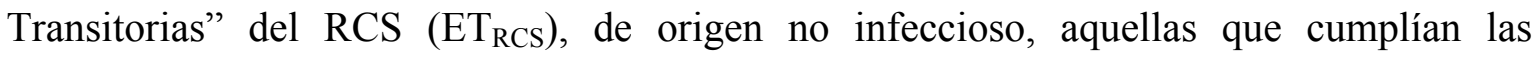
siguientes características:

1- En ubres libres de IIM, el RCS de ambas glándulas sufrían un aumento importante, de al menos 2.5 veces, respecto al día anterior. En ubres infectadas, con mamitis unilateral, se comprobaba que el aumento del RCS señalado anteriormente se producía en la glándula sana, y los recuentos también aumentaban en la glándula infectada

2- Durante la elevación, el RCS de cada glándula superaba los 0,7 millones de céls/ml en primíparas y 1 millón de céls/ml en multíparas.

3- Después de uno o varios días, el RCS de ambas glándulas y de la ubre retornaba a valores similares a los precedentes a la elevación. 


\subsection{Análisis estadístico}

Los resultados del RCS por glándula y ubre, registrados diariamente en ambos experimentos, fueron analizados utilizando el siguiente modelo estadístico de medidas repetidas:

$\mathrm{Y}_{\mathrm{ijklmn}}=\mu+\mathrm{Año}_{\mathrm{i}}+\mathrm{Grupo}_{\mathrm{j}}+\mathrm{NL}_{\mathrm{k}}+\mathrm{ES}_{1}+\mathrm{Gla}_{\mathrm{m}}\left(\mathrm{Año}_{\mathrm{i}} \mathrm{Grupo}_{\mathrm{j}} \mathrm{NL}_{\mathrm{k}} \mathrm{ES}_{\mathrm{l}}\right)+$ Día $_{\mathrm{n}}+$ $\mathrm{Grupo}_{\mathrm{j}} * \mathrm{Año}_{\mathrm{i}}+\mathrm{Grupo}_{\mathrm{j}}^{*} \mathrm{Día}_{\mathrm{n}}+\mathrm{NL}_{\mathrm{k}} * \mathrm{Día}_{\mathrm{n}}+\mathrm{ES}_{\mathrm{l}} * \mathrm{Día}_{\mathrm{n}}+\mathrm{Año}_{\mathrm{i}}{ }^{*} \mathrm{Grupo}_{\mathrm{j}}{ }^{*}$ Día $_{\mathrm{n}}+$ $\mathrm{NL}_{\mathrm{k}} * \mathrm{Grupo}_{\mathrm{j}}{ }^{*}$ Día $_{\mathrm{n}}+\mathrm{ES}_{1} * \mathrm{Grupo}_{\mathrm{j}} * \mathrm{Día}_{\mathrm{n}}+\mathrm{e}_{\mathrm{ijklmn}}$

Siendo:

$\mathrm{Y}_{\mathrm{ijklmn}}=\log _{10} \mathrm{RCS}$

$A \tilde{n}_{i}=$ efecto fijo del año (1 y 2)

$\mathrm{Grupo}_{\mathrm{j}}=$ efecto fijo del grupo $(\mathrm{SC}-$ celos sincronizados- $\mathrm{y}$ control)

$\mathrm{NL}_{\mathrm{k}}=$ efecto fijo del número de lactación i ( $\left.1 \mathrm{y} \geq 2\right)$

$\mathrm{ES}_{1}=$ efecto fijo del estado sanitario de la glándula o ubre (sanas o infectadas)

$\mathrm{Gla}_{\mathrm{m}}\left(\mathrm{Año}_{\mathrm{i}} \mathrm{Grupo}_{\mathrm{j}} \mathrm{NL}_{\mathrm{k}} \mathrm{ES}_{\mathrm{l}}\right)=$ efecto aleatorio de la glándula $\mathrm{k}$ (1 a 136) o ubre $\mathrm{k}(1 \mathrm{a}$ 68) dentro del Año, Grupo $_{\mathrm{j}}, \mathrm{NL}_{\mathrm{k}} \mathrm{y} \mathrm{ES}_{1}$

Día ${ }_{\mathrm{n}}=$ efecto fijo del día (26)

Grupo $_{j}^{*} \mathrm{Año}_{\mathrm{i}} / \mathrm{Grupo}_{\mathrm{j}}^{*} \mathrm{Día}_{\mathrm{n}} / \mathrm{NL}_{\mathrm{k}}{ }^{*} \mathrm{Día}_{\mathrm{n}} / \mathrm{ES}_{1} * \mathrm{Día}_{\mathrm{n}}$ = efecto fijo de las interacciones dobles correspondientes

$\mathrm{Año}_{\mathrm{i}}{ }^{*} \mathrm{Grupo}_{\mathrm{j}}{ }^{*} \mathrm{Día}_{\mathrm{n}}$ / $\mathrm{NL}_{\mathrm{k}}{ }^{*} \mathrm{Grupo}_{\mathrm{j}}{ }^{*}$ Día $_{\mathrm{n}} / \mathrm{ES}_{\mathrm{l}}{ }^{*} \mathrm{Grupo}_{\mathrm{j}}{ }^{*}$ Día $_{\mathrm{n}}$ = efecto fijo de las interacciones triples correspondientes

$\mathrm{e}_{\mathrm{ijkl}}=$ efecto aleatorio del error residual

Las variables de producción y composición de la leche fueron analizadas con el modelo anterior, pero sin considerar el efecto "año" ni sus interacciones (las citadas variables solo fueron registradas en el segundo experimento) y añadiendo al modelo una covariable correspondiente a la media de los valores obtenidos en los 6 días del periodo pre-experimental (previo al inicio del tratamiento hormonal).

El porcentaje de PMN y el recuento de PMN fueron analizados estadísticamente con el siguiente modelo:

$$
\mathrm{Y}_{\mathrm{ijk}}=\mu+\mathrm{Grupo}_{\mathrm{i}}+\mathrm{Gla}_{\mathrm{j}}\left(\mathrm{Grupo}_{\mathrm{i}}\right)+\mathrm{Día}_{\mathrm{k}}+\mathrm{Grupo}_{\mathrm{i}}{ }^{*} \mathrm{Día}_{\mathrm{k}}+\mathrm{e}_{\mathrm{ijk}}
$$


Siendo:

Grupo $_{\mathrm{i}}=$ efecto fijo del grupo $\left(\mathrm{i}=1\right.$ glándulas que manifestaron una $\mathrm{ET}_{\mathrm{RCS}}$, del grupo $\mathrm{SC} ; \mathrm{j}=2$ glándulas que no manifestaron una $\mathrm{ET}_{\mathrm{RCS}}$, del grupo Control)

Gla $_{j}\left(\right.$ Grupo $\left._{\mathrm{i}}\right)=$ efecto fijo de la glándula (24) jerarquizadas al Grupo i

Día $_{\mathrm{k}}=$ efecto fijo del día $(-2,-1,0,+1$ y +2$)$, considerando el día de máximo recuentos durante una $\mathrm{ET}_{\mathrm{RCS}}$ (día 0), y los días previos $(-2$ y -1$)$ y posteriores $(+1 \mathrm{y}+2)$ a los días en que se manifestó la ET para cada animal.

En los análisis estadísticos de los modelos [1] y [2] el RCS fue analizado en $\log _{10}$, con objeto de normalizar su distribución (Ali y Shook, 1980), utilizando el Procedimiento MIXED del paquete estadístico SAS (SAS, 2008).

La frecuencia de cabras que manifestaron al menos una $\mathrm{ET}_{\mathrm{RCS}}$, según el Grupo (SC y Control), número de lactación y estado sanitario de la ubre, fue analizado estadísticamente con el test $\chi^{2}$ utilizando el Procedimiento FREQ del mismo programa estadístico citado anteriormente.

\section{RESULTADOS}

La detección de celos realizada en los días +1 y +2 confirmó que todas las cabras del grupo SC (excepto 2 que no fueron consideradas en los resultados) se encontraban en ese momento en celo; por el contrario, ninguna cabra del grupo control manifestó comportamiento de celo en el día +1 .

Respecto al RCS de la leche de ubre, se observó que la interacción Grupo*Día fue significativa $(\mathrm{p}<0.001$; Tabla 1). Considerando los resultados conjuntos de los dos años (Tabla 2 y Figura 1c), se verificó que el RCS se elevó significativamente en el grupo SC, respecto al grupo Control, en los días $0(\mathrm{p}<0.05),+1(\mathrm{p}<0.001)$ y $+2(\mathrm{p}<0.01)$. Por el contrario, en todos los otros días del ensayo los recuentos de ambos grupos experimentales no mostraron diferencias significativas (Tabla 2). La interacción Año*Grupo*Día también resultó significativa $(\mathrm{p}<0.001)$, lo cual podría ser debido a que los recuentos del grupo SC 
TABLA 1. Resultados del análisis estadístico utilizado para estudiar la influencia de diversos factores sobre las variables de RCS, determinado por glándula y ubre, y la producción y composición de la leche ordeñada registrada por ubre

\begin{tabular}{|c|c|c|c|c|c|c|c|}
\hline \multirow{3}{*}{ Factores } & \multicolumn{7}{|c|}{ Variables } \\
\hline & \multicolumn{2}{|c|}{$\log \mathrm{RCS}^{1}$} & \multirow{2}{*}{ Producción ${ }^{2}$} & \multirow{2}{*}{ Grasa $^{2}$} & \multirow{2}{*}{ Proteína $^{2}$} & \multirow{2}{*}{ Lactosa $^{2}$} & \multirow{2}{*}{$\begin{array}{l}\text { Materia } \\
\text { seca }^{2}\end{array}$} \\
\hline & Glándulas & Ubres & & & & & \\
\hline Año & NS & NS & - & - & - & - & - \\
\hline Grupo & NS & NS & NS & NS & NS & NS & NS \\
\hline NL & $* * *$ & $* *$ & $* * *$ & $*$ & $* *$ & NS & * \\
\hline ES & $* *$ & $* *$ & NS & $\mathrm{NS}$ & $\mathrm{NS}$ & $*$ & NS \\
\hline Día & *** & *** & $* * *$ & $* * *$ & *** & *** & *** \\
\hline Grupo* Año & NS & NS & - & - & - & - & - \\
\hline Grupo * Día & $* * *$ & $* * *$ & $* *$ & NS & $* * *$ & NS & $* *$ \\
\hline NL * Día & $* *$ & $*$ & $*$ & $*$ & $*$ & $\mathrm{NS}$ & $*$ \\
\hline ES * Día & NS & NS & NS & NS & NS & NS & NS \\
\hline NL * Grupo* Día & NS & NS & NS & NS & NS & NS & NS \\
\hline ES * Grupo* Día & NS & $\mathrm{NS}$ & NS & NS & NS & NS & $\mathrm{NS}$ \\
\hline Año* Grupo*Día & $* * *$ & $* * *$ & - & - & - & - & - \\
\hline Covariable & - & - & $* * *$ & $* * *$ & $* * *$ & $* * *$ & $* * *$ \\
\hline
\end{tabular}

${ }^{1}$ Resultados obtenidos en los experimentos realizados en los años 1 y 2

${ }^{2}$ Resultados obtenidos en el experimento realizado en el año 2

TABLA 2. Comparación del $\operatorname{logRCS}$ (céls $/ \mathrm{ml}$ ), en la leche de ubre, entre el grupo de cabras que recibió un tratamiento de sincronización de celos (SC) y otro grupo de animales que no recibió ningún tratamiento (control), en los experimentos realizados en el año 1 y 2.

\begin{tabular}{|c|c|c|c|c|c|c|c|c|c|}
\hline \multirow{2}{*}{ Día } & \multicolumn{3}{|c|}{ Año 1 } & \multicolumn{3}{c|}{ Año 2 } & \multicolumn{2}{c|}{ Total (Año 1+ Año 2 ) } \\
\cline { 2 - 11 } & $\begin{array}{c}\text { SC } \\
(\mathrm{n}=18)\end{array}$ & $\begin{array}{c}\text { Control } \\
(\mathrm{n}=15)\end{array}$ & $\begin{array}{c}\text { Niv.Si } \\
\mathrm{g}\end{array}$ & $\begin{array}{c}\mathrm{SC} \\
(\mathrm{n}=16)\end{array}$ & $\begin{array}{c}\text { Control } \\
(\mathrm{n}=19)\end{array}$ & $\begin{array}{c}\text { Niv.Si } \\
\mathrm{g}\end{array}$ & $\begin{array}{c}\text { SC } \\
(\mathrm{n}=34)\end{array}$ & $\begin{array}{c}\text { Control } \\
(\mathrm{n}=34)\end{array}$ & $\begin{array}{c}\text { Niv.Si } \\
\mathrm{g}\end{array}$ \\
\hline-4 & 5.39 & 5.50 & $\mathrm{NS}$ & 5.51 & 5.52 & $\mathrm{NS}$ & 5.51 & 5.53 & $\mathrm{NS}$ \\
\hline-3 & 5.59 & 5.75 & $\mathrm{NS}$ & 5.55 & 5.46 & $\mathrm{NS}$ & 5.48 & 5.49 & $\mathrm{NS}$ \\
\hline-2 & 5.44 & 5.66 & $\mathrm{NS}$ & 5.61 & 5.57 & $\mathrm{NS}$ & 5.53 & 5.63 & $\mathrm{NS}$ \\
\hline-1 & 5.85 & 5.83 & $\mathrm{NS}$ & 5.56 & 5.51 & $\mathrm{NS}$ & 5.74 & 5.68 & $\mathrm{NS}$ \\
\hline $0^{\mathrm{RE}}$ & 5.94 & 5.52 & $*$ & 5.64 & 5.51 & $\mathrm{NS}$ & 5.80 & 5.52 & $*$ \\
\hline 1 & 6.08 & 5.57 & $* *$ & 5.93 & 5.49 & $*$ & 6.00 & 5.54 & $* * *$ \\
\hline 2 & 6.04 & 5.62 & $*$ & 6.05 & 5.61 & $*$ & 6.04 & 5.63 & $* *$ \\
\hline 3 & 5.62 & 5.59 & $\mathrm{NS}$ & 5.93 & 5.56 & $*$ & 5.76 & 5.59 & $\mathrm{NS}$ \\
\hline 4 & 5.81 & 5.73 & $\mathrm{NS}$ & 5.73 & 5.54 & $\mathrm{NS}$ & 5.78 & 5.65 & $\mathrm{NS}$ \\
\hline 5 & 5.87 & 5.73 & $\mathrm{NS}$ & 5.77 & 5.60 & $\mathrm{NS}$ & 5.85 & 5.67 & $\mathrm{NS}$ \\
\hline 6 & 6.19 & 6.10 & $\mathrm{NS}$ & 5.78 & 5.69 & $\mathrm{NS}$ & 5.90 & 5.83 & $\mathrm{NS}$ \\
\hline 7 & 6.05 & 6.17 & $\mathrm{NS}$ & 5.80 & 5.71 & $\mathrm{NS}$ & 5.94 & 5.95 & $\mathrm{NS}$ \\
\hline 8 & 5.81 & 5.85 & $\mathrm{NS}$ & 5.73 & 5.77 & $\mathrm{NS}$ & 5.82 & 5.90 & $\mathrm{NS}$ \\
\hline 9 & 5.64 & 5.79 & $\mathrm{NS}$ & 5.61 & 5.82 & $\mathrm{NS}$ & 5.64 & 5.81 & $\mathrm{NS}$ \\
\hline 10 & 5.54 & 5.60 & $\mathrm{NS}$ & 5.58 & 5.70 & $\mathrm{NS}$ & 5.62 & 5.75 & $\mathrm{NS}$ \\
\hline 11 & 5.61 & 5.66 & $\mathrm{NS}$ & 5.55 & 5.67 & $\mathrm{NS}$ & 5.61 & 5.68 & $\mathrm{NS}$ \\
\hline 12 & 5.65 & 5.64 & $\mathrm{NS}$ & 5.57 & 5.61 & $\mathrm{NS}$ & 5.63 & 5.70 & $\mathrm{NS}$ \\
\hline 13 & 5.65 & 5.79 & $\mathrm{NS}$ & 5.62 & 5.60 & $\mathrm{NS}$ & 5.66 & 5.72 & $\mathrm{NS}$ \\
\hline ES & 0.119 & 0.122 & - & 0.156 & 0.126 & - & 0.09 & 0.08 & - \\
\hline
\end{tabular}

RE : retirada de las esponjas

ES: Error estándar 


\section{a) Año 1}

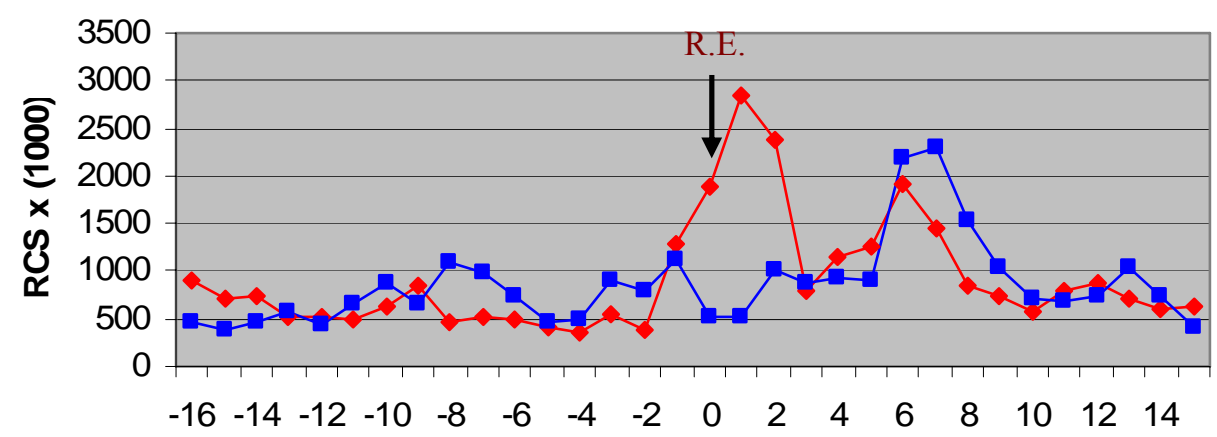

b) Año 2

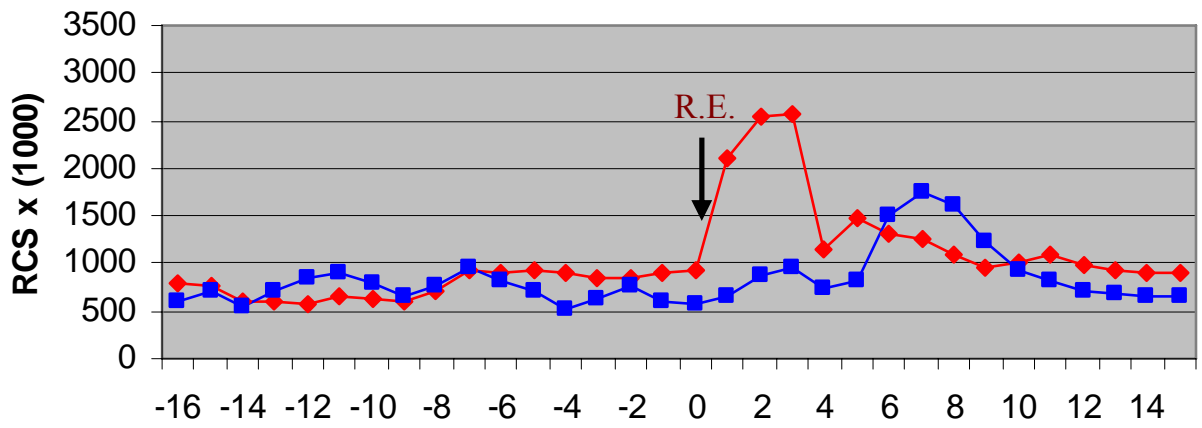

c) Años 1+2

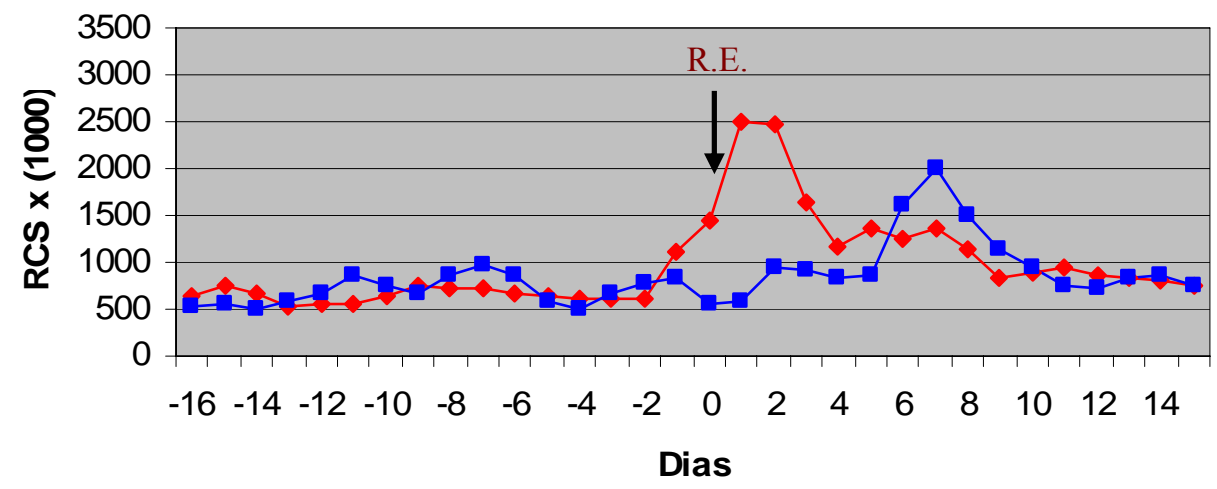

$\rightarrow$ SC $\rightarrow$ Control

FIGURA 1. Evolución diaria de las medias aritméticas del RCS (céls $/ \mathrm{ml}$ ) en la leche de ubre en dos grupos de cabras (SC - tratamiento hormonal de sincronización de celos- y Control), en cada uno de los años que se realizó el experimento. R.E.: momento de la retirada de las esponjas. 
empezaron a elevarse antes en el experimento realizado en el primer año (diferencias significativas en los días $0,+1 \mathrm{y}+2$ ) que en el experimento llevado a cabo en el segundo año (diferencias significativas en los días $+1,+2$ y +3 ; Tabla 2 y Figuras 1a y 1b). En cualquier caso, podemos destacar la coincidencia de que en ambos experimentos los recuentos se elevaron significativamente durante tres días consecutivos, en los días en que las cabras estaban en celo (inducido hormonalmente).

La interacción Numero de Lactación*Grupo*Día no resultó significativa (Tabla 1). En la Tabla 3 se observa que, tanto en las cabras primera lactación como en las de dos o más lactaciones, el RCS del grupo SC se elevó significativamente en los Días +1 y +2 , respecto al grupo Control (Figura 2) La interacción Estado Sanitario*Grupo*Día tampoco resultó significativa (Tabla 1), de modo que el tratamiento hormonal para inducir celos provocó, tanto en las ubres sanas como en las infectadas, un aumento significativo del RCS (Días +1 y +2 ), respecto al grupo Control (Tabla 4; Figura 3). Un hecho a destacar es que, en las ubres sanas, el celo inducido elevó el RCS hasta alcanzar unos valores (media aritmética del orden de 2- 2,3 millones de células/ml; Figura 3a) que fueron superiores a los que mostraban las ubres infectadas (tanto del grupo SC como control) en los días anteriores a la presencia de celos inducidos (medias aritméticas alrededor de 1-1,5 millones de células/ml; Figura 3b). Esto mismo se puede observar con el RCS registrado a nivel de glándula (Figura 4).

Por otra parte, en la Figura 1 también podemos observar que en el grupo Control los recuentos se elevaron entre los días $+6 \mathrm{y}+8$, aunque las diferencias con el grupo SC no llegaron a ser significativas (Tablas 2 y 3). Esta tendencia se aprecia en los dos experimentos realizados, tanto en las cabras primíparas como en multíparas, y en las ubres/glándulas sanas como en las infectadas (Figuras 2,3 y 4).

Respecto a la producción de leche, la interacción Grupo*Día fue significativa (Tabla 1). Ello fue debido a que la producción diminuyó significativamente en el grupo SC en los días $0,+1 \mathrm{y}+2$, respecto al grupo control, mientras que en el resto del periodo experimental las diferencias no fueron significativas. En los tres días citados, la media de la producción de leche en el grupo SC fue un 13\% inferior respecto al grupo control (1959 $\mathrm{ml}$ vs $2260 \mathrm{ml}$, respectivamente; Tabla 5) 
TABLA 3. Comparación del $\operatorname{logRCS}$ (céls $/ \mathrm{ml}$ ), en la leche de ubre, entre el grupo de cabras que recibió un tratamiento de sincronización de celos (SC) y otro grupo de animales que no recibió ningún tratamiento (control), según el número de lactación de las cabras.

\begin{tabular}{|c|c|c|c|c|c|c|}
\hline \multirow{2}{*}{ Día } & \multicolumn{3}{|c|}{$\begin{array}{l}\text { Lactación } 1 \\
\quad(n=22)\end{array}$} & \multicolumn{3}{|c|}{$\begin{array}{c}\text { Lactación } \geq 2 \\
(\mathrm{n}=46)\end{array}$} \\
\hline & $\begin{array}{c}\mathrm{SC} \\
(\mathrm{n}=10)\end{array}$ & $\begin{array}{l}\text { Control } \\
(\mathrm{n}=12)\end{array}$ & Niv.Sig & $\begin{array}{c}\mathrm{SC} \\
(\mathrm{n}=24)\end{array}$ & $\begin{array}{l}\text { Control } \\
(\mathrm{n}=22)\end{array}$ & Niv.Sig \\
\hline-4 & 5.41 & 5.30 & NS & 5.67 & 5.74 & NS \\
\hline-3 & 5.29 & 5.33 & $\mathrm{NS}$ & 5.65 & 5.65 & NS \\
\hline-2 & 5.42 & 5.41 & NS & 5.66 & 5.87 & NS \\
\hline-1 & 5.84 & 5.46 & NS & 5.84 & 5.90 & NS \\
\hline $0^{\mathrm{RE}}$ & 5.79 & 5.28 & NS & 5.96 & 5.76 & NS \\
\hline 1 & 5.98 & 5.32 & $* *$ & 6.14 & 5.74 & $* *$ \\
\hline 2 & 5.88 & 5.33 & $*$ & 6.22 & 5.91 & $*$ \\
\hline 3 & 5.56 & 5.37 & NS & 5.98 & 5.83 & NS \\
\hline 4 & 5.84 & 5.55 & NS & 5.83 & 5.78 & NS \\
\hline 5 & 5.92 & 5.59 & NS & 5.91 & 5.81 & NS \\
\hline 6 & 5.90 & 5.70 & NS & 5.96 & 5.90 & NS \\
\hline 7 & 5.91 & 5.77 & NS & 6.01 & 6.19 & NS \\
\hline 8 & 5.60 & 5.78 & NS & 5.80 & 6.00 & NS \\
\hline 9 & 5.45 & 5.81 & NS & 5.80 & 5.90 & NS \\
\hline 10 & 5.40 & 5.59 & NS & 5.80 & 5.84 & NS \\
\hline 11 & 5.45 & 5.52 & NS & 5.81 & 5.82 & NS \\
\hline 12 & 5.52 & 5.59 & NS & 5.80 & 5.83 & NS \\
\hline 13 & 5.63 & 5.62 & NS & 5.79 & 5.83 & NS \\
\hline ES & 0.186 & 0.149 & - & 0.10 & 0.102 & - \\
\hline
\end{tabular}

RE: retirada de esponjas

ES: error estándar

a) Lactación $=1$

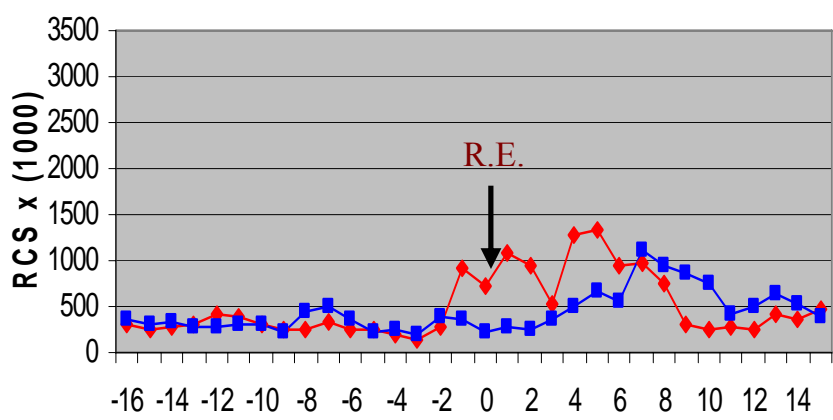

b) Lactación $\geq 2$

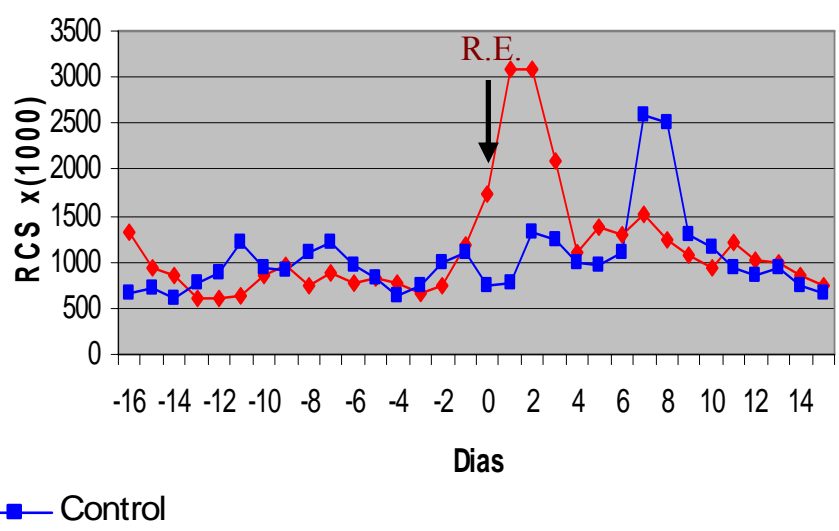

FIGURA 2 Evolución diaria de las medias aritméticas del RCS (céls/ml) en la leche de ubre en el grupo de cabras SC (sincronización de celos) y Control, según el número de lactación de las cabras. R.E.: retirada de las esponjas. 
TABLA 4. Comparación del $\log R C S$ (céls $/ \mathrm{ml}$ ), en la leche de ubre, entre el grupo de cabras que recibió un tratamiento de sincronización de celos (SC) y otro grupo de animales que no recibió ningún tratamiento (control), según el estado sanitario de la ubre

\begin{tabular}{|c|c|c|c|c|c|c|}
\hline \multirow{2}{*}{ Día } & \multicolumn{3}{|c|}{$\begin{array}{c}\text { Sanas } \\
(\mathrm{n}=45)\end{array}$} & \multicolumn{3}{c|}{$\begin{array}{c}\text { Infectadas } \\
(\mathrm{n}=23)\end{array}$} \\
\cline { 2 - 7 } & $\begin{array}{c}\mathrm{SC} \\
(\mathrm{n}=23)\end{array}$ & $\begin{array}{c}\text { Control } \\
(\mathrm{n}=22)\end{array}$ & Niv.Sig & $\begin{array}{c}\text { SC } \\
(\mathrm{n}=11)\end{array}$ & $\begin{array}{c}\text { Control } \\
(\mathrm{n}=12)\end{array}$ & Niv.Sig \\
\hline-4 & 5.32 & 5.37 & $\mathrm{NS}$ & 5.76 & 5.71 & $\mathrm{NS}$ \\
\hline-3 & 5.25 & 5.34 & $\mathrm{NS}$ & 5.68 & 5.97 & $\mathrm{NS}$ \\
\hline-2 & 5.34 & 5.43 & $\mathrm{NS}$ & 5.76 & 5.83 & $\mathrm{NS}$ \\
\hline-1 & 5.50 & 5.56 & $\mathrm{NS}$ & 6.10 & 5.80 & $\mathrm{NS}$ \\
\hline 0 & 5.61 & 5.40 & $\mathrm{NS}$ & 6.04 & 5.64 & $\mathrm{NS}$ \\
\hline 1 & 5.89 & 5.41 & $* * *$ & 6.22 & 5.69 & $*$ \\
\hline 2 & 5.87 & 5.42 & $* *$ & 6.23 & 5.83 & $*$ \\
\hline 3 & 5.61 & 5.46 & $\mathrm{NS}$ & 6.04 & 5.76 & $\mathrm{NS}$ \\
\hline 4 & 5.54 & 5.52 & $\mathrm{NS}$ & 6.21 & 5.87 & $\mathrm{NS}$ \\
\hline 5 & 5.56 & 5.58 & $\mathrm{NS}$ & 6.29 & 5.86 & $\mathrm{NS}$ \\
\hline 6 & 5.59 & 5.61 & $\mathrm{NS}$ & 6.25 & 6.05 & $\mathrm{NS}$ \\
\hline 7 & 5.71 & 5.88 & $\mathrm{NS}$ & 6.30 & 6.13 & $\mathrm{NS}$ \\
\hline 8 & 5.62 & 5.79 & $\mathrm{NS}$ & 5.99 & 6.03 & $\mathrm{NS}$ \\
\hline 9 & 5.48 & 5.75 & $\mathrm{NS}$ & 5.82 & 5.96 & $\mathrm{NS}$ \\
\hline 10 & 5.49 & 5.64 & $\mathrm{NS}$ & 5.81 & 5.84 & $\mathrm{NS}$ \\
\hline 11 & 5.44 & 5.58 & $\mathrm{NS}$ & 5.78 & 5.78 & $\mathrm{NS}$ \\
\hline 12 & 5.42 & 5.53 & $\mathrm{NS}$ & 5.80 & 5.83 & $\mathrm{NS}$ \\
\hline 13 & 5.48 & 5.55 & $\mathrm{NS}$ & 5.90 & 5.91 & $\mathrm{NS}$ \\
\hline $\mathrm{ES}$ & 0.110 & 0.112 & - & 0.160 & 0.124 & - \\
\hline $\mathrm{RE}$ & & & & & \\
\hline
\end{tabular}

RE: retirada de esponjas $\quad$ ES: error estándar

a) Ubras sanas

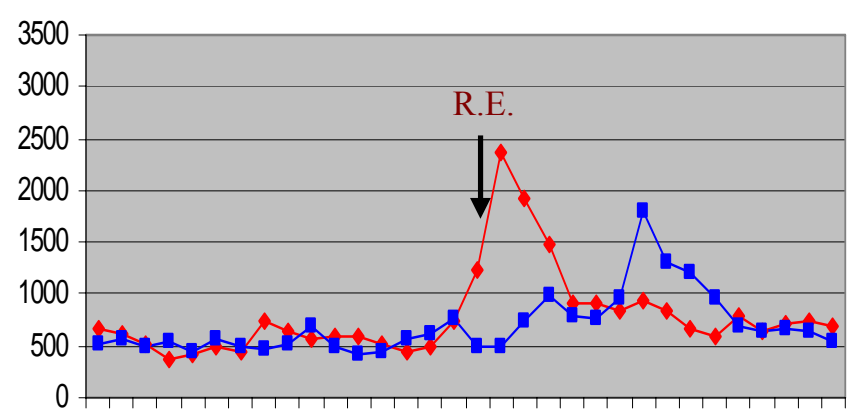

$\begin{array}{llllllllllllllll}-16 & -14 & -12 & -10 & -8 & -6 & -4 & -2 & 0 & 2 & 4 & 6 & 8 & 10 & 12 & 14\end{array}$

Dias

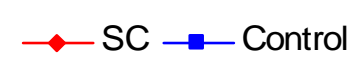

b) Ubres infectadas

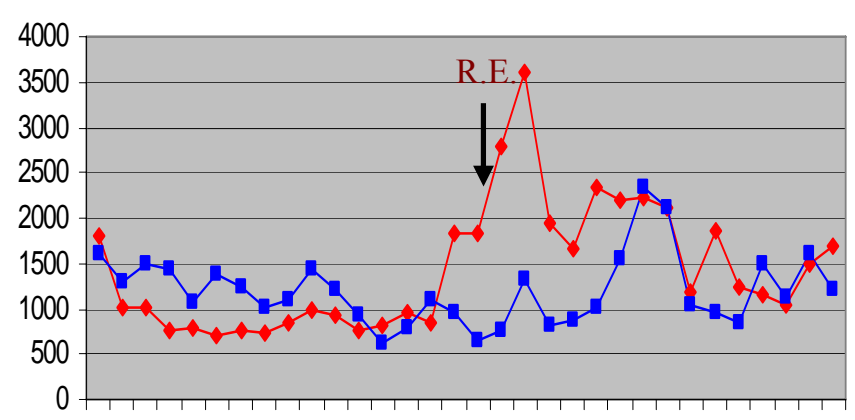

$\begin{array}{llllllllllllllll}-16 & -14 & -12 & -10 & -8 & -6 & -4 & -2 & 0 & 2 & 4 & 6 & 8 & 10 & 12 & 14\end{array}$

Dias

FIGURA 3 Evolución diaria de las medias aritméticas del RCS (x10 $0^{3}$ céls $\left./ \mathrm{ml}\right)$ en la leche de ubre en el grupo de cabras SC (sincronización de celos) y Control, según el estado sanitario de la ubre 
a) Glán. Sanas. Lactación $=1$

( $\mathrm{SC}, \mathrm{n}=16$; Control, $\mathrm{n}=18$ )

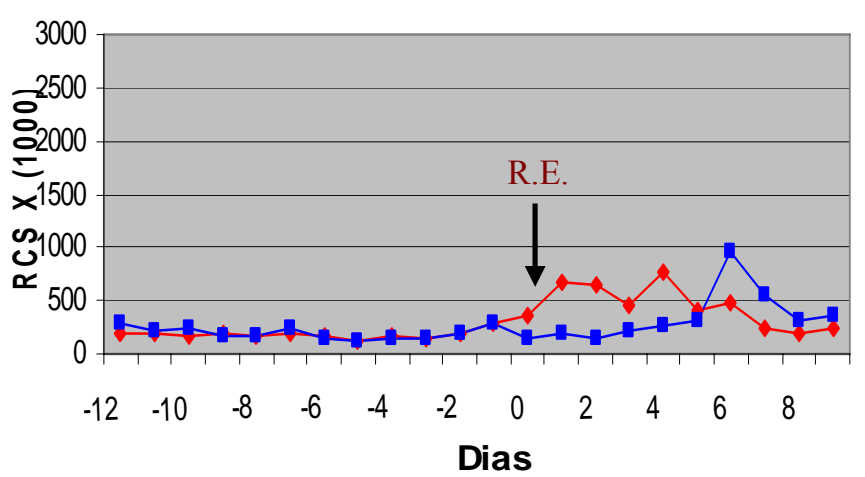

b) Glán. Sanas.Lactación $\geq \mathbf{2}$

(SC, $\mathrm{n}=30$; Control, $\mathrm{n}=26$ )

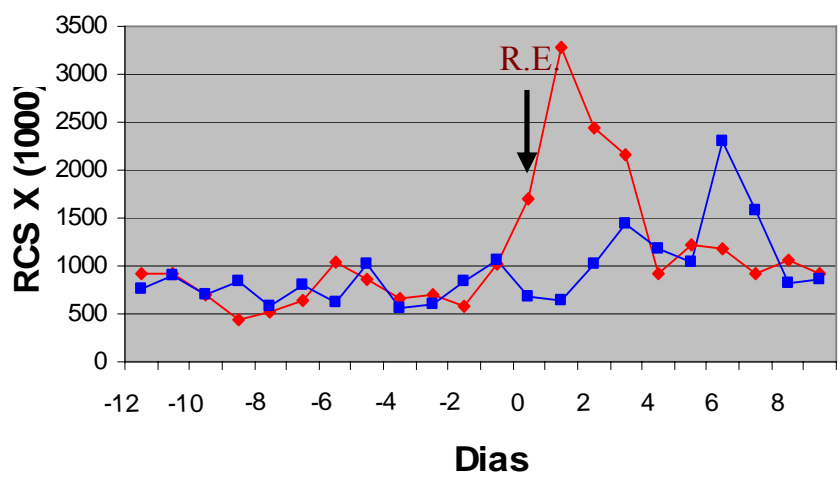

$\leftrightarrow$ SC $\rightarrow$ Control

a) Glán. Infectadas. Lactación $=1$

(SC, $\mathrm{n}=4$; Control, $\mathrm{n}=6$ )

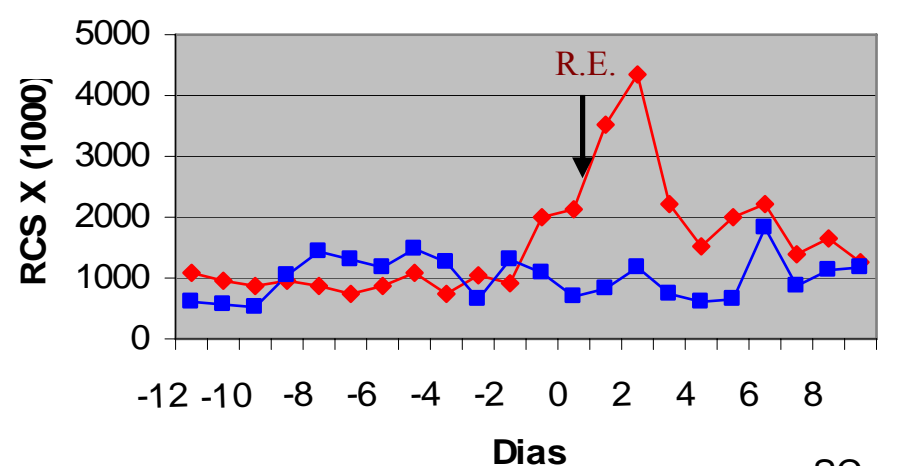

$\multimap$ SC $\rightarrow$ Control b) Glán. Infectadas.Lactación $\geq \mathbf{2}$

(SC, $\mathrm{n}=18$; Control, $\mathrm{n}=18$ )

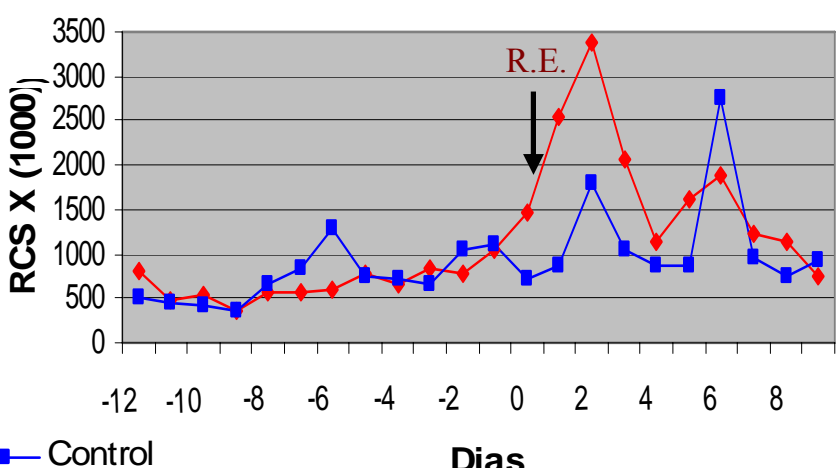

Dias

FIGURA 4. Evolución diaria de las medias aritméticas del RCS (céls $/ \mathrm{ml}$ ) en la leche de glándula en el grupo de cabras SC (sincronización de celos) y Control, según el estado sanitario de la ubre y el número de lactación. RE: retirada de las esponjas.

En cuanto a la composición de la leche, la interacción Grupo*Día fue significativa para la proteína $(\mathrm{P}<0.001)$ y la materia seca $(\mathrm{p}<0.01)$, y no lo fue para la grasa y la lactosa (Tabla 1).

En el caso de la proteína, la leche del grupo SC presentó valores significativamente más elevados en los días $0,+1,+2 \mathrm{y}+3$, mientras que en el resto del periodo experimental las diferencias no fueron significativas (Tabla 5). Lo mismo ocurrió con la materia seca, aunque en este caso las diferencias fueron significativas tan solo en los días 0 y +1 (Tabla $5)$. 
(1)

\begin{tabular}{|c|c|c|c|c|c|c|c|c|c|c|c|c|c|c|c|c|c|c|c|c|}
\hline \multirow{3}{*}{ 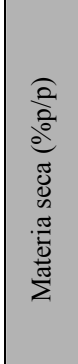 } & $\begin{array}{l}\stackrel{\infty}{\dot{00}} \\
\dot{n} \\
\dot{\vec{z}}\end{array}$ & $\tilde{Z}$ & $\tilde{z}$ & $\tilde{z}$ & $\tilde{Z}$ & $\tilde{z}$ & * & * & $\tilde{z}$ & $\tilde{z}^{n}$ & $\bar{z}$ & $\tilde{z}$ & $\tilde{z}$ & $\bar{z}$ & $\tilde{z}$ & $\tilde{z}$ & $\tilde{z}$ & $\tilde{z}$ & $\tilde{z}$ & \\
\hline & \begin{tabular}{|l}
$\overline{\bar{g}}$ \\
$\bar{\Xi}$
\end{tabular} & 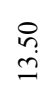 & 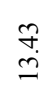 & $\stackrel{n}{n}$ & $\stackrel{\vec{\vartheta}}{\vec{g}}$ & $\underset{g}{\stackrel{+}{~}}$ & $\underset{\Xi}{=}$ & $\begin{array}{l}0 \\
\stackrel{m}{2}\end{array}$ & $\begin{array}{l}\tilde{I} \\
\stackrel{-}{2}\end{array}$ & $\stackrel{\circ}{\stackrel{9}{g}}$ & $\stackrel{\ddot{n}}{\ddot{n}}$ & $\stackrel{\circ}{\stackrel{m}{g}}$ & $\begin{array}{l}\stackrel{\infty}{\infty} \\
\text { İ }\end{array}$ & 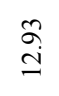 & $\vec{\sigma}$ & $\stackrel{\vec{m}}{\stackrel{m}{2}}$ & $\underset{\vec{g}}{\vec{g}}$ & $\begin{array}{l}\infty \\
\stackrel{\text { I }}{-}\end{array}$ & $\begin{array}{l}\infty \\
\infty \\
\stackrel{\sim}{\simeq}\end{array}$ & $\stackrel{5}{\circ}$ \\
\hline & U & 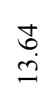 & $\stackrel{\infty}{\stackrel{\infty}{\rightarrow}}$ & 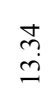 & $\stackrel{\vec{m}}{\stackrel{\vec{g}}{2}}$ & $\underset{\mathfrak{g}}{\stackrel{f}{\rightarrow}}$ & $\stackrel{\hat{\theta}}{g}$ & 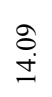 & $\begin{array}{l}\vec{n} \\
\vec{n}\end{array}$ & $\stackrel{\widehat{్}}{\underline{\Omega}}$ & $\begin{array}{l}\stackrel{n}{n} \\
\stackrel{n}{n}\end{array}$ & 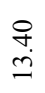 & $\stackrel{\circ}{\stackrel{ }{g}}$ & $\begin{array}{l}\check{a} \\
\text { త }\end{array}$ & $\begin{array}{l}\stackrel{\infty}{ } \\
\stackrel{\text { I }}{-}\end{array}$ & $\stackrel{\text { a }}{\mathrm{d}}$ & $\underset{d}{\stackrel{t}{g}}$ & $\begin{array}{l}\vec{\partial} \\
\dot{\vec{g}}\end{array}$ & $\begin{array}{l}\stackrel{\infty}{ } \\
\stackrel{]}{]}\end{array}$ & స్రి \\
\hline \multirow[b]{2}{*}{$\int_{\tilde{c}}^{a}$} & $\mid \begin{array}{l}\text { bj } \\
\dot{\omega} \\
\vec{z} \\
\dot{z}\end{array}$ & $\tilde{z}$ & $\tilde{z}$ & $\tilde{z}$ & $\tilde{z}$ & $\tilde{z}$ & $\tilde{z}$ & $\tilde{z}$ & $\tilde{z}$ & $\tilde{z}$ & $\tilde{z}$ & $\tilde{z}$ & $\tilde{z}$ & $\bar{z}$ & $\tilde{z}$ & $\tilde{z}$ & $\tilde{z}$ & $\tilde{z}$ & $\tilde{z}$ & ' \\
\hline & \begin{tabular}{|l}
$\overline{0}$ \\
$\overline{0}$
\end{tabular} & $\stackrel{?}{+}$ & $\underset{\forall}{\stackrel{J}{*}}$ & $\stackrel{?}{\&}$ & 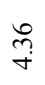 & $\underset{f}{\stackrel{f}{\forall}}$ & $\stackrel{?}{+}$ & 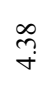 & 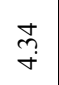 & 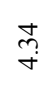 & $\stackrel{\widetilde{z}}{+}$ & ণิ & $\stackrel{\text { Tे}}{\underset{f}{2}}$ & $\stackrel{\infty}{\underset{\sim}{+}}$ & 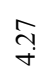 & $\stackrel{\sim}{\sim}$ & $\stackrel{\infty}{\stackrel{\infty}{+}}$ & $\underset{\tilde{\sigma}}{\sim}$ & 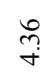 & $\stackrel{\tilde{o}}{0}$ \\
\hline
\end{tabular}

范

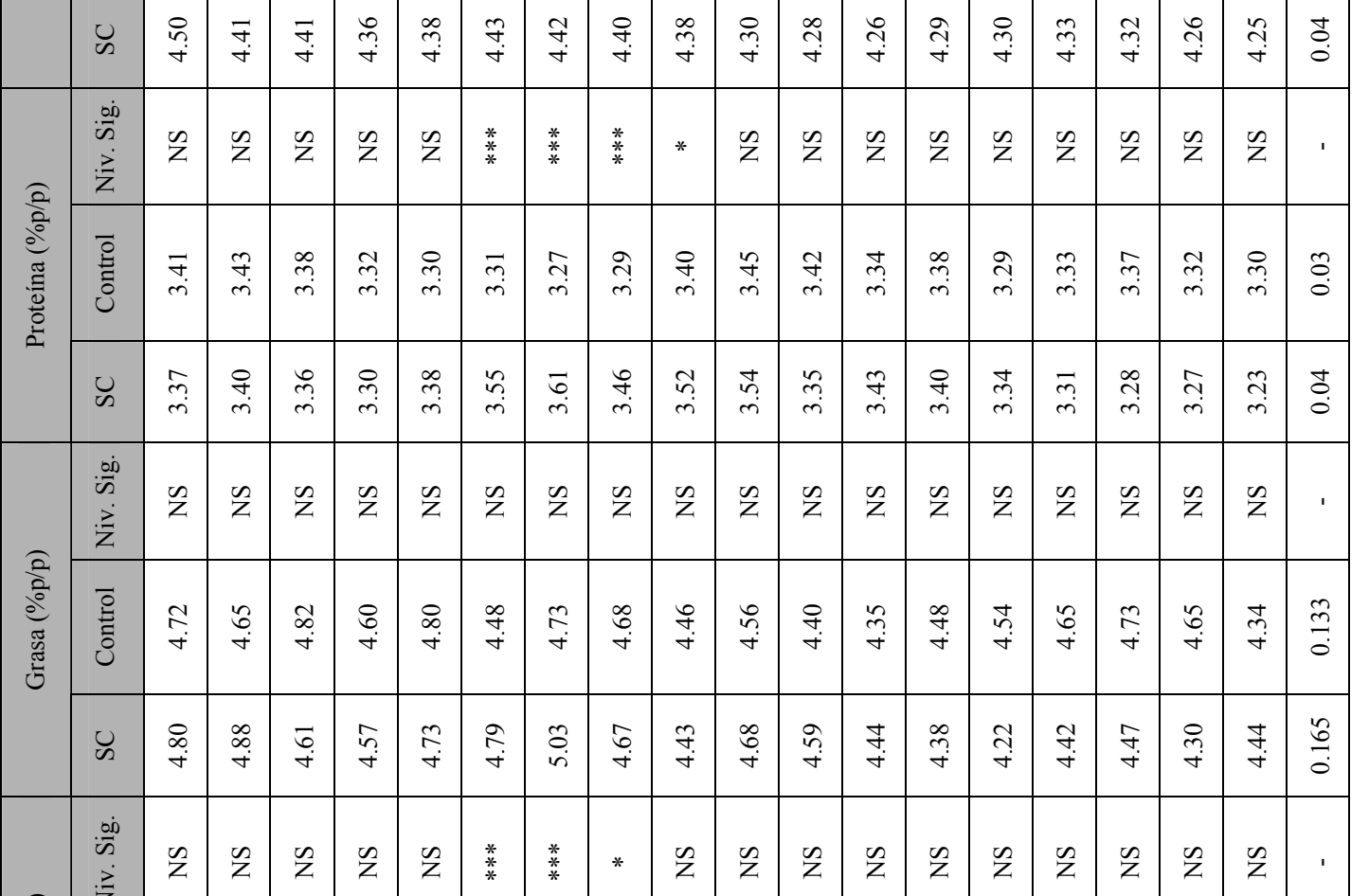




\subsection{Elevaciones transitorias del RCS}

A lo largo del periodo experimental se identificaron el mismo número $(n=29)$ de elevaciones transitorias del RCS ( $\mathrm{ET}_{\mathrm{RCS}}$ ) en el grupo SC que en el grupo Control, si bien su distribución temporal fue diferente. Esto puede observarse en la Figura 5, donde se ha representado, para cada día, el número de cabras que presentaban una $\mathrm{ET}_{\mathrm{RCS}}$ en cada uno de los grupos experimentales. En el grupo SC la mayor frecuencia de $\mathrm{ET}_{\mathrm{RCS}}$ apareció en los días $+1,+2 \mathrm{y}+3$, de modo que 20 cabras del grupo SC tuvieron una $\mathrm{ET}_{\mathrm{RCS}}$ en uno o varios de estos tres días. Por tanto, vemos que de las 34 cabras del grupo SC que manifestaron el celo entre los días +1 y +2 , casi el $60 \%$ mostraron una $\mathrm{ET}_{\mathrm{RCS}}$ en los tres días citados anteriormente. También se observa en la Figura 5 que en los días +6 y +7 un $26 \%$ de las cabras del grupo SC (9 de 34) manifestaron una $\mathrm{ET}_{\mathrm{RCS}}$. Por otra parte, en el grupo Control, la mayor frecuencia de $\mathrm{ET}_{\mathrm{RCS}}$ se produjo entre los días $+7 \mathrm{y}+9$, afectando a al $41 \%$ de los animales de este grupo (14 de 34).

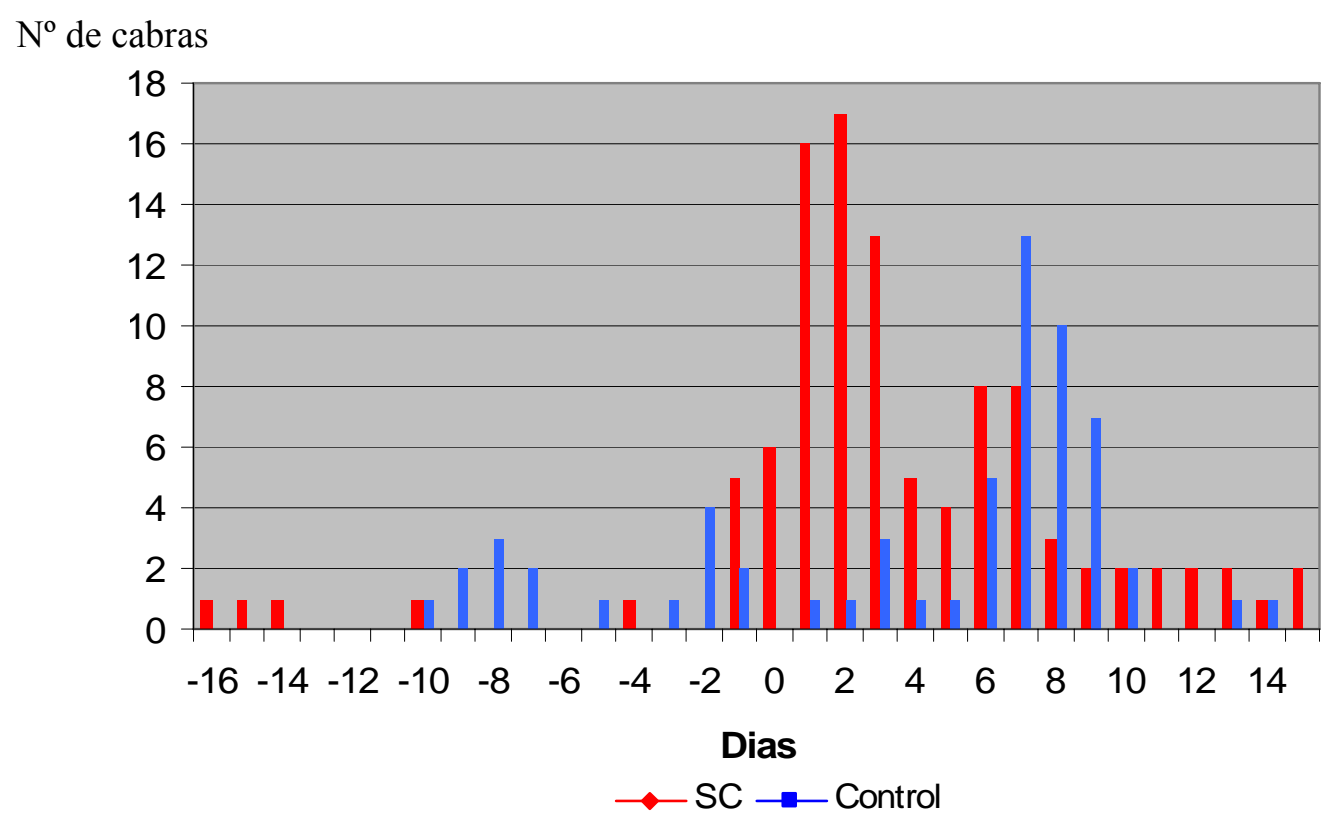

FIGURA 5. Evolución diaria del número de cabras que presentaban en un mismo día una

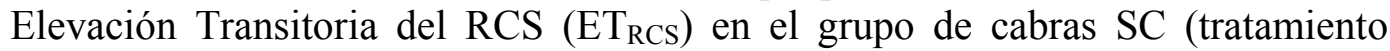
hormonal de sincronización de celos) y Control.

La mayoría de las $\mathrm{ET}_{\mathrm{RCS}}$ tuvieron una duración de 1 a 3 días, tanto en el grupo SC como el grupo Control. Esta misma duración también se observó tanto en las cabras sanas 
como en infectadas, y en las de primera lactación como en las de lactaciones superiores (Tablas 6a y 6b).

TABLA 6. Distribución de las $\mathrm{ET}_{\mathrm{RCS}}$ identificadas en el grupo de cabras $\mathrm{SC}$ (sincronización de celos) y Control, según el estado sanitario de la ubre, el número de lactación y los día que duró cada $\mathrm{ET}_{\mathrm{RCS}}$.

\section{a) Grupo SC}

\begin{tabular}{|c|c|c|c|c|c|c|c|}
\hline \multirow{2}{*}{$\begin{array}{l}\text { E.S. } \\
\text { Ubre }\end{array}$} & \multirow{2}{*}{$\begin{array}{c}\mathrm{N}^{\mathrm{a}} \\
\text { Lactació }\end{array}$} & \multicolumn{6}{|c|}{ DIAS QUE DURÓ CADA ET $\mathrm{RCS}_{\mathrm{R}}$} \\
\hline & & 1 & 2 & 3 & 4 & $\geq 5$ & Total \\
\hline \multirow{3}{*}{ Sana } & 1 & 2 & 3 & 0 & 1 & 1 & 7 \\
\hline & $\geq 2$ & 4 & 3 & 3 & 0 & 2 & 12 \\
\hline & Todas & 6 & 6 & 3 & 1 & 3 & 19 \\
\hline \multirow{3}{*}{ Infectada } & 1 & 0 & 1 & 2 & 0 & 0 & 3 \\
\hline & $\geq 2$ & 0 & 2 & 3 & 0 & 2 & 7 \\
\hline & Todas & 0 & 3 & 5 & 0 & 2 & 10 \\
\hline \multirow{3}{*}{ Todas } & 1 & 2 & 4 & 2 & 1 & 1 & 10 \\
\hline & $\geq 2$ & 4 & 5 & 6 & 0 & 4 & 18 \\
\hline & Todas & 6 & 9 & 8 & 1 & 5 & 29 \\
\hline
\end{tabular}

\section{b) Grupo Control}

\begin{tabular}{|c|c|c|c|c|c|c|c|}
\hline \multirow{2}{*}{$\begin{array}{c}\text { E.S. } \\
\text { Ubre }\end{array}$} & $\mathrm{N}^{\mathrm{a}}$ & \multicolumn{8}{|c|}{ DIAS QUE DURÓ CADA ET } \\
Lactació
\end{tabular}

Por otra parte, también podemos destacar que la proporción de cabras que manifestaron al menos una $\mathrm{ET}_{\mathrm{RCS}}$ a lo largo de todo el experimento no difirió significativamente $(\mathrm{p}>0.05)$ entre ambos grupos experimentales, considerando todos los animales (73.5\% y $64.7 \%$ en los grupos SC y Control, respectivamente; Tabla 7) o bien considerando de forma separada los animales libres de IIM (73.9\% y 68.1\%), animales con 
IIM (72.7\% y 58.3\%) y en las cabras multíparas (70.8\% y $77.2 \%)$. En las primíparas hubo más diferencia entre el grupo SC (80\%) y el grupo Control (41.6\%), de modo casi llegó a ser significativa $(\mathrm{p}=0.06$; Tabla 7$)$.

En el grupo $\mathrm{SC}$, la proporción de cabras que manifestaron una $\mathrm{ET}_{\mathrm{RCS}}$ no difirió significativamente entre las cabras de primera y segunda o más lactaciones $(80.0 \%$ y $70.8 \%$, respectivamente). Por el contrario, en el grupo Control, la proporción de cabras primíparas que manifestaron una $\mathrm{ET}_{\mathrm{RCS}}$ fue significativamente inferior respecto a las cabras multíparas (41.6\% y 77.2\%, respectivamente; $\mathrm{p}<0.05$; Tabla 7$)$.

TABLA .7 Numero de cabras (n) que manifestaron al menos una $\mathrm{ET}_{\mathrm{RCS}}$ a lo largo del experimento en el grupo SC (sincronización de celos) y Control, según número de lactación y estado sanitario de la ubre

\begin{tabular}{|c|c|c|c|c|c|c|c|c|c|c|}
\hline \multirow{3}{*}{ Factor } & \multicolumn{10}{|c|}{ Grupo } \\
\hline & \multicolumn{3}{|c|}{$\mathrm{SC}$} & \multicolumn{3}{|c|}{ Control } & \multirow{2}{*}{ Niv. Sig } & \multicolumn{3}{|c|}{ Total } \\
\hline & $\mathrm{n}$ & & $\%$ & $\mathrm{n}$ & & $\%$ & & $\mathrm{n}$ & & $\%$ \\
\hline Lactación 1 & 8 & $(10)$ & 80 & 5 & (12) & 41.6 & $\begin{array}{c}\mathrm{NS} \\
(p=0.06)\end{array}$ & 13 & $(22)$ & 59.1 \\
\hline Lactación $\geq 2$ & 17 & (24) & 70.8 & 17 & (22) & 77.2 & NS & 34 & (46) & 73.9 \\
\hline Niv.sig & \multicolumn{3}{|c|}{ NS } & \multicolumn{3}{|c|}{ * } & & \multicolumn{3}{|c|}{ NS } \\
\hline Cabras Sanas & 17 & $(23)$ & 73.9 & 15 & (22) & 68.1 & NS & 32 & $(45)$ & 71.1 \\
\hline Cabras infectadas & 8 & (11) & 72.7 & 7 & $(12)$ & 58.3 & NS & 15 & (23) & 65.2 \\
\hline Niv.sig & \multicolumn{3}{|c|}{$\mathrm{NS}$} & \multicolumn{3}{|c|}{$\mathrm{NS}$} & - & \multicolumn{2}{|c|}{ NS } & \\
\hline Todas & 25 & $(34)$ & 73.5 & 22 & (34) & 64.7 & NS & 47 & $(68)$ & 69.1 \\
\hline
\end{tabular}

( ) : número total de cabras en cada subgrupo

En las $\mathrm{ET}_{\mathrm{RCS}}$ identificadas, los recuentos aumentaron entre 2.5 y 180 veces respecto a los valores previos al inicio de la elevación. En la Figura 6 se ha representado el incremento máximo del RCS durante cada elevación, en relación al RCS que existía antes de iniciarse la elevación (RCSprevio: media de los tres días previos al inicio de la ET). Este incremento máximo se ha expresado de dos formas, como diferencia (RCSmáxRCSprevio; Figura 6a) y como relación (RCSmáx/RCSprevio, Figura 6b). Debemos precisar que, para no tener problemas de escala, en la Figura $6 \mathrm{~b}$ no se han representado un caso de $\mathrm{ET}_{\mathrm{RCS}}$ en el que se incrementó 180 veces el RCS (pasó de 80 mil a 15 millones de céls $/ \mathrm{ml}$ en un solo día, para descender en 5 días a 100 mil céls $/ \mathrm{ml}$ ). En la citada figura se aprecia que, a medida que las cabras presentaban mayores recuentos previos, tendió a aumentar el incremento de RCS expresado como diferencia (RCSmáx-RCSprevio; Figura 
6a), pero este incremento tendió a disminuir cuando se expresa como relación (RCSmáx/RCSprevio; Figura 6b). En ambos casos la regresión lineal fue significativa $(\mathrm{p}<0.05$ y $\mathrm{p}<0.01$, respectivamente)
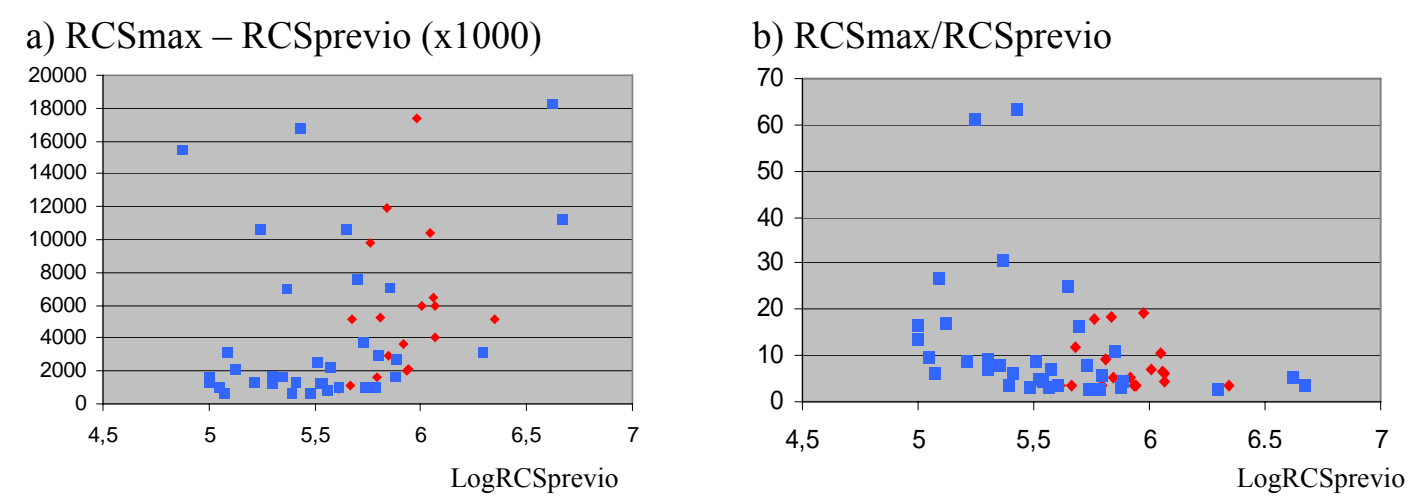

- ubres infectadas $\square$ ubres sanas

FIGURA 6. Incremento máximo del RCS (céls/ml) durante las $\mathrm{ET}_{\mathrm{RCS}}$, según el RCS (en $\log$ ) que tenían los animales en los tres días previos al estrés (RCSprevio). Incremento de RCS expresado como: a) diferencia (RCSmax-RCSprevio) y b) relación (RCSmax/RCSprevio).

Se hizo un análisis estadístico para estudiar si el incremento de RCS durante las $\mathrm{ET}_{\mathrm{RCS}}$ dependía del estado sanitario de la ubre, el número de lactación o el tipo de elevación (provocadas por el celo inducido o otras elevaciones), encontrando que solo el número de lactación llegaba a tener un efecto significativo cuando el incremento se expresa como diferencia (menores elevaciones en las cabras de primer parto que en las de dos o más partos; $\mathrm{p}<0.05$ )

En la Tabla 8 se presenta el recuento de PMN por glándula en 6 cabras libres de IIM del grupo SC que manifestaron simultáneamente síntomas de celo y una ET $_{\mathrm{RCS}}$, considerando 5 días: dos días previos al inicio de la elevación, el día de la elevación en que se alcanzaron los máximos recuentos, y dos días posteriores a la finalización de la elevación. Además, en dicha Tabla también se recoge la evolución del recuento de PMN en 6 cabras sanas del grupo Control (sin manifestar celo ni $\mathrm{ET}_{\mathrm{RCS}}$ ) durante los mismos 5 días considerados anteriormente. La interacción Grupo*Día no afectó significativamente al porcentaje de PMN, observándose que en el grupo SC, este porcentaje fue similar en el día de la $\operatorname{ET}_{\mathrm{RCS}}(55.9 \%)$, respecto a los días anteriores (56-57\%) y posteriores a dicha 
elevación (48-53\%). Por consiguiente, en los días en que se produjo el aumento del RCS, también se elevó significativamente el recuento total de PMN, llegando a alcanzar un valor medio, en log, de 6.02 (media geométrica de 1.047 .000 cels $/ \mathrm{ml}$ ), el cual fue significativamente más elevado que los valores obtenidos en los días anteriores $(\operatorname{logRCS}=5.38$ y 5.52$)$ y posteriores (logRCS: 5.62 y 5.66$)$ a las elevaciones transitorias. Por el contrario, en las cabras del grupo Control, el recuento total de células somáticas, el porcentaje de PMN y el recuento total de PMN no variaron significativamente en los cinco días considerados.

TABLA 8. Evolución durante 5 días del RCS (en log), del porcentaje de leucocitos polimorfonucleares (PMN) y del recuento de PMN (en log) en la leche de glándula de 6 cabras del grupo SC (sincronización de celos) y 6 cabras del grupo Control..

\begin{tabular}{|c|c|c|c|c|c|c|}
\hline \multirow{2}{*}{ Día ${ }^{1}$} & \multicolumn{2}{|c|}{ LOG RCS (céls/ml) } & \multicolumn{2}{|c|}{ PMN (\%) } & \multicolumn{2}{|c|}{ LOG RPMN (céls/ml) } \\
\hline & Grupo SC & Control & Grupo SC & Control & Grupo SC & Control \\
\hline-2 & $5.62^{a}$ & 5.30 & 56.3 & 58.0 & $5.38^{\mathrm{a}}$ & 5.02 \\
\hline-1 & $5.75^{\mathrm{ad}}$ & 5.25 & 57.0 & 52.6 & $5.52^{\mathrm{ad}}$ & 4.94 \\
\hline $\mathrm{ET}_{\mathrm{RCS}}$ & $6.26^{b}$ & 5.24 & 55.9 & 57.3 & $6.02^{b}$ & 5.00 \\
\hline 1 & $5.93^{c}$ & 5.23 & 53.4 & 54.3 & $5.66^{c}$ & 4.96 \\
\hline 2 & $5.89^{\mathrm{cd}}$ & 5.25 & 48.0 & 52.1 & $5.62^{\mathrm{cd}}$ & 4.96 \\
\hline ES & 0.11 & 0.13 & 4.3 & 3.8 & 0.11 & 0.15 \\
\hline Niv.sig & $* *$ & NS & NS & NS & $* * *$ & NS \\
\hline $\begin{array}{l}\text { Niv sig. } \\
\text { Grup*Día }\end{array}$ & \multicolumn{2}{|c|}{$* *$} & \multicolumn{2}{|c|}{ NS } & \multicolumn{2}{|c|}{$* * *$} \\
\hline
\end{tabular}

Todas las cabras estaban libres de IIM. Las cabras del grupo SC manifestaron celo y, simultáneamente, una $\mathrm{ET}_{\mathrm{RCS}}$

${ }^{1}$ Dos días previos al inicio de la $\mathrm{ET}_{\mathrm{RCS}}(-2 \mathrm{y}-1)$, el día en que se produjo el RCS máximo $\left(\mathrm{ET}_{\mathrm{RCS}}\right)$ y los días posteriores a la finalización de la $\mathrm{ET}_{\mathrm{RCS}}(+1 \mathrm{y}+2)$

ES: error estándar

$a, b, c, d$ Letras diferentes en una misma columna indica diferencias significativas $(\mathrm{p}<0.05)$

\section{DISCUSIÓN}

Este trabajo ha confirmado que los celos inducidos hormonalmente provocan un aumento transitorio en los recuentos medios de un lote de cabras. Durante los tres primeros días alrededor del celo aumentaron significativamente los recuentos, pero también se 
observó en el lote tratado una ligera elevación a los 5-6 días tras los primeros celos. Además, también es remarcable que en el lote Control aumentaran los recuentos a la semana de iniciarse los celos en el lote SC. Por ejemplo, en esos días un $41 \%$ de las cabras del lote Control presentaron una $\mathrm{ET}_{\mathrm{RCS}}$. Este incremento del RCS en el grupo Control ya fue observado por Mcdougall and Voermans (2002), y supuestamente indicaría que las cabras que salieron en celo por el tratamiento hormonal inducirían una agrupación de celos en las cabras del grupo Control que estuvieran en anoestro estacional (Walkden-Brown et al., 1999). Por tanto, es probable que en una explotación que lleve a cabo una inducción de celos (tratamientos hormonales o efecto macho) los recuentos de la leche de tanque permanezcan más elevados durante casi una semana tras el inicio de los primeros celos.

De acuerdo a Moroni et al. (2007), el aumento del RCS se inicia con la regresión luteal (disminución de progesterona) y aumento de los estrógenos en sangre. Sin embargo, en nuestro caso hubo bastante variabilidad individual en la relación entre el celo y el RCS. Por ejemplo, solo el $60 \%$ de las cabras que estaban en celo presentaron una $\mathrm{ET}_{\mathrm{RCS}}$; además, en algunos de estos animales los recuentos empezaron a aumentar en los días -1 y 0 (ambos, antes de retirar las esponjas) y en otros fue en el día +1 e incluso en el día +2 .

El efecto del celo sobre el RCS no llegó a diferir significativamente entre las ubres sanas e infectadas (interacción ES*Grupo*Día no significativo), lo cual coincide con lo encontrado por Mcdougall y Voermans (2002). Por otra parte, el citado efecto tampoco difirió significativamente según el número de lactación (NL) de las cabras (interacción NL*Grupo*Día no significativo). No obstante, otros datos sugieren que el celo incrementa en menor medida los recuentos en las cabras primíparas que en las multíparas. Por ejemplo, considerando exclusivamente las glándulas sanas del lote SC, durante el celo las medias aritméticas de los recuentos aumentaron en las cabras primíparas desde 200.000 hasta 600.000 céls $/ \mathrm{ml}$, mientras que en las multíparas este incremento fue mayor, desde 600.000 hasta 3.200.000 céls/ml (Figura 4). Además, en las $\mathrm{ET}_{\mathrm{RCS}}$ identificadas, el incremento máximo alcanzado fue menor en las cabras primíparas que en las multíparas. No obstante, no se dispone de ningún trabajo en la bibliografía con el que comparar estos resultados.

El celo también provocó un moderado descenso en la producción de leche (año 2), lo cual ya había sido descrito anteriormente por otros autores (Peaker and Linzell, 1974). 
Mcdougall and Voermans (2002) también observan que el celo tiende a disminuir la producción de leche, aunque las diferencias no llegaron a ser significativas. En cualquier caso, el descenso productivo observado en nuestro trabajo en modo alguno puede explicar, por si solo, a través de un efecto de dilución/concentración, el aumento del RCS (las medias aritméticas pasaron de 900.000 a 2.500 .000 de céls $/ \mathrm{ml}$ es decir un incremento de más del 180\%, mientras que la producción tan solo disminuyó en un 13\%), lo cual discrepa de lo sugerido por Paape et al (2001). Respecto a la composición de la leche, el celo incrementó significativamente la proteína y no afectó a la grasa y lactosa, lo cual coincide con lo observado por Moroni et al. (2007) y Christodoulopoulos et al. (2008).

Las $\mathrm{ET}_{\mathrm{RCS}}$ acaecidas durante los celos inducidos fueron similares en duración y recuentos máximos al resto de $\mathrm{ET}_{\mathrm{RCS}}$ identificadas durante el experimento, y a las que fueron identificadas en el Estudio 2. Por tanto, es probable que el aumento de los recuentos medios del lote que se observó puntualmente en este último Estudio fuera provocados por una agrupación de celos. No obstante, queda abierta la posibilidad de que existan otros factores, como el estrés, que también pudieran provocar estas $\mathrm{ET}_{\mathrm{RCS}}$, tal y como han sugerido otros autores (Lerondelle et al., 1992; Corrales et al., 1997; Salama et al., 2003; Karzis et al., 2004). Resulta interesante el hecho de que en las $\mathrm{ET}_{\mathrm{RCS}}$ el incremento de los recuentos (como diferencia) tiende a ser más elevado en aquellas cabras que parten de un mayor RCS antes de la elevación. Sin embargo, cuando el incremento se expresa en porcentaje, la tendencia es justo la contraria.

En este trabajo no hemos podido demostrar que el incremento de RCS que se produce durante el celo sea debido principalmente a un incremento de los leucocitos PMN, dado que su porcentaje no varió respecto a los valores obtenidos antes y después de haberse producido las elevaciones en los recuentos. Aunque no podemos saber si las células epiteliales también se incrementan durante el celo, el resultado anterior confirma que no son este tipo de células las que exclusivamente incrementan durante el celo, tal y como había sido sugerido por Moroni et al. (2007). 


\section{CONCLUSIONES}

1- En el ganado caprino, el celo provoca un incremento importante del RCS en la leche. Este incremento es transitorio, con una duración normalmente de 1-3 días en una cabra individual y, probablemente, de alrededor de una semana en la leche de tanque de un lote de cabras sometidas a una sincronización de celos.

2- Estadísticamente no se ha podido demostrar que el celo eleve más los recuentos en las cabras infectadas que en las sanas, o en las multíparas respecto a las primíparas. Sin embargo, ciertos datos apuntan a que en la leche de tanque aumentarían más los recuentos en las cabras multíparas.

3- Existe una gran variabilidad individual en el efecto del celo sobre el RCS. Por ejemplo, tan solo en el $60 \%$ de los animales que estaban en celo inducido hormonalmente aumentaron suficientemente los recuentos como para ser considerados como $\mathrm{ET}_{\mathrm{RCS}}$. En el restante $40 \%$ de cabras los recuentos aumentaron en poca medida durante el celo.

4- El incremento de RCS que se produce durante el celo (aumento del 180\% en las medias aritméticas) no puede explicarse por los cambios en la producción de leche (descenso de un $13 \%$ ). Durante el celo también aumenta el porcentaje de proteína y materia seca de la leche.

5- Las $\mathrm{ET}_{\mathrm{RCS}}$ que se produjeron durante los celos inducidos tuvieron características similares al resto de $\mathrm{ET}_{\mathrm{RCS}}$ identificadas en este Estudio y en el Estudio 2 de la presente Tesis Doctoral. No obstante, no podemos descartar que existen otros factores, distintos del celo, que también pueden provocar estas $\mathrm{ET}_{\mathrm{RCS}}$.

6- Durante el celo se eleva el RCS, pero el porcentaje de leucocitos PMN en la leche no cambia. Por tanto, el celo no eleva específicamente un solo tipo de las células somáticas de la leche, como podrían ser los leucocitos PMN o las células epiteliales. 


\section{AGRADECIMIENTOS}

Al profesor A.Contreras y su equipo, de la Universidad de Murcia, por la ayuda prestada para poder realizar el recuento de PMN en la leche.

\section{BIBLIOGRAFÍA}

ALEADRI, M.; FAGIOLO, A.; CALDERINI, P.; COLAFRANCESCO, R.; GIANGOLINI, G.; ROSATI, R.; DE MICHELIS, F. (1996). Studies conduced on somatic cells counts of goats milk. En: Somatic Cells and milk of Small Ruminant. (Ed:Rubino,R.).Wageningen Pers.(EAAP,77) : 65-70. Animal. IX : 29-42.

ALI, A.K.A.; SHOOK, G.E. (1980). An optimum transformation for somatic cell concentration in milk. Journal of Dairy Science. 63:487-490.

BERGONIER,D.;DECRÉMOUX,R.;RUPP,R.;LAGRIFFOUL,G.;BERTHELOT ,X. (2003). Mastitis of dairy small ruminants. Vet. Res.34: 689-716 .INRA, EDP Sciences, DOI: $10.1051 /$ vetres :2003030

CALDERINI, P.; COLAFRANCESCO, R.; FAGIOLO, A.; REITANO ,M.E.; DE MICHELIS, F.(1996). Somatic cells count in milk from mastitis-free goats intensively reared and controlled until the sixth lactation .(1996). En: Somatic Cells and milk of Small Ruminant. (Ed:Rubino,R.).Wageningen Pers.(EAAP,77):177-181.

CHRISTODOULOPOULOS,G.; SOLOMAKOS,N.; KATSOULOS, P.D.; MINAS, A.; K KRITAS, S.K.; (2008) . Influence of oestrus on the heat stability and other characteristics of milk from dairy goats. Journal of Dairy Research 75: 64-68.

CORRAleS, J.C.; CONTRERAS, A.; SÁNChez, A.; MARCO, J.; RABAL, F. (1997). Adaptación de las condiciones de la aplicación de la directiva comunitaria 92/46 para el recuento de células somáticas, a nivel de tanque, en leche de ganado caprino. XXI Jornadas Científicas de la Sociedad Española de Ovinotecnia y Caprinotecnia. Logroño. 221-227

DE CRÉMOUX, R.; PILLET, R.; DUCELlieZ, M. ; HEUCHEL, V. ; POUTREL,B. (1996). Influence du nombre et du stade de lactation sur les numerations cellulaire du lait chevre. En: Somatic Cells and milk of Small Ruminant. (Ed:Rubino,R.).Wageningen Pers.(EAAP,77) : 161-165.

DULIN, A.; PAAPE, M.; SCHULTZE, W.; WEINLAND, B. (1983). Effect of parity, stage of lactation, and intramammary infection on concentration of somatic cells and cytoplasmic particles in goat milk. Journal of Dairy Science. 66:2426-2433. 
HARMON, R. J. (1994). Physiology of mastitis and factors affecting somatic cell. Journal of Dairy Science. 77: 2103-2112.

GONZALO, C. (2005). Somatic cell of sheep and goat milks: analytical, sanitary, productive and technological aspects. Special Issue of the International Dairy Federation 0501/part 3 (future of sheep and goats dairy sector) :128-133.

KALOGRIDOU-VASSILIADOU, D. (1992). Mastitis-related pathogens in goat milk. Small Ruminant Research. 4:203-212.

KARZIS, J.; DONKIN, E.F.; PETZER, I.M. (2004). Antibiotic residue whithdrawal periods in milk of saanen dairy goats and udder tissue irritation : preliminary results. South African Journal of Animal Science. 34: 262-265. (supp1)

LERONDELLE, C.; RICHARD, Y.; ISSARTIAL, J. (1992). Factors affecting somatic cell counts in goat milk. Small Ruminant Research. 8: 129-139.

LUENGO, C.;SANCHEZ,A.;CORRALES,J.C.; FERNANDEZ, E.; CONTRERAS, A. (2004). Influence of intramammary infection and non-infection factors on somatic cell counts in dairy goats. Journal of Dairy Research. 71: 169-174.

MARTÍNEZ, B. (2000). El recuento de células somáticas en la leche de cabra: factores de variación y efecto sobre la producción y composición de la leche. Tesis doctoral. Universidad Politécnica De Valencia .307p.

MCDOUGALL , S.; VOERMANS , M. (2002). Influence of Estrus on Somatic Cell Count in Dairy Goats .J. Dairy Science. 85:378-383.

MORONI, P. ; PISONI,G.; VAN LIER,E.; ACUÑA,S.; DAMIAN, J.P; MEIKER .; A. (2007) . Influence of estrus of dairy goat on somatic cell ,milk trait,and sex steroid receptors in the mammary gland . Journal of Animal Science. 90 : 790- 797.

PAAPE, M.J.; POUTREL, B.; CONTRERAS, A.; MARCO, J.C.; CAPUCO; A.V.(2001). Milk somatic cells and lactation in small ruminants .Journal of Dairy Science . 84 (E.suppl) E: 237-E244.

PAAPE, M.J.; WIGGANS, G.R.; BANNERMAN, D.D.; THOMAS , D.L.; SANDERS A.H.; CONTRERAS A.; MORONI P.; MILLER R.H. (2007). Monitoring goat and sheep milk somatic cell counts. Small Ruminant Research 68 1-2:114-125.

PEAKER, M.; LINZELL, J.L. (1974). The effects of oestrus and exogenous oestrogens on milk secretion in the goat. Journal of Endocrinol. 61:243-253.

PIRISI, A.;. LAURET, A; DUBEUF ,J.P. (2007). Basic and incentive payments for goat and sheep milk in relation to quality. Small Ruminant Research. 68 1-2:167-178.

SIERRA, D.; SANCHEZ, A.; LUENGO, C.; CORRALES, J. C.;MORLAES, C. T.;CONTRERAS, A.;GONZALO,C.(2006).Temperature effects on Fossomatic cell counts in goats milk. International Dairy Journal, 16: 385-387. 
SIERRA, D.; SÁNCHEZ, A.; CORRALES, J.C.; CONTRERAS, A. (1999). Differential cell counts in goat's milk. En: Milking and milk production of dairy sheep and goats. (Ed: Barillet, F. and Zervas, N. P.). Wageningen Pers. (EAAP, 95): 178-180.

SALAMA, A.A; CAJA, G.; ALBANELL, E.; SUCH, X.; CASALS, R.;PLAIXATS, J. (2003). Effects of dietary supplements of zinc-methionine on milk production, udder health and zinc metabolism in dairy goats. Journal of Dairy Research .70:9-17.

SAS. (2008). User guide statistics. Version9.1. SAS Institut, Cary, NC.

WALDEN-BROWN, S.W.; MARTIN, G.B.; RESTALL, B.J. (1999). Role of malefemale interaction in regulating reproduction in sheep and goats.Journal of Reproduction fertil.Supp.52:243-257.

WILSON, D.J.; STEWART, K.N.; SEARS, P.M. (1995). Effects of stage of lactation, production, parity and season on somatic cell counts in infected and uninfected dairy goats Small Ruminant Research. 16: 165-169. 
VII. CUARTO ESTUDIO

EFECTO DE VARIOS TIPOS DE ESTRÉS SOBRE EL RECUENTO DE CÉLULAS SOMÁTICAS EN LA LECHE DE CABRA 


\section{CUARTO ESTUDIO}

\section{EFECTO DE VARIOS TIPOS DE ESTRÉS SOBRE EL RECUENTO DE CÉLULAS SOMÁTICAS EN LA LECHE DE CABRA}

\section{INTRODUCCIÓN}

El estrés desencadena en los animales una serie de mecanismos fisiológicos, entre los cuales podemos citar la activación del eje Hipotalámo-Hipofisis-Adrenal, un incremento en la secreción de glucocorticoides (cortisol y corticosterona) y un aumento de los leucocitos en sangre, junto a una reducción del ratio linfocitos/PMN sanguíneos (Merlot, 2004). Además, en el ganado vacuno también se ha visto que el estrés del transporte aumenta, in vitro, la capacidad de migración de los neutrófilos, lo que indicaría que estos poseen una mayor capacidad para alcanzar las zonas extravasculares (Yagi et al., 2004). Por consiguiente, podríamos cuestionarnos si ciertas situaciones estresantes podrían provocar una elevación del RCS en la leche.

En vacuno, los trabajos que han estudiado la relación entre el estrés y el RCS han obtenido resultados dispares. Así, algunos autores han encontrado que al someter a los animales a un fuerte ejercicio (andar unos $10 \mathrm{~km}$ al día; Coulon et al., 2004) o al ser transportados en camiones durante 4 h (Yagi et al., 2004) se produce un aumento del cortisol en sangre y del RCS en la leche, así como un descenso de la producción de leche. Por el contrario, otros autores encontraron que el estrés térmico (Paape et al., 1973), el reagrupamiento (Arave y Albright, 1976), el traslado a nuevas instalaciones (Varner et al., 1983) o las pequeñas corrientes eléctricas ( Lefcourt et al., 1985; Gorewit et al., 1992) no afectaban al RCS. Así mismo, los intentos de aumentar el RCS administrando a los animales corticosteroides o ACTH también han obtenido resultados contradictorios, ya que en algunos casos no se encontró ningún efecto (Paape et al., 1973) mientras que en otros si que detectaron incrementos, aunque estos fueron modestos (Wegner et al., 1976). En cualquier caso, parece que el estrés podría afectar en mayor medida al RCS en las vacas 
con infección intramamaria (IIM) que en las vacas sanas (Reneau, 1986; Coulon et al., 2004).

En el ganado caprino, los factores de naturaleza no infecciosa, como el número y estado de lactación, ejercen una mayor influencia sobre el RCS que en el ganado vacuno y ovino (Bergonier et al., 2003; Haenlein, 2002; Paape et al., 2007; Raynal-Ljutovac et al., 2007). Además, en caprino también se ha comprobado que el RCS individual presenta una elevada variabilidad diaria (Randy et al., 1988; Zeng et al., 1997), mostrando en ocasiones

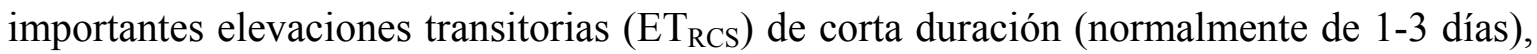
en las cuales los recuentos aumentan en una cabra de 2 a 20 veces en un solo día (Estudio 2 de la presente Tesis Doctoral). Por el momento, se ha demostrado que el celo eleva el RCS (McDougall y Voermans, 2002; Moroni, 2007; Christodoulopoulos et al., 2008) y provoca $\mathrm{ET}_{\mathrm{RCS}}$ (Estudio 3 de la presente Tesis Doctoral), pero se desconoce si existen otros factores no infecciosos que también tengan el mismo efecto. Algunos autores sugieren o han encontrado que ciertas situaciones aparentemente estresantes, relacionadas con la alimentación (acidosis ruminal), la vacunación contra la enterotoxemia (Lerondelle et al., 1992), las campañas de saneamiento (extracciones de sangre o intradermoreacciones tuberculínicas; Corrales et al., 1997) y el ordeño (Salama et al., 2003; Karzis et al., 2004) elevan el RCS. Sin embargo, son escasos los trabajos que han estudiado específicamente el efecto de un estrés fisiológico sobre el RCS en el ganado caprino. Tan solo se dispone de dos trabajos que estudiaron el estrés del transporte en camión, durante 45 minutos (McDougall et al., 2002) o 8 horas (Decarvalho et al., 2009), mostrando en ambos casos una elevación del cortisol plasmático, pero sin provocar un aumento en el RCS de la leche.

El objetivo de este estudio fue determinar como afectan varios tipos de estrés sobre el RCS y la producción y composición de la leche; además también se controló la concentración de cortisol en sangre, como indicador fisiológico del nivel de estrés que sufrían los animales. Se ensayaron tres tipos de situaciones que, potencialmente, podrían generar un estrés agudo en los animales: la extracción del estiércol en la explotación, el reagrupamiento de los animales y el contacto de los animales con un perro con actitud agresiva. Las dos primeras situaciones ocurren habitualmente en las explotaciones comerciales, mientras que la tercera se eligió como ejemplo de estrés extremo. 


\section{MATERIAL Y MÉTODOS}

Los experimentos del presente estudio se llevaron a cabo en la granja de ganado caprino de raza Murciano-Granadina de la UPV. Esta explotación dispone de 85 cabras en lactación y está libre de brucelosis, tuberculosis y agalaxia contagiosa. Además, la prevalencia del virus del AEC es muy baja (tan solo dos cabras positivas en los últimos 3 años, siempre las mismas, las cuales no fueron utilizadas en los experimentos). Todos los animales eran ordeñados una vez al día $(8: 00 \mathrm{~h})$ con una rutina que incluía el apurado a máquina e inmersión de los pezones en yodo tras la retirada de las pezoneras.

\subsection{Diseño experimental}

Se plantearon tres experimentos con el objeto de estudiar el efecto de tres tipos de estrés (uno en cada experimento) sobre el RCS y la producción y composición de la leche de cabra.

\section{Experimento 1}

Se estudió el efecto del estrés provocado por la extracción del estiércol. Esta práctica se realiza con un tractor dos veces al año y provoca que los animales sufran un aparente estrés durante varias horas (estrés visual, auditivo, traslado de los animales ...). Para ello, se utilizaron 30 cabras (6 de primer parto, 10 de segundo parto y 14 de tercer o más partos) que se encontraban entre el segundo y cuarto mes de lactación. De estos animales, 18 estaban libres de IIM y 12 presentaban mamitis subclínica unilateral (10) o bilateral (2); todas las infecciones estuvieron causadas por Estafilococos coagulasanegativo, excepto una infección provocada por Streptococcus spp.

El experimento tuvo una duración de 6 días consecutivos: dos días previos al estrés (días -2 y -1), el día 0 en el que todos los animales, tras el ordeño, sufrieron el estrés (entre las 11:00h y 16:00 h del día 0; Figura 1) y los tres días siguientes (días $+1,+2$ y +3 ). Diariamente se controló, para cada animal, la producción, composición y el RCS de la leche total ordeñada, el RCS por glándula y los niveles de cortisol en sangre. Además, se llevaron a cabo 3 análisis bacteriológicos por glándula (días $-2,+1$ y +3 ). 

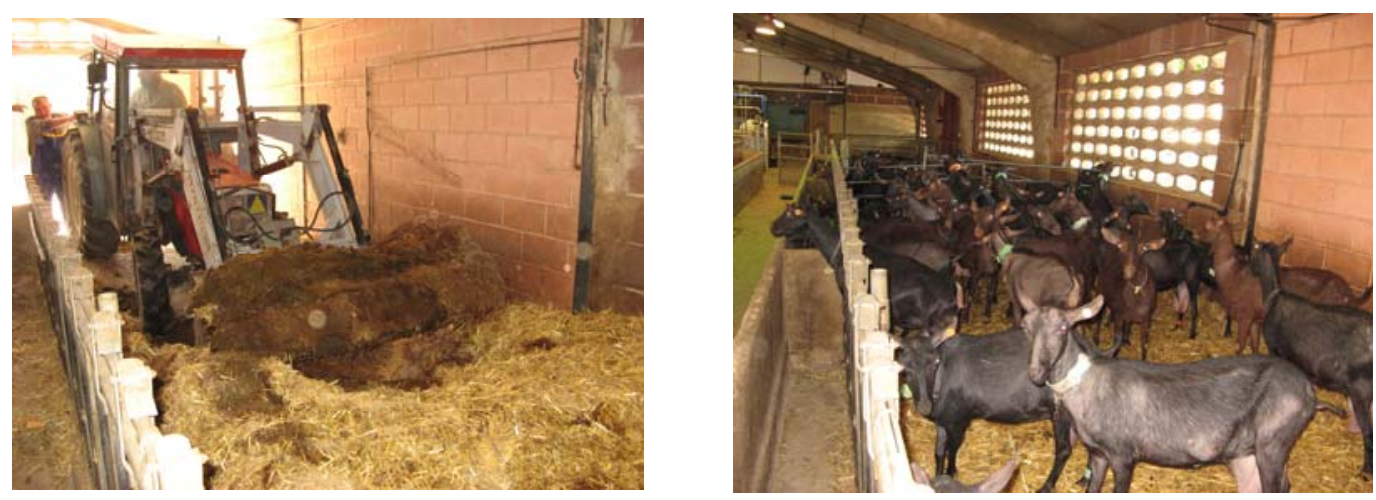

FIGURA 1. Extracción del estiércol y traslado de los animales (experimento 1)

\section{Experimento 2}

Se estudió el efecto del estrés provocado por el reagrupamiento de los animales. Se utilizaron 70 cabras (19 primíparas y 50 multíparas) de raza Murciano-Granadina, de las cuales 43 tenían la ubre sana y 27 presentaban mamitis subclínica, unilateral (22) o bilateral (5); las infecciones estuvieron causadas por estafilococos coagulasa-negativo (29 glándulas), Corynebacterium spp (1 glándula), Streptococcus spp (1 glándula) y un Gram negativo (1 glándula). Todos los animales se encontraban entre el segundo y cuarto mes de lactación y estaban alojados inicialmente en 3 parques distintos $(\mathrm{P} 1=19$ primíparas; $\mathrm{P} 2=25$ multíparas; P3= 26 multíparas). Las cabras multíparas (P2, P3) habían estado alojadas en sus respectivos parques durante los últimos 8 meses, mientras que las cabras primíparas (P1) siempre habían estado alojadas juntas desde su nacimiento y nunca habían tenido contacto físico con las cabras multíparas.

El experimento tuvo una duración de 8 días: $-4,-3,-2,-1,0,1,2$ y 3 . A las 12:00 h del día 0 se llevó a cabo un reagrupamiento de los animales, generándose tres grupos de animales:

a) Grupo A o Control: 12 cabras (4 primíparas y 8 multíparas) que permanecieron en el mismo parque, sin mezclarse con otros animales ( $\mathrm{P} 1=4 ; \mathrm{P} 2=4 ; \mathrm{P} 3=4)$. Estos animales no sufrieron estrés de cambio de local ni de reagrupamiento con nuevos animales, aunque si hubo una reducción del tamaño del grupo y de la superficie del local en el que se encontraban. 
b) Grupo B: 29 cabras (5 primíparas y 24 multíparas; P1=5, P2=12, P3=12) que permanecieron en el mismo parque (separadas del grupo A por una valla) al cual se añadían las cabras del grupo C. Estos animales no sufrían estrés de cambio de local, pero si de reagrupamiento, ya que a cada parque se añadían nuevas cabras (igual número de cabras residentes como nuevas).

c) Grupo C: 29 cabras (10 primíparas y 19 multíparas) que se cambiaron de local (2 de P2 y 3 de P3 se trasladaron al P1; 5 de P1 y 7 de P3 se trasladaron al P2; 5 de P1 y 7 de P2 se trasladaron al P3). Estos animales sufrieron dos tipos de estrés: cambio de local y de reagrupamiento con otras cabras.

Esta nueva distribución se mantuvo durante los tres días posteriores (días $+1,+2$ y +3 ). Debemos puntualizar que una cabra multípara del grupo $\mathrm{C}$ sufrió un trastorno patológico en el día 0 (menor ingestión de alimento y disminución de la producción en un $70 \%)$ y no fue considerada en los análisis estadísticos. En los 8 días del presente experimento se registraron las mismas variables del experimento 1. Además también se registró el comportamiento de los animales, principalmente la presencia de luchas (Figura 2) en las 5 horas posteriores al reagrupamiento (día 0) y, en los siguientes días, en las dos horas siguientes tras finalizar el ordeño (días $+1,+2$ y +3$)$.
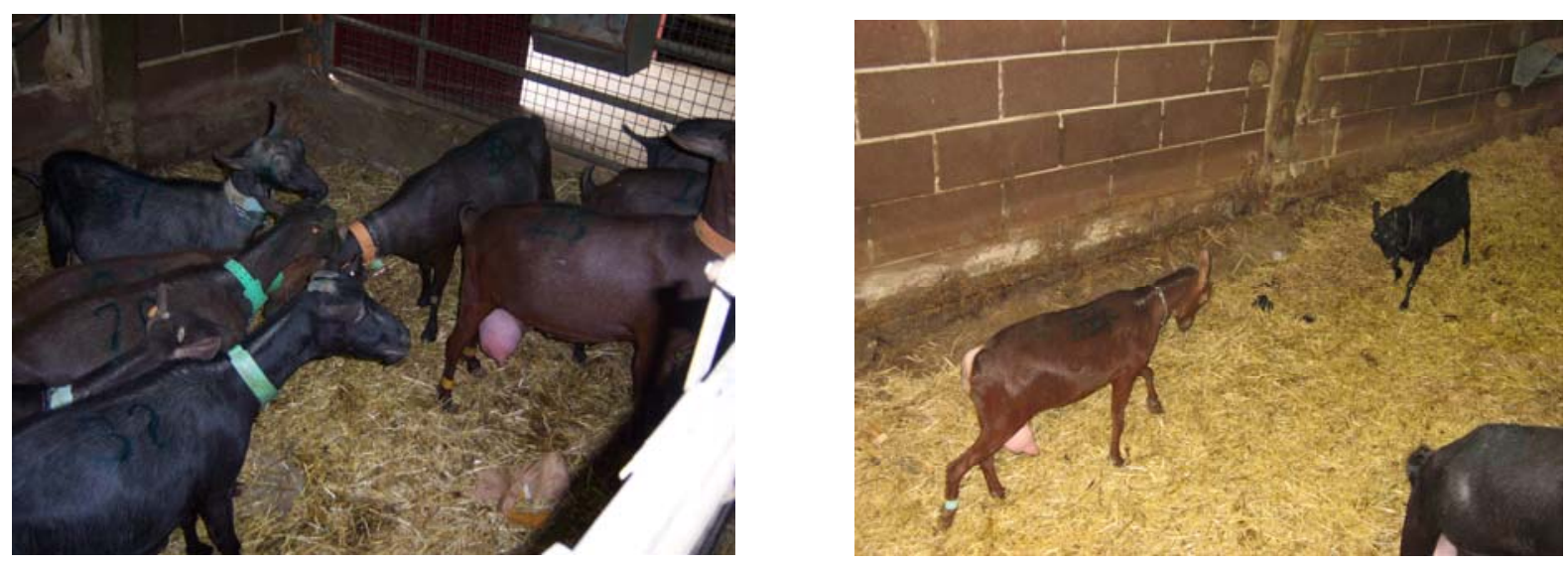

FIGURA 2. Luchas entre las cabras después del reagrupamiento (experimento 2) 


\section{Experimento 3}

Se estudió el efecto de someter a los animales a un fuerte estrés, el cual consistió en introducir un perro con las cabras durante unos 30 minutos. Se utilizaron un total de 38 cabras (13, 5 y 20 de primer, segundo y tercer o más partos, respectivamente) que se encontraban entre el tercer y quinto mes de lactación, y que estaban alojadas en tres parques. De estos animales, 24 estaban libres de infección intramamaria y 14 presentaban mamitis subclínica unilateral (10) o bilateral (4); todas las infecciones estaban causadas por Estafilococos coagulasa negativo, excepto una glándula en la que se identificó un Gram negativo.

El experimento tuvo una duración de 8 días: días -4, -3, -2, -1, 0, 1, 2 y 3. En el día 0 los animales fueron asignados a dos grupos (A o "control"=19 cabras; B o "estrés"= 19 cabras), de modo que fueran homogéneos en cuanto a número de lactación, estado sanitario de la ubre y nivel productivo. A las 12:30 h del día 0, las cabras del grupo B se trasladaron juntas a un parque de unos $70 \mathrm{~m}^{2}$ situado a 50 metros de la explotación y se introdujo un perro en dicho parque durante unos 30 minutos. Un operario también permanecía en el parque con el objeto de prevenir que el perro ocasionara lesiones físicas a los animales (Figura 3). Posteriormente, las cabras volvieron al interior de la explotación, a sus parques respectivos, y permanecieron junto a las cabras del grupo A durante el resto del experimento. Diariamente se registró, para cada animal, las mismas variables descritas en el experimento 1.
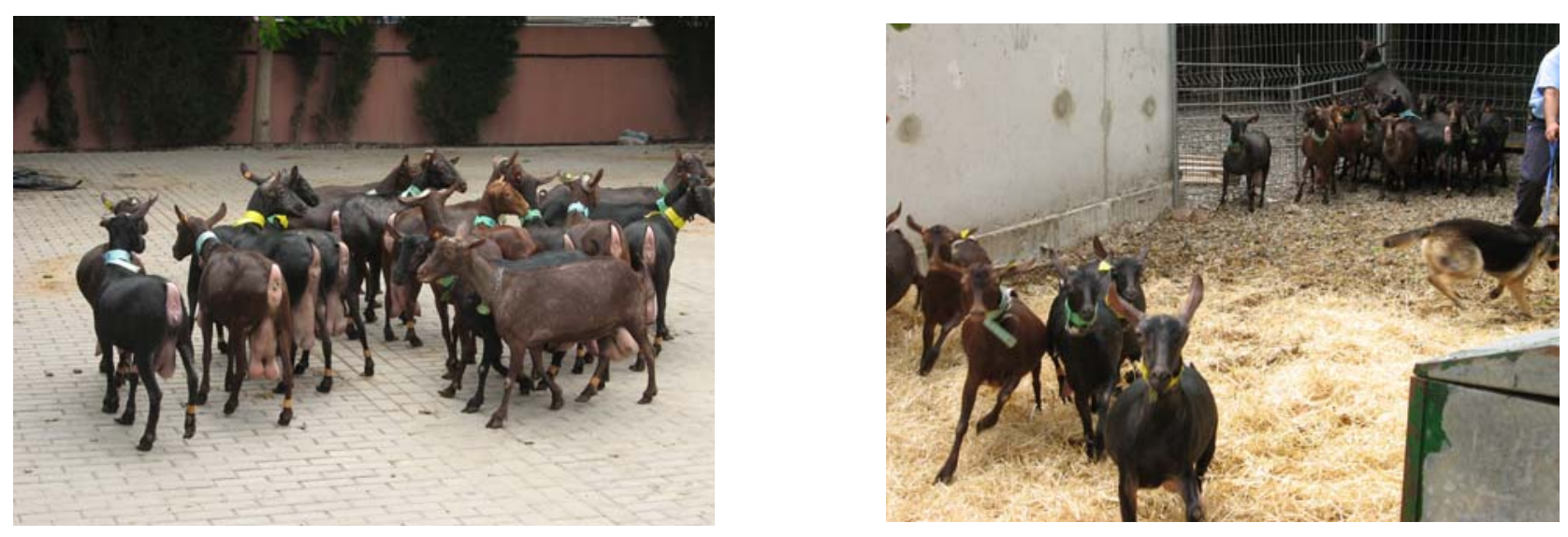

FIGURA 3. Traslado de los animales al exterior de la explotación y estrés ocasionado por el contacto con un perro (experimento 3). 


\subsection{Variables medidas}

La leche total ordeñada (leche máquina más leche de apurado a máquina) de cada animal se registró mediante medidores volumétricos de 3.5 litros de capacidad, graduados con divisiones de $50 \mathrm{ml}$ (Esneder Ref. 90001; Industrias Berango S.L).

El RCS y la composición de la leche de ubre se determinaron en una muestra de la leche total ordeñada de cada animal, tomada directamente de los medidores volumétricos. El RCS por glándula se llevó a cabo en una muestra de leche de unos $40 \mathrm{ml}$ de cada pezón por separado, obtenida mediante ordeño manual antes de la puesta de pezoneras. Todas las muestras se tomaron en frascos de polipropileno de $50 \mathrm{ml}$ y permanecieron en refrigeración $\left(4^{\circ} \mathrm{C}\right)$ entre 24 y 36 h hasta que fueron analizadas en el laboratorio. El RCS se analizó mediante el método Fluoro-opto-electrónico (ISO/IDF, 2008) utilizando un equipo automático (Fossomatic 5000; Foss-Electric S.A.). La composición de la leche (grasa, proteína, lactosa y materia seca) se determinó por espectroscopía del infrarrojo medio (MilkoScan FT120, Foss Electric S.A.).

Las muestras para el análisis bacteriológico se tomaron por glándula antes del ordeño. Para ello, se limpiaba el extremo del pezón con algodón empapado con alcohol etílico al 70\%; a continuación se eliminaban los primeros chorros y se recogían unos $5 \mathrm{ml}$ de leche en tubos estériles de cristal de $10 \mathrm{ml}$, provistos de tapón. Las muestras permanecieron en refrigeración $\left(4^{\circ} \mathrm{C}\right)$ un máximo de $24 \mathrm{~h}$ realizándose el análisis de acuerdo a la metodología descrita en Materiales y Métodos Generales.

Para el análisis del cortisol se recogió diariamente, siempre a las 13:00h, una muestra de unos $3.5 \mathrm{ml}$ de sangre de cada animal. Las muestras se tomaban de la vena yugular, con jeringuillas de plástico, y se trasvasaban a tubos de vidrio de $4.5 \mathrm{ml}$ que contenían $54 \mu \mathrm{l}$ de $15 \%$ de solución EDTA. Las muestras fueron centrifugadas, inmediatamente tras su recogida, a 1500 g (3.500 rpm) durante 20 minutos; a continuación el plasma fue distribuido en tubos eppendorf que fueron congelados a $-40{ }^{\circ} \mathrm{C}$ hasta su análisis. La concentración del cortisol en plasma fue analizado en el Departamento de Fisiología Animal de la Facultad de Veterinaria de la Universidad Complutense de Madrid mediante la técnica de EIA (Munro y Lasley, 1988). La sensibilidad del ensayo fue de 0.03 
ng/ml y los coeficientes de variación intra-análisis y inter-análisis fueron de 5.7 y $8.9 \%$, respectivamente.

\subsection{Definición de una elevación transitoria del RCS}

Basándose en el criterio definido por Martínez (2000), y en los resultados del Estudio 1 de esta Tesis Doctoral, solamente se contabilizaron como "Elevaciones Transitorias" del RCS (ET $\mathrm{RCS}_{\text {, }}$, de origen no infeccioso, aquellas que cumplían las siguientes características:

1- En ubres libres de IIM, el RCS de ambas glándulas sufrían un aumento importante, de al menos 2.5 veces, respecto al día anterior. En ubres infectadas, con mamitis unilateral, se comprobaba que el aumento del RCS señalado anteriormente se producía en la glándula sana y también aumentaba en la glándula infectada

2- El RCS en la leche de ubre (muestra del control lechero) era, al menos, de 1 millón de céls/ml (0,7 millones en primíparas)

3- Después de uno o varios días, el RCS de ambas glándulas retornaba a valores similares a los precedentes a la elevación.

\subsection{Análisis estadístico}

\subsubsection{Primer experimento}

Todas las variables fueron analizadas utilizando el siguiente modelo estadístico:

$\mathrm{Y}_{\mathrm{ijk} \mathrm{l}}=\mu+\mathrm{NL}_{\mathrm{i}}+\mathrm{ESj}+\mathrm{Cab}_{\mathrm{k}}\left(\mathrm{NL}_{\mathrm{i}} \mathrm{ESj}\right)+\mathrm{Dia}_{1}+\mathrm{NL}_{\mathrm{i}} * \mathrm{Dia}_{1}+\mathrm{ESj}^{*} \mathrm{Día}_{1}+\mathrm{e}_{\mathrm{ijkl}}$

Siendo:

Yijkl: variable analizada: RCS (en log), cortisol, producción y composición de la leche ordeñada 
$\mathrm{NLi}=$ efecto fijo del número de lactación $(1,2$ y 3$)$

$E S j=$ efecto fijo del estado sanitario de la ubre $: i=1$ ubres sanas $(n=18) ; i=2$ ubres con una infección intramamaria en al menos una glándula $(\mathrm{n}=12)$

$\mathrm{Cab}_{\mathrm{k}}(\mathrm{NLi} \mathrm{ESj})=$ efecto aletorio de la cabra $\mathrm{k}$ (1 a 30) jerarquizado dentro del número de lactación i

$\mathrm{Dia}_{1}=$ efecto fijo del día $1(-2,-1,0,+1,+2,+3)$

$\mathrm{NL}_{\mathrm{i}} * \mathrm{Dia}_{1}=$ efecto fijo de la interacción número de lactación $\mathrm{x}$ día

$\mathrm{ESj} * \mathrm{Dial}=$ efecto fijo de la interacción estado sanitario $\mathrm{x}$ día

eijkl= error residual

\subsubsection{Segundo experimento}

El análisis estadístico se realizó de forma separada para las cabras primíparas y multíparas. Los modelos utilizados fueron los siguientes:

Cabras primíparas:

$$
\mathrm{Y}_{\mathrm{ijk}}=\mu+\mathrm{Grupo}_{\mathrm{i}}+\mathrm{Cab}_{\mathrm{j}}\left(\mathrm{Grupo}_{\mathrm{i}}\right)+\mathrm{Dia}_{\mathrm{k}}+\mathrm{Grupo}_{\mathrm{i}}{ }^{*} \mathrm{Dia}_{\mathrm{k}}+\mathrm{COV}_{\mathrm{j}}+\mathrm{e}_{\mathrm{ijk}}
$$

Siendo:

$\mathrm{Y}_{\mathrm{ijk}}$ : variable analizada: RCS (en log), cortisol y producción y composición de leche total ordeñada

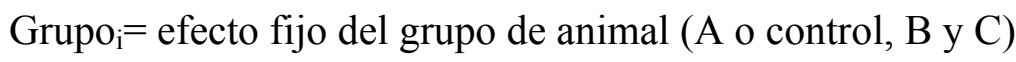

$\mathrm{Cab}_{\mathrm{j}}\left(\mathrm{Grupo}_{\mathrm{i}}\right)=$ efecto aleatorio de la cabra $\mathrm{j}$ (1 a 70) jerarquizado dentro del Grupo de animal i

$\operatorname{Dia}_{\mathrm{k}}=$ efecto fijo del día $\mathrm{k}(-2,-1,0,1,2$ y 3$)$

$\mathrm{Grupo}_{\mathrm{i}}{ }^{*} \mathrm{Dia}_{\mathrm{k}}=$ efecto fijo de la interacción grupo $\mathrm{x}$ día

$\mathrm{COV}_{\mathrm{j}}=$ Covariable. Para cada animal, valor medio obtenido en los días -3 y -4 .

$\mathrm{e}_{\mathrm{ijk}}=$ error residual

\section{Cabras multiparas:}




$$
\begin{aligned}
& \mathrm{Y}_{\mathrm{ijkl}}=\mu+\mathrm{Grupo}_{\mathrm{i}}+\mathrm{ES}_{\mathrm{j}}+\mathrm{Cab}_{\mathrm{k}}\left(\mathrm{Grupo}_{\mathrm{i}} \mathrm{ES}_{\mathrm{j}}\right)+\mathrm{Dia}_{\mathrm{l}}+\mathrm{Grupo}_{\mathrm{i}}{ }^{*} \mathrm{Dia}_{\mathrm{l}}+\mathrm{ES}_{\mathrm{j}}{ }^{*} \mathrm{Dia}_{\mathrm{l}}+ \\
& \mathrm{Grupo}_{\mathrm{i}}{ }^{*} \mathrm{ES}_{\mathrm{j}} * \mathrm{Dia}_{\mathrm{l}}+\mathrm{COV}_{\mathrm{k}}+\mathrm{e}_{\mathrm{ijkl}}
\end{aligned}
$$

Siendo los nuevos factores:

$\mathrm{ES}_{\mathrm{j}}=$ efecto fijo del estado sanitario de la ubre (l=1 ambas glándulas sanas, $\mathrm{n}=27 ; 1=2$ al menos una glándula infectadas, $\mathrm{n}=24$ )

$\mathrm{ES}_{\mathrm{j}} * \mathrm{Dia}_{\mathrm{l}}=$ efecto fijo de la interacción Estado Sanitario x Dia

$\mathrm{Grupo}_{\mathrm{i}}{ }^{*} \mathrm{ES}_{\mathrm{j}}{ }^{*}$ Dia $_{1}=$ efecto fijo de la interacción triple Grupo x ES x Dia

\subsubsection{Tercer experimento}

El análisis estadístico se realizó de forma separada para las cabras de primera y segunda lactación, por una parte, y los de tres o más lactaciones, por otra, utilizando los mismos modelos descritos en el segundo experimento. En este experimento, el factor Grupo tan solo contempló dos niveles: A o Control y B o estrés.

Todos los análisis estadísticos se realizaron de acuerdo a Littell et al (1998), utilizando el PROC MIXED del paquete estadístico SAS. El RCS fue analizado en log10, con objeto de normalizar su distribución (Ali y Shook, 1980), y no se tuvo en cuenta el efecto de la covariable en los modelos [1] y [2] descritos anteriormente.

\section{RESULTADOS}

\section{Experimento 1}

El RCS (en log) tan solo estuvo afectado significativamente por el factor Estado Sanitario de la ubre (sanas: 5.34 \pm 0.10 ; infectadas: $5.99 \pm 0.14 ; \mathrm{p}<0.001$ ). El factor Día no llegó a afectar significativamente al RCS ( $\mathrm{p}=0.06)$, a pesar de que en los días $0,+1 \mathrm{y}+2$ se observó un ligero aumento de los recuentos (5.68-5.75; Tabla 1). De todos modos, debemos precisar que el máximo recuento medio (5.75) se alcanzó en el ordeño del día 0 , 
es decir antes de someter a los animales al estrés, por lo que no parece que esta ligera elevación del RCS esté asociada al factor estresante estudiado. El factor Número de Lactación y las interacciones Día*Estado Sanitario y Día*Número de lactación tampoco resultaron significativas.

TABLA 1. Evolución diaria del RCS (céls/ml) durante el experimento 1, según el número de lactación, estado sanitario de la ubre y grupo de RCS de las cabras

\begin{tabular}{|c|c|c|c|c|c|c|c|c|c|}
\hline \multirow{3}{*}{ Día } & \multicolumn{3}{|c|}{ NL } & \multicolumn{4}{|c|}{ Estado Sanitario de la ubre } & \multirow{2}{*}{\multicolumn{2}{|c|}{$\begin{array}{l}\text { Todas } \\
(\mathrm{n}=30)\end{array}$}} \\
\hline & \multirow{2}{*}{ 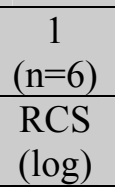 } & \multirow{2}{*}{$\begin{array}{c}\begin{array}{c}2 \\
(\mathrm{n}=10)\end{array} \\
\mathrm{RCS} \\
(\log )\end{array}$} & \multirow{2}{*}{$\begin{array}{c}\begin{array}{c}\geq 3 \\
(\mathrm{n}=14)\end{array} \\
\mathrm{RCS} \\
(\log )\end{array}$} & \multicolumn{2}{|c|}{ Sana $(n=18)$} & \multicolumn{2}{|c|}{ Infectada $\quad(n=12)$} & & \\
\hline & & & & $\begin{array}{c}\text { RCS } \\
(\log )\end{array}$ & $\begin{array}{c}\mathrm{RCS}\left(\mathrm{x} 10^{3}\right) \\
(\mathrm{m} \pm \mathrm{DS})\end{array}$ & $\begin{array}{c}\text { RCS } \\
(\log )\end{array}$ & $\begin{array}{c}\mathrm{RCS}\left(\mathrm{x} 10^{3}\right) \\
(\mathrm{m} \pm \mathrm{DS})\end{array}$ & $\begin{array}{c}\text { RCS } \\
\text { (Log) }\end{array}$ & $\begin{array}{c}\mathrm{RCS}\left(\mathrm{x} 10^{3}\right) \\
(\mathrm{m} \pm \mathrm{DS})\end{array}$ \\
\hline-2 & 5,58 & 5,58 & 5,71 & 5,28 & $393 \pm 652$ & 5,98 & $1569 \pm 1878$ & 5,63 & $863 \pm 1389$ \\
\hline-1 & 5,59 & 5,62 & 5,69 & 5,33 & $384 \pm 510$ & 5,94 & $1162 \pm 711$ & 5,64 & $695 \pm 703$ \\
\hline 0 & 5,63 & 5,81 & 5,81 & 5,39 & $416 \pm 540$ & 6,11 & $2496 \pm 2920$ & 5,75 & $1248 \pm 2116$ \\
\hline 1 & 5,23 & 5,72 & 5,82 & 5,28 & $440 \pm 667$ & 5,90 & $2748 \pm 4889$ & 5,68 & $1363 \pm 3264$ \\
\hline 2 & 5,58 & 5,70 & 5,82 & 5,38 & $541 \pm 1014$ & 6,02 & $2206 \pm 2392$ & 5,70 & $1173 \pm 1829$ \\
\hline 3 & 5,49 & 5,54 & 5,78 & 5,30 & $430 \pm 737$ & 5,91 & $1369 \pm 1322$ & 5,61 & $806 \pm 1096$ \\
\hline ES & 0.22 & 0.15 & 0.12 & 0.11 & - & 0.16 & - & 0.09 & - \\
\hline Niv.Sig & - & - & - & - & - & - & - & NS & - \\
\hline
\end{tabular}

Respecto al resto de variables, el factor Día no afectó significativamente a la producción de leche, el cortisol, la proteína ni a la lactosa (Tabla 2). Este factor si que influyó significativamente sobre el contenido en grasa y materia seca de la leche, dado que en el día +1 (primer ordeño después del estrés) ambas variables tendieron a disminuir respecto a los días anteriores, aunque las diferencias tan solo fueron significativas respecto al día -2 . No obstante, también podemos destacar que en el día +3 nuevamente se obtuvieron valores similares de grasa y materia seca que en el día +1 , a pesar de que en el día anterior (día +2$)$ no se había provocado ningún tipo de estrés. El resto de factores estudiados (Estado Sanitario, Número de Lactación y sus interacciones con el factor Día) no afectaron significativamente a la producción de leche, el cortisol ni la composición de la leche.

Durante los 6 días del experimento tan solo se observó una $\mathrm{ET}_{\mathrm{RCS}}$, con una duración de 2 días ( días 0 y +1 ), en una cabra multípara con mamitis unilateral. Sin embargo, esta elevación no estaría asociada al estrés provocado, dado que se inició el día 0 , 
es decir, antes de someter a los animales al estrés relacionado con la extracción del estiércol.

TABLA 2. Evolución diaria de la producción y composición de la leche y del cortisol en plasma en las cabras utilizadas en el experimento 1

\begin{tabular}{|c|c|c|c|c|c|c|}
\hline Día & $\begin{array}{c}\text { Producción } \\
(\mathrm{ml} / \mathrm{día})\end{array}$ & $\begin{array}{c}\text { Grasa } \\
(\% \mathrm{p} / \mathrm{p})\end{array}$ & $\begin{array}{c}\text { Proteína } \\
(\% \mathrm{p} / \mathrm{p})\end{array}$ & $\begin{array}{c}\text { Lactosa } \\
(\% \mathrm{p} / \mathrm{p})\end{array}$ & $\begin{array}{c}\text { Materia Seca } \\
(\% \mathrm{p} / \mathrm{p})\end{array}$ & $\begin{array}{c}\text { Cortisol } \\
(\mathrm{ng} / \mathrm{ml})\end{array}$ \\
\hline-2 & 2397 & $4,80^{\mathrm{a}}$ & 3,25 & 4,52 & $13,48^{\mathrm{a}}$ & 11,7 \\
\hline-1 & 2439 & $4,72^{\mathrm{ab}}$ & 3,22 & 4,56 & $13,36^{\mathrm{ab}}$ & 13,4 \\
\hline 0 & 2463 & $4,70^{\mathrm{ab}}$ & 3,29 & 4,50 & $13,40^{\mathrm{ab}}$ & 14.9 \\
\hline 1 & 2421 & $4,57^{\mathrm{b}}$ & 3,24 & 4,50 & $13.19^{\mathrm{b}}$ & 14.4 \\
\hline 2 & 2380 & $4,82^{\mathrm{a}}$ & 3,30 & 4,50 & $13,62^{\mathrm{a}}$ & 12.8 \\
\hline 3 & 2432 & $4,50^{\mathrm{b}}$ & 3,29 & 4,48 & $13,15^{\mathrm{b}}$ & 13.6 \\
\hline ES & 99 & 0.13 & 0.06 & 0.05 & 0.20 & 3.1 \\
\hline Niv.Sig & NS & $*$ & $\mathrm{NS}$ & $\mathrm{NS}$ & $*$ & $\mathrm{NS}$ \\
\hline
\end{tabular}

\section{Experimento 2}

Tanto en las cabras primíparas como en las multíparas, ni el factor Día ni la interacción Grupo*Día afectaron significativamente al RCS (Tabla 3). Así, en cada uno de los grupos experimentales, el $\operatorname{logRCS}$ en el Día 1 (primer ordeño después del reagrupamiento) fue similar a los recuentos de los días anteriores y posteriores (primíparas Tabla 4a; multíparas Tabla 4b). Además, en las cabras multíparas las interacciones Día*Estado Sanitario y Grupo*Estado Sanitario*Día tampoco influyeron significativamente sobre el RCS (Tabla 3), de modo que tanto en las cabras sanas como en las infectadas los recuentos no aumentaron significativamente en el Día 1 (Figura 4a). No obstante, cuando en el análisis estadístico solamente se consideraron los animales con altos recuentos (media geométrica en los días -2, -1 y 0 superior a 1 millón de céls $/ \mathrm{ml}: 19$ cabras, de las cuales 14 infectadas y 5 bacteriológicamente sanas), el factor día fue significativo, elevándose ligeramente los recuentos en los días 1 y 2 (diferencias significativas solamente respecto a los días -2 y 0 ; Figura 1b). 
TABLA 3. Resultados del análisis estadístico del Experimento 2.

a) Lactación $=1$

\begin{tabular}{|c|c|c|c|c|}
\hline Factores & Grupo & Día & Grupo $*$ Día & Cov \\
\hline Log RCS & NS & NS & NS & - \\
\hline Prod. Leche & NS & $*$ & $* *$ & $* * *$ \\
\hline Cortisol & NS & NS & NS & NS \\
\hline Grasa & NS & $* *$ & NS & $* * *$ \\
\hline Proteína & NS & $* *$ & NS & $* * *$ \\
\hline Lactosa & NS & $* * *$ & NS & $* * *$ \\
\hline Materia seca & NS & $* * *$ & NS & $* * *$ \\
\hline
\end{tabular}

\section{b) Lactación $\geq 2$}

\begin{tabular}{|c|c|c|c|c|c|c|c|}
\hline Factores & Grupo & $\begin{array}{c}\text { Estado sanitario } \\
(\text { ES) }\end{array}$ & Día & Grupo * Día & ES*Día & Grupo*ES*Día & Cov \\
\hline Log RCS & NS & $* * *$ & NS & NS & NS & NS & - \\
\hline Prod. Leche & NS & NS & NS & NS & NS & NS & $* * *$ \\
\hline Cortisol & NS & NS & NS & NS & NS & NS & NS \\
\hline Grasa & NS & NS & $* * *$ & NS & NS & NS & $* * *$ \\
\hline Proteína & NS & NS & $* * *$ & NS & NS & NS & $* * *$ \\
\hline Lactosa & NS & NS & $* * *$ & NS & NS & NS & $* * *$ \\
\hline Materia seca & NS & NS & $* * *$ & NS & NS & NS & $* * *$ \\
\hline
\end{tabular}

a) Según estado sanitario

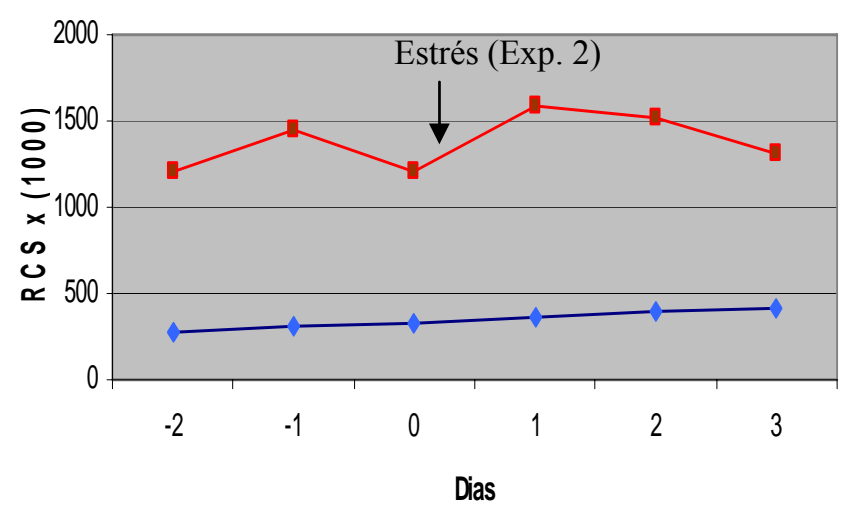

$\rightarrow-$ Sanas $\rightarrow-$ Infectadas b) Según RCS

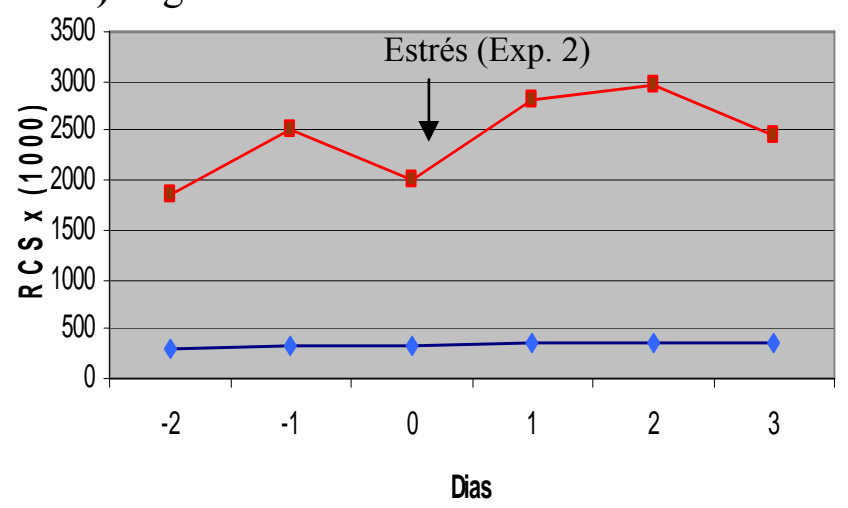

$\longrightarrow$ RCS bajo - RCS alto

FIGURA 4. Evolución diaria de la media geométrica del RCS en las cabras multíparas del experimento 2. . a) Según el estado sanitario de la ubre (sanas $n=26$; infectadas $n=24$ ). b) Según el RCS previo al estrés (Bajo, $<1$ millón céls/ml, $\mathrm{n}=31$; Alto, $>1$ millón de céls $/ \mathrm{ml}, \mathrm{n}=19$ ) 
TABLA 4. Evolución diaria del RCS (céls/ml) en los tres grupos de cabras del experimento $2(\mathrm{~A}, \mathrm{~B}, \mathrm{C})$, separadas según número de lactación

a) Lactación $=1$

\begin{tabular}{|c|c|c|c|c|c|c|c|c|}
\hline \multirow{2}{*}{ Día } & \multicolumn{4}{|c|}{ Log RCS } & \multicolumn{4}{c|}{ RCS $(\mathrm{m} \pm$ DS) x 10 } \\
\cline { 2 - 9 } & $\begin{array}{c}\mathrm{A}=4) \\
(\mathrm{n}=4)\end{array}$ & $\begin{array}{c}\mathrm{B} \\
(\mathrm{n}=5)\end{array}$ & $\begin{array}{c}\mathrm{C} \\
(\mathrm{n}=10)\end{array}$ & $\begin{array}{c}\text { Todas } \\
(\mathrm{n}=19)\end{array}$ & $\begin{array}{c}\text { A } \\
(\mathrm{n}=4)\end{array}$ & $\begin{array}{c}\mathrm{B} \\
(\mathrm{n}=5)\end{array}$ & $\begin{array}{c}\mathrm{C} \\
(\mathrm{n}=10)\end{array}$ & $\begin{array}{c}\text { Todas } \\
(\mathrm{n}=19)\end{array}$ \\
\hline-2 & 5.06 & 5.30 & 5.40 & 5.25 & $142 \pm 105$ & $365 \pm 440$ & $298 \pm 183$ & $283 \pm 261$ \\
\hline-1 & 5.10 & 5.26 & 5.46 & 5.28 & $148 \pm 94$ & $250 \pm 211$ & $341 \pm 202$ & $277 \pm 195$ \\
\hline 0 & 5.05 & 5.16 & 5.41 & 5.21 & $125 \pm 69$ & $188 \pm 149$ & $293 \pm 165$ & $230 \pm 157$ \\
\hline 1 & 5.04 & 5.27 & 5.48 & 5.27 & $125 \pm 72$ & $253 \pm 203$ & $505 \pm 603$ & $351 \pm 457$ \\
\hline 2 & 5.01 & 5.16 & 5.42 & 5.20 & $114 \pm 63$ & $216 \pm 203$ & $366 \pm 326$ & $274 \pm 273$ \\
\hline 3 & 5.01 & 5.13 & 5.40 & 5.18 & $116 \pm 63$ & $220 \pm 192$ & $308 \pm 186$ & $244 \pm 179$ \\
\hline ES & 0.17 & 0.15 & 0.11 & 0.09 & - & - & - & - \\
\hline
\end{tabular}

b) Lactación $\geq 2$

\begin{tabular}{|c|c|c|c|c|c|c|c|c|}
\hline \multirow{2}{*}{ Día } & \multicolumn{4}{|c|}{ Log RCS } & \multicolumn{4}{c|}{ RCS (m DS) x 10 } \\
\cline { 2 - 9 } & $\begin{array}{c}\mathrm{A} \\
(\mathrm{n}=8)\end{array}$ & $\begin{array}{c}\mathrm{B} \\
(\mathrm{n}=24)\end{array}$ & $\begin{array}{c}\mathrm{C} \\
(\mathrm{n}=18)\end{array}$ & $\begin{array}{c}\text { Todas } \\
(\mathrm{n}=50)\end{array}$ & $\begin{array}{c}\mathrm{A} \\
(\mathrm{n}=8)\end{array}$ & $\begin{array}{c}\mathrm{B} \\
(\mathrm{n}=24)\end{array}$ & $\begin{array}{c}\mathrm{C} \\
(\mathrm{n}=18)\end{array}$ & $\begin{array}{c}\text { Todas } \\
(\mathrm{n}=50)\end{array}$ \\
\hline-2 & 5.82 & 5.77 & 5.75 & 5.78 & $1005 \pm 815$ & $1081 \pm 1306$ & $1089 \pm 1165$ & $1072 \pm 1169$ \\
\hline-1 & 5.84 & 5.88 & 5.79 & 5.84 & $1146 \pm 1066$ & $1414 \pm 1718$ & $1741 \pm 3076$ & $1489 \pm 2209$ \\
\hline 0 & 5.81 & 5.83 & 5.76 & 5.80 & $949 \pm 905$ & $1148 \pm 1167$ & $1384 \pm 1957$ & $1201 \pm 1452$ \\
\hline 1 & 5.99 & 5.92 & 5.74 & 5.88 & $1774 \pm 1800$ & $1806 \pm 2578$ & $1092 \pm 1355$ & $1539 \pm 2071$ \\
\hline 2 & 6.00 & 5.84 & 5.80 & 5.88 & $2134 \pm 2325$ & $1708 \pm 3904$ & $2142 \pm 4769$ & $1933 \pm 3983$ \\
\hline 3 & 5.94 & 5.93 & 5.74 & 5.87 & $1508 \pm 1692$ & $1641 \pm 2062$ & $1024 \pm 1405$ & $1405 \pm 1788$ \\
\hline ES & 0.18 & 0.11 & 0.12 & 0.08 & - & - & - & - \\
\hline
\end{tabular}

Grupo A: Control ; Grupo B: reagrupamiento, sin cambiar de local Grupo C: reagrupamiento, con cambio de local ES : Error estándar

A lo largo de este experimento solamente se detectaron 5 Elevaciones Transitorias del RCS (1 primípara y 4 multíparas; 2 cabras sanas y 3 cabras con mamitis unilateral) que ocurrieron en el día -1 (1 cabra multípara infectada) y en el día +1 (4 cabras). Estas últimas estuvieron distribuidas entre los 3 grupos experimentales: 1 en el grupo A o Control, 2 en el grupo B y 1 en el grupo C.

El cortisol en plasma no estuvo afectado significativamente por ninguno de los factores estudiados (Tabla 3). En los tres grupos experimentales, los valores de cortisol del Día 0 (muestra tomada una hora tras el reagrupamiento) y días posteriores no difirieron significativamente respecto a los registrados en los días precedentes (-1 y -2), tanto en las cabras primíparas como en las multíparas (Tabla 5). 
TABLA 5. Evolución diaria del cortisol en sangre (ng/ml) en los tres grupos de cabras del experimento 2 (A B C), separadas según el número de lactación

\begin{tabular}{|c|c|c|c|c|c|c|c|c|}
\hline \multirow[b]{3}{*}{ Día } & \multicolumn{8}{|c|}{ Cortisol (ng/ml) } \\
\hline & \multicolumn{4}{|c|}{ Lactación $=1$} & \multicolumn{4}{|c|}{ Lactación $\geq 2$} \\
\hline & $\begin{array}{c}\mathrm{A} \\
(\mathrm{n}=4)\end{array}$ & $\begin{array}{c}B \\
(n=5)\end{array}$ & $\begin{array}{c}C \\
(n=10)\end{array}$ & $\begin{array}{l}\text { Todas } \\
(\mathrm{n}=19)\end{array}$ & $\begin{array}{c}\mathrm{A} \\
(\mathrm{n}=8)\end{array}$ & $\begin{array}{c}B \\
(n=24)\end{array}$ & $\begin{array}{c}\mathrm{C} \\
(\mathrm{n}=18)\end{array}$ & $\begin{array}{c}\text { Todas } \\
(\mathrm{n}=50)\end{array}$ \\
\hline-2 & 8.0 & 5.5 & 6.0 & 6.5 & 5.22 & 6.23 & 8.62 & 7.52 \\
\hline-1 & 14.3 & 18.9 & 11.6 & 15.0 & 4.78 & 8.71 & 11.07 & 7.85 \\
\hline 0 & 5.9 & 3.4 & 8.3 & 5.9 & 5.41 & 4.03 & 6.11 & 5.19 \\
\hline 1 & 7.0 & 5.0 & 13.7 & 10.5 & 3.66 & 6.91 & 5.43 & 5.33 \\
\hline 2 & 15.0 & 6.8 & 5.6 & 9.8 & 6.93 & 9.92 & 9.34 & 8.73 \\
\hline 3 & 12.1 & 9.1 & 7.9 & 10.1 & 4.67 & 7.86 & 7.51 & 6.45 \\
\hline ES & 8.5 & 7.6 & 5.3 & 4.2 & 3.5 & 1.9 & 2.2 & 1.5 \\
\hline
\end{tabular}

Respecto a la producción de leche, los resultados fueron distintos entre las cabras de primer parto y las de partos superiores. En las cabras primíparas, la interacción Grupo*Día fue significativa $(\mathrm{p}<0.01)$, lo cual fue debido a que las cabras del Grupo C (trasladadas a los parques de cabras multíparas) disminuyeron significativamente la producción de leche en los días 1 y 2 (entre 100-200 ml; Tabla 6), mientras que en las cabras de los grupos A y B no disminuyó significativamente la producción de leche en estos días. En el caso de las cabras multíparas, ni el factor Día ni la interacción Grupo*Día influyeron significativamente sobre la producción de leche (Tabla 1); además, la interacción Grupo*Día*Estado Sanitario tampoco resultó significativa.

TABLA 6. Evolución diaria de la producción de leche en los tres grupos de cabras del experimento 2 ( $\mathrm{A}, \mathrm{B}$ y $\mathrm{C}$ ), separadas según el número de lactación

\begin{tabular}{|c|c|c|c|c|c|c|c|c|}
\hline \multirow[b]{3}{*}{ Día } & \multicolumn{8}{|c|}{ Producción de leche (ml/día) } \\
\hline & \multicolumn{4}{|c|}{ Lactación 1} & \multicolumn{4}{|c|}{ Lactación $\geq 2$} \\
\hline & $\begin{array}{c}\mathrm{A} \\
(\mathrm{n}=4)\end{array}$ & $\underset{(\mathrm{n}=5)}{\mathrm{B}}$ & $\underset{(\mathrm{n}=10)}{\mathrm{C}}$ & $\begin{array}{l}\text { Todas } \\
(\mathrm{n}=19)\end{array}$ & $\begin{array}{c}\mathrm{A} \\
(\mathrm{n}=8)\end{array}$ & $\begin{array}{c}\mathrm{B} \\
(\mathrm{n}=24)\end{array}$ & $\begin{array}{c}\mathrm{C} \\
(\mathrm{n}=18)\end{array}$ & $\begin{array}{c}\text { Todas } \\
(\mathrm{n}=50)\end{array}$ \\
\hline-2 & 1827 & 1930 & $1943^{a}$ & 1900 & 2532 & 2521 & 2520 & 2520 \\
\hline-1 & 1726 & 1921 & $1918^{\mathrm{a}}$ & $1855^{a}$ & 2542 & 2530 & 2514 & 2529 \\
\hline 0 & 1843 & 2014 & $1904^{\mathrm{a}}$ & $1921^{\mathrm{ab}}$ & 2527 & 2526 & 2492 & 2515 \\
\hline 1 & $1757_{\alpha}$ & $2074_{\beta}$ & $1758^{b} \alpha$ & $1867^{\mathrm{a}}$ & 2545 & 2498 & 2441 & 2495 \\
\hline 2 & $1851_{\alpha \beta}$ & $1989_{B}$ & $1768^{b}{ }_{\alpha}$ & $1903^{a}$ & 2512 & 2540 & 2530 & 2528 \\
\hline 3 & 1834 & 2011 & $1898^{\mathrm{a}}$ & $1996^{b}$ & 2565 & 2616 & 2539 & 2573 \\
\hline ES & 102 & 89 & 64 & 49 & 66 & 37 & 44 & 29 \\
\hline
\end{tabular}

$a, b$ Letras distintas en una misma columna indica diferencias significativas $(\mathrm{p}<0.05)$

$\alpha, \beta \quad$ Letras distintas en una misma fila indica diferencias significativas $(\mathrm{p}<0.05)$

Grupo A: Control ; Grupo B: reagrupamiento, sin cambiar de local Grupo C: reagrupamiento, con cambio de local

ES : Error estándar 
Todas las variables de la composición de la leche (grasa, proteína, lactosa y materia seca) estuvieron afectadas por el factor Día, pero en ningún caso fue significativa la interacción Grupo*Día. En el caso de la grasa y materia seca se observó que en el día 1 disminuyeron significativamente respecto a otros días del experimento, tanto en las cabras de primer parto como de las de partos superiores (Tabla 7a y 7b). Respecto a la proteína y lactosa los resultados fueron más variables, dado que en las cabras primíparas también disminuyeron significativamente en el primer ordeño tras el reagrupamiento (día 1), pero esto no ocurrió en las cabras multíparas.

Prácticamente todas las cabras multíparas tuvieron uno o varios actos de lucha (cabeza con cabeza) en las cinco horas siguientes al reagrupamiento y en los días posteriores. También fueron frecuentes otros comportamientos, como la presencia de pelo erizado o, cuando finalizaba una lucha, la cabra presuntamente vencedora realizaba el efecto macho o intentaba montar a la cabra derrotada. En el caso de las cabras primíparas transferidas a los parques de multíparas (grupo C), tendieron a mantenerse agrupadas en una zona del parque, y la mayoría rehuían los desafíos que recibían de las otras cabras. La mayoría de las luchas tuvieron una duración inferior a 5 minutos, pero en algunos casos (15 cabras) fueron de entre 15 y 30 minutos. El análisis estadístico realizado, considerando solamente estos 15 animales, tampoco puso en evidencia un efecto significativo del factor Día, ni de la interacción Día*Estado Sanitario, sobre las variables estudiadas (logRCS, cortisol, producción y composición de la leche).

\section{Experimento 3}

Los resultados fueron distintos según el número de lactación de las cabras. En las cabras de 1+2 partos el factor Día afectó significativamente a casi todas las variables, pero la interacción Grupo*Día solo afectó significativamente al cortisol $(p<0.001)$ y no influyó significativamente sobre el RCS ni sobre la producción ni la composición de la leche (Tabla 8a). Así, el cortisol aumentó significativamente en el grupo Estrés en el día 0 (muestras tomadas tras el estrés), alcanzando un valor medio de $20.29 \mathrm{ng} / \mathrm{ml}$, mientras que en el grupo Control los valores de cortisol permanecieron bajos en el citado día (4.45 $\mathrm{ng} / \mathrm{ml} ; \mathrm{p}<0.001$; Tabla 9). En el resto de variables las pequeñas tendencias observadas en el Día +1 (primer ordeño tras el estrés) ocurrieron tanto en el grupo Estrés como en el 
TABLA 7. Evolución diaria de la composición de la leche en los tres grupos de cabras del experimento $2,(\mathrm{~A} ; \mathrm{B} ; \mathrm{C})$ separadas según en el número de lactación.

0 . Lactación $=1$

\begin{tabular}{|c|c|c|c|c|c|c|c|c|}
\hline \multirow{2}{*}{ Día } & \multicolumn{4}{|c|}{ Grasa $(\% \mathrm{p} / \mathrm{p})$} & \multicolumn{4}{c|}{ Proteína $(\% \mathrm{p} / \mathrm{p})$} \\
\cline { 2 - 9 } & $\begin{array}{c}\mathrm{A} \\
(\mathrm{n}=4)\end{array}$ & $\begin{array}{c}\mathrm{B} \\
(\mathrm{n}=5)\end{array}$ & $\begin{array}{c}\mathrm{C} \\
(\mathrm{n}=10)\end{array}$ & $\begin{array}{c}\text { Todas } \\
(\mathrm{n}=19)\end{array}$ & $\begin{array}{c}\mathrm{A} \\
(\mathrm{n}=4)\end{array}$ & $\begin{array}{c}\mathrm{B} \\
(\mathrm{n}=5)\end{array}$ & $\begin{array}{c}\mathrm{C} \\
(\mathrm{n}=10)\end{array}$ & $\begin{array}{c}\text { Todas } \\
(\mathrm{n}=19)\end{array}$ \\
\hline-2 & 4.97 & 5.01 & 4.62 & $4.87^{\mathrm{a}}$ & 3.40 & 3.43 & 3.40 & $3.41^{\mathrm{ab}}$ \\
\hline-1 & 5.06 & 4.90 & 4.71 & $4.89^{\mathrm{a}}$ & 3.42 & 3.42 & 3.39 & $3.41^{\mathrm{ab}}$ \\
\hline 0 & 4.89 & 4.14 & 4.61 & $4.55^{\mathrm{bc}}$ & 3.41 & 3.49 & 3.42 & $3.45^{\mathrm{a}}$ \\
\hline 1 & 4.44 & 4.24 & 4.51 & $4.40^{\mathrm{b}}$ & 3.38 & 3.40 & 3.34 & $3.37^{\mathrm{b}}$ \\
\hline 2 & 4.69 & 4.68 & 4.77 & $4.71^{\mathrm{ac}}$ & 3.45 & 3.47 & 3.41 & $3.44^{\mathrm{a}}$ \\
\hline 3 & 4.99 & 4.62 & 4.86 & $4.82^{\mathrm{a}}$ & 3.43 & 3.42 & 3.37 & $3.41^{\mathrm{ab}}$ \\
\hline ES & 0.24 & 0.23 & 0.16 & 0.12 & 0.05 & 0.04 & 0.03 & 0.02 \\
\hline
\end{tabular}

\begin{tabular}{|c|c|c|c|c|c|c|c|c|}
\hline \multirow{2}{*}{ Día } & \multicolumn{4}{|c|}{ Lactosa $(\% \mathrm{p} / \mathrm{p})$} & \multicolumn{4}{c|}{ Materia seca $(\% \mathrm{p} / \mathrm{p})$} \\
\cline { 2 - 9 } & $\begin{array}{c}\mathrm{A}=4) \\
(\mathrm{n}=4)\end{array}$ & $\begin{array}{c}\mathrm{B} \\
(\mathrm{n}=5)\end{array}$ & $\begin{array}{c}\mathrm{C} \\
(\mathrm{n}=10)\end{array}$ & $\begin{array}{c}\text { Todas } \\
(\mathrm{n}=19)\end{array}$ & $\begin{array}{c}\mathrm{A} \\
(\mathrm{n}=4)\end{array}$ & $\begin{array}{c}\mathrm{B} \\
(\mathrm{n}=5)\end{array}$ & $\begin{array}{c}\mathrm{C} \\
(\mathrm{n}=10)\end{array}$ & $\begin{array}{c}\text { Todas } \\
(\mathrm{n}=19)\end{array}$ \\
\hline-2 & 4.71 & 4.73 & 4.72 & $4.72^{\mathrm{a}}$ & 14.10 & 13.98 & 13.72 & $13.92^{\mathrm{a}}$ \\
\hline-1 & 4.70 & 4.72 & 4.70 & $4.70^{\mathrm{a}}$ & 14.17 & 14.07 & 13.77 & $14.00^{\mathrm{a}}$ \\
\hline 0 & 4.70 & 4.74 & 4.67 & $4.70^{\mathrm{a}}$ & 13.91 & 13.26 & 13.60 & $13.59^{\mathrm{b}}$ \\
\hline 1 & 4.64 & 4.68 & 4.62 & $4.65^{\mathrm{b}}$ & 13.33 & 13.14 & 13.36 & $13.28^{\mathrm{c}}$ \\
\hline 2 & 4.61 & 4.63 & 4.61 & $4.62^{\mathrm{b}}$ & 13.71 & 13.81 & 13.76 & $13.76^{\mathrm{ab}}$ \\
\hline 3 & 4.70 & 4.73 & 4.67 & $4.70^{\mathrm{a}}$ & 14.09 & 13.73 & 13.89 & $13.91^{\mathrm{a}}$ \\
\hline ES & 0.04 & 0.03 & 0.02 & 0.02 & 0.24 & 0.23 & 0.16 & 0.12 \\
\hline
\end{tabular}

b) Lactación $\geq 2$

\begin{tabular}{|c|c|c|c|c|c|c|c|c|}
\hline \multirow{2}{*}{ Día } & \multicolumn{4}{|c|}{ Grasa $(\% \mathrm{p} / \mathrm{p})$} & \multicolumn{4}{c|}{ Proteína $(\% \mathrm{p} / \mathrm{p})$} \\
\cline { 2 - 9 } & $\begin{array}{c}\mathrm{A} \\
(\mathrm{n}=8)\end{array}$ & $\begin{array}{c}\mathrm{B} \\
(\mathrm{n}=24)\end{array}$ & $\begin{array}{c}\mathrm{C} \\
(\mathrm{n}=18)\end{array}$ & $\begin{array}{c}\text { Todas } \\
(\mathrm{n}=50)\end{array}$ & $\begin{array}{c}\mathrm{A} \\
(\mathrm{n}=8)\end{array}$ & $\begin{array}{c}\mathrm{B} \\
(\mathrm{n}=24)\end{array}$ & $\begin{array}{c}\mathrm{C} \\
(\mathrm{n}=18)\end{array}$ & $\begin{array}{c}\text { Todas } \\
(\mathrm{n}=50)\end{array}$ \\
\hline-2 & 4.36 & 4.31 & 4.27 & $4.32^{\mathrm{a}}$ & 3.28 & 3.29 & 3.29 & $3.29^{\mathrm{a}}$ \\
\hline-1 & 4.39 & 4.29 & 4.26 & $4.32^{\mathrm{a}}$ & 3.29 & 3.29 & 3.28 & $3.29^{\mathrm{a}}$ \\
\hline 0 & 4.44 & 4.30 & 4.26 & $4.33^{\mathrm{a}}$ & 3.36 & 3.32 & 3.32 & $3.33^{\mathrm{bd}}$ \\
\hline 1 & 4.30 & 4.05 & 4.00 & $4.12^{\mathrm{b}}$ & 3.31 & 3.33 & 3.29 & $3.31^{\mathrm{ad}}$ \\
\hline 2 & 4.59 & 4.35 & 4.25 & $4.40^{\mathrm{a}}$ & 3.41 & 3.41 & 3.36 & $3.40^{\mathrm{c}}$ \\
\hline 3 & 4.47 & 4.28 & 4.26 & $4.34^{\mathrm{a}}$ & 3.36 & 3.33 & 3.33 & $3.34^{\mathrm{b}}$ \\
\hline ES & 0.13 & 0.07 & 0.09 & 0.06 & 0.03 & 0.02 & 0.02 & 0.01 \\
\hline
\end{tabular}

\begin{tabular}{|c|c|c|c|c|c|c|c|c|}
\hline \multirow{2}{*}{ Día } & \multicolumn{4}{|c|}{ Lactosa $(\% \mathrm{p} / \mathrm{p})$} & \multicolumn{4}{c|}{ Materia seca $(\% \mathrm{p} / \mathrm{p})$} \\
\cline { 2 - 9 } & $\begin{array}{c}\mathrm{A} \\
(\mathrm{n}=8)\end{array}$ & $\begin{array}{c}\mathrm{B} \\
(\mathrm{n}=24)\end{array}$ & $\begin{array}{c}\mathrm{C} \\
(\mathrm{n}=18)\end{array}$ & $\begin{array}{c}\text { Todas } \\
(\mathrm{n}=50)\end{array}$ & $\begin{array}{c}\mathrm{A} \\
(\mathrm{n}=8)\end{array}$ & $\begin{array}{c}\mathrm{B} \\
(\mathrm{n}=24)\end{array}$ & $\begin{array}{c}\mathrm{C} \\
(\mathrm{n}=18)\end{array}$ & $\begin{array}{c}\text { Todas } \\
(\mathrm{n}=50)\end{array}$ \\
\hline-2 & 4.38 & 4.39 & 4.36 & $4.38^{\mathrm{ab}}$ & 12.94 & 12.81 & 12.82 & $12.86^{\mathrm{a}}$ \\
\hline-1 & 4.40 & 4.39 & 4.37 & $4.39^{\mathrm{a}}$ & 12.96 & 12.85 & 12.83 & $12.88^{\mathrm{a}}$ \\
\hline 0 & 4.38 & 4.38 & 4.35 & $4.37^{\mathrm{ab}}$ & 13.08 & 12.86 & 12.86 & $12.93^{\mathrm{a}}$ \\
\hline 1 & 4.36 & 4.37 & 4.35 & $4.36^{\mathrm{b}}$ & 12.85 & 12.59 & 12.54 & $12.66^{\mathrm{b}}$ \\
\hline 2 & 4.32 & 4.31 & 4.28 & $4.30^{\mathrm{c}}$ & 13.31 & 12.98 & 12.84 & $13.04^{\mathrm{a}}$ \\
\hline 3 & 4.39 & 4.36 & 4.36 & $4.37^{\mathrm{ab}}$ & 13.13 & 12.86 & 12.89 & $12.96^{\mathrm{a}}$ \\
\hline ES & 0.03 & 0.02 & 0.02 & 0.01 & 0.15 & 0.09 & 0.10 & 0.07 \\
\hline
\end{tabular}

$a, b, c, d$ Letras distintas en una misma columna indica diferencias significativas $(p<0.05)$

Grupo A: Control ; Grupo B: reagrupamiento sin cambiar de local Grupo C: reagrupamiento, con cambio de local

ES : Error estándar 
TABLA. 8 Resultados del análisis estadístico del Experimento 3.

a) Lactación $=1+2$

\begin{tabular}{|c|c|c|c|c|}
\hline Factores & Grupo & Día & Grupo * Día & Cov \\
\hline Log RCS & NS & $* *$ & NS & - \\
\hline Prod. Leche & NS & $* *$ & NS & $* * *$ \\
\hline Cortisol & NS & $* *$ & $* * *$ & NS \\
\hline Grasa & NS & $*$ & NS & $* *$ \\
\hline Proteína & NS & $* * *$ & NS & $* * *$ \\
\hline Lactosa & NS & NS & NS & $* * *$ \\
\hline Materia seca & NS & NS & NS & $* * *$ \\
\hline
\end{tabular}

\section{b) Lactación $\geq 3$}

\begin{tabular}{|c|c|c|c|c|c|c|c|}
\hline Factores & Grupo & $\begin{array}{c}\text { Estado } \\
\text { sanitario } \\
(\text { ES })\end{array}$ & Día & Grupo * Día & ES * Día & $\begin{array}{c}\text { Grupo * Día * } \\
\text { ES }\end{array}$ & Cov \\
\hline Log RCS & NS & $* *$ & $* * *$ & $* * *$ & NS & NS & - \\
\hline Prod. Leche & NS & NS & $* *$ & $*$ & NS & NS & $* * *$ \\
\hline Cortisol & NS & NS & $* *$ & $* * *$ & NS & NS & $*$ \\
\hline Grasa & NS & $*$ & NS & $*$ & NS & NS & $*$ \\
\hline Proteína & NS & NS & NS & NS & $*$ & NS & $* * *$ \\
\hline Lactosa & NS & NS & $*$ & $*$ & NS & NS & $* * *$ \\
\hline Materia seca & NS & NS & NS & NS & NS & NS & $* * *$ \\
\hline
\end{tabular}

TABLA 9. Evolución diaria del cortisol en sangre $(\mathrm{ng} / \mathrm{ml})$ en los dos grupos de cabras del experimento 3, separadas según el número de lactación

\begin{tabular}{|c|c|c|c|c|c|c|}
\hline \multirow{2}{*}{ Día } & \multicolumn{6}{|c|}{ Cortisol } \\
\cline { 2 - 7 } & \multicolumn{3}{|c|}{ Lactación $1+2$} & \multicolumn{3}{c|}{ Lactación $\geq 3$} \\
\cline { 2 - 7 } & $\begin{array}{c}\text { Control } \\
\mathrm{n}=9\end{array}$ & $\begin{array}{c}\text { Estrés } \\
\mathrm{n}=9\end{array}$ & Niv.sig & $\begin{array}{c}\text { Control } \\
\mathrm{n}=10\end{array}$ & $\begin{array}{c}\text { Estrés } \\
\mathrm{n}=10\end{array}$ & Niv.sig \\
\hline-2 & 4.10 & $4.45^{\mathrm{a}}$ & $\mathrm{NS}$ & 4.29 & $4.61^{\mathrm{a}}$ & $\mathrm{NS}$ \\
\hline-1 & 6.85 & $4.17^{\mathrm{a}}$ & $\mathrm{NS}$ & 8.23 & $4.83^{\mathrm{a}}$ & $\mathrm{NS}$ \\
\hline 0 & 4.45 & $20.29^{\mathrm{b}}$ & $* * *$ & 4.00 & $38.36^{\mathrm{b}}$ & $* * *$ \\
\hline 1 & 7.23 & $9.50^{\mathrm{a}}$ & $\mathrm{NS}$ & 5.41 & $3.88^{\mathrm{a}}$ & $\mathrm{NS}$ \\
\hline 2 & 5.27 & $6.56^{\mathrm{a}}$ & $\mathrm{NS}$ & 5.53 & $4.31^{\mathrm{a}}$ & $\mathrm{NS}$ \\
\hline 3 & 4.67 & $5.32^{\mathrm{a}}$ & $\mathrm{NS}$ & 4.32 & $4.57^{\mathrm{a}}$ & $\mathrm{NS}$ \\
\hline ES & 2.34 & 2.34 & - & 4.88 & 4.56 & - \\
\hline
\end{tabular}

NS: Efecto no significativo

$* * \mathrm{p}<0.001$

ES: Error estándar

$\mathrm{a}, \mathrm{b}$ Letras distintas en una misma columna indica diferencias significativas $(\mathrm{p}<0.05)$ 
grupo Control, lo cual explica que la interacción Grupo*Día no fuera significativa. Así, en la Tabla 10 se observa que en el día +1 el RCS de estas cabras se elevó ligera y significativamente en ambos grupos respecto a los días anteriores y posteriores (5.43 vs 5.21-5.31; $\mathrm{p}<0.05$ ). Lo mismo ocurrió con la producción de leche (en el día +1 disminuyó ligeramente respecto a días anteriores y posteriores 80-170 ml; Tabla 11), la grasa (tendió a elevarse) y la proteína (tendió a disminuir), presentando una evolución similar tanto en el grupo Estrés como en el grupo Control. Por su parte, la lactosa y materia seca no variaron significativamente con el factor Día (Tabla 12a)

TABLA 10. Evolución diaria del RCS (céls/ml) en los dos grupos de cabras del experimento 3, separadas según número de lactación

\begin{tabular}{|c|c|c|c|c|c|c|c|c|c|c|}
\hline \multirow{3}{*}{ Día } & \multicolumn{5}{|c|}{ Lactación $1+2$} & \multicolumn{5}{|c|}{ Lactación $\geq 3$} \\
\hline & \multicolumn{2}{|c|}{$\operatorname{RCS}(\mathrm{m} \pm \mathrm{DS}) \times 10^{3}$} & \multicolumn{3}{|c|}{$\log \operatorname{RCS}(m \pm E S)$} & \multicolumn{2}{|c|}{$\operatorname{RCS}(\mathrm{m} \pm \mathrm{DS}) \times 10^{3}$} & \multicolumn{3}{|c|}{$\log \mathrm{RCS}(\mathrm{m} \pm \mathrm{ES})$} \\
\hline & Control & Estrés & Control & Estrés & Todas & Control & Estrés & Control & Estrés & Niv.sig \\
\hline-2 & $288 \pm 390$ & $234 \pm 378$ & 5.33 & 5.11 & $5.22^{\mathrm{a}}$ & $867 \pm 642$ & $684 \pm 427$ & 5.88 & $5.71^{\mathrm{a}}$ & NS \\
\hline-1 & $370 \pm 502$ & $625 \pm 948$ & 5.41 & 5.22 & $5.31^{\mathrm{a}}$ & $1211 \pm 1194$ & $1218 \pm 1526$ & 5.92 & $5.81^{\mathrm{a}}$ & NS \\
\hline 0 & $246 \pm 209$ & $239 \pm 346$ & 5.41 & 5.14 & $5.27^{\mathrm{a}}$ & $1180 \pm 1250$ & $670 \pm 627$ & 5.94 & $5.69^{\mathrm{a}}$ & NS \\
\hline 1 & $333 \pm 370$ & $306 \pm 249$ & 5.52 & $5 . .33$ & $5.43^{b}$ & $1028 \pm 905$ & $3697 \pm 2805$ & 5.94 & $6.48^{\mathrm{b}}$ & $* *$ \\
\hline 2 & $247 \pm 292$ & $190 \pm 192$ & 5.37 & 5.11 & $5.24^{\mathrm{a}}$ & $743 \pm 475$ & $1220 \pm 888$ & 5.81 & $6.04^{\mathrm{c}}$ & NS \\
\hline 3 & $235 \pm 294$ & $336 \pm 676$ & 5.27 & 5.15 & $5.21^{\mathrm{a}}$ & $654 \pm 479$ & $729 \pm 560$ & 5.86 & $5.79^{\mathrm{a}}$ & NS \\
\hline ES & & & 0.17 & 0.17 & 0.12 & & & 0.10 & 0.10 & - \\
\hline
\end{tabular}

NS: Efecto no significativo.

ES: Error estándar

$a, b, c$. Letras distintas en una misma columna indica diferencias significativas $(p<0.05)$

$n^{\circ}$ de cabras :lactación 1+2: control $n=9$, estrés $n=9$. Lactación 3: control $n=10$, estrés $n=10$.

TABLA 11 Evolución diaria de la producción de leche en los dos grupos de cabras del experimento 3 (Control y Estrés), separadas según el número de lactación

\begin{tabular}{|c|c|c|c|c|c|c|}
\hline \multirow{3}{*}{ Día } & \multicolumn{6}{|c|}{ Producción de leche (ml/día) } \\
\hline & \multicolumn{3}{|c|}{ Lactación $1+2$} & \multicolumn{3}{|c|}{ Lactación $\geq 3$} \\
\hline & Control & Estrés & Todas & Control & Estrés & Niv.sig \\
\hline-2 & 2235 & 2290 & $2265^{a}$ & 2330 & $2351^{\mathrm{ac}}$ & NS \\
\hline-1 & 2191 & 2208 & $2200^{a}$ & 2341 & $2393^{a}$ & NS \\
\hline 0 & 2224 & 2215 & $2219^{a}$ & 2298 & $2381^{\mathrm{a}}$ & NS \\
\hline 1 & 2118 & 2126 & $2122^{b}$ & 2243 & $2084^{\mathrm{b}}$ & $*$ \\
\hline 2 & 2218 & 2273 & $2246^{\mathrm{a}}$ & 2328 & $2275^{\text {cd }}$ & NS \\
\hline 3 & 2149 & 2290 & $2219^{a}$ & 2273 & $2225^{\mathrm{d}}$ & NS \\
\hline ES & 71 & 71 & 50 & 59 & 59 & - \\
\hline
\end{tabular}


TABLA 12 Evolución diaria de la composición de la leche (grasa, proteína, lactosa y materia seca) en los dos grupos de cabras del experimento 3 (Control y Estrés), separadas según el número de lactación

a) Lactación $1+2$

\begin{tabular}{|c|c|c|c|c|c|c|c|c|c|c|c|c|}
\hline \multirow{2}{*}{ Día } & \multicolumn{3}{|c|}{ Grasa $(\% \mathrm{p} / \mathrm{p})$} & \multicolumn{3}{c|}{ Proteína $(\% \mathrm{p} / \mathrm{p})$} & \multicolumn{3}{c|}{ Lactosa $(\% \mathrm{p} / \mathrm{p})$} & \multicolumn{3}{c|}{ Materia Seca $(\% \mathrm{p} / \mathrm{p})$} \\
\cline { 2 - 15 } & Control & Estrés & Todas & Control & Estrés & Todas & Control & Estrés & Todas & Control & Estrés & Todas \\
\hline-2 & 4.81 & 4.74 & $4.78^{\mathrm{a}}$ & 3.40 & 3.36 & $3.38^{\mathrm{a}}$ & 4.64 & 4.66 & 4.65 & 13.81 & 13.67 & 13.74 \\
\hline-1 & 4.94 & 4.82 & $4.88^{\mathrm{ab}}$ & 3.39 & 3.33 & $3.36^{\mathrm{a}}$ & 4.63 & 4.64 & 4.64 & 13.85 & 13.69 & 13.77 \\
\hline 0 & 5.01 & 4.73 & $4.87^{\mathrm{ab}}$ & 3.36 & 3.34 & $3.35^{\mathrm{a}}$ & 4.61 & 4.66 & 4.63 & 13.93 & 13.61 & 13.77 \\
\hline 1 & 5.09 & 4.97 & $5.03^{\mathrm{b}}$ & 3.34 & 3.26 & $3.29^{\mathrm{b}}$ & 4.61 & 4.62 & 4.62 & 13.89 & 13.75 & 13.82 \\
\hline 2 & 4.81 & 4.95 & $4.88^{\mathrm{ab}}$ & 3.37 & 3.35 & $3.36^{\mathrm{a}}$ & 4.62 & 4.63 & 4.63 & 13.73 & 13.84 & 13.79 \\
\hline 3 & 4.74 & 4.79 & $4.77^{\mathrm{a}}$ & 3.39 & 3.33 & $3.36^{\mathrm{a}}$ & 4.64 & 4.62 & 4.63 & 13.54 & 13.61 & 13.58 \\
\hline ES & 0.17 & 0.17 & 0.12 & 0.04 & 0.04 & 0.03 & 0.03 & 0.03 & 0.02 & 0.18 & 0.18 & 0.13 \\
\hline
\end{tabular}

b) lactación $\geq 3$

\begin{tabular}{|c|c|c|c|c|c|c|c|c|c|c|c|c|}
\hline \multirow{2}{*}{ Día } & \multicolumn{4}{|c|}{ Grasa $(\% \mathrm{p} / \mathrm{p})$} & \multicolumn{3}{c|}{ Proteína $(\% \mathrm{p} / \mathrm{p})$} & \multicolumn{3}{c|}{ Lactosa $(\% \mathrm{p} / \mathrm{p})$} & \multicolumn{3}{c|}{ Materia Seca $(\% \mathrm{p} / \mathrm{p})$} \\
\cline { 2 - 15 } & Control & Estrés & Niv.Sig & Control & Estrés & Todas & Control & Estrés & Niv.Sig & Control & Estrés & Niv.Sig \\
\hline-2 & 4.79 & $4.77^{\mathrm{a}}$ & NS & 3.47 & 3.42 & 3.44 & 4.31 & $4.34^{\mathrm{a}}$ & NS & 13.50 & 13.48 & 13.49 \\
\hline-1 & 4.83 & $4.81^{\mathrm{a}}$ & NS & 3.46 & 3.40 & 3.43 & 4.34 & $4.35^{\mathrm{a}}$ & NS & 13.52 & 13.55 & 13.53 \\
\hline 0 & 4.88 & $4.72^{\mathrm{a}}$ & NS & 3.45 & 3.37 & 3.41 & 4.33 & $4.39^{\mathrm{a}}$ & NS & 13.58 & 13.49 & 13.54 \\
\hline 1 & 4.79 & $5.04^{\mathrm{b}}$ & NS & 3.43 & 3.38 & 3.41 & 4.35 & $4.31^{\mathrm{b}}$ & NS & 13.48 & 13.76 & 13.62 \\
\hline 2 & 4.86 & $4.86^{\mathrm{ab}}$ & NS & 3.45 & 3.44 & 3.44 & 4.39 & $4.40^{\mathrm{a}}$ & NS & 13.62 & 13.70 & 13.66 \\
\hline 3 & 4.91 & $4.74^{\mathrm{a}}$ & NS & 3.43 & 3.42 & 3.43 & 4.34 & $4.40^{\mathrm{a}}$ & NS & 13.61 & 13.51 & 13.56 \\
\hline ES & 0.12 & 0.12 & - & 0.04 & 0.04 & 0.03 & 0.04 & 0.04 & - & 0.14 & 0.14 & 0.10 \\
\hline
\end{tabular}

NS: Efecto no significativo ES: Error estándar

$\mathrm{a}, \mathrm{b}, \mathrm{c}, \mathrm{d}$. Letras distintas en una misma columna indica diferencias significativas $(\mathrm{p}<0.05)$

$n^{\circ}$ de cabras :lactación 1+2: control $n=9$, estrés $n=9$. Lactación 3: control $n=10$, estrés $n=10$

En las cabras de 3 o más partos la interacción Grupo*Día afectó significativamente al cortisol $(\mathrm{p}<0.001)$, al RCS $(\mathrm{p}<0.001)$, la producción de leche $(\mathrm{p}<0.05)$, la grasa $(\mathrm{p}<0.05)$ y la lactosa $(\mathrm{p}<0.05)$. En el día 0 el cortisol se elevó significativamente $(\mathrm{p}<0.001)$ en el grupo Estrés (muestras de sangre recogidas tras el estrés, $38.4 \mathrm{ng} / \mathrm{ml}$; Tabla 9), mientras que en el grupo Control el cortisol permaneció en valores bajos ( $4 \mathrm{ng} / \mathrm{ml})$. Por su parte, en el ordeño del día +1 (primer ordeño tras el estrés) se produjo un aumento brusco del RCS en las cabras del grupo Estrés (log RCS: 6.48 céls $/ \mathrm{ml}$; media geométrica: 3.020 .000 céls $/ \mathrm{ml}$ ), mientras que en el grupo Control los recuentos fueron similares respecto a los días anteriores y posteriores (log RCS: 5.94; media geométrica: 871.000 células/ml; Tabla 10). Así mismo, en el día +1 la producción de leche del grupo Estrés $(2084 \mathrm{ml} /$ día $)$ disminuyó significativamente $(\mathrm{p}<0.001)$, tanto 
respecto a los valores precedentes (alrededor de $300 \mathrm{ml}$; un descenso del 12.5\%) como respecto a la producción del grupo Control en ese mismo día $(160 \mathrm{ml}$; un descenso del 7.1\%; Tabla 11). En ese mismo día la leche del grupo Estrés presentó, respecto al día precedente, un aumento significativo de la grasa (5.04 vs $4.72 \%$; $<<0.001)$ y un descenso significativo de la lactosa (4.31 vs $4.39 \%$; $<<0.001$ ); no obstante en ambos casos las diferencias respecto al grupo Control no llegaron a ser significativas en ningún día del experimento (Tabla 12b). La proteína y la materia seca no estuvieron afectados significativamente por el factor Día ni por la interacción Grupo*Día.

En las cabras de 3 o más lactaciones la interacción triple Grupo*Estado Sanitario*Día no resultó significativa para ninguna variable. En la Figura 5 podemos ver la evolución del RCS en las cabras sanas e infectadas del grupo estrés, apreciándose que en el día +1 se elevaron los recuentos tanto en las ubres sanas como en las afectadas de mamitis subclínica. En valor absoluto (RCS día +1 menos RCS día 0), el RCS se elevó más en las cabras infectadas que en las sanas $(4.557 .000$ céls $/ \mathrm{ml}$ vs 1.458 .000 céls $/ \mathrm{ml}$, respectivamente), pero si se expresa el incremento de células como una relación (RCS día +1 dividido por el RCS del día 0) fue al revés (6.6 vs 7.1, respectivamente). Así mismo, el incremento absoluto de células somáticas producido por el estrés tendió a ser más elevado en aquellos animales que partían de mayores recuentos $(\mathrm{p}<0.001$; Figura $6 \mathrm{~A})$, pero expresando el incremento como una relación, la tendencia nuevamente fue la inversa ( $\mathrm{p}<0.01$; Figura 6B). Por otra parte, no se encontró que el incremento de RCS en el día +1 estuviera correlacionado significativamente con el cortisol plasmático ni con la caída de producción de leche.

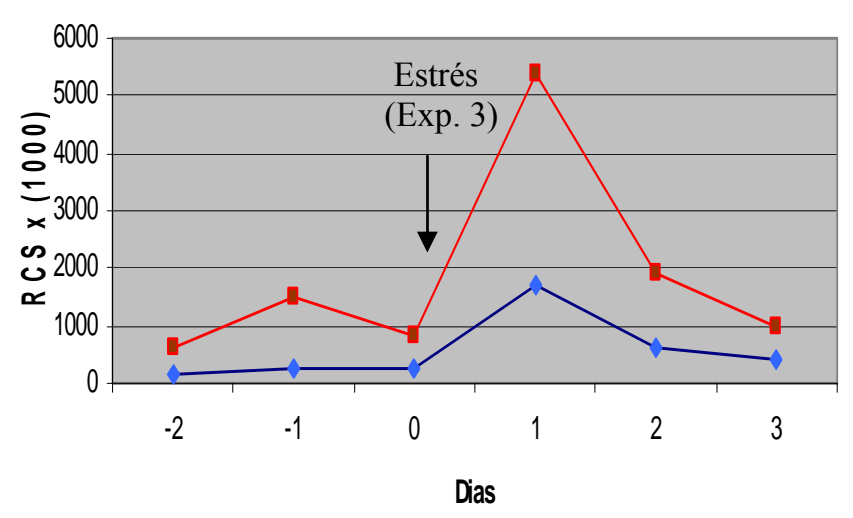

$\rightarrow$ Sanas $\rightarrow$ - Infectadas 
FIGURA 5. Evolución diaria de la media geométrica del RCS (céls $/ \mathrm{ml}$ ) en las cabras de $\geq 3$ partos sometidas a un estrés extremo, según el estado sanitario de la ubre ( sanas $\mathrm{n}=6$; infectadas $\mathrm{n}=4$; Experimento 3 ).

A) RCSmax - RCSprevio (x1000)

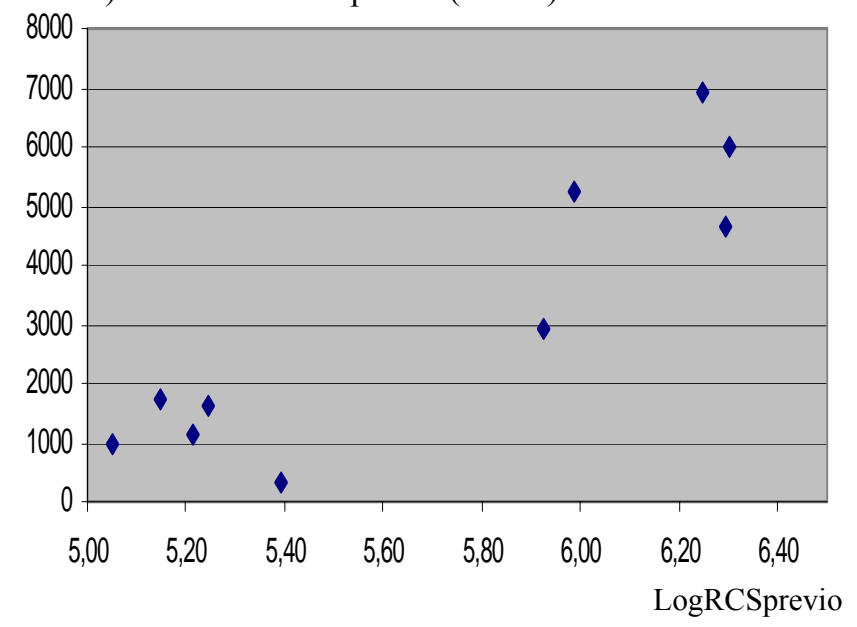

B) RCSmax/RCSprevio

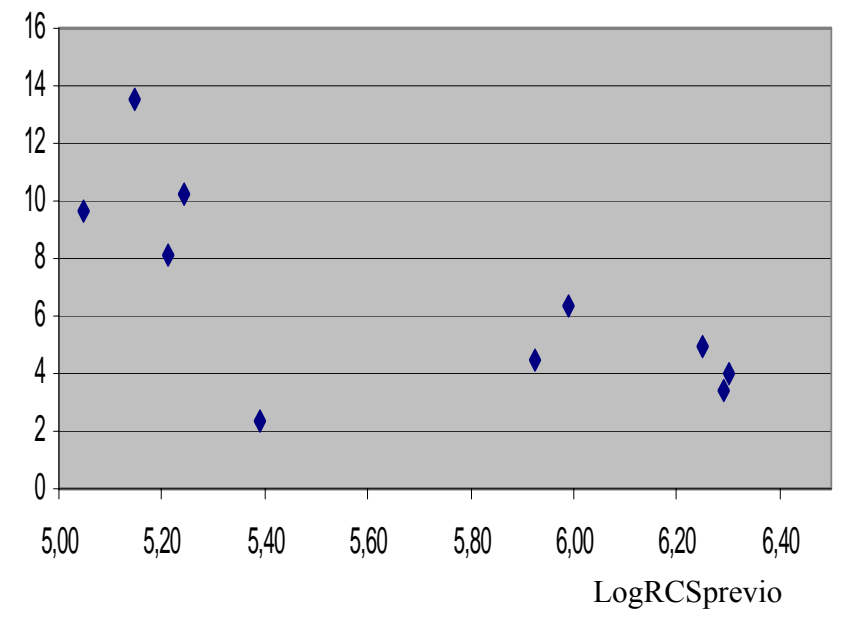

FIGURA 6. Incremento de células somáticas en las cabras de 3 o más partos sometidas a un estrés extremo $(\mathrm{n}=10)$, según el RCS (céls/ml) que tenían estos animales en los dos días previos al estrés (RCSprevio). Incremento de RCS expresado como: A) diferencia (RCSmax-RCSprevio) o B) relación (RCSmax/RCSprevio)

En las cabras de 1+2 partos tan solo se detectó una $\mathrm{ET}_{\mathrm{RCS}}$, la cual ocurrió en el día +1 en una cabra del grupo Estrés (1 caso de 9 cabras), mientras que en el grupo Control no se identificó ninguna $\mathrm{ET}_{\mathrm{RCS}}$ a lo largo del experimento.

En las cabras de 3 o más partos se identificaron un total de $15 \mathrm{ET}_{\mathrm{RCS}}$, la mayoría de las cuales aparecieron en el grupo Estrés en el día +1, concretamente en 9 de las 10 cabras del grupo, presentando una duración de uno o dos días (4 y 5 casos, respectivamente); además también se identificaron en el grupo Estrés $2 \mathrm{ET}_{\mathrm{RCS}}$ en el día -1. Las $4 \mathrm{ET}_{\mathrm{RCS}}$ restantes ocurrieron en el grupo Control distribuidas a lo largo del experimento (1, 2 y 1 casos en los días $-2,-1 \mathrm{y}+2$, respectivamente).

\section{DISCUSIÓN}

Experimentos 1 y 2

En este trabajo no se ha podido demostrar que dos situaciones aparentemente estresantes, que habitualmente ocurren en las explotaciones comerciales (extracción del 
estiércol y el reagrupamiento de los animales), provoquen una elevación significativa del RCS en la leche, tanto en las cabras primíparas como en multíparas, y en cabras sanas como en afectadas de IIM. Además, tampoco se elevaron los niveles de cortisol en sangre.

En el caso de la extracción del estiércol con un tractor, las situaciones potencialmente estresantes fueron: a) el traslado a los animales a un nuevo parque dentro de la misma nave; b) la disminución del espacio por animal (de $1 \mathrm{~m}^{2}$ a $0.5 \mathrm{~m}^{2}$ por cabra) y, c) el impacto sonoro y visual del tractor durante el proceso (5-6 horas). En el caso del reagrupamiento de los animales, la alteración de la jerarquía provocó un incremento de las agresiones, lo que coincide con otros trabajos previos (Fernández et al., 2007; Andersen et al., 2008). Sin embargo, el hecho que en ambos experimentos no se detectara una elevación del cortisol plasmático sugiere que ambas situaciones no fueron tan estesantes para los animales como podría suponerse a priori.

Algunos trabajos han demostrado que cuando a los animales se les somete repetidamente a un estrés fisiológico existe un proceso de adaptación, de modo que llega un momento en que ya no se elevan los niveles de cortisol sanguíneo. En nuestro caso, la extracción del estiércol se suele llevar a cabo 2 ó 3 veces al año y el reagrupamiento de los animales también suele realizarse habitualmente en las épocas de cubrición y en los primeros meses de la lactación. Además, debemos recordar que el ganado caprino es una especie extremadamente jerárquica, de modo que las cabras están habituadas a participar en actos de lucha desde su juventud. Por ejemplo, Andersen et al. (2007) tampoco encuentran que, en cabras gestantes, el reagrupamiento de los animales provoque una elevación del cortisol plasmático, aunque en este caso los registros no se llevaron a cabo inmediatamente, sino un día después de realizar el reagrupamiento.

No se dispone de trabajos que hayan estudiado anteriormente en el ganado caprino el efecto del reagrupamiento sobre el RCS. En el ganado vacuno existe más información, aunque los resultados no son claros. Así, en algunos casos se encuentra que el reagrupamiento (Arve y Albright, 1976) o el traslado de los vacas a nuevos alojamientos (Varner et al., 1983) no afectan al RCS, mientras que otros autores detectan un aumento del RCS en la leche de tanque (de 175.000 a 420.000 cels $/ \mathrm{ml}$ ) tras realizar la mezcla de grupos (Whittlestone et al., 1970). 
Aunque el reagrupamiento de los animales no elevó significativamente el RCS, debemos destacar que en el primer ordeño realizado tras el reagrupamiento (día 1) hubo 6 cabras que manifestaron una $\mathrm{ET}_{\mathrm{RCS}}$, a pesar de que en estos animales tampoco se elevaron los niveles de cortisol (días 0 y 1 ).

La producción de leche tan solo disminuyó significativamente en las cabras primíparas que fueron trasladadas a los parques de multíparas (experimento 2), siendo este descenso alrededor del 10\%. Es probable que este descenso productivo no fuera por el posible estrés, sino más bien a un descenso en la ingestión de alimento. Efectivamente, estas cabras ( 5 en cada parque de multíparas; 10 en total) permanecieron juntas en un extremo del parque, y la mayoría rehuían cualquier tipo de agresión procedente de las cabras multíparas, lo que les dificultaba su acceso a la comida. Por otra parte, el hecho de que las cabras con mayor actividad de lucha (15 cabras adultas estuvieron golpeándose, cabeza con cabeza, durante más de 15 minutos seguidos) tampoco presentaran, en el siguiente ordeño, un descenso significativo en la producción de leche, podría reforzar la hipótesis de que este tipo de agresión, al ser habitual en el ganado caprino, no ocasiona un estrés importante en los animales. Nuestros resultados discrepan parcialmente de los encontrados por Fernández et al. (2007), ya que estos autores encontraron un descenso del $10 \%$ en la producción de leche tras el reagrupamiento de las cabras, pero en este experimento se utilizaron mayoritariamente cabras primíparas (11 de un total de 15 animales).

En ambos experimentos se observó que, en el primer ordeño tras iniciarse la situación potencialmente estresante, el porcentaje de grasa y materia seca de la leche tendieron a disminuir respecto a los valores precedentes. En el segundo experimento, la tendencia citada también ocurrió en el grupo Control, lo cual sugiere que los cambios que se produjeron en estos animales (disminución del tamaño de grupo y de la superficie del parque, aún manteniendo la misma superficie por animal, de $1,1 \mathrm{~m}^{2}$ ) fueron suficientes para influir sobre este parámetro. En ganado vacuno, Varner et al. (1983) también encuentran un descenso en el porcentaje de grasa de la leche tras el traslado de los animales a nuevas instalaciones, aunque en este caso también se produjo un descenso en la producción de leche. 


\section{Tercer experimento}

En este experimento se ha comprobado que si las cabras sufren un estrés extremo y puntual se produce una elevación del cortisol en sangre, pero solamente en los animales de mayor edad se eleva significativamente el RCS, con independencia del estado sanitario de la ubre, asociado a un moderado descenso en la producción de leche (entre un 8 y un 15\%). El incremento del RCS es importante, ya que en casi todas las cabras de tres o más partos (9 de 10) se produjo una $\mathrm{ET}_{\mathrm{RCS}}$ en el primer ordeño realizado tras el estrés, con incrementos entre 2 y 20 veces respecto al ordeño precedente. Estas elevaciones fueron similares a las observadas durante el celo inducido (estudio 3).

Este resultado es novedoso, ya que es la primera vez que en el ganado caprino se demuestra que un estrés fisiológico, confirmado mediante una elevación del cortisol en sangre, provoca un importante incremento del RCS. En ganado vacuno, Whittlestone et al. (1970) también demostraron que el aislamiento de los animales y/o el contacto con un perro puede ocasionar una elevación del RCS, aunque en este experimento los recuentos se elevaron más en las vacas con un historial previo de mamitis. En nuestro caso, solamente cuando el incremento de RCS se expresó como diferencia, también se observó que el estrés incrementó más los recuentos en las cabras infectadas que en las sanas.

El hecho de que el estrés ensayado no elevara el RCS en las cabras jóvenes sugiere que, ante el mismo estímulo, las cabras de primer y segundo parto pueden sufrir menos estrés fisiológico, reflejado por el menor nivel de cortisol plasmático, de modo que éste no sería suficiente para incrementar los leucocitos en sangre y/o su capacidad para migrar desde los vasos sanguíneos hasta los tejidos.

Por último, dado que en las cabras jóvenes el fuerte estrés ensayado apenas afectó a la producción de leche, a pesar del incremento de cortisol en sangre, refuerza la hipótesis formulada anteriormente de que la caída de producción de las cabras primíparas en el experimento 2, en las cuales no se detectó un aumento del cortisol plasmático, no fue debido a un efecto directo del estrés, sino a que los animales tuvieron un menor acceso al alimento. 


\section{CONCLUSIONES}

1) La extracción del estiércol y el reagrupamiento, dos situaciones aparentemente estresantes que ocurren habitualmente en las explotaciones de ganado caprino, provocan los siguientes efectos sobre los animales:

- No afectan de modo importante al RCS, con independencia del número de lactación de los animales (primíparas y multíparas) y el estado sanitario de la ubre (sanas y con mamitis subclínica). No obstante, el reagrupamiento tiende a elevar ligeramente el RCS en las cabras que ya partían de recuentos altos $(>1$ millón céls $/ \mathrm{ml})$.

- No se eleva el cortisol en sangre, lo que sugiere que no se produce un estrés elevado en los animales.

- La producción de leche disminuye sensiblemente en las cabras primíparas que se trasladan a los parques de multíparas (descenso del 8-10\% durante dos días). En el resto de casos la producción de leche apenas varía.

- Afecta en poca medida a la composición de la leche, con una tendencia a disminuir la grasa y materia seca.

2) Un estrés puntual y extremo, generado por el contacto de las cabras durante unos 30 minutos con un perro, provoca los siguientes efectos en los animales:

- En las cabras de mayor edad (3 o más partos) se eleva de forma importante el RCS, de modo que casi todos animales presentan una $\mathrm{ET}_{\mathrm{RCS}}$ de 1 ó 2 días de duración. Por el contrario, en las cabras más jóvenes apenas se elevan los recuentos. En valor absoluto el RCS aumenta más en las cabras con IIM que en las cabras sanas, pero sucede al contrario si se expresa en valor relativo (relación entre post-estrés y pre-estrés).

- Se eleva significativamente el cortisol en sangre tanto en las cabras jóvenes como en las de mayor edad. 
- En las cabras de 3 o más partos disminuye la producción de leche (7-12\%), aumenta la grasa y disminuye la lactosa. En las cabras de menor edad apenas se observan cambios en la producción y composición de la leche.

\section{BIBLIOGRAFIA}

ALI, A.K.A.; SHOOK, G.E. (1980). An optimum transformation for somatic cell concentration in milk. Journal of Dairy Science. 63:487-490.

ANDERSEN, I.L.; ROUSSEL, S.; ROPSTAD,E.; BRAASTAD,B.O.; STEINHEIM, G.; JANCZAK, A.M.; JØRGENSEN, G.M.; BØE, K.E. (2008). Social instability increases aggression in groups of dairy goats, but with minor consequences for the goats' growth, kid production and development . Applied Animal Behaviour Science Volume 114, Issues 1-2, November 2008, Pages 132-148

ARVE, C.W.; ALBRIGHT, J.L. (1976). Social rank and physiological traits of dairy cows as influenced by changing group memberships. Journal of Dairy Science. 59: $\mathrm{Nr}$ 1 .

\section{BERGONIER,D.;DECRÉMOUX,R.;RUPP,R.;LAGRIFFOUL,G.;BERTHE}

LOT ,X. (2003). Mastitis of dairy small ruminants. Vet. Res.34: 689-716 .INRA, EDP Sciences, DOI: 10.1051/vetres :2003030

\section{CHRISTODOULOPOULOS,G., SOLOMAKOS,N.; KATSOULOS, P.D.; MINAS,} A.; K KRITAS, S.K.; (2008) . Influence of oestrus on the heat stability and other characteristics of milk from dairy goats. Journal of Dairy Research 75: 64-68.

COULON , J. B ; PRADEL, P; COCHARD, T; POUTREL, B. (1998). Effect of extreme walking conditions for dairy cows on milk yield, chemical composition, and somatic cell. Journal of Dairy Science. 81: 994-1003

CORRALES, J.C.; CONTRERAS, A.; SÁNCHEZ, A.; MARCO, J.; RABAL, F. (1997). Adaptación de las condiciones de la aplicación de la directiva comunitaria 92/46 para el recuento de células somáticas, a nivel de tanque, en leche de ganado caprino. XXI Jornadas Científicas de la Sociedad Española de Ovinotecnia y Caprinotecnia. Logroño. 221-227.

DECARVALHO, M.; SIMENSEN, E.; FJERDINGBY, N.;LARSEN, S.; ZANELLA, A.J. (2009). Measuring welfare indicators in dairy goats through salivary cortisol and somatic cell counts (scc). AS ( Noruega) 499-501. http://www.umb.no/statisk/husdyrforsoksmoter/2009/129.pdf

FERNÁNDEZ, M.A.; ALVAREZ, L. ; ZARCO, L.(2007). Regrouping in lactating goats increases aggression and decreases milk production. Small Ruminant Research.. 70 2-3 : 228-232. 
GOREWIT, R.C.; ANESHANSLEY, D.J.; PRICE, L.R. (1992). Effects of Voltages on Cows over a Complete Lactation. 1. Milk Production and Composition. J. Dairy Sciece. 75:2719-2725.

HAENLEIN, G.F.W. (2002). Relationship of somatic cell counts in goat milk to mastitis and productivity. Small Ruminant Research 45. 163- 178.

ISO/IDF. (2008) Milk - Enumeration of somatic cells. - Part 2: Guidance on the operation of fluoro-opto-electronic counters. ISO 13366-2 .IDF 148-2

KARZIS, J.; DONKIN, E.F.; PETZER, I.M. (2004). Antibiotic residue whithdrawal periods in milk of saanen dairy goats and udder tissue irritation : preliminary results. South African Journal of Animal Science. 34: 262-265. (supp1)

LEFCOURT, A. M; KAHL, S.; AKERS, R.M. (1986). Correlation of Indices of Stress with Intensity of Electrical Shock for Cows. Journal of Dairy Science. 69: 833-842.

LERONDELLE, C.; RICHARD, Y.; ISSARTIAL, J. (1992). Factors affecting somatic cell counts in goat milk. Small Ruminant Research. 8: 129-139.

LITTELL, R.C.; HENRY, P.R.; AMMERMAN, C.B. (1998). Statitiscal analysis of repeated measures data using SAS procedures. Journal of Animal Science. 76:12161231 .

MARTÍNEZ, B. (2000). El recuento de células somáticas en la leche de cabra: factores de variación y efecto sobre la producción y composición de la leche. Tesis doctoral. Universidad Politécnica De Valencia .307p.

MC DOUGALL, S.;ANNISS, F.M; CULLUM, A.A. (2002). Effect of transport stress on somatic cell counts in dairy goats. Proceedings of New Zealand Society of Animal Health. 62: 16-18.

MCDOUGALL , S.; VOERMANS , M. (2002). Influence of Estrus on Somatic Cell Count in Dairy Goats .J. Dairy Science. 85:378-383.

MERLOT, E. (2004). Conséquences du stress sur la fonction immunitaire chez les animaux d'elevage. Inra Prod.anim .17 (4):255-264.

MORONI , P. ; PISONI ,G.; VAN LIER , E.; ACUÑA ,S. ; DAMIAN .; J.P ; MEIKER ,A.(2007). Influence of estrus of dairy goat on somatic cell ,milk trait,and sex steroid receptors in the mammary gland . Journal of Animal Science. 90 : 790- 797.

MUNRO, C.J.; LASLEY, B.L. (1988). Non-radiometric methods for immunoassay of steroid hormones. Prog. Clin. Biol. Res. 285:289-329.0..

PAAPE , M.J.; SCHULTZE, W.D.; MILLER, R.H.; SMITH, J.W. (1973). Thermal stress and circulating erythrocytes, leucocytes, and milk somatic cells. Journal of Dairy Science. 56: Nr 1. 
PAAPE, M.J.; WIGGANS, G.R.; BANNERMAN , D.D.; THOMAS, D.L.; SANDERS A.H., CONTRERAS,A., MORONI, P.; MILER, R.H. (2007). Monitoring goat and sheep milk somatic cell counts. Small Ruminant Research 68 : 114-125.

RANDY, H.A.;WILDMAN, E. E; CALER, W. A.; TULLOCH, G. L. (1988) Effect of age and time of milking on day-to-day variation in milk yield, milk constituents and somatic cell counts .Small Ruminant Research. 1: 151-155.

RAYNAL-LJUTOVAC, K.; PIRISI, A.; DE CREMOUX, R.; GONZALO, C.(2007). Somatic cells of goat and sheep milk: Analytical, sanitary, productive and technological aspects. Small Ruminant Research. 68: 1-2 126-144.

RENEAU, J.K.; (1986). Effective use of Dairy Herd Improvement somatic cell counts in mastitis control. J. Dairy Sci. 69:1708.

SAlAMA, A.A; CAJA, G.; ALBANELL, E.; SUCH, X.; CASAlS, R.; PlaIXATS, J.(2003). Effects of dietary supplements of zinc-methionine on milk production, udder health and zinc metabolism in dairy goats. Journal of Dairy Research 70:9-17.

VARNER, M.A.; JOHNSON, B.H.; BRITT, J.H.; MC DANIEL, B.T.; MOCHRIE, R.D. (1983). Influence of Herd Relocation upon Production and Endocrine Traits of Dairy Cows . Journal of Dairy Science. 66: 466-474.

WEGNER, T.N.; SCHUH, J.D.; NELSON, F.E.; STOTT, G.H. (1976). Effect of stress on blood leucocyte and milk somatic cell counts in dairy cows .Journal of Dairy Science. 59: $\mathrm{Nr} 5$.

YAGI , Y.; SHIONO, H.; CHIKAYAMA, Y.; OHNUMA, A.; NAKAMURA, I.; YAYOU, K.I. (2003). Transport stress increase somatic cell in milk, and enhances the migration capacity of peripheral blood neutrophils of dairy cows. Clinical Pathology.

ZENG, S.S.; ESCOBAR E.N.; POPHAM, T. (1997). Daily variations in somatic cell count, composition, and production of Alpine goat milk. Small Ruminant Research 26: 253-260.

WEGNER, T. N. ; SCHUH, J. D. ; NELSON, F. E. ; STOTT, G. H. (1976). Effect of Streess on Blood Leucocyte and Milk Somatic Cell Counts in Dairy Cows . Journal of Dairy Science. 59 (5): 949-956

WHITTLESTONE, W.G.; KILGOUR, R. ; DE LANGEN, H. ; DUIRS, G. (1970)

Behavioral stress and cell count of bovine milk J. Milk Food Technol. 33:217 